\title{
A INFLUÊNCIA DAS AÇÕES REPETIDAS NA ADERÊNCIA AÇO-CONCRETO
}

\section{REJANE MARTINS FERNANDES}

Dissertação apresentada à Escola de Engenharia de São Carlos, da Universidade de São Paulo, como parte dos requisitos para obtenção do Título de Mestre em Engenharia de Estruturas.

Orientadora: Prof ${ }^{a}$. Dr ${ }^{a}$. ANA LÚCIA HOMCE DE CRESCE EL DEBS 
Dedico a mainha, pessoa que mais amo nesse mundo. 


\section{AGRADECIMENTOS}

Agradeço primeiramente a Deus, pela oportunidade, proteção e força ao longo dessa caminhada.

Em especial a mainha, vovó Palmira e tia Laura, pelo amor, carinho, incentivo em todos os momentos e confiança que depositaram em mim.

A Ana Lúcia Homce de Cresce El Debs, pela orientação, apoio, incentivo e, acima de tudo, a amizade e a compreensão.

A toda minha família e amigos de Natal, cujas palavras me deram estímulo para a continuidade desse trabalho.

Aos amigos da turma: Alio, Ana Cláudia, Edna, Eduardo, George, Gerson, Marcelo, Palmira, Patrícia Garcia, Patrícia Lizi, Roberto, Rodrigo, Valentim, Yuri e respectivos, pela amizade e apoio nas horas mais difíceis.

A todos os amigos do departamento que me conquistaram nesses dois anos.

A Nadir e Eliana, pela amizade e ajuda na elaboração das referências bibliográficas.

Aos funcionários da secretaria, especialmente a Rosi e Marta, pela atenção, paciência e dedicação nos serviços prestados.

Ao professor Toshiaki Takeya, pelas contribuições dadas para a investigação experimental.

À toda equipe do laboratório: Amaury, João, Jorge, Luiz, Mário, Maury, Valdir e Ricardo pelo empenho e ajuda na pesquisa experimental.

Aos professores João Bento de Hanai e Humberto Breves Coda, pelas sugestões no exame da qualificação.

A Larissa Driemeier pelo auxílio e esforço na tentativa de simulação numérica do problema.

À CAPES, pela bolsa de estudos nesses dois anos de mestrado.

A todos que direta ou indiretamente contribuíram para o desenvolvimento dessa pesquisa. 


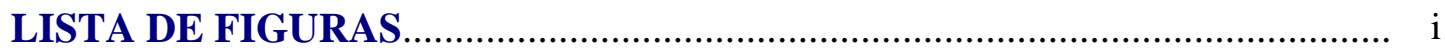

LISTA DE TABELAS................................................................... viii

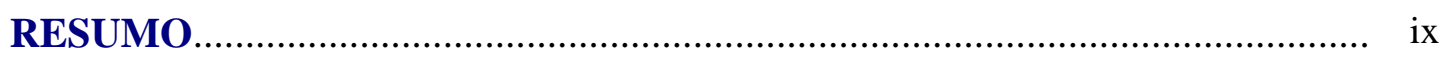

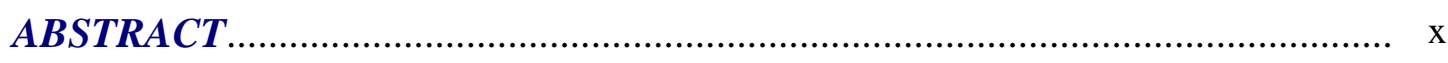

CAPÍTULO 1 - INTRODUÇÃO ............................................................... 1

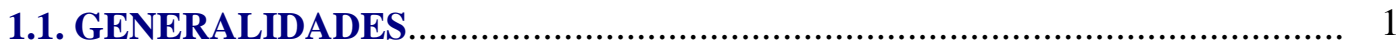

1.2. OBJETIVOS

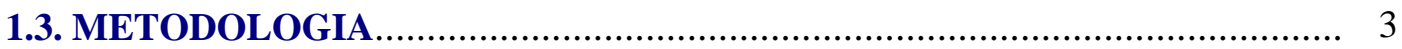

1.4. APRESENTAÇÃO ............................................................................ 3

CAPÍTULO 2 - COMPORTAMENTO DA ADERÊNCIA ................................ 5

2.1. DEFINIÇÃO DE ADERÊNCIA........................................................... 5

2.2. COMPONENTES DA ADERÊNCIA................................................... 6

2.2.1. ADERÊNCIA POR ADESÃO ................................................................. 6

2.2.2. ADERÊNCIA POR ATRITO.............................................................. 7

2.2.3. ADERÊNCIA MECÂNICA..................................................................... 8

2.3. MOBILIZAÇÃO DA ADERÊNCIA NA FISSURAÇÃO.............................. 9

2.4. CAUSAS DAS TENSÕES DE ADERÊNCIA.............................................. 12

2.5. FATORES QUE INFLUENCIAM A ADERÊNCIA............................... 13

2.6. RUPTURA DA ADERÊNCIA......................................................... 13

2.7. COMPORTAMENTO DA ADERÊNCIA SOB CARREGAMENTO

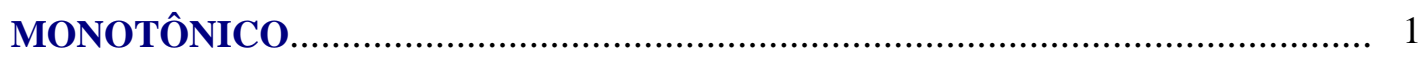


2.8. COMPORTAMENTO DA ADERÊNCIA COM A UTILIZAÇÃO DE FIBRAS NA MATRIZ DE CONCRETO..................................................... 23

2.9. MODELOS PARA O COMPORTAMENTO DA ADERÊNCIA................... 26

2.10. PRESCRIÇÕES DAS NORMAS SOBRE ADERÊNCIA.......................... 32

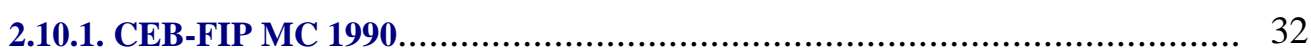

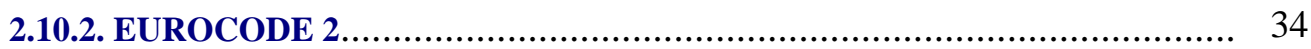

2.10.3. NB-1/78 (NBR 6118) .............................................................. 35

2.11. DETERMINAÇÃO DA RESISTÊNCIA DE ADERÊNCIA....................... 36

CAPÍTULO 3 - ADERÊNCIA SOB AÇÕES CÍCLICAS................................ 38

3.1. CLASSIFICAÇÃO DAS AÇÕES PARA ANÁlISE DA

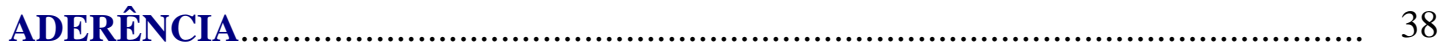

3.2. COMPORTAMENTO DA ADERÊNCIA SOB AÇÃO CÍCLICA................ 39

3.2.1. AÇÃO REPETIDA (CÍCLICA UNIDIRECIONAL) ................................ 40

3.2.2. AÇÃO CÍCLICA ALTERNADA....................................................... 48

3.3. COMPORTAMENTO DA ADERÊNCIA EM SERVIÇO.......................... 57

3.4. COMPORTAMENTO DE NÓS DE PÓRTICOS SOB AÇÃO CÍCLICA....... 58

3.5. ANÁlise dAS AÇÕes CíCliCAS SOB O PONTO DE VISTA DA

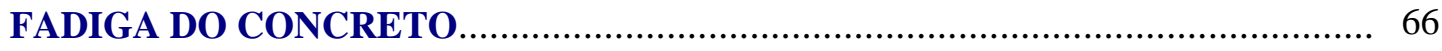

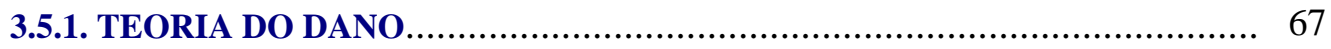

3.5.2. INFLUÊNCIA DAS AÇÕES CÍCLICAS NAS FLECHAS DE VIGAS DE

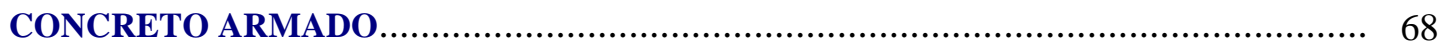

CAPÍTULO 4 - INVESTIGAÇÃO EXPERIMENTAL DA ADERÊNCIA...... 71

4.1. CONSIDERAÇÕES INICIAIS........................................................... 71

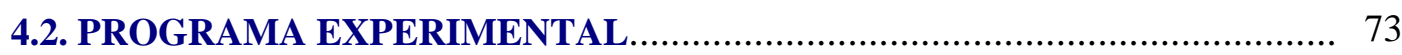

4.3. MATERIAIS UTILIZADOS NA CONFECÇÃO DO CONCRETO.............. 74

4.4. DOSAGEM DOS MATERIAIS........................................................ 76

4.5. CONFECÇÃO E CARACTERIZAÇÃO DO CONCRETO.......................... 76

4.5.1. RESISTÊNCIA À COMPRESSÃO....................................................... 79

4.5.2. RESISTÊNCIA À TRAÇÃO........................................................... 80

4.5.3. COMPORTAMENTO TENSÃO-DEFORMAÇÃO................................... 81

4.5.4. MÓDULO DE DEFORMAÇÃO LONGITUDINAL................................ 82

4.5.5. COEFICIENTE DE POISSON....................................................... 83 


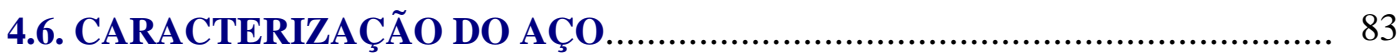

4.7. INSTRUMENTOS E EQUIPAMENTOS UTILIZADOS.......................... 87

4.8. PROCEDIMENTO DE ENSAIO ..................................................... 89

4.9. ENSAIO PILOTO COM EXTENSÔMETRO ............................................. 89

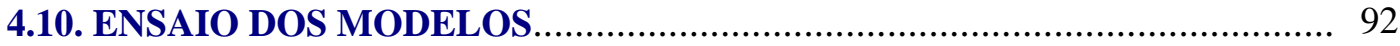

CAPÍTULO 5 - ANÁLISE NUMÉRICA DA ADERÊNCIA............................ 94

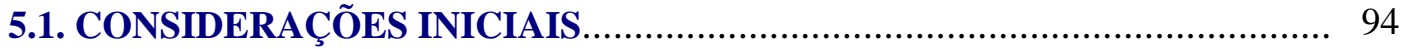

5.2. SINGULARIDADES DO CONTATO NO ANSYS .................................... 96

5.3. PARÂMETROS PARA MODELAGEM DO MODELO............................ 98

5.4. ELEMENTOS FINITOS UTILIZADOS ................................................. 99

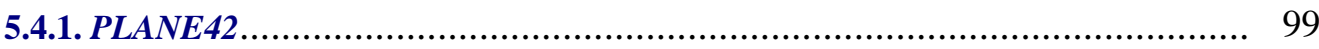

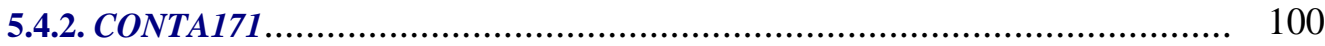

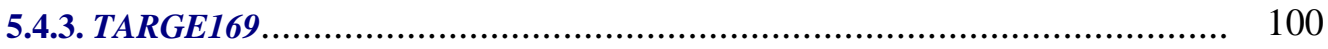

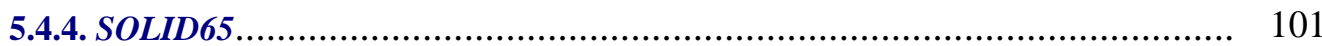

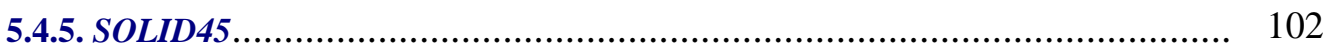

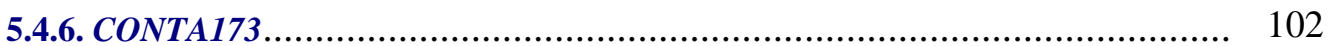

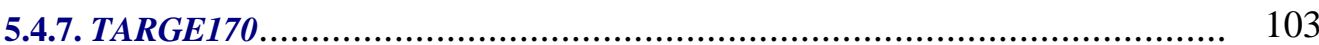

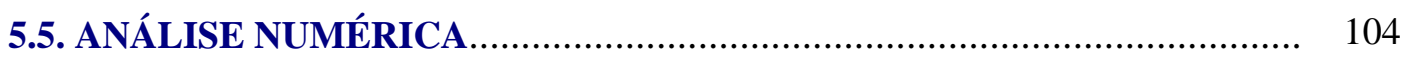

5.5.1. MODELO BIDIMENSIONAL COM A BARRA LISA (PT10-2D) .............. 104

5.5.2. MODELO TRIDIMENSIONAL COM A BARRA LISA (PT10-3D) ............ 105

CAPÍTULO 6 - APRESENTAÇÃO E ANÁLISE DOS RESULTADOS........ 107

6.1. RUPTURA DOS MODELOS ............................................................ 107

6.2. CARACTERIZAÇÃO DO CONCRETO E DO AÇO.................................. 108

6.3. COMPORTAMENTO MONOTÔNICO DA ADERÊNCIA......................... 110

6.3.1. MODELOS PILOTO.................................................................... 110

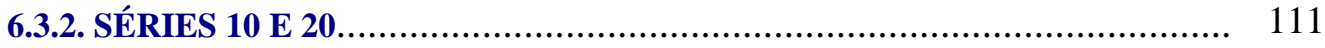

6.4. CÁlCULO DA RESISTÊNCIA DE ADERÊNCIA SEGUNDO AS NORMAS

6.4.1. CEB-FIP MC 1990....................................................................... 113

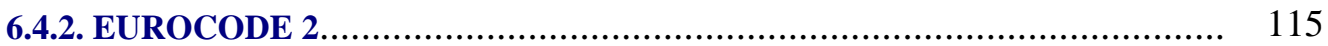

6.4.3. NB-1/78 (NBR 6118) ....................................................................... 116 
6.5. COMPARAÇÃO DA ADERÊNCIA MONOTÔNICA EXPERIMENTAL

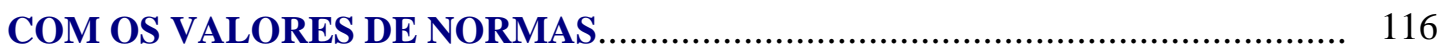

6.6. COMPORTAMENTO DA ADERÊNCIA SOB CARREGAMENTO

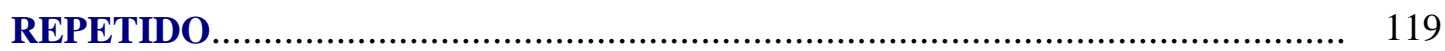

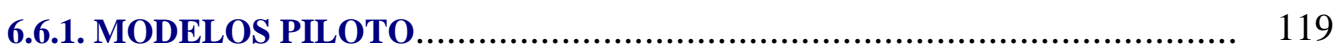

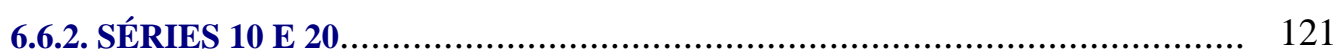

6.7. ANÁLISE NUMÉRICA DA ADERÊNCIA MONOTÔNICA...................... 133

6.7.1. MODELO PT10-2D........................................................................ 133

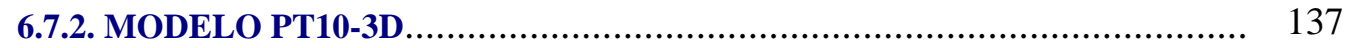

CAPÍTULO 7 - CONSIDERAÇÕES FINAIS............................................ 143

7.1. CONCLUSÕES........................................................................................ 143

7.2. SUGESTÕES PARA NOVAS PESQUISAS.......................................... 147

REFERÊNCIAS BIBLIOGRÁFICAS.................................................... 149

BIBLIOGRAFIA COMPLEMENTAR ................................................ 154 
FIGURA 2.1 - Aderência por adesão. 7

FIGURA 2.2 - Aderência por atrito........................................................................ 8

FIGURA 2.3 - Aderência mecânica.............................................................................. 8

FIGURA 2.4 - Explicação das designações em uma barra ideal com nervuras anulares e áreas possíveis de ruptura dos consolos de concreto entre nervuras - REHM apud

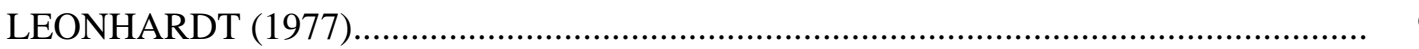

FIGURA 2.5 - Fissuração por tração........................................................................ 10

FIGURA 2.6 - Fissuração estabilizada......................................................................... 11

FIGURA 2.7 - Microfissuras (fissuras secundárias) entre fissuras principais, em uma barra de concreto armado sob tração centrada - GOTO apud LEONHARDT (1977)......... 12

FIGURA 2.8 - Ruptura por aderência por: (a) fissuração por fendilhamento em concreto não-confinado; (b) arrancamento em concreto confinado.................................................... 14

FIGURA 2.9 - Fendilhamento longitudinal do concreto - FUSCO (1995),....................... 15

FIGURA 2.10 - Transferência de esforços por aderência - FUSCO (1995)....................... 16

FIGURA 2.11 - Curva tensão de aderência versus deslizamento típica para carregamento monotônico - adaptada de ACI COMMITTE 408 (1991)............................. 17

FIGURA 2.12 - Curvas de aderência para as misturas com consumo de cimento de 400

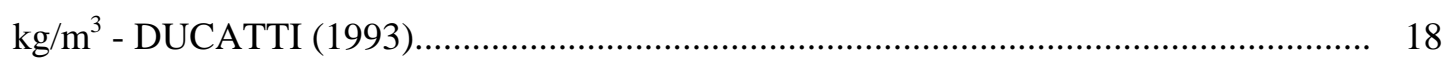

FIGURA 2.13 - Corpos-de-prova de barra vertical e horizontal - BARBOSA (1998)...... 19

FIGURA 2.14 - Comparação das barras horizontais e verticais - BARBOSA (1998)...... 20 
FIGURA 2.15 - Influência da armadura de confinamento na relação local tensão de aderência versus deslizamento de barras nervuradas - SOROUSHIAN et al (1991)......

FIGURA 2.16 - Influência da resistência de compressão na relação local tensão de aderência-deslizamento de barras nervuradas em concreto confinado - SOROUSHIAN et al (1991).

FIGURA 2.17 - Soma de PA em intervalos de $10 \mathrm{~s}$ e tensão de aderência versus tempo -

BALÁZS (1993).

FIGURA 2.18 - Tipos de ruptura monotônica dos diferentes modelos - HOTA \& NAAMAN (1997).

FIGURA 2.19 - Curva teórica tensão de aderência-deslizamento - TASSIOS (1979)....... 26

FIGURA 2.20 - Tensões entre fissuras transversais consecutivas - TASSIOS (1979)...... 27

FIGURA 2.21 - Fissuras transversais e de fendilhamento - TASSIOS (1979)_................. 28

FIGURA 2.22 - Possível estágio de ruptura da aderência para concreto confinado e barra nervurada - TASSIOS (1979).

FIGURA 2.23 - Hipótese do mecanismo da resistência de aderência residual $\tau_{\mathrm{r}}$ TASSIOS (1979).

FIGURA 2.24 - Mecanismo de aderência monotônica - ELIGEHAUSEN et al apud CEB (1996).

FIGURA 2.25 - Relação analítica tensão de aderência versus deslizamento (carregamento monotônico) - CEB-FIP MC 1990.

FIGURA 2.26 - Corpo-de-prova para o ensaio de arrancamento - RILEM-FIP-CEB (1973)

FIGURA 3.1 - Corpo-de-prova double pull-out - LARANJEIRAS (1976).

FIGURA 3.2 - Resultados experimentais do processo da fadiga da aderência devido ao carregamento repetido $\left(\mathrm{d}_{\mathrm{b}}=8 \mathrm{~mm}, \mathrm{f}_{\mathrm{y}}=400 \mathrm{MPa}, \mathrm{f}_{\mathrm{c}}{ }^{\prime}=16 \mathrm{MPa}, \mathrm{l}_{\mathrm{b}}=12 \mathrm{~d}_{\mathrm{b}}\right)$ : (a) Diagrama força-deslizamento; (b) Diagrama deslizamento-número de ciclos; (c) Diagrama monotônico tensão de aderência-deslizamento - BALÁZS (1991).

FIGURA 3.3 - Crescimento do deslizamento devido à força repetida crescente periodicamente $\left(\mathrm{d}_{\mathrm{b}}=8 \mathrm{~mm}, \mathrm{f}_{\mathrm{y}}=400 \mathrm{MPa}, \mathrm{f}_{\mathrm{c}}{ }^{\prime}=16 \mathrm{MPa}, \mathrm{l}_{\mathrm{b}}=12 \mathrm{~d}_{\mathrm{b}}\right)$ - BALÁZS (1991)......

FIGURA 3.4 - Acúmulo do dano da aderência em relação à regra de Palmgren-Miner $\left(\mathrm{d}_{\mathrm{b}}=8 \mathrm{~mm}, \mathrm{f}_{\mathrm{y}}=400 \mathrm{MPa}, \mathrm{f}_{\mathrm{c}}{ }^{\prime}=16 \mathrm{MPa}, \mathrm{l}_{\mathrm{b}}=12 \mathrm{~d}_{\mathrm{b}}\right)-$ BALÁZS $(1991)$.

FIGURA 3.5 - PA acumulado e deslizamento versus tempo para carregamento repetido $\left(\phi 16, \alpha_{\mathrm{sb}}=0,065, \mathrm{f}_{\mathrm{y}}=500 \mathrm{MPa}, \mathrm{l}_{\mathrm{b}}=20 \mathrm{~mm}, \mathrm{f}_{\mathrm{c}}=35 \mathrm{MPa}\right)-$ BALÁZS (1993). 
FIGURA 3.6 - PA acumulado e deslizamento versus tempo para carregamento de longa duração $\left(\phi 16, \alpha_{\mathrm{sb}}=0,065, \mathrm{f}_{\mathrm{y}}=500 \mathrm{MPa}, \mathrm{l}_{\mathrm{b}}=20 \mathrm{~mm}, \mathrm{f}_{\mathrm{c}}=35 \mathrm{MPa}\right)-$ BALÁZS (1993) ... 46

FIGURA 3.7 - Comparação dos resultados experimentais com o CEB-FIP MC 1990 para diferentes níveis de carregamento repetido - KOCH \& BALÁZS (1993).

FIGURA 3.8 - Deslizamento na extremidade descarregada versus número de ciclos REHM \& ELIGEHAUSEN apud CEB (1996).

FIGURA 3.9 - Influência do carregamento repetido na resistência de aderência monotônica - REHM \& ELIGEHAUSEN apud CEB (1996).

FIGURA 3.10 - Relação tensão de aderência versus deslizamento para carregamento cíclico alternado- TASSIOS (1979)

FIGURA 3.11 - Curvas tensão de aderência-deslizamento para diferentes amplitudes de deslizamentos - ELIGEHAUSEN et al apud CEB (1996)..

FIGURA 3.12 - Mecanismo de aderência cíclica - ELIGEHAUSEN et al apud CEB (1996)...

FIGURA 3.13 - Comparação das curvas tensão de aderência-deslizamento monotônica e cíclica allternada: (a) sem inversão de sinal do deslizamento; (b) com inversão de sinal do deslizamento - HAWKINS et al (1982).

FIGURA 3.14 - Comportamento da aderência devido ao carregamento de baixo-ciclo ACI COMMITTE 408 (1991).

FIGURA 3.15 - Resultados experimentais com inversão de deslizamento controlado $\left(d_{b}\right.$ $=16 \mathrm{~mm}$ (barra nervurada), $\mathrm{f}_{\mathrm{y}}=400 \mathrm{MPa}, \mathrm{f}_{\mathrm{c}}{ }^{\prime}=25 \mathrm{MPa}, \mathrm{l}_{\mathrm{b}}=2 \mathrm{~d}_{\mathrm{b}}$ ): (a) curva forçadeslizamento; (b) deterioração da tensão máxima de aderência; (c) deterioração da tensão máxima de atrito - BALÁZS (1991).

FIGURA 3.16 - Resultados experimentais com inversão de força controlada em quatro níveis diferentes de força $\left(\mathrm{d}_{\mathrm{b}}=16 \mathrm{~mm}\right.$ (barra nervurada), $\mathrm{f}_{\mathrm{y}}=400 \mathrm{MPa}, \mathrm{f}_{\mathrm{c}}{ }^{\prime}=25 \mathrm{MPa}, \mathrm{l}_{\mathrm{b}}$ $\left.=2 d_{b}\right)$ : curva força-deslizamento - BALÁZS (1991).

FIGURA 3.17 - Deterioração da aderência devido a deslizamento alternado crescente $\left(\mathrm{d}_{\mathrm{b}}=8 \mathrm{~mm}\right.$ (barra nervurada), $\left.\mathrm{f}_{\mathrm{y}}=400 \mathrm{MPa}, \mathrm{f}_{\mathrm{c}}{ }^{\prime}=25 \mathrm{MPa}, \mathrm{l}_{\mathrm{b}}=6 \mathrm{~d}_{\mathrm{b}}\right)-$ BALÁZS (1991)... 57

FIGURA 3.18 - Corpo-de-prova do ensaio das quatro barras - VALLE (1994)................ 57

FIGURA 3.19 - Transmissão de forças através do: (a) núcleo de um nó intacto; (b) núcleo de um nó após a perda de aderência em um certo trecho - TASSIOS (1979). 
FIGURA 3.20 - (a) Análise elástica por elementos finitos do arrancamento de uma barra com indicação das tensões principais axissimétricas em um raio de 0,45 " ocasionadas por um deslocamento aplicado na barra de 0,00005" para a direita; (b) Fissuras inclinadas normais às tensões de tração; (c) Fissuras de fendilhamento devido à pressão normal atuante na barra - POPOV (1984).......

FIGURA 3.21 - Núcleo típico de pilar para análise da ancoragem de uma barra com comprimento longo - POPOV (1984)...

FIGURA 3.22 - Experimentos cíclicos alternados com barra \#10 para forças iguais aplicadas simultaneamente em ambas as extremidades da barra - POPOV (1984).

FIGURA 3.23 - Modelo do ensaio para determinação do comportamento local tensão de aderência-deslizamento em concreto confinado - POPOV (1984).

FIGURA 3.24 - Curva cíclica alternada experimental tensão de aderência-deslizamento para uma barra \#8 - adaptada de POPOV (1984).

FIGURA 3.25 - Porção sombreada simulando o nó viga-pilar - MORITA et al (1992).... 64

FIGURA 3.26 - Tipo de fissuração observada no modelo $\mathrm{n}^{\mathrm{o}} 5$ que rompeu por aderência - MORITA et al (1992)

FIGURA 3.27 - Curvas força-deslizamento do modelo n⿳0 6 que rompeu por aderência MORITA et al (1992).

FIGURA 3.28 - Variação da flecha máxima versus número de ciclos para as vigas VSA - BRAGUIM (1995)

FIGURA 4.1 - Materiais na betoneira após a mistura....................................................... 77

FIGURA 4.2 - Moldagem dos modelos....................................................................... 77

FIGURA 4.3 - Moldagem dos corpos-de-prova cilíndricos $10 \mathrm{~cm}$ x $20 \mathrm{~cm}$..................... 78

FIGURA 4.4 - Ensaio de módulo de elasticidade com CPs $10 \mathrm{~cm}$ x $20 \mathrm{~cm}$...................... 79

FIGURA 4.5 - (a) Comportamentos típicos tensão-deformação de pasta de cimento, agregado e concreto; (b) Curva tensão-deformação do concreto...................................... 82

FIGURA 4.6 - Ensaio da armadura sob tração........................................................... 84

FIGURA 4.7 - Diagrama tensão-deformação do aço....................................................... 85

FIGURA 4.8 - Tipos de limite de escoamento............................................................. 86

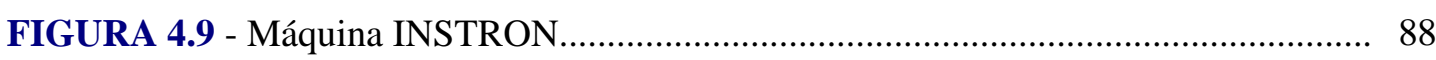

FIGURA 4.10 - Detalhe do dispositivo e da instrumentação do ensaio............................. 89

FIGURA 4.11 - Fôrmas dos modelos piloto 1 e 2 ............................................................. 90

FIGURA 4.12 - Instrumentação da armadura dos modelos piloto 1 e 2 2........................... 90 
FIGURA 4.13 - (a) Ruptura do modelo piloto 2; (b) Degradação da aderência pelos extensômetros na armadura dos modelos piloto 1 e 2 ........................................................ 91

FIGURA 4.14 - Fôrmas dos modelos: (a) Série 10; (b) Série 20..................................... 92

FIGURA 4.15 - Detalhe da fôrma dos modelos............................................................... 93

FIGURA 5.1 - Calibragem dos parâmetros do material com o modelo de dano de Mazars para carregamento cíclico 95

FIGURA 5.2 - Ruptura ao cisalhamento do concreto entre as nervuras 95

FIGURA 5.3 - Modelo de atrito para o contato superfície-superfície.................................. 98

FIGURA 5.4 - Elemento finito PLANE42 ……….................................................... 99

FIGURA 5.5 - Elemento finito CONTA171 _............................................................... 100

FIGURA 5.6 - Elemento finito TARGE169_.......................................................... 101

FIGURA 5.7 - Elemento finito SOLID65 .................................................................... 101

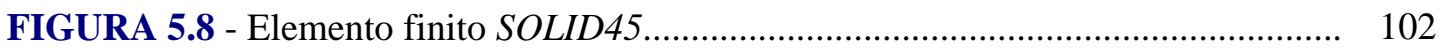

FIGURA 5.9 - Elemento finito CONTA173 ……..................................................... 103

FIGURA 5.10 - Elemento finito TARGE170_........................................................... 104

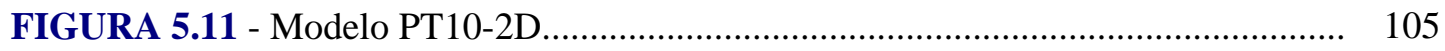

FIGURA 5.12 - Modelo PT10-3D ......................................................................... 106

FIGURA 6.1 - (a) Ruptura por arrancamento de um modelo; (b) Corte de um modelo... 108

FIGURA 6.2 - Diagrama tensão-deformação do concreto.................................................. 109

FIGURA 6.3 - Diagrama tensão-deformação do aço........................................................ 109

FIGURA 6.4 - Curva monotônica tensão de aderência-deslizamento dos modelos

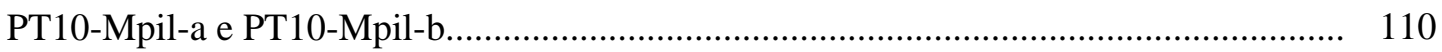

FIGURA 6.5 - Curva monotônica tensão de aderência-deslizamento dos modelos

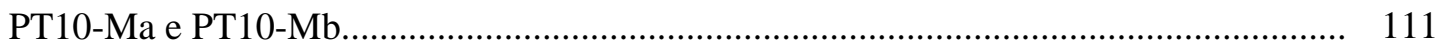

FIGURA 6.6 - Curva monotônica tensão de aderência-deslizamento dos modelos PT20-Ma e PT20-Mb.

FIGURA 6.7 - Digrama representativo das fases do comportamento da aderência dos ensaios monotônicos

FIGURA 6.8 - Curva média dos modelos das séries 10 e 20.

FIGURA 6.9 - Comparação dos valores de $\tau_{\mathbf{1}}$, $\tau_{\mathbf{b u}}$ e $\mathbf{s}_{\mathbf{u}}$ experimentais com os propostos pelas normas

FIGURA 6.10 - Comparação da série 10 com o CEB-FIP MC90.................................... 119

FIGURA 6.11 - Comparação da série 20 com o CEB-FIP MC90.................................... 119 
FIGURA 6.12 - Curva repetida tensão de aderência-deslizamento do modelo PT10Rpil

FIGURA 6.13 - Curva monotônica tensão de aderência-deslizamento do modelo PT10-Rpil e PT10-Mref.

FIGURA 6.14 - Modelo PT10-1Ra: (a) Curva tensão de aderência-deslizamento; (b) Curva deslizamento-número de ciclos; (c) História do carregamento; (d) Oscilação do deslizamento a cada meio ciclo.

FIGURA 6.15 - Modelo PT10-1Rb: (a) Curva tensão de aderência-deslizamento; (b) Curva deslizamento-número de ciclos; (c) História do carregamento; (d) Oscilação do deslizamento a cada meio ciclo......

FIGURA 6.16 - Modelo PT10-2Ra: (a) Curva tensão de aderência-deslizamento; (b) Curva deslizamento-número de ciclos; (c) História do carregamento; (d) Oscilação do deslizamento a cada meio ciclo.......

FIGURA 6.17 - Modelo PT10-2Rb: (a) Curva tensão de aderência-deslizamento; (b) Curva deslizamento-número de ciclos; (c) História do carregamento; (d) Oscilação do deslizamento a cada meio ciclo.

FIGURA 6.18 - Modelo PT20-1R: (a) Curva tensão de aderência-deslizamento; (b) Curva deslizamento-número de ciclos; (c) História do carregamento; (d) Oscilação do deslizamento a cada meio ciclo...

FIGURA 6.19 - Modelo PT20-2R: (a) Curva tensão de aderência-deslizamento; (b) Curva deslizamento-número de ciclos; (c) História do carregamento; (d) Oscilação do deslizamento a cada meio ciclo...

FIGURA 6.20 - Modelo PT20-3R: (a) Curva tensão de aderência-deslizamento; (b) Curva deslizamento-número de ciclos; (c) História do carregamento; (d) Oscilação do deslizamento a cada meio ciclo.

FIGURA 6.21 - Modelo PT20-4R: (a) Curva tensão de aderência-deslizamento; (b) Curva deslizamento-número de ciclos; (c) História do carregamento; (d) Oscilação do deslizamento a cada meio ciclo.

FIGURA 6.22 - Curva monotônica tensão de aderência-deslizamento dos modelos repetidos com a média dos modelos monotônicos de referência da Série 10.

FIGURA 6.23 - Curva monotônica tensão de aderência-deslizamento dos modelos repetidos com a média dos modelos monotônicos de referência da Série 20.

FIGURA 6.24 - Digrama representativo do comportamento da aderência dos ensaios repetidos. 
FIGURA 6.25 - Curva força-deslizamento da média (PT10-Ma e PT10Mb) e PT10-2D 134

FIGURA 6.26 - Deformada - PT10-2D...................................................................... 134

FIGURA 6.27 - Deslizamento - PT10-2D .................................................................... 134

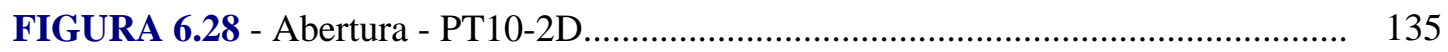

FIGURA 6.29 - Penetração - PT10-2D....................................................................... 135

FIGURA 6.30 - Pressão - PT10-2D ......................................................................... 136

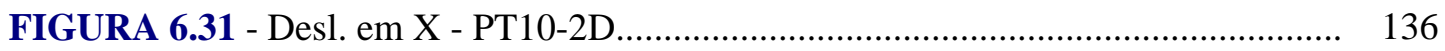

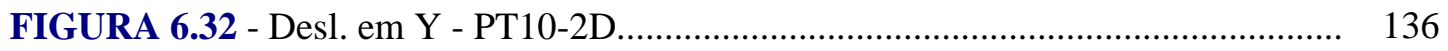

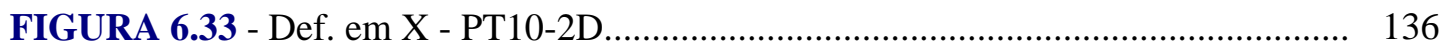

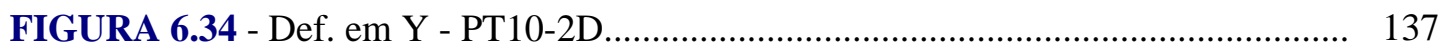

FIGURA 6.35 - Def. em XY - PT10-2D....................................................................... 137

FIGURA 6.36 - Curva força-deslizamento da média (PT10-Ma e PT10Mb) e PT10-3D 138

FIGURA 6.37 - Deformada - PT10-3D..................................................................... 138

FIGURA 6.38 - Deslizamento - PT10-3D.................................................................. 138

FIGURA 6.39 - Desl. em Z (CONTA173) - PT10-3D.................................................... 139

FIGURA 6.40 - Desl. em Z (TARGE170) - PT10-3D.................................................... 139

FIGURA 6.41 - Deformação em X - PT10-3D........................................................... 140

FIGURA 6.42 - Deformação em Y - PT10-3D........................................................... 140

FIGURA 6.43 - Abertura - PT10-3D........................................................................ 141

FIGURA 6.44 - Penetração - PT10-3D....................................................................... 141

FIGURA 6.45 - Pressão - PT10-3D ........................................................................ 141

FIGURA 6.46 - Def. em XZ - PT10-3D ................................................................ 141

FIGURA 6.47 - Def. em YZ - PT10-3D ................................................................ 141

FIGURA 6.48 - Def. em XZ no concreto e no aço - PT10-3D......................................... 142

FIGURA 6.49 - Def. em YZ no concreto e no aço - PT10-3D........................................ 142 


\section{LISTA DE TABELAS}

TABELA 2.1 - Parâmetros para definir a relação média tensão de aderênciadeslizamento para barra nervurada (de acordo com as equações 2.1 a 2.4). 33

TABELA 2.2 - Parâmetros para definir a relação média tensão de aderênciadeslizamento para barra lisa (de acordo com as equações 2.1 a 2.4).

TABELA 2.3 - Valores de projeto da resistência de aderência para boas condições de aderência - EUROCODE 2 (1992) 34

TABELA 4.1 - Resumo das características gerais dos modelos. 72

TABELA 4.2 - Análise granulométrica do agregado miúdo (NBR 7217/87) 74

TABELA 4.3 - Análise granulométrica do agregado graúdo (NBR 7217/87). 75

TABELA 4.4 - Características dos materiais utilizados no concreto. 75

TABELA 4.5 - Consumo dos materiais utilizados na confecção do concreto. 76

TABELA 4.6 - Instrumentos utilizados nos ensaios.................................................... 87

TABELA 6.1 - Caracterização do concreto.................................................................. 108

TABELA 6.2 - Caracterização do aço............................................................................. 109

TABELA 6.3 - Comparação dos valores de $\tau_{\mathbf{l}}$, $\tau_{\mathbf{b u}}$ e $\mathbf{s}_{\mathbf{u}}$ experimentais com os propostos pelas normas. 
FERNANDES, R.M. (2000). A influência das ações repetidas na aderência aço-concreto. São Carlos, 2000. 155p. Dissertação (Mestrado) - Escola de Engenharia de São Carlos, Universidade de São Paulo.

Este trabalho descreve o comportamento da aderência do concreto armado sob ações monotônicas e repetidas através de uma revisão bibliográfica e de ensaios de arrancamento padronizados. A influência de alguns parâmetros foi analisada, como diâmetro da armadura, tipo e amplitude de carregamento. Os resultados dos ensaios monotônicos foram comparados com as recomendações do CEB-FIP MC 1990, EUROCODE 2 e NB-1/78. Também foi realizada a análise numérica da aderência monotônica por meio de elementos finitos. Considerou-se a barra lisa, elementos de contato entre o aço e concreto e comportamento elástico-linear dos materiais; pois a ruína experimental da ligação ocorreu pelo corte do concreto entre as nervuras. A resistência monotônica da ligação ficou compreendida entre condições boas e ruins de aderência. Os resultados calculados de acordo com as normas foram muito diferentes em relação aos valores experimentais, e apresentaram uma dispersão muito grande. A força repetida ocasionou a perda de aderência pelo crescimento progressivo dos deslizamentos. Os modelos numéricos não representaram o comportamento experimental, devido à resposta força-deslizamento não-linear.

Palavras-chave: concreto armado, aderência, força monotônica, força repetida, arrancamento, elementos finitos. 
FERNANDES, R.M. (2000). The influence of repeated loads on the steel-concrete bond. São Carlos, 2000. 155p. Dissertação (Mestrado) - Escola de Engenharia de São Carlos, Universidade de São Paulo.

This research describes the bond behaviour in reinforced concrete under monotonic and repeated loading through a state-of-art and standard pull-out tests. The influence of some parameters was analysed as deformed bar diameter, type and amplitude of loading. The monotonic test results were compared with recommendations of CEB-FIP MC 1990, EUROCODE 2 and NB-1/78. The numerical analysis of monotonic bond was realized through finite elements. It was considered smooth bar, contact elements between the steel and concrete, and materials as of linear-elastic behaviour, because the experimental degradation of bond was caused by concrete between the ribs sheared off. The monotonic bond resistance resulted between good and bad bond conditions. The results calculated according to the codes were very different from the experimental values and very disperse. The repeated loading causes bond degradation by progressive increase of slip. The numerical specimens did not represent the experimental behaviour because of the non-linear load-slip response.

Keywords: reinforced concrete, bond, monotonic loading, repeated loading, pull-out, finite elements. 


\section{1}

\section{INTRODUÇÃO}

\subsection{GENERALIDADES}

Atualmente, com o crescente avanço das técnicas de construção e dos conhecimentos científicos ligados à Engenharia, têm sido projetadas estruturas cada vez mais esbeltas. Para fazer isso com segurança, é preciso conhecer melhor o comportamento do material, que no caso do concreto armado, é de grande complexidade, pois, mesmo em serviço, as estruturas de concreto armado apresentam não-linearidade física, ou seja, a seção do elemento estrutural trabalha fissurada.

A existência do concreto armado deve-se essencialmente à solidariedade que existe entre o aço e o concreto, denominada de aderência.

Uma das principais contribuições da aderência para o concreto armado é garantir uma boa capacidade de utilização da estrutura, através da limitação da abertura de fissuras e uma melhor distribuição dessas ao longo da peça, podendo evitar flechas excessivas e rupturas localizadas.

A aderência é também utilizada para a ancoragem da força de tração pelo equilíbrio na zona de ancoragem com as bielas de compressão, que se propagam pelo concreto a partir da extremidade da armadura. Entretanto, uma boa ancoragem por aderência das barras com extremidades retas depende das nervuras, devido à resistência ao cisalhamento do concreto entre as nervuras.

Esse mecanismo de transferência de tensões entre o aço e o concreto é de grande complexidade, fortemente afetado pelas ações às quais a peça está submetida. 
Além da perda de rigidez associada a uma maior propagação de fissuras, a ação cíclica, um dos tipos das ações dinâmicas, ocasiona uma diminuição da aderência entre o aço e o concreto.

De forma geral, pode-se dizer que as consequiências da atuação dessas ações na estrutura são:

- ruptura por fadiga da aderência, a qual é caracterizada por um maior deslocamento relativo entre a armadura e o concreto;

- ruína prematura da ligação em um nível de tensão mais baixo que o relativo à ação monotônica;

- aumento das deformações nos elementos estruturais, devido à diminuição da rigidez e da aderência.

A forma clássica de se avaliar o efeito dos carregamentos cíclicos nas estruturas costuma ser através do estudo da fadiga. Entretanto, nos últimos anos, tem surgido uma nova abordagem para o problema, mediante o estudo da degradação da ligação aço-concreto.

Nesse trabalho, será dado o enfoque na aderência em barras nervuradas sob força monotônica e repetida.

\subsection{OBJETIVOS}

O principal objetivo da presente pesquisa consiste em se fazer uma análise crítica do comportamento da aderência sob força monotônica e repetida através da investigação experimental, por meio de ensaio de arrancamento padronizado. Será analisada a forma de ruptura, a capacidade última da ligação, a influência do nível de solicitação da força repetida e do deslizamento residual na ruptura da ligação, para dois diâmetros de armadura. Em relação à força monotônica, será realizada uma comparação dos resultados experimentais com os obtidos das recomendações das normas CEB-FIP MC 1990, EUROCODE 2 e NB-1/78 (NBR 6118).

Será apresentada também uma modelagem numérica do ensaio monotônico, procurando-se analisar o comportamento do elemento de contato colocado entre os dois materiais. 


\subsection{METODOLOGIA}

A primeira etapa deste trabalho consistiu em uma revisão bibliográfica sobre o problema da aderência sob ações monotônicas e cíclicas, de modo a fornecer os conhecimentos necessários para a realização desta pesquisa.

Como uma segunda etapa, foram realizadas simultaneamente a investigação experimental e a análise numérica da aderência. O modelo dos ensaios de arrancamento é o padronizado pela RILEM-FIP-CEB (1973). A modelagem numérica, realizada no programa computacional Ansys, por meio de elementos finitos, simula o mesmo corpo-de-prova utilizado na pesquisa experimental.

\subsection{APRESENTAÇÃO}

No primeiro capítulo, é feita uma abordagem geral do problema da aderência, enfatizando-se o efeito das ações cíclicas. Em seguida, são apresentados os objetivos, a metodologia e o conteúdo da dissertação.

O segundo capítulo descreve a análise da aderência em geral, mostrando os principais mecanismos de mobilização, modelos de comportamento propostos e resultados disponíveis na literatura.

É dado um enfoque ao problema da aderência sob ação cíclica, no terceiro capítulo, com a apresentação de modelos de comportamento e resultados da literatura.

São descritos, no quarto capítulo, todos os aspectos da experimentação física dos modelos, tais como: caracterização dos materiais, metodologia empregada nos ensaios, instrumentação utilizada, procedimentos de confecção e esquema da fôrma dos modelos.

No quinto capítulo, será mostrada a análise numérica da aderência monotônica, indicando os elementos finitos utilizados, discretização dos modelos, hipóteses e parâmetros adotados na modelagem.

O sexto capítulo apresenta os resultados obtidos na investigação experimental e na análise numérica, juntamente com a sua análise e discussão. 
São apresentadas as conclusões finais desse trabalho, com sugestões para novas pesquisas sobre o assunto, no sétimo capítulo.

As referências bibliográficas e a bibliografia complementar utilizadas no desenvolvimento desta pesquisa são descritas em seguida, finalizando a dissertação. 


\section{COMPORTAMENTO DA ADERÊNCIA}

\subsection{DEFINIÇÃO DE ADERÊNCIA}

Um dos principais requisitos para o bom funcionamento do concreto armado é a eficiência da ligação aço-concreto. A nível global de comportamento, a aderência garante que a deformação da armadura como um todo seja igual à das fibras vizinhas de concreto. Entretanto, o comportamento local da aderência é mais complexo, pois envolve descontinuidades como as fissuras e, conseqüentemente, deslocamentos relativos entre a armadura e o concreto. Portanto, as deformações do aço e do concreto não são exatamente iguais.

Pode-se definir aderência como sendo o mecanismo de transferência de tensões que existe na interface entre a barra de aço da armadura e o concreto que a envolve. Esse fenômeno é tão importante, que a própria definição de concreto armado se condiciona à sua existência. A forma usual de consideração dessa ligação tem sido por meio da definição de uma "tensão de aderência", e sua distribuição ao longo da interface tem sido exaustivamente investigada, já que seu conhecimento é essencial para a compreensão do comportamento de ancoragens retas, dos ganchos e das emendas.

A eficiência dessa ligação pode ser convenientemente quantificada através da relação tensão de aderência versus deslizamento, a qual representa a variação da tensão que surge na interface do aço com o concreto, relacionada ao deslocamento 
relativo entre a barra da armadura e o concreto envolvente. Valores máximos desse deslizamento podem ser usados para definir a destruição da aderência, geralmente associados a um certo estado de deformações e fissuração.

O estudo do problema mais simples a ser considerado, o da ancoragem das barras em suas extremidades, pode ser feito mediante ensaios físicos e numéricos de arrancamento de barras de aço de blocos de concreto, onde o objetivo é a utilização da aderência para a completa transferência da força da barra de aço para o concreto subjacente. Um estudo mais elaborado sobre o assunto, aplicado ao problema usual de vigas, seria quando da mobilização da aderência na flexão, em função de alterações da força na barra da armadura, devido à variação de momento fletor.

\subsection{COMPONENTES DA ADERÊNCIA}

Embora a concepção de um valor médio da tensão de aderência seja conveniente, a transferência de forças está associada a uma combinação das parcelas relativas à adesão, ao atrito e à aderência mecânica. Esta divisão, entretanto, é meramente didática, não sendo possível determinar-se cada componente isoladamente, devido à complexidade dos fenômenos envolvidos.

\subsubsection{ADERÊNCIA POR ADESÃO}

A adesão ou aderência química surge devido às ligações físico-químicas na interface durante as reações de pega do cimento. Essa parcela, caracterizada por uma resistência de adesão $\mathbf{R}_{\mathbf{b 1}}$ como indicada na figura 2.1, pode ser constatada através da separação de um bloco concretado sobre uma chapa metálica. Neste caso, verifica-se somente a existência da ligação por adesão. 


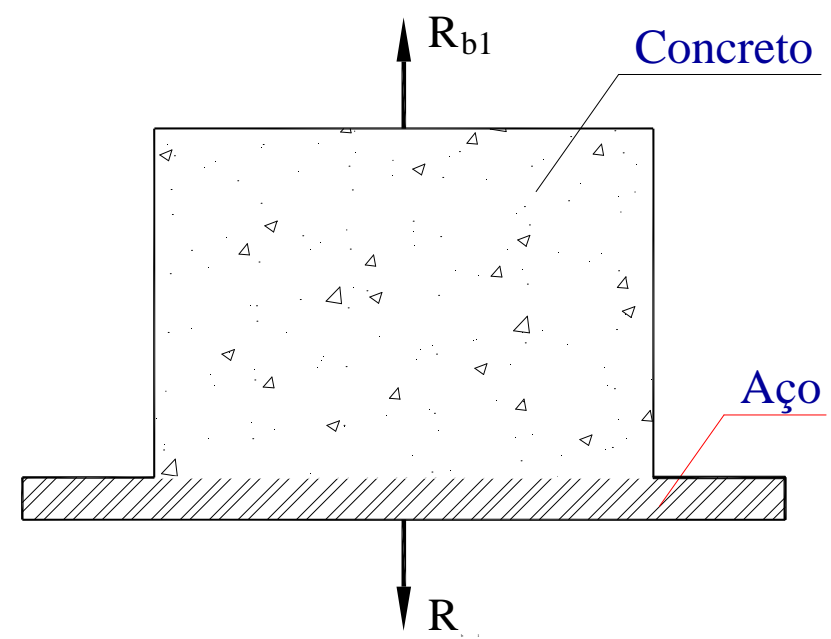

FIGURA 2.1 - Aderência por adesão

Geralmente, considera-se que a adesão seja destruída pelas ações de serviço ou retração do concreto e que as tensões de aderência próximas da ruptura sejam mobilizadas principalmente pelo engrenamento mecânico entre as nervuras. Entretanto, de acordo com o ACI COMMITTEE 408 (1991), dados recentes comparando o comportamento de barras lisas com barras revestidas com epoxi mostram que a parcela de adesão pode ter uma grande contribuição na aderência no caso de ruptura por fendilhamento, fenômeno que será descrito no item 2.6.

\subsubsection{ADERÊNCIA POR ATRITO}

A parcela relativa ao atrito é decorrente da ação das forças de atrito existentes entre os dois materiais. Estas forças dependem do coeficiente de atrito entre o aço e o concreto, o qual é função da rugosidade superficial da barra. A aderência por atrito, a qual se manifesta devido à pressão transversal do concreto sobre a armadura como, por exemplo, a de retração ou de confinamento, pode ser determinada através de ensaios de arrancamento, que consistem na aplicação de uma força de tração $\mathbf{R}_{\mathbf{b 2} 2}$ na barra, conforme a figura 2.2. Neste caso, além da contribuição relativa ao atrito, existe uma parcela de aderência por adesão. 


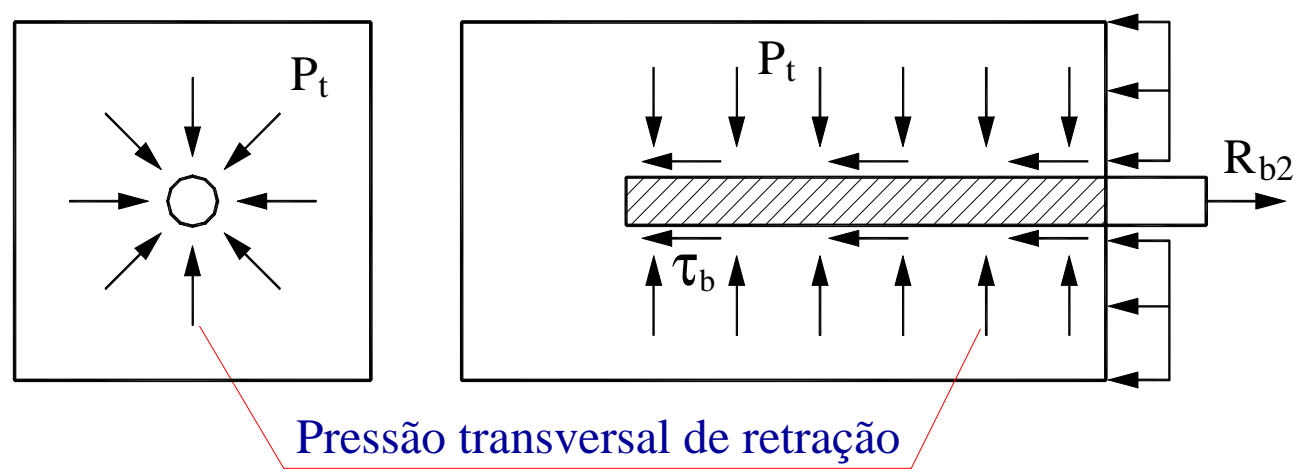

FIGURA 2.2 - Aderência por atrito

\subsubsection{ADERÊNCIA MECÂNICA}

Essa componente, caracterizada pela força $\mathbf{R}_{\mathbf{b 3}}$ da figura 2.3, está associada a forças concentradas de compressão que surgem perpendiculares às faces das nervuras no momento em que a barra é tracionada e tende a deslizar. Estas forças provocam a micro-fissuração e o micro-esmagamento do concreto na região das nervuras. Mesmo em barras lisas, existe o efeito da aderência mecânica, devido às irregularidades superficiais decorrentes do processo de laminação.

\section{Barra lisa}

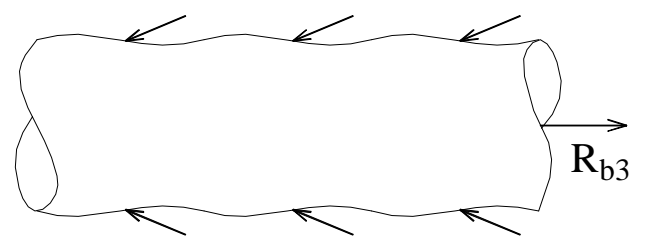

Barra nervurada

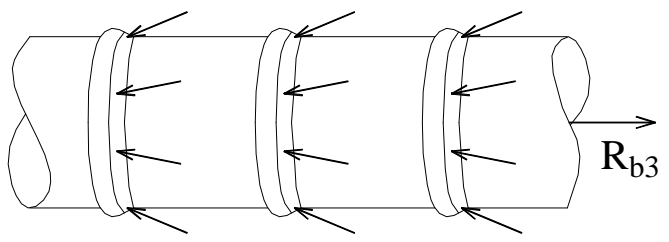

FIGURA 2.3 - Aderência mecânica

Em barras nervuradas, o valor da resistência de aderência mecânica depende da forma e da inclinação das nervuras, da altura a e da distância livre entre elas c. De acordo com REHM ${ }^{1}$ apud LEONHARDT (1977), a superfície relativa $\mathbf{f}_{\mathbf{R}}{ }^{*}$ fornece uma medida de comparação utilizável para barras de perfis diferentes. Esta superfície

\footnotetext{
${ }^{1}$ REHM, G. (1969). Kriterien zur Beurteilung von Bewehrungsstäben mit hochwertigem Verbund. Stahlbetonbau, Berlin, p.79-96 apud LEONHARDT (1977)
} 
nervurada relativa $\left(\mathbf{f}_{\mathbf{R}}\right)^{*}$ é definida pela relação entre a superfície das nervuras $\left(\mathbf{F}_{\mathbf{R}}\right)^{*}$, área de contato dos consolos de concreto sobre as nervuras, e a superfície lateral $\left(\mathbf{F}_{\mathbf{M}}\right)^{*}$ do cilindro a ser "cortado", como ilustra a figura 2.4.

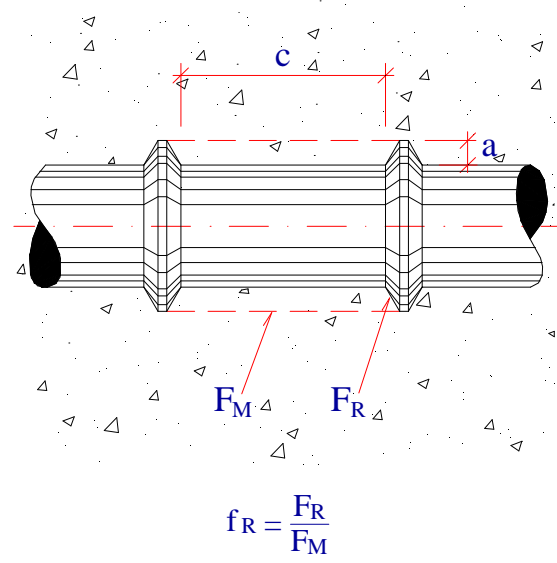

(a) Barra nervurada (idealizada)

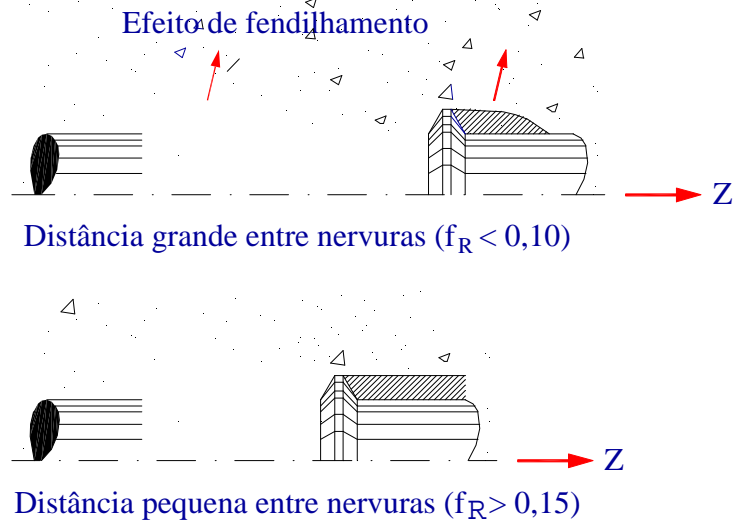

(b) Área de ruptura dos consolos de concreto entre as nervuras

FIGURA 2.4 - Explicação das designações em uma barra ideal com nervuras anulares e áreas possíveis de ruptura dos consolos de concreto entre nervuras

- REHM apud LEONHARDT (1977) -

\subsection{MOBILIZAÇÃO DA ADERÊNCIA NA FISSURAÇÃO}

A aderência aço-concreto permite que as forças de tração possam ser absorvidas pelas armaduras. Quando as tensões de tração são suficientemente baixas, o concreto não apresenta fissuras e resiste à tração, permanecendo no Estádio I. Na presença de maiores solicitações de tração, a resistência do concreto à tração é atingida, ocasionando a fissuração da peça. A partir daí, o concreto está no Estádio II.

Com a passagem do Estádio I para o estádio II, nas seções fissuradas, a tensão de tração no concreto se anula, causando um correspondente crescimento da tensão de tração na armadura, como apresenta a figura 2.5. Este modelo de tirante, entretanto, é idealizado, ou seja, não são consideradas as microfissuras próximas da

\footnotetext{
* Notação mantida de LEONHARDT (1977).
} 
fissura principal, que ocasionam os deslizamentos localizados, como indica a figura 2.7 .

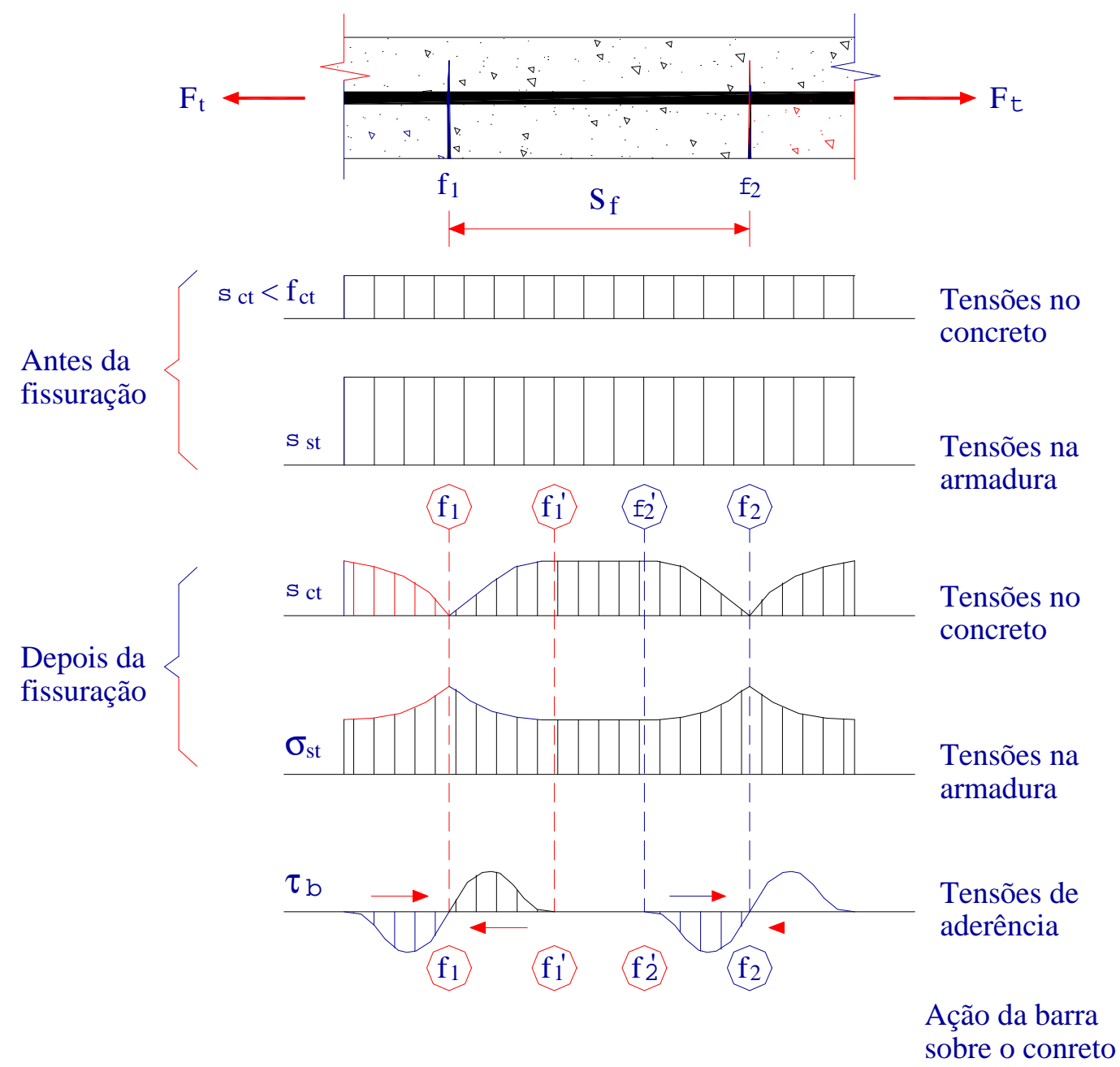

FIGURA 2.5 - Fissuração por tração

Nas seções fissuradas, a tensão na armadura atinge o valor máximo. Nas seções mais afastadas da fissura, a tensão diminui e o concreto é tracionado novamente, devido à aderência.

$\mathrm{Na}$ figura 2.5 , entre as fissuras $\mathbf{f}_{\mathbf{1}}$ e $\mathbf{f}_{\mathbf{2}}$, distantes entre si de $\mathbf{s}_{\mathbf{f}}$, as tensões de aderência são mobilizadas apenas nos trechos $\overline{\mathbf{f}_{\mathbf{1}} \mathbf{f}_{\mathbf{1}}^{\prime}}$ e $\overline{\mathbf{f}_{\mathbf{2}} \mathbf{f}_{\mathbf{2}}^{\prime}}$. Logo, no trecho $\overline{\mathbf{f}_{\mathbf{1}}^{\prime} \mathbf{f}_{\mathbf{2}}^{\prime}}$, as tensões no concreto e na armadura são constantes. Elevando-se o nível de carregamento, a tensão na armadura aumenta, podendo a tensão no concreto crescer também. Portanto, as tensões de aderência podem ser mobilizadas no trecho $\overline{\mathbf{f}_{\mathbf{1}}^{\prime} \mathbf{f}_{\mathbf{2}}^{\prime}}$ 
com a possibilidade de surgir uma nova fissura $\mathbf{f}_{\mathbf{3}}$ entre as já existentes, como ilustra a figura 2.6.

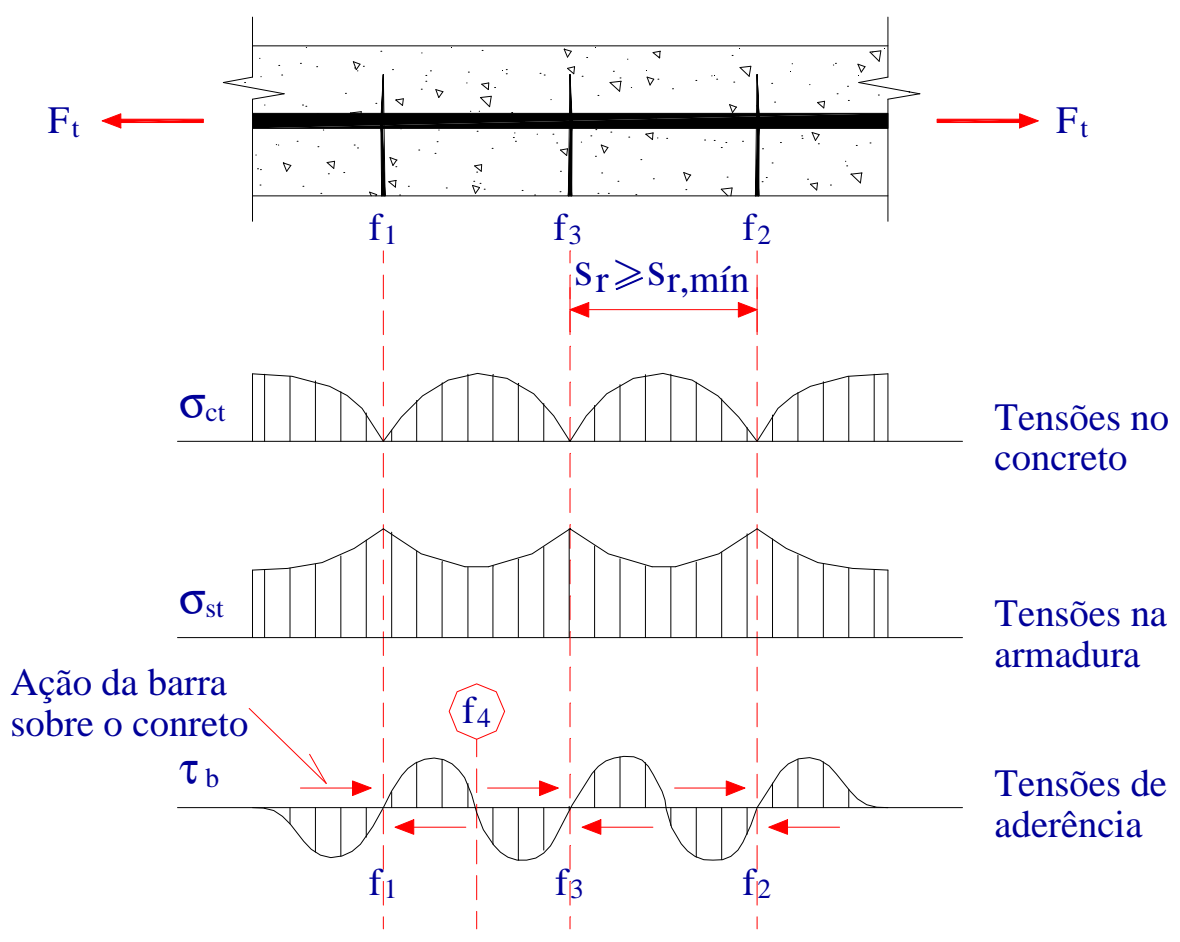

FIGURA 2.6 - Fissuração estabilizada

Após a formação da nova fissura $\mathbf{f}_{3}$, no trecho $\overline{\mathbf{f}_{1} \mathbf{f}_{2}}$, a tensão no concreto dependerá da capacidade de transferência de tensões da armadura para o concreto. $\mathrm{O}$ espaçamento das fissuras não pode ser inferior a um valor mínimo. Se as tensões de aderência mobilizadas no trecho $\overline{\mathbf{f}_{\mathbf{1}} \mathbf{f}_{\mathbf{4}}}$ e $\overline{\mathbf{f}_{\mathbf{4}} \mathbf{f}_{\mathbf{3}}}$ não forem suficientes para que a resistência à tração do concreto seja alcançada, não haverá formação de uma nova fissura entre $\mathbf{f}_{\mathbf{1}}$ e $\mathbf{f}_{\mathbf{3}}$.

No estudo realizado por GOTO ${ }^{1}$ apud LEONHARDT (1977) sobre os fenômenos de aderência, foi demonstrado que a força de tração ocasiona uma microfissuração (fissuras secundárias internas entre fissuras principais) no concreto envolvente e, conseqüentemente, a perda de adesão, tornando-se cada vez mais

\footnotetext{
${ }^{1}$ GOTO, Y. (1971). Cracks formed in concrete around deformed tension bars. ACI Journal, v.68, n.4, p.244-51, Apr. apud LEONHARDT (1977)
} 
importante a ancoragem mecânica (figura 2.7). No caso de ações repetidas, esse fenômeno se torna mais intenso.
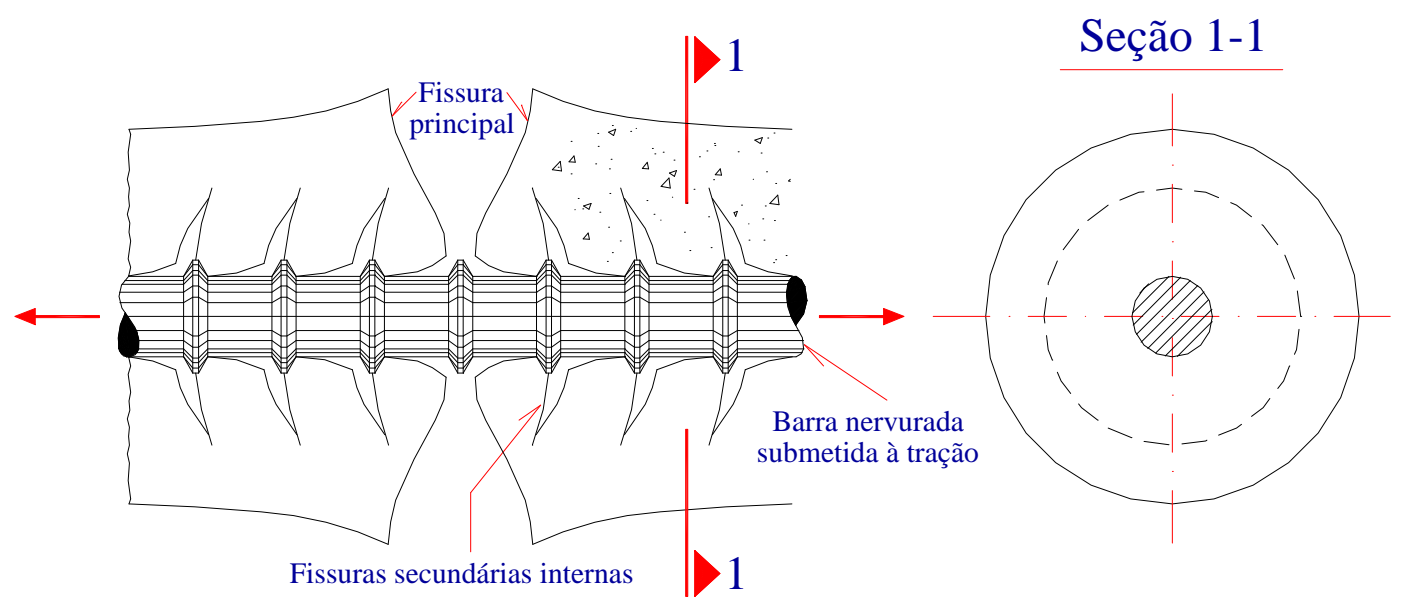

FIGURA 2.7 - Microfissuras (fissuras secundárias) entre fissuras principais, em uma barra de concreto armado sob tração centrada

- GOTO apud LEONHARDT (1977) -

\subsection{CAUSAS DAS TENSÕES DE ADERÊNCIA}

As tensões de aderência, as quais surgem devido à variação de tensões no aço em um determinado trecho, têm as seguintes causas:

- Ações externas - influenciam alterações das tensões de tração e compressão no aço;

- Fissuras - acarretam um acréscimo de tensões na armadura aumentando, por conseguinte, as tensões de aderência;

- Forças de ancoragem nas extremidades das barras - pelas tensões de aderência, a força atuante na barra é transferida ao concreto;

- Variações de temperatura - a maior condutibilidade térmica do aço induz a uma deformação maior das barras de aço em relação ao concreto, elevando as tensões de aderência e podendo ocasionar a ruptura do cobrimento;

- Retração do concreto - é impedida pela barra de aço, ocasionando tensões de tração no concreto e tensões de compressão na armadura; 
- Deformação lenta do concreto em peças comprimidas de concreto armado (pilares) - devido ao encurtamento causado pela deformação lenta, a armadura sofre um acréscimo de tensões de compressão, aliviando o concreto.

\subsection{FATORES QUE INFLUENCIAM A ADERÊNCIA}

Dentre os vários fatores que influenciam o comportamento da aderência sob ações monotônicas e cíclicas, alguns são citados abaixo:

- Características do concreto e dos seus componentes

- Classe do aço

- Tensão de escoamento do aço (se houver escoamento da armadura)

- Cobrimento e espaçamento da armadura

- Diâmetro da armadura

- Comprimento de ancoragem

- Tipo e geometria da nervura

- Efeitos de confinamento

- Quantidade e posição da armadura transversal

- Posição da armadura em relação à concretagem

- Repetição do carregamento

- Número de ciclos e amplitude do carregamento cíclico

- Tipo, velocidade e duração do carregamento

- Temperatura

- Revestimento da armadura

\subsection{RUPTURA DA ADERÊNCIA}

Existem dois tipos de rupturas da aderência para corpos-de-prova sob ação monotônica: ruptura por arrancamento direto da barra e fendilhamento do cobrimento do concreto. 
A primeira ocorre quando existe um confinamento suficiente da armadura, permitindo o corte do concreto entre as nervuras. Esse modo de ruptura está relacionado principalmente à resistência do concreto e ao tipo e à geometria das nervuras.

Os diferentes modos de ruptura da aderência entre o concreto confinado e não confinado podem ser ilustrados na figura 2.8. O confinamento devido às barras de aço diminui a propagação e a abertura das fissuras, proporcionando o arrancamento da barra.

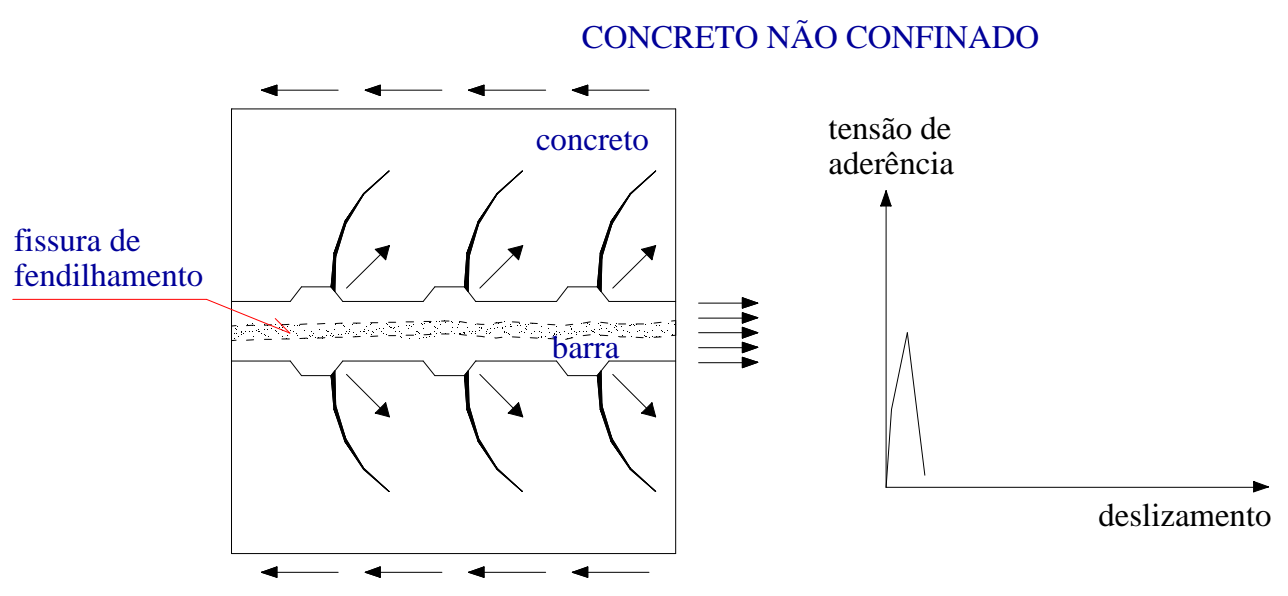

(a)

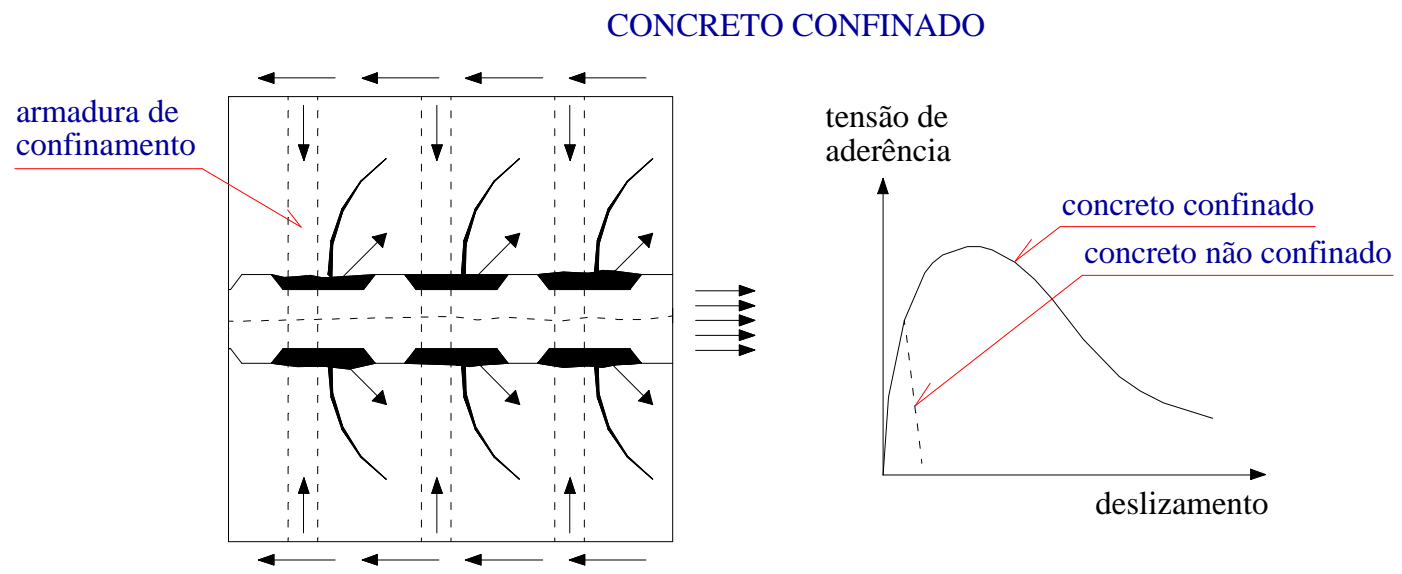

(b)

FIGURA 2.8 - Ruptura por aderência por: (a) fissuração por fendilhamento em concreto não-confinado; (b) arrancamento em concreto confinado 
O fendilhamento do cobrimento pode ser definido como o efeito da tração circunferencial ocasionado pelas componentes radiais das tensões de compressão que transferem o esforço do aço para o concreto. Esse tipo de ruptura ocorre quando o confinamento é insuficiente para garantir o arrancamento completo da barra. As tensões radiais de tração oriundas das tensões diagonais de compressão ocasionam um pressão no concreto em torno da barra, tornando essa região microfissurada e sujeita ao fendilhamento paralelo ao eixo da armadura, como indicam as figuras $2.9 \mathrm{e}$ 2.10. As fissuras de fendilhamento geradas pelas tensões circunferenciais de tração tendem a se propagar em direção às bordas, resultando na perda do cobrimento e da aderência. O número de barras e sua configuração ao longo do elemento são os principais fatores que influenciam a orientação dessas fissuras.

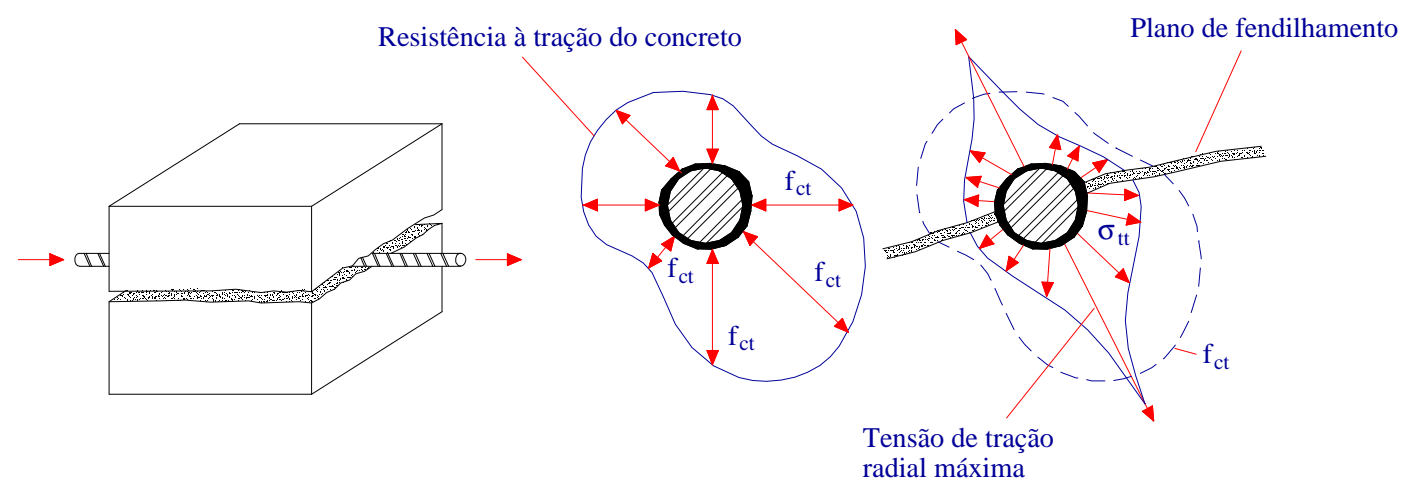

FIGURA 2.9 - Fendilhamento longitudinal do concreto - FUSCO (1995) -

No caso de ação cíclica, o modo de ruptura devido ao carregamento com um número de ciclos relativamente pequeno (low-cycle) é muito semelhante ao do carregamento monotônico. Já para o caso de carregamento com um número de ciclos elevado (high-cycle), pode ocorrer ruína similar; entretanto, deve-se considerar também a possibilidade de ruptura por fadiga do aço e do concreto. 


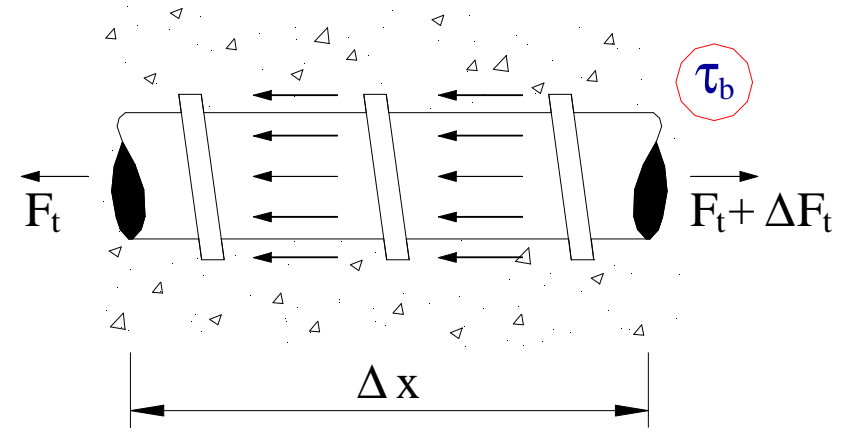

Solicitação tangencial convencional
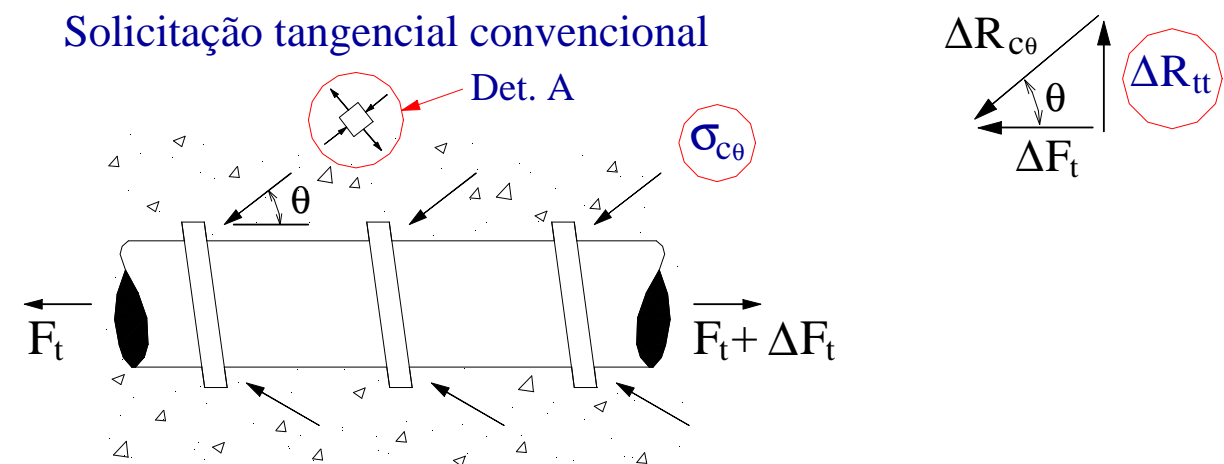

Solicitação de compressão diagonal

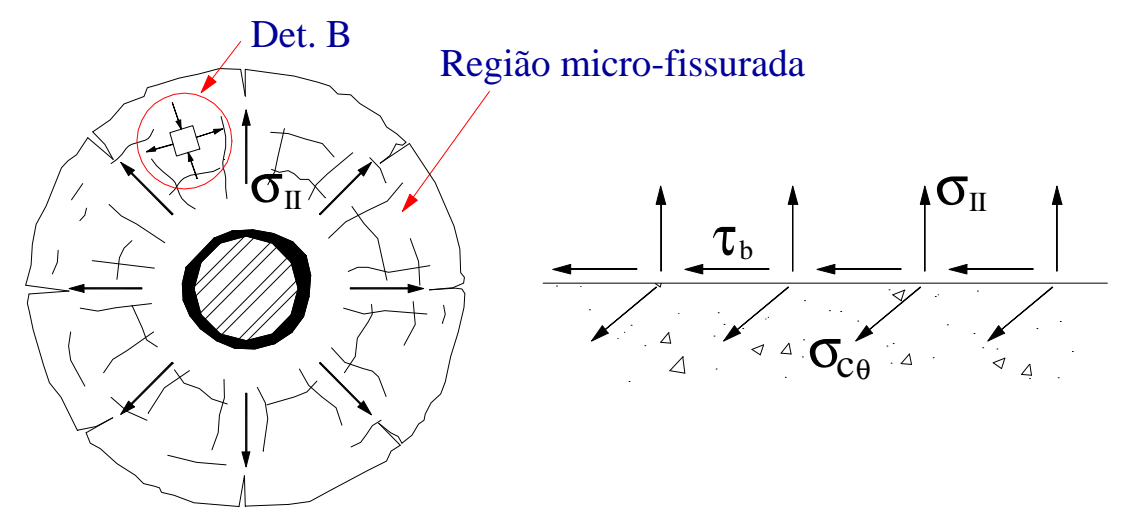

FIGURA 2.10 - Transferência de esforços por aderência - FUSCO (1995) -

\subsection{COMPORTAMENTO DA ADERÊNCIA SOB CARREGAMENTO MONOTÔNICO}

O ACI COMMITTEE 408 (1991) publicou um artigo sobre aderência, onde se faz uma explanação geral sobre o problema, e definem-se os parâmetros mais importantes, como os modos de ruptura, componentes de resistência da aderência, fatores que influenciam a aderência e critérios de projeto. 
O comportamento típico de uma barra sob carregamento monotônico e com ruptura por arrancamento é apresentado na figura 2.11. Tanto o grau de confinamento como o estado de tensão no concreto envolvente à barra (tração ou compressão) influenciam a relação tensão de aderência versus deslizamento.

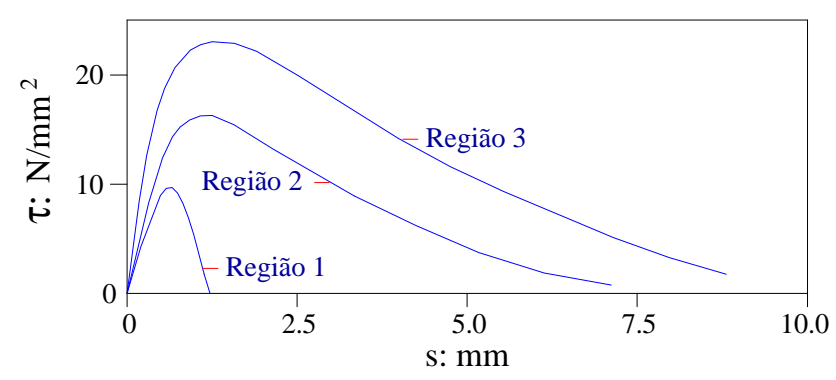

Região 1: Concreto não-confinado* sob tração Região 2: Concreto confinado*

Região 3: Concreto não-confinado* sob compressão

* na direção da força

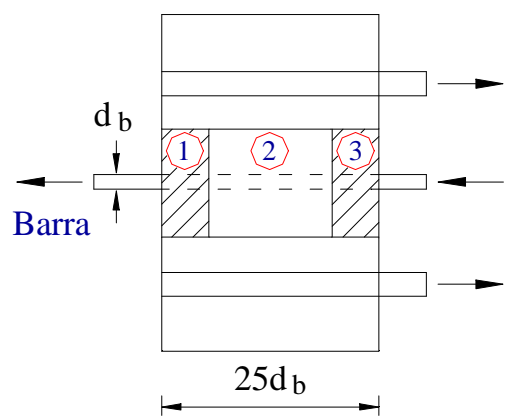

FIGURA 2.11 -Curva tensão de aderência versus deslizamento típica para carregamento monotônico - adaptada de ACI COMMITTE 408 (1991) -

DUCATTI (1993) realizou ensaios de arrancamento (ASTM C-234) em espécimes de Concreto de Alto Desempenho (CAD) sob carregamento monotônico e de curta duração.

A curva tensão de aderência versus deslizamento para os CADs, como a indicada na figura 2.12, tem o mesmo andamento, pelo menos qualitativamente das correspondentes aos concretos comuns.

No programa experimental, foi analisada a influência de alguns parâmetros sobre a relação entre a tensão de aderência e o deslizamento, como: resistência à compressão do concreto, posição das barras em relação à concretagem e teor de microssílica.

Pelos resultados das tensões máximas de aderência em função da resistência à compressão do concreto, constatou-se que, como exposto por SOROUSHIAN et al (1991), a resistência última de aderência aumenta quase proporcionalmente à raiz quadrada da resistência à compressão. 


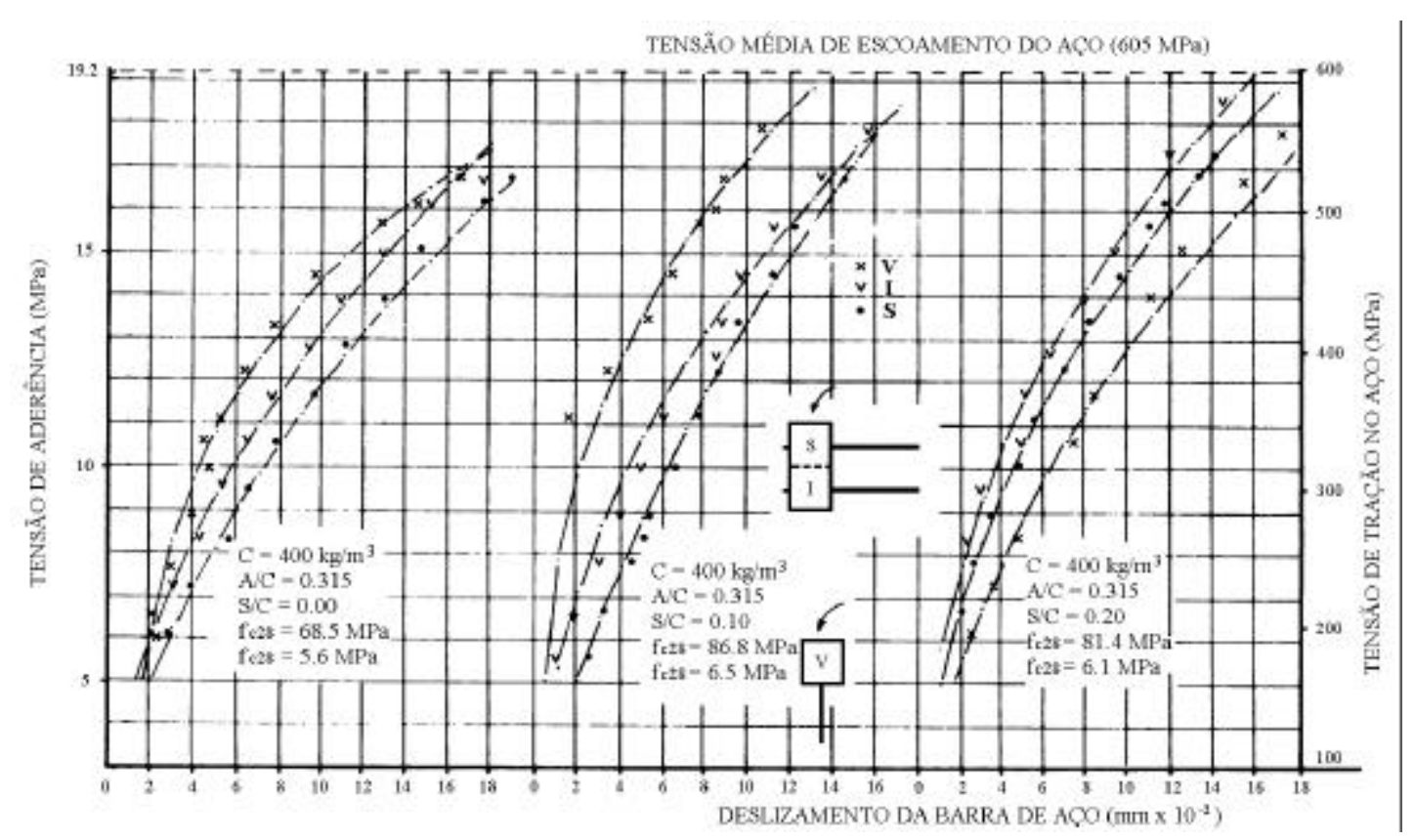

FIGURA 2.12 - Curvas de aderência para as misturas com consumo de cimento de $400 \mathrm{~kg} / \mathrm{m}^{3}$

- DUCATTI (1993) -

Através da comparação dos resultados dos ensaios ASTM C-234 com os de REHM $^{1}$ apud DUCATTI (1993), constatou-se que a posição das barras em relação a direção e sentido de concretagem dos modelos influi de maneira menos acentuada sobre a aderência nos CADs em relação aos concretos comuns. Entretanto, para os CADs de mesmo traço, esta influência se torna visível, embora pequena, para as barras com diferentes posições em relação ao preenchimento do espécime (barras verticais, horizontais inferiores e superiores). As barras horizontais inferiores apresentaram uma maior resistência de aderência que as horizontais superiores e as verticais. Estas últimas tiveram o pior desempenho de aderência, devido às forças de arrancamento terem sido aplicadas no mesmo sentido de sedimentação do concreto.

Em relação à microssílica, a sua presença no CAD aumentou a capacidade de aderência. Verificou-se que, para os diversos consumos de cimento empregados nos ensaios ASTM C-234, existe uma tendência do valor de $10 \%$ de adição de

\footnotetext{
${ }^{1}$ REHM, G. (1996). The basic principles of the bond between steel and concrete. C \& CA Library Translation n.134 (Ûber die Grundlagen des Verbundes Zwischen Stahl und Beton. Deutscher Ausschuss für Stahlbeton, Heft 138, p.59, 1961). London, Cement and Concrete Association, p.66 apud DUCATTI (1993).
} 
microssílica proporcionar uma maior resistência de aderência, principalmente nas misturas de consistência mais fluida (abatimento $>200 \mathrm{~mm}$ ). Segundo GJORV et al ${ }^{1}$ apud DUCATTI (1993), este crescimento da resistência é atribuído por teores crescentes de microssílica, à densificação e à diminuição da espessura da zona de transição entre o concreto e a barra de aço.

BARBOSA (1998) apresentou um estudo experimental e numérico relativo ao Concreto de Alto Desempenho (CAD) sobre a aderência e o comportamento de vigas sob flexão.

Em relação à aderência, procurou-se avaliar a influência da posição das barras em relação à concretagem. Os modelos foram confeccionados segundo as posições das barras verticais (cubo de $20 \mathrm{~cm}$ × $20 \mathrm{~cm}$ x $20 \mathrm{~cm}$ ) e das barras horizontais (prisma de $20 \mathrm{~cm} \times 20 \mathrm{~cm} \times 40 \mathrm{~cm}$ ), conforme a figura 2.13 .

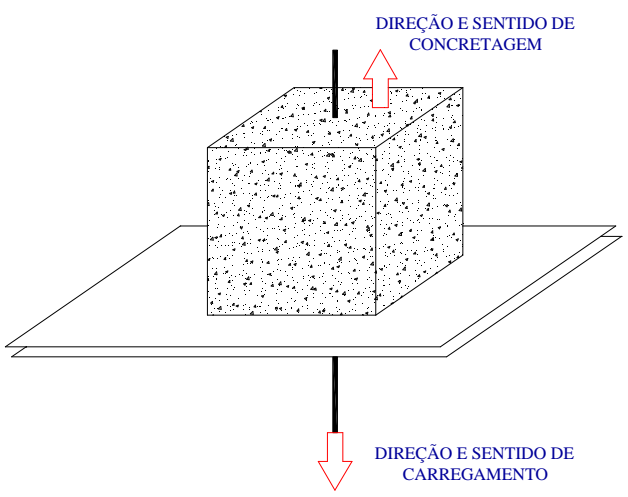

CORPO DE PROVA DE BARRA VERTICAL

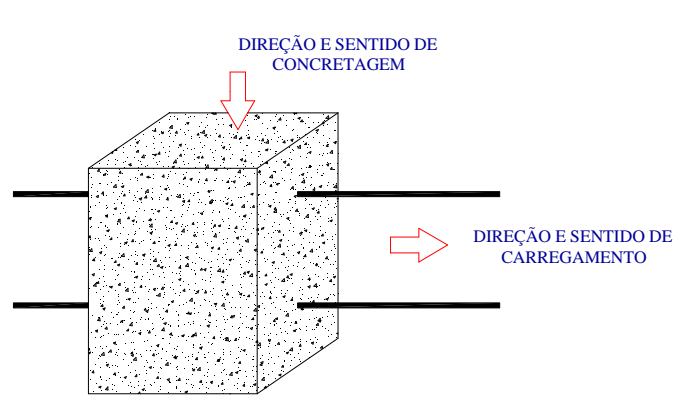

CORPO DE PROVA DE BARRA HORIZONTAL

FIGURA 2.13 - Corpos-de-prova de barra vertical e horizontal - BARBOSA (1998) -

De acordo com os resultados experimentais, constatou-se que as variações de resistência observadas em relação à posição das barras durante a moldagem são menores nos concretos de alto desempenho do que nos concretos convencionais. A explicação para essa pouca sensibilidade do CAD deve-se a dois fatos:

${ }^{1}$ GJORV, O.E.; MONTEIRO, P.J.M.; MEHTA, P.K. (1990). Effect of condensed silica fume on the steel-concrete bond. ACI Materials Journal, v.87, n.6, p.573-80, Nov./Dec. apud DUCATTI (1993). 
- De um lado, as barras verticais foram arrancadas no sentido contrário ao da concretagem, sendo desfavorável à resistência da ligação;

- Por outro lado, os concretos de alto desempenho possuem uma compacidade maior que os convencionais.

Na figura 2.14, são indicadas as curvas que representam a parte ascendente do deslizamento em função da força aplicada para o caso das barras ensaiadas na posição vertical e horizontal. No início da degradação da ligação, de um modo geral, a barra vertical apresenta uma resistência de aderência menor que a barra horizontal, sobretudo a barra horizontal inferior. Entretanto, em certos casos, a parte ascendente da curva da barra horizontal superior é mais baixa que a da barra vertical, principalmente para idades do concreto inferiores a 14 dias.

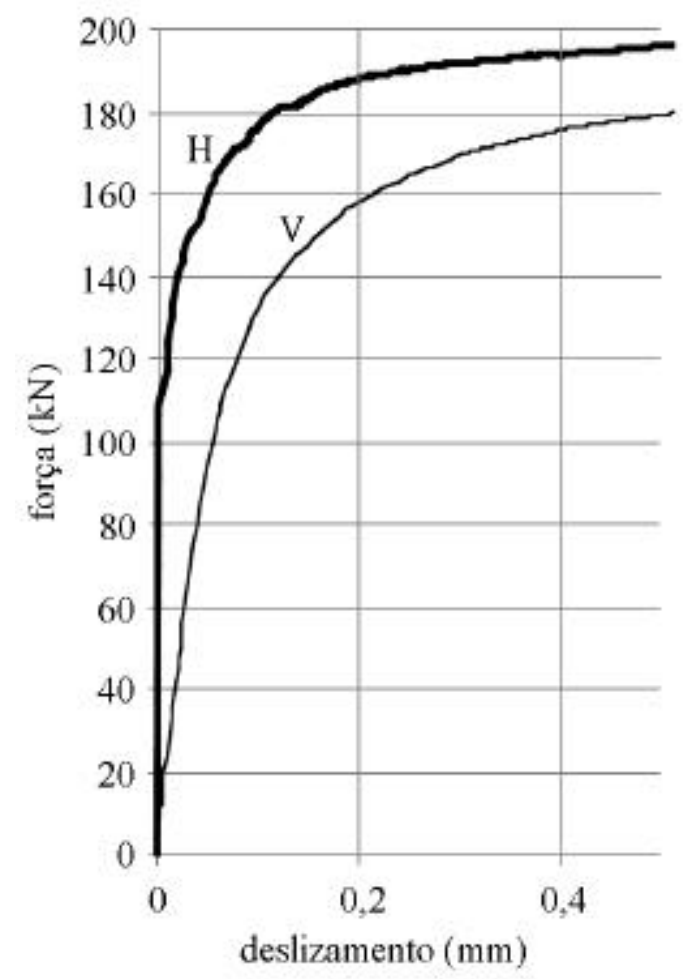

FIGURA 2.14 - Comparação das barras horizontais e verticais - BARBOSA (1998) -

SOROUSHIAN et al (1991) realizaram uma investigação experimental com o objetivo de analisar os efeitos do confinamento e da resistência à compressão do concreto no comportamento da aderência local de barras nervuradas em nós de concreto armado. 
$\mathrm{Na}$ figura 2.15, são ilustradas as relações tensão de aderência versus deslizamento para os espécimes com diferentes espaçamentos das armaduras transversais, as quais proporcionam o confinamento do concreto no nó. A ruptura dos modelos de concreto simples ocorreu de uma maneira frágil devido às fissuras por fendilhamento. Já a presença da armadura vertical do pilar proporcionou uma certa ductilidade pela restrição do crescimento da fissuração por fendilhamento, mudando o modo de ruptura para o arrancamento da barra. Entretanto, a diferença entre os modelos com armadura vertical com e sem armadura transversal foi praticamente insignificante. Como a fissuração por fendilhamento nestes espécimes ocorreu paralelamente ao plano da armadura transversal, a sua influência no comportamento da aderência tornou-se pequena, a não ser com uma pequena melhoria que pode ser atribuída à redução da fissuração cisalhante próxima da interface aço-concreto.

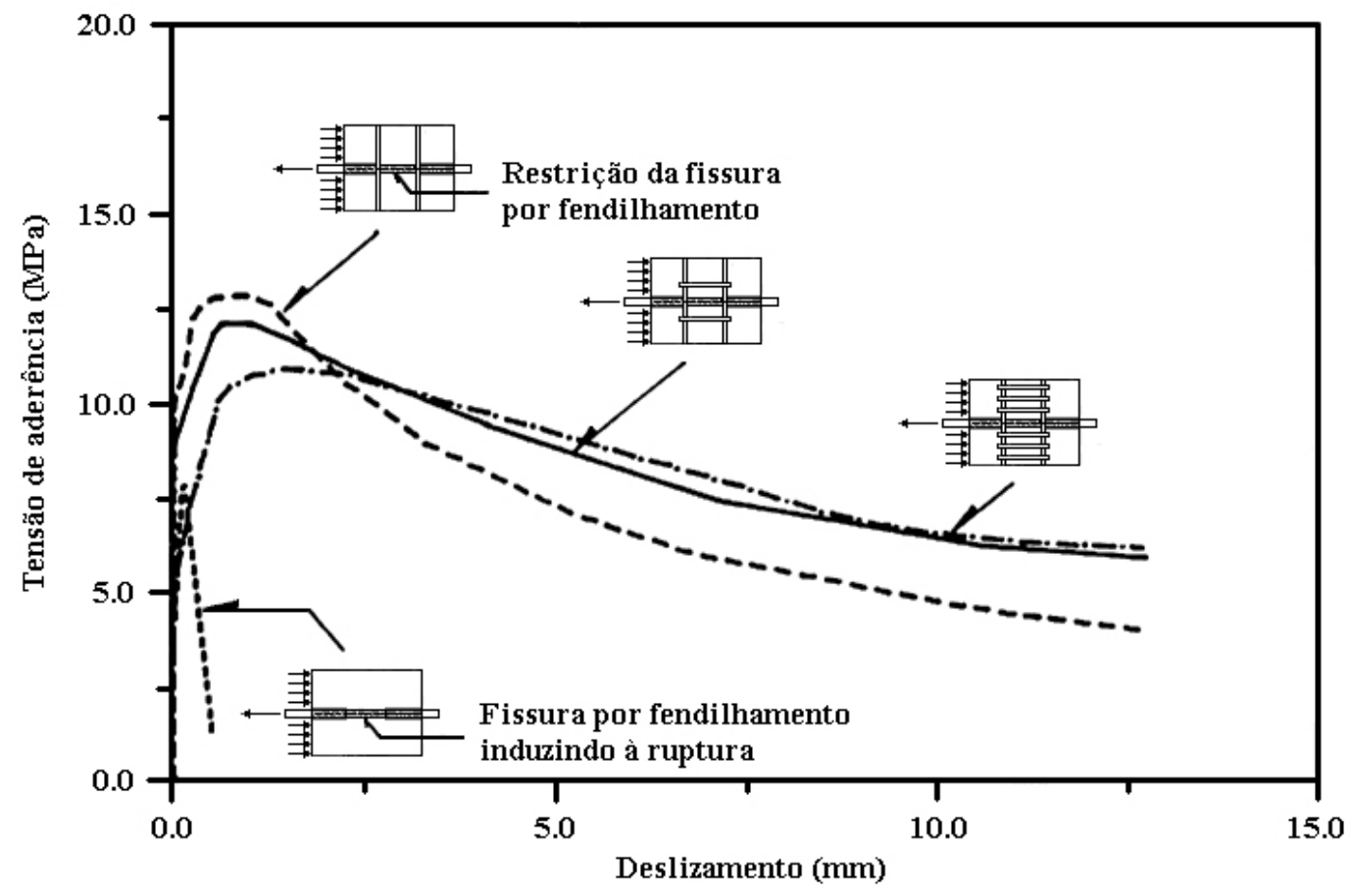

FIGURA 2.15 - Influência da armadura de confinamento na relação local tensão de aderência versus deslizamento de barras nervuradas - SOROUSHIAN et al (1991) -

Os efeitos da resistência à compressão do concreto nas características locais de aderência são apresentados na figura 2.16. A resistência de aderência, correspondente ao valor máximo da curva tensão de aderência versus deslizamento, 
aumentou com o crescimento da resistência à compressão. Entretanto, os outros valores característicos de tensão e deslizamento da curva foram pouco influenciados por essa variável.

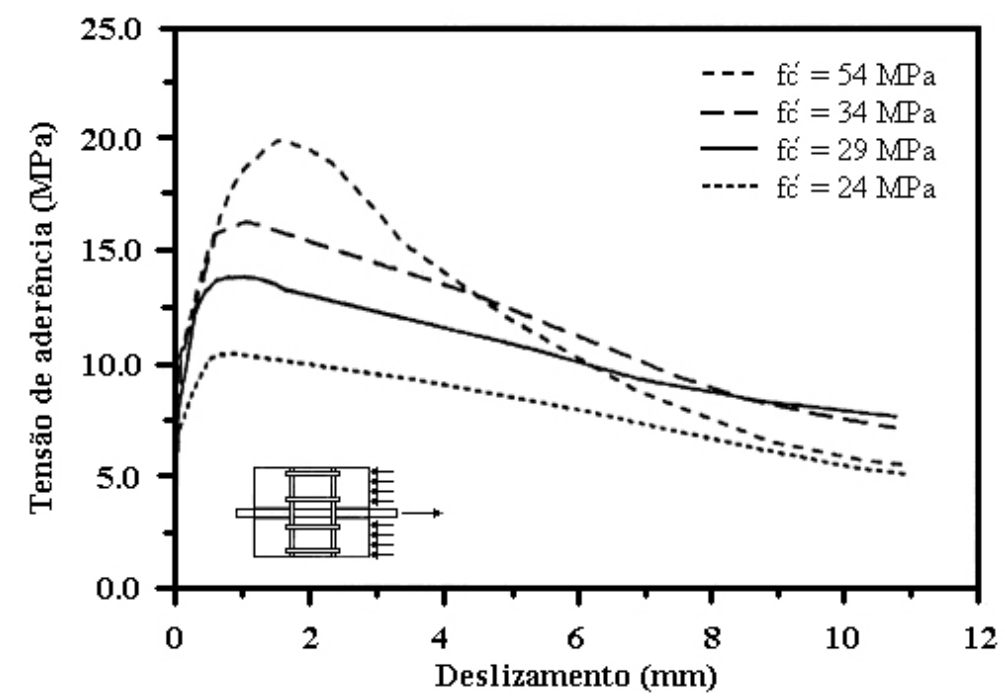

FIGURA 2.16 - Influência da resistência de compressão na relação local tensão de aderência-deslizamento de barras nervuradas em concreto confinado - SOROUSHIAN et al (1991) -

BALÁZS et al (1993) utilizaram a técnica de emissão acústica para analisar a degradação na camada de interação aço-concreto através de ensaios de arrancamento em espécimes sob carregamento monotônico crescente, repetido e de longa duração. Essa técnica, a qual detecta danos locais na interface dos dois materiais através de efeitos acústicos da liberação de energia, tem a grande vantagem de registrar sinais do processo de deterioração durante toda a história do carregamento sem perturbação no modelo.

Para carregamento monotônico, como observado na figura 2.17, as duas formas completamente independentes de medidas indicaram tendências semelhantes, pois as amplitudes maiores por intervalo de tempo foram registradas na região das maiores tensões de aderência, e em seguida, ambos foram reduzidos. 


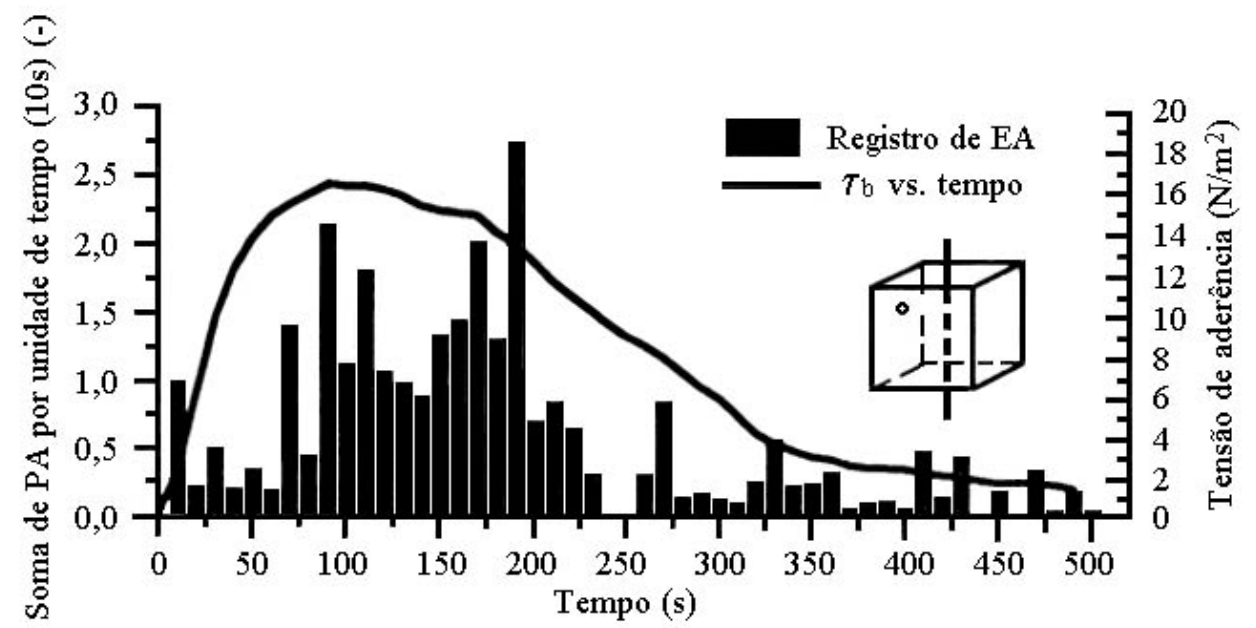

FIGURA 2.17 - Soma de PA em intervalos de $10 \mathrm{~s}$ e tensão de aderência versus tempo - BALÁZS (1993) -

\subsection{COMPORTAMENTO DA ADERENCIA COM A UTILIZAÇÃO DE FIBRAS NA MATRIZ DE CONCRETO}

O uso de fibras de aço em quantidades apropriadas no concreto tem mostrado ser adequado em zonas sísmicas, principalmente por aumentar a resistência de aderência, a absorção de energia, a ductilidade e a segurança contra a ruína das estruturas sujeitas a carregamento cíclico alternado.

HOTA \& NAAMAN (1997) realizaram um estudo experimental sobre o comportamento da aderência em matrizes de concreto reforçado com fibras de aço sob carregamento monotônico e cíclico.

Nos ensaios, foi analisada a influência de alguns parâmetros como:

- quatro tipos de materiais: Concreto Reforçado com Fibras - 2\% - (FRC), Concreto com uma quantidade de fibras relativamente alta - 5\% a $20 \%$ - (SIFCON), Concreto Simples (CS), e Concreto Confinado com armadura em espiral (CC);

- duas resistências à compressão: $63 \mathrm{MPa}$ e $35 \mathrm{MPa}$, para cada tipo de material;

- três tipos diferentes de carregamento: monotônico, cíclico unidirecional (repetido) e cíclico alternado.

Foram observados três tipos de ruptura para carregamento monotônico, de acordo com a figura 2.18: 
- Ruptura por fendilhamento

- Ruptura por arrancamento por atrito

- Ruptura por arrancamento cônico.

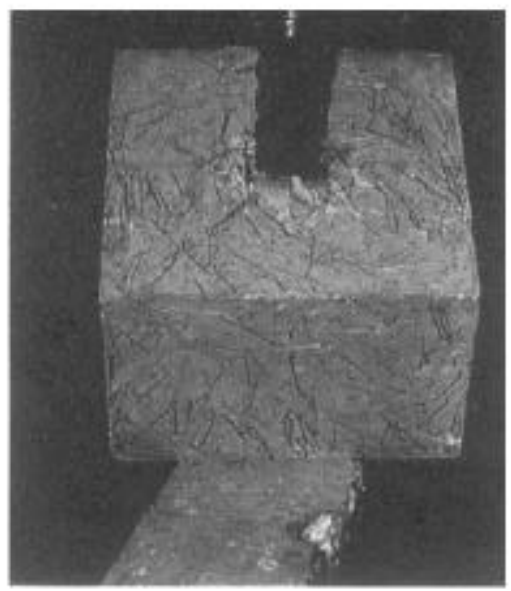

Ruptura por arrancamento por atrito $35 \mathrm{MPa}-\mathrm{SIFCON}$

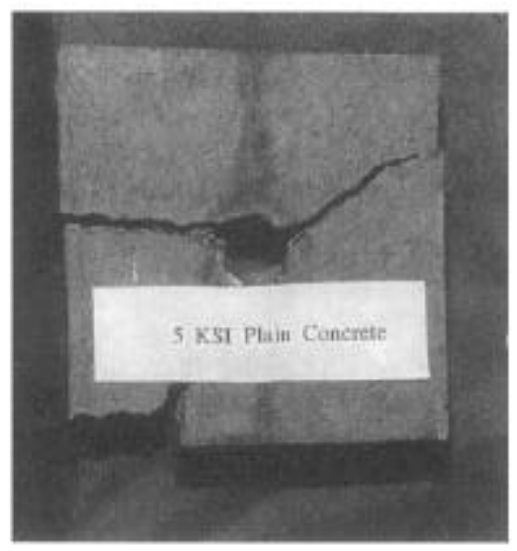

Ruptura por fendilhamento $35 \mathrm{MPa}-\mathrm{CS}$

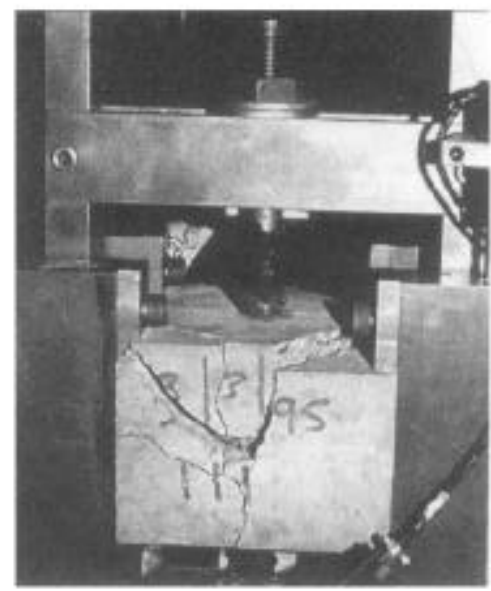

Ruptura por arrancamento cônico $35 \mathrm{MPa}-\mathrm{CC}-\mathrm{Vf}-\mathrm{esp}=3 \%$

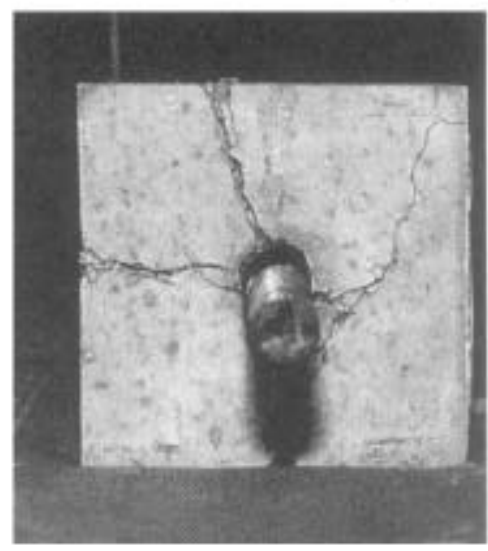

Ruptura por fendilhamento $35 \mathrm{MPa}-\mathrm{FRC}$

FIGURA 2.18 - Tipos de ruptura monotônica dos diferentes modelos - HOTA \& NAAMAN (1997) -

Observou-se para os três tipos de carregamento, alguns fatos importantes:

- Os modelos de SIFCON romperam por arrancamento devido ao atrito. Os espécimes de CS apresentaram, geralmente, uma ruptura por fendilhamento nas proximidades da força máxima. A ruptura dos modelos de FRC se iniciou com o arrancamento devido ao atrito, finalizando-se com o fendilhamento, quando a 
abertura de fissura atingiu um certo valor crítico. Os espécimes de CC romperam por arrancamento do tronco de cone.

- A adição de fibras na matriz de concreto diminuiu lentamente a degradação póspico da curva tensão de aderência versus deslizamento, em comparação com os modelos sem fibras, aumentando assim, a ductilidade.

- Tanto a força máxima de arrancamento como o deslizamento correspondente cresceram com o aumento na quantidade de fibras.

- Como os modelos de SIFCON tinham um volume de fibras relativamente elevado, apresentaram o melhor desempenho, com resistência de aderência, absorção de energia e ductilidade maiores.

Com o crescimento da resistência à compressão do concreto, houve uma melhoria na resistência de aderência apenas nos casos de carregamento monotônico e repetido.

Através de ensaios de arrancamento direto, Pull-Out-Test, segundo a RILEMFIP-CEB (1973), em corpos-de-prova cúbicos de concreto, VIEIRA \& DAL MOLIN (1995), analisaram a influência das variáveis fator água/aglomerante e porcentagem de adição de microssílica na aderência aço-concreto para barras nervuradas.

Observou-se nos ensaios que tanto a diminuição do fator água/aglomerante, como a adição de microssílica, de um modo geral, melhoram o comportamento de aderência, por produzir um aumento na resistência à compressão e à tração do concreto, variáveis que governam a resistência de aderência. A microssílica afeta a morfologia e microestrutura da zona de transição aço-pasta de cimento, diminuindo a porosidade e espessura desta zona. Tal fato pode ser explicado pela redução da água livre acumulada na interface aço-concreto durante a moldagem, pela redução da orientação preferencial dos cristais de hidróxido de sódio na zona de transição e pela densificação desta zona devido às reações pozolânicas entre o hidróxido de cálcio e a microssílica.

Conforme já esperado, a ruptura da aderência em concretos de alta resistência caracterizou-se por ser mais frágil (maiores carregamentos para pequenos deslizamentos) que os concretos de baixa resistência (menores carregamentos para maiores deslizamentos). 


\subsection{MODELOS PARA O COMPORTAMENTO DA ADERÊNCIA}

O comportamento da aderência pode ser explicado por diversos modelos disponíveis na literatura. Entre estes, o proposto por TASSIOS (1979), apresenta vários estágios do desenvolvimento de tensões com seus respectivos deslocamentos, segundo a figura 2.19 .

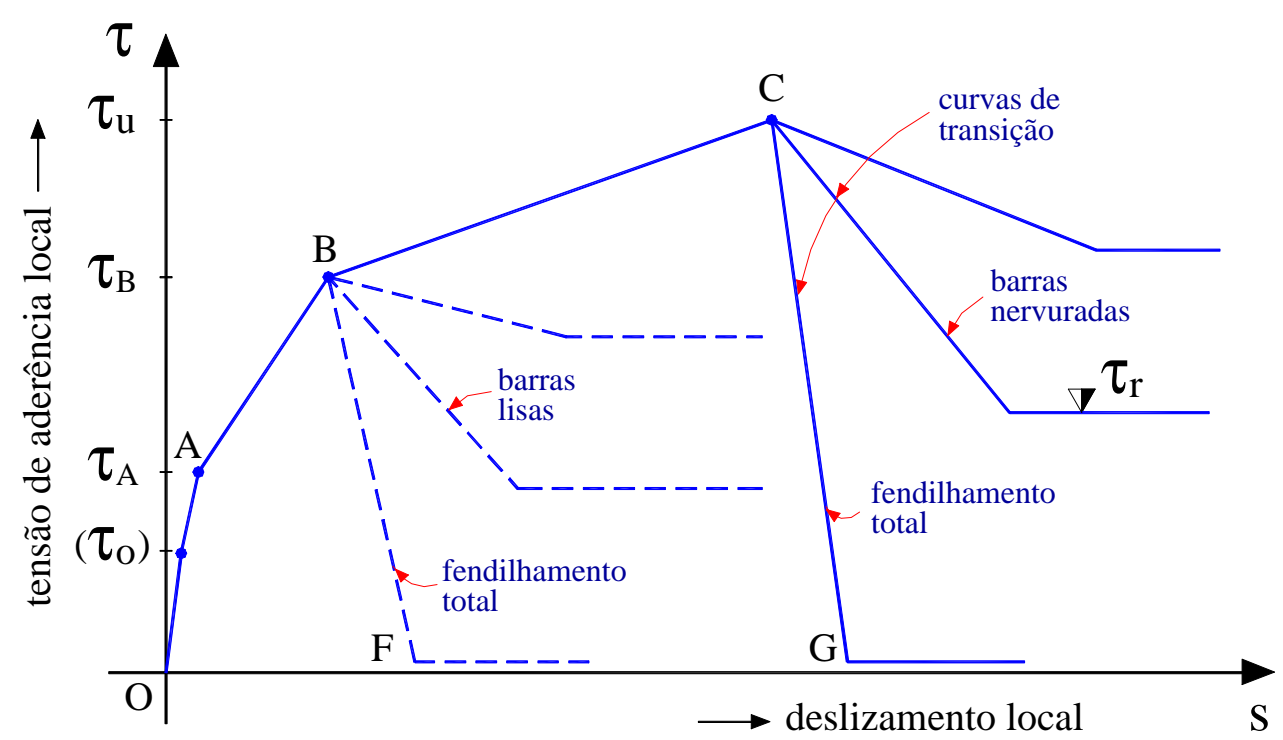

FIGURA 2.19 - Curva teórica tensão de aderência-deslizamento - TASSIOS (1979) -

Antes da tensão de aderência química $\tau_{\mathbf{o}}$ ser atingida, ocorrem deslizamentos extremamente pequenos, da ordem de poucos microns $(\mu)$. Com o aumento do carregamento, ocorre a ruptura da adesão, caracterizada pelo nível de tensão $\tau_{\mathbf{o}}$, e a posterior mobilização do engrenamento mecânico tanto entre a pasta de cimento e as irregularidades microscópicas da superfície da armadura, no caso de barras lisas, como entre o concreto e as nervuras, no caso de barras nervuradas. Após a tensão $\tau_{\mathrm{A}}$, surgem as primeiras fissuras internas (transversais e diagonais), devido às tensões de tração da força de arrancamento ultrapassarem a resistência à tração do concreto. A partir deste ponto, a rigidez do concreto é reduzida, caracterizada por uma inclinação menor da curva. 
Após a primeira fissuração interna, a distribuição de tensão ao longo da interface depende das condições de carregamento e de contorno. As tensões radiais de compressão $\sigma_{\mathbf{y}}$ e as longitudinais de tração $\sigma_{\mathbf{x}}$ surgem pela tentativa de arrancamento da barra. Devido à ação combinada de $\tau, \sigma_{\mathbf{x}}, \sigma_{\mathbf{y}}$ mais as possíveis tensões longitudinais e radiais externas, como a pressão de retração, são produzidas grandes tensões diagonais de tração $\sigma_{\mathbf{I}}$, que causam as fissuras diagonais transversais ao longo da armadura indicadas na figura 2.20.
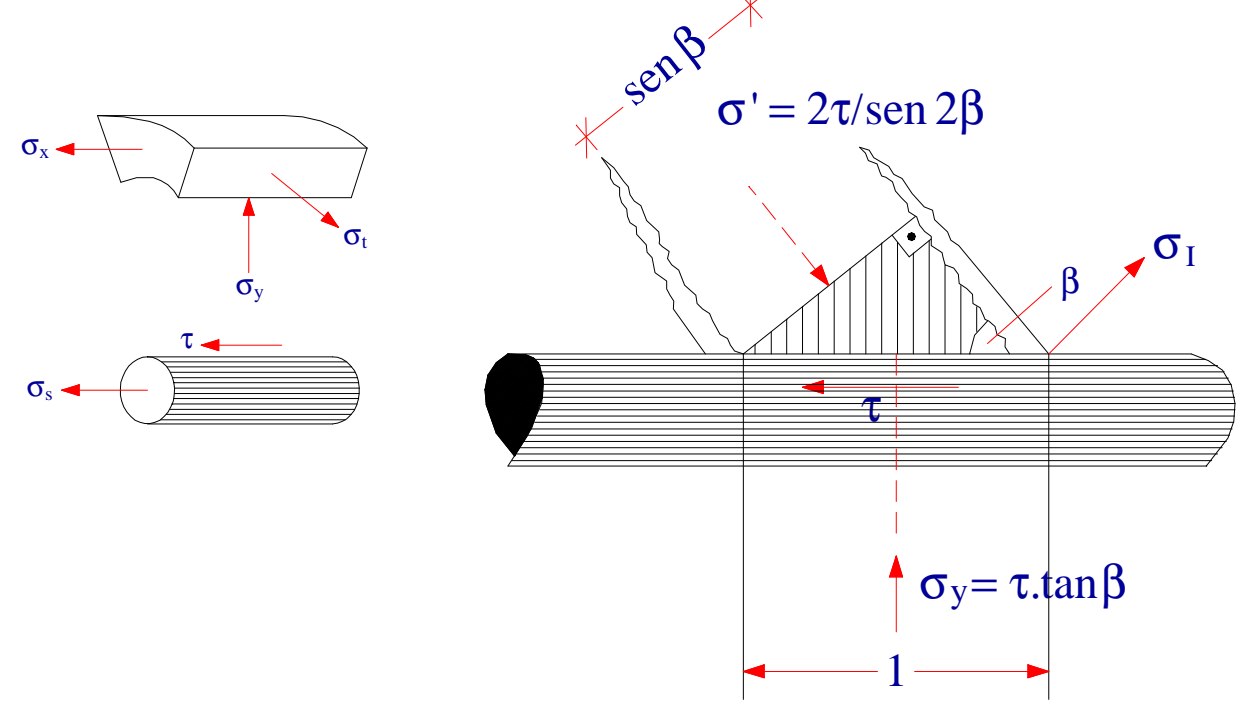

FIGURA 2.20 - Tensões entre fissuras transversais consecutivas - TASSIOS (1979) -

Simultaneamente ou logo após a fissuração transversal, as tensões de compressão $\sigma_{\mathbf{y}}$ também originam as tensões de tração circunferenciais $\sigma_{t}$, que produzem as fissuras por micro-fendilhamento interno, como ilustra a figura 2.21. Entretanto, geralmente os valores de $\sigma_{\mathrm{t}}$ são menores que os de $\sigma_{\mathrm{I}}$ para esse estágio de carregamento, fazendo a fissuração transversal anteceder o micro-fendilhamento. 

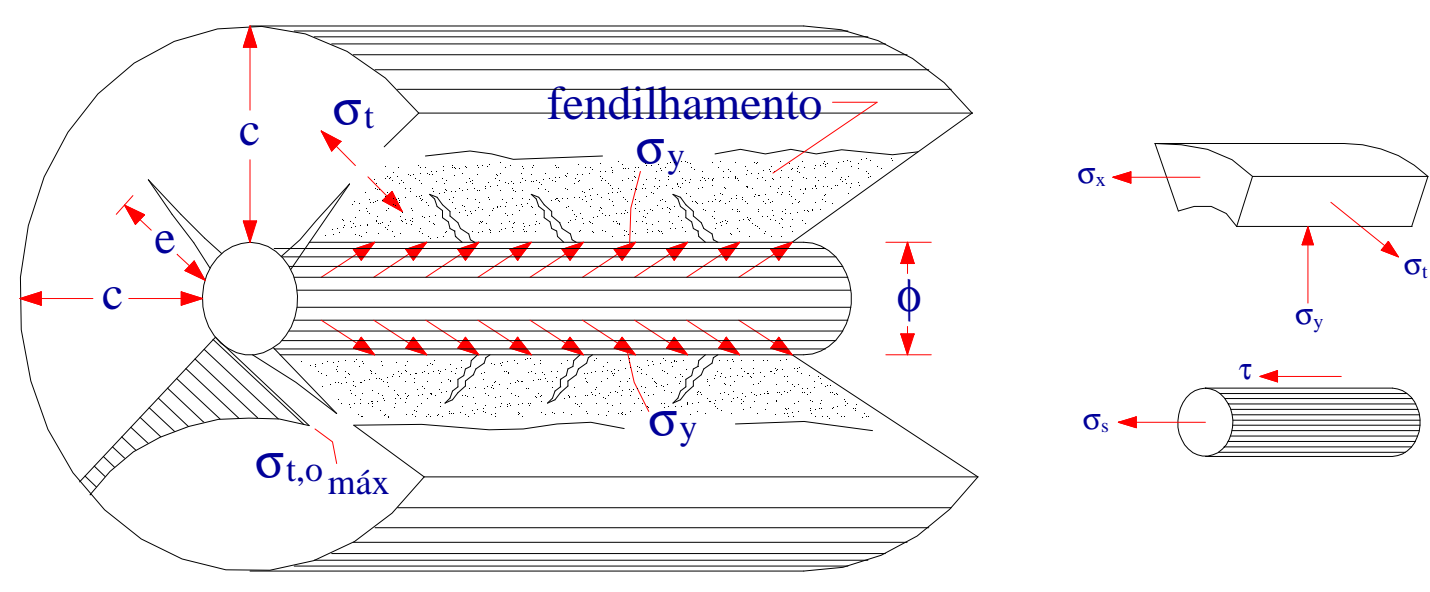

FIGURA 2.21 - Fissuras transversais e de fendilhamento

- TASSIOS (1979) -

No trecho $\mathrm{AB}$, ocorre a perda parcial do engrenamento e é introduzida então, uma componente de atrito para contribuir com a aderência. À medida que o carregamento continua crescendo, as fissuras de fendilhamento se propagam radialmente e longitudinalmente, até a tensão $\tau_{\mathbf{B}}$ ser alcançada. A partir deste nível, as barras lisas são perfeitamente arrancadas, deixando um orifício quase intacto, enquanto o concreto, no caso de barras nervuradas, rompe por fendilhamento quando não há confinamento suficiente (ramo BF da curva).

A possível ruptura da aderência para barras nervuradas com ação do confinamento pode ser ilustrada pela figura 2.22 , onde se considera que o principal mecanismo remanescente de aderência seja devido ao engrenamento entre as nervuras, combinado com uma considerável destruição do concreto envolvente. $\mathrm{O}$ "dente" de concreto existente entre as fissuras transversais consecutivas está sob a ação de uma tensão de compressão $\sigma_{\mathbf{c}}$ igual a $\mathbf{2} \tau_{\mathbf{u}}$, de uma pequena parcela de confinamento, reduzida devido à degradação do concreto circundante, e de uma diminuição na região de atuação das tensões cisalhantes. A degradação total da ligação é ocasionada pela ruptura dessas bielas de compressão. 


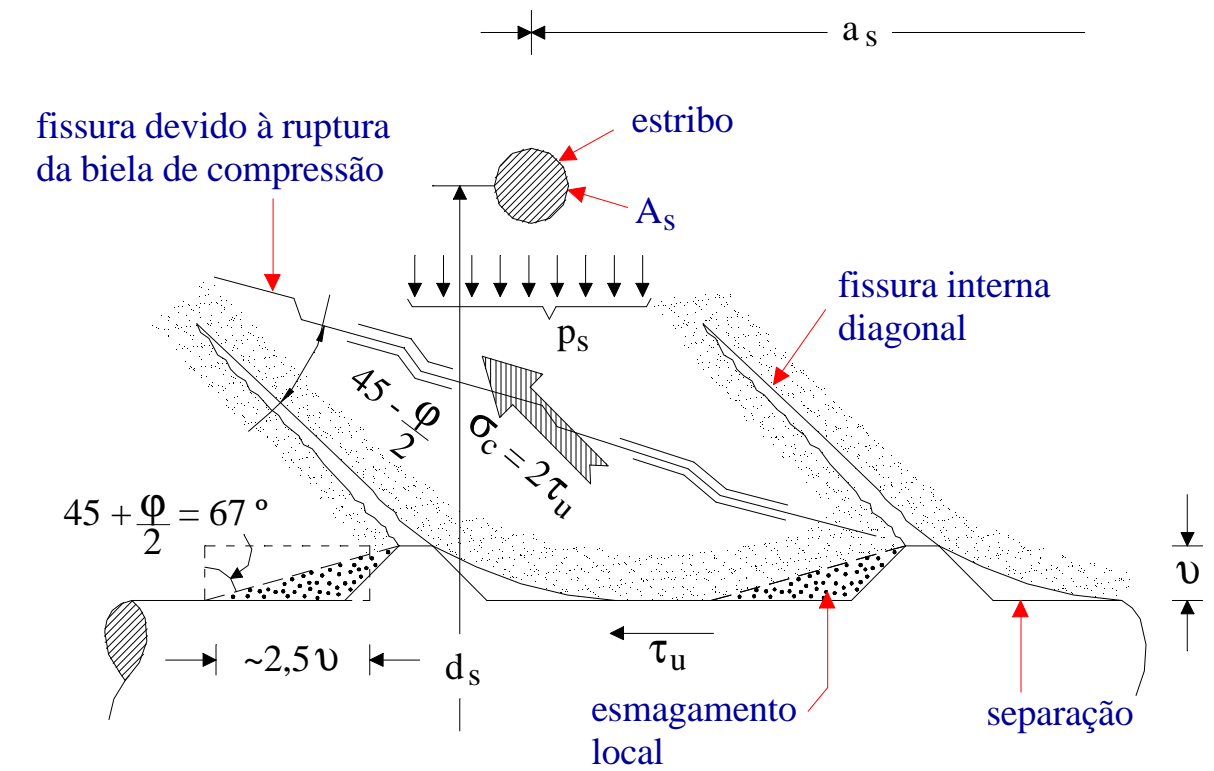

FIGURA 2.22 - Possível estágio de ruptura da aderência para concreto confinado e barra nervurada

- TASSIOS (1979) -

Após este estágio, para as barras nervuradas, o único mecanismo de aderência restante é o atrito, que também contribuía anteriormente. Sob as condições de ensaio de deformação controlada, pode-se capturar o comportamento da aderência, após a ruptura. Após o pico do diagrama (ponto C), ocorre um decréscimo brusco da curva, até um certo valor, que caracteriza a resistência residual de aderência $\tau_{\mathbf{r}}$. Contudo, quando o fendilhamento se desenvolve ao longo de todo o cobrimento, a tensão de aderência residual é quase nula.

A tentativa de identificar esse patamar de tensão residual, quando o fendilhamento não é generalizado devido à presença de uma armadura transversal mínima, é feita na figura 2.23. O dente de concreto de forma quase triangular apresenta a tendência de movimento junto com a barra. $\mathrm{O}$ principal mecanismo de oposição a este movimento ocorre devido ao engrenamento concreto-concreto ao longo a fissura $\mathrm{AB}$ (ruptura das bielas de compressão). 


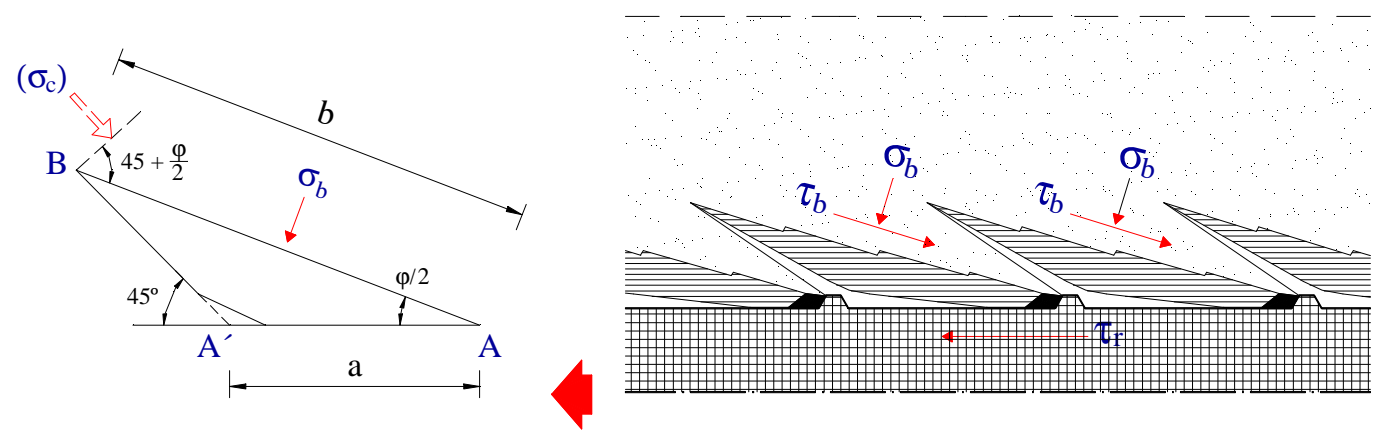

FIGURA 2.23 - Hipótese do mecanismo da resistência de aderência residual $\tau_{\mathbf{r}}$ - TASSIOS (1979) -

O comportamento monotônico de interação entre o aço e o concreto pode ser explicado qualitativamente por ELIGEHAUSEN et $\mathrm{al}^{1}$ apud CEB (1996) Bulletin d'Information n.230. De acordo com a figura 2.24, para pequenas tensões de aderência (ponto A), as fissuras cisalhantes começam a se propagar a partir do topo das nervuras; seu crescimento e tamanho é controlado pela pressão de confinamento, a qual pode ser exercida pela armadura transversal. Grande parte da transferência de forças é atribuída ao engrenamento mecânico, com um ângulo de inclinação $\alpha$ de $30^{\circ}$. Aumentando o carregamento, ocorre o esmagamento local do concreto na face das nervuras, produzindo uma redução da inclinação da tangente à curva (ponto B). Quando a tensão última de aderência é atingida (ponto C), as fissuras cisalhantes se estendem ao longo de um comprimento considerável e o concreto próximo às nervuras é esmagado. Neste ponto, a linha de ação da força tem um ângulo de aproximadamente $45^{\circ}$. Aumentando-se o deslizamento a partir deste nível, a tensão de aderência decresce lentamente. No momento em que as fissuras cisalhantes atingem a base da nervura adjacente (ponto D), as tensões de aderência continuam a decrescer. Quando o deslizamento torna-se igual ao espaçamento entre as nervuras, apenas uma parcela do atrito passa a mobilizar a aderência (ponto E).

\footnotetext{
${ }^{1}$ ELIGEHAUSEN, R. et al. (1983). Local bond stress-slip relationships of deformed bars under generalized excitations. Berkeley, University of California, Earthquake Engineering Research Center. (Report No. UCB/EERC 83-23) apud CEB (1996)
} 


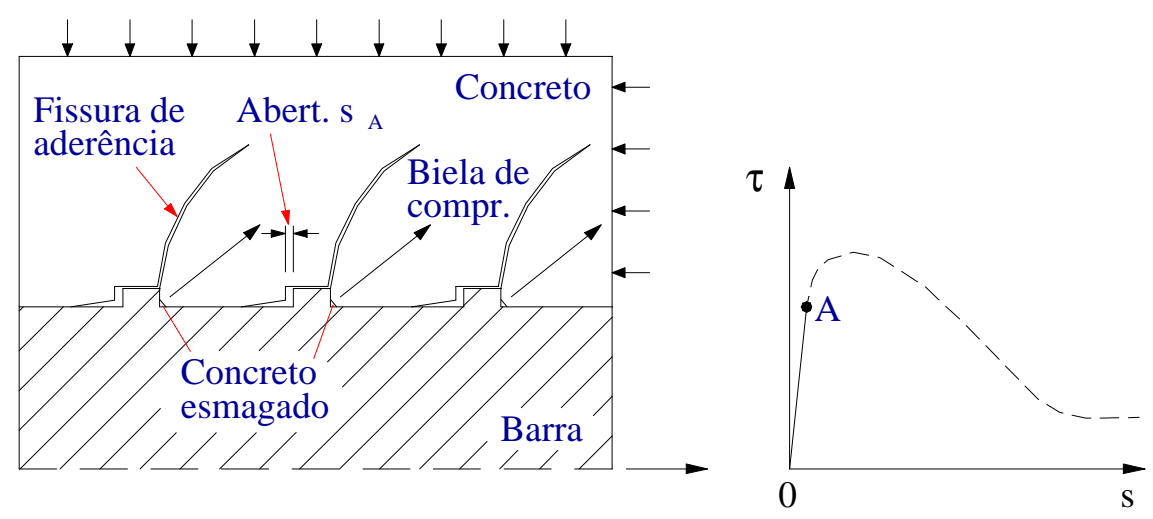

(a)
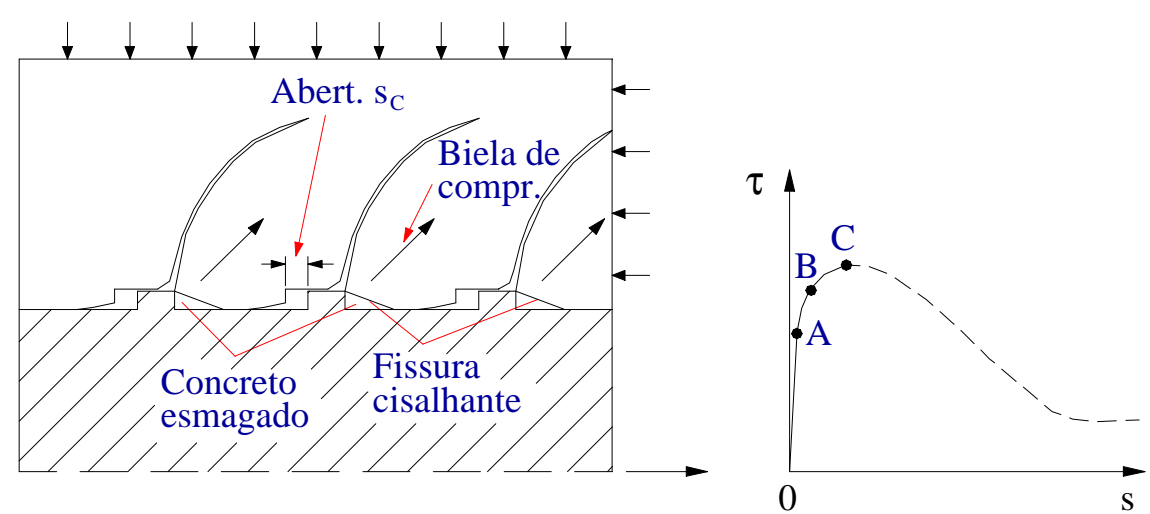

(b)
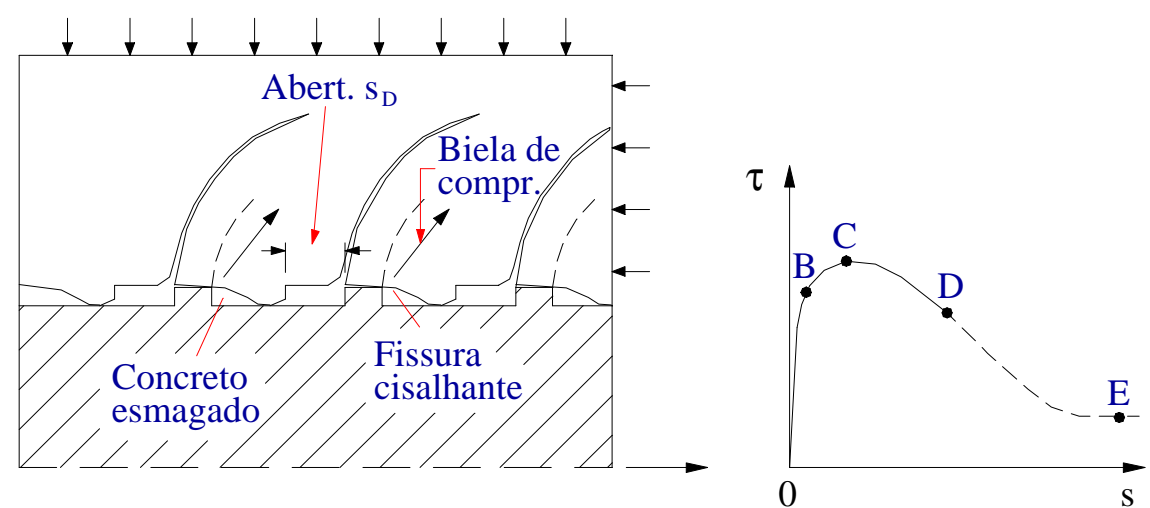

(c)

FIGURA 2.24 - Mecanismo de aderência monotônica

- ELIGEHAUSEN et al apud CEB (1996) - 


\subsection{PRESCRIÇÕES DAS NORMAS SOBRE ADERÊNCIA}

\subsubsection{CEB-FIP MC 1990}

No modelo aproximado do CEB-FIP MC 1990 (1991) para carregamento monotônico, as tensões de aderência entre o concreto e a armadura podem ser calculadas como uma função do deslocamento relativo $\mathbf{s}$, de acordo com a figura 2.25 e as equações 2.1 a 2.4 :

$$
\begin{array}{rlr}
\tau & =\tau_{\text {bu }}\left(\frac{\mathbf{s}}{\mathbf{s}_{1}}\right)^{\alpha} & \mathbf{0} \leq \mathbf{s} \leq \mathbf{s}_{1} \\
\tau=\tau_{\text {bu }} & \mathbf{s}_{1}<\mathbf{s} \leq \mathbf{s}_{2} \\
\tau=\tau_{\text {bu }}-\left(\tau_{\text {bu }}-\tau_{\mathrm{f}}\right)\left(\frac{\mathbf{s}-\mathbf{s}_{2}}{\mathbf{s}_{3}-\mathbf{s}_{2}}\right) & \mathbf{s}_{2}<\mathbf{s} \leq \mathbf{s}_{3} \\
\tau=\tau_{\mathrm{f}} & \mathbf{s}_{3}<\mathbf{s}
\end{array}
$$

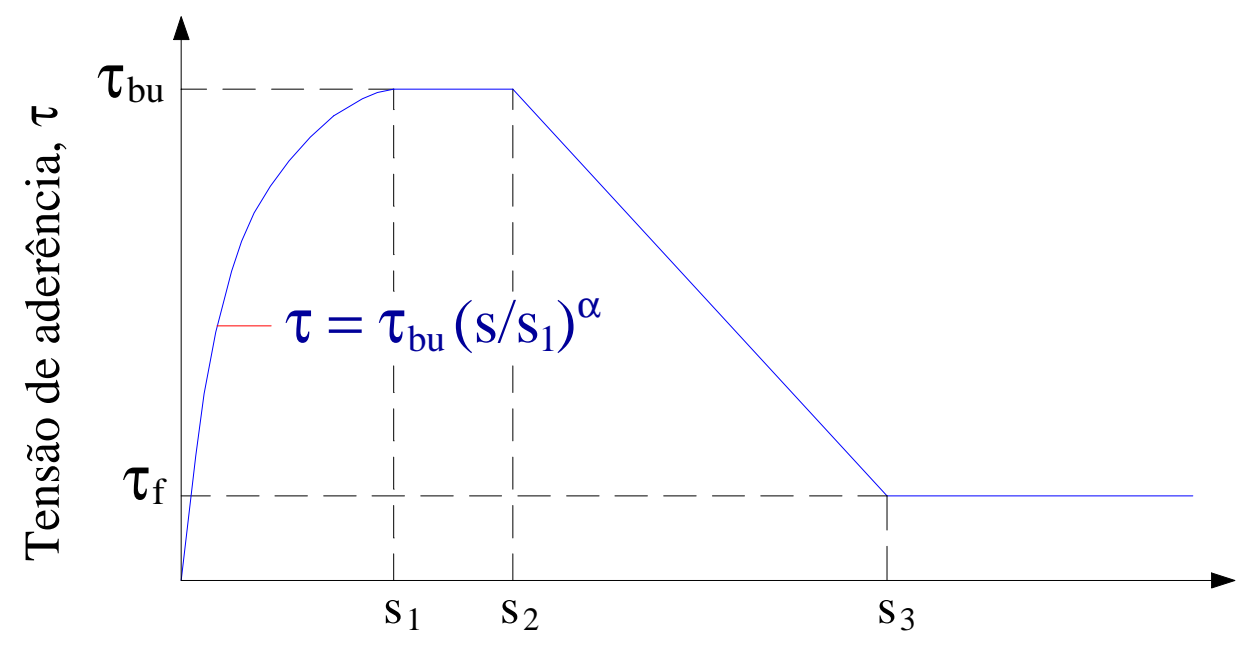

Deslizamento, $\mathrm{s}$

FIGURA 2.25 - Relação analítica tensão de aderência versus deslizamento (carregamento monotônico)

- CEB-FIP MC 1990 -

Na tabela 2.1, diferentes valores dos parâmetros $\mathbf{s}_{\mathbf{1}}, \mathbf{s}_{\mathbf{2}}, \mathbf{s}_{\mathbf{3}}, \boldsymbol{\alpha}$ e $\tau_{\mathbf{b u}}$ para armadura nervurada são propostos para regiões de concreto não-confinado (ruptura 
por fendilhamento do concreto) e para regiões de concreto confinado (ruptura por arrancamento).

TABELA 2.1 - Parâmetros para definir a relação média tensão de aderência-deslizamento para barra nervurada (de acordo com as equações 2.1 a 2.4)

\begin{tabular}{||c|c|c|c|c||}
\hline \multirow{2}{*}{ Valor } & \multicolumn{2}{|c|}{$\begin{array}{c}\text { Concreto não- } \\
\text { confinado }\end{array}$} & \multicolumn{2}{c|}{ Concreto confinado $^{* *}$} \\
\hline \multirow{2}{*}{\begin{tabular}{c} 
Condições de aderência \\
\cline { 2 - 5 }
\end{tabular}} & Boas & $\begin{array}{c}\text { Todos os } \\
\text { outros casos }\end{array}$ & Boas & $\begin{array}{c}\text { Todos os } \\
\text { outros casos }\end{array}$ \\
\hline $\mathbf{s}_{\mathbf{1}}$ & $0,6 \mathrm{~mm}$ & $0,6 \mathrm{~mm}$ & \multicolumn{2}{|c|}{$1,0 \mathrm{~mm}$} \\
\hline $\mathbf{s}_{\mathbf{2}}$ & $0,6 \mathrm{~mm}$ & $0,6 \mathrm{~mm}$ & \multicolumn{2}{|c|}{$3,0 \mathrm{~mm}$} \\
\hline $\mathbf{s}_{\mathbf{3}}$ & $1,0 \mathrm{~mm}$ & $2,5 \mathrm{~mm}$ & \multicolumn{2}{|c|}{$\begin{array}{c}\text { Distância entre as } \\
\text { nervuras }\end{array}$} \\
\hline $\boldsymbol{\alpha}$ & \multicolumn{2}{|c|}{0,4} & \multicolumn{2}{|c|}{0,4} \\
\hline$\tau_{\mathbf{b u}}$ & $2,0 \sqrt{\mathrm{f}_{\mathrm{ck}}}$ & $1,0 \sqrt{\mathrm{f}_{\mathrm{ck}}}$ & $2,5 \sqrt{\mathrm{f}_{\mathrm{ck}}}$ & $1,5 \sqrt{\mathrm{f}_{\mathrm{ck}}}$ \\
\hline$\tau_{\mathbf{f}}$ & \multicolumn{2}{|c|}{$0,15 \tau_{\mathrm{bu}}$} & \multicolumn{2}{|c|}{$0,40 \tau_{\mathrm{bu}}$} \\
\hline
\end{tabular}

"Ruptura por fendilhamento do concreto

${ }^{* * *}$ Ruptura por arrancamento da barra

Nas colunas 2 e 3 da tabela 2.1, os valores são válidos para um cobrimento c $=1 \phi$ e um mínimo de armadura transversal igual a

$$
\mathbf{A}_{\text {st,mín }}=0,25 n A_{\mathrm{s}}
$$

Onde:

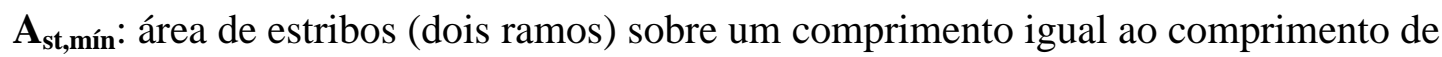
ancoragem

n: número de barras envolvidas pelos estribos

$\mathbf{A}_{\text {s: }}$ : área de uma barra

Os valores das colunas 4 e 5 são válidos para concreto confinado (cobrimento $\mathbf{c} \geq \mathbf{5} \phi_{\mathrm{s}}$ ou armadura transversal com $\mathbf{A}_{\mathbf{s t}}>\mathbf{n} \mathbf{A}_{\mathbf{s}}$ ) ou pressão transversal elevada ( $\mathbf{p} \geq$ 7,5 MPa).

Se $\mathbf{A}_{\text {st,mín }}<\mathbf{A}_{\mathbf{s t}}<\mathbf{n} \mathbf{A}_{\mathbf{s}}$ e $\mathbf{0}<\mathbf{p}<\mathbf{7 , 5} \mathbf{M P a}$, os valores de $\mathbf{s}_{\mathbf{1}}, \mathbf{s}_{\mathbf{3}}, \tau_{\mathbf{b u}}$ e $\tau_{\mathbf{f}}$ podem ser interpolados linearmente entre os valores para concreto não confinado e para 
concreto confinado, respectivamente. Se $\mathbf{A}_{\text {st }}>\mathbf{A}_{\text {st,mín ocorre simultaneamente a uma }}$ pressão transversal, os efeitos são adicionados.

Os parâmetros dados na tabela 2.2 são válidos para barras lisas, tanto em concreto confinado como não-confinado.

TABELA 2.2 - Parâmetros para definir a relação média tensão de aderência-deslizamento para barra lisa (de acordo com as equações 2.1 a 2.4)

\begin{tabular}{|c|c|c|c|c||}
\hline \multirow{2}{*}{ Valor } & \multicolumn{2}{|c|}{ Aço laminado a frio } & \multicolumn{2}{c|}{ Aço laminado a quente } \\
\hline & \multicolumn{2}{|c|}{ Condições de aderência } & \multicolumn{2}{c|}{ Condições de aderência } \\
\cline { 2 - 5 } & Boas & $\begin{array}{c}\text { Todos os } \\
\text { outros casos }\end{array}$ & Boas & $\begin{array}{c}\text { Todos os } \\
\text { outros casos }\end{array}$ \\
\hline $\mathbf{s}_{\mathbf{1}}=\mathbf{s}_{\mathbf{2}}=\mathbf{s}_{\mathbf{3}}$ & $0,01 \mathrm{~mm}$ & $0,01 \mathrm{~mm}$ & $0,1 \mathrm{~mm}$ & $0,1 \mathrm{~mm}$ \\
\hline$\alpha$ & 0,5 & 0,5 & 0,5 & 0,5 \\
\hline$\tau_{\mathbf{b u}}=\tau_{\mathbf{f}}$ & $0,1 \sqrt{\mathrm{f}_{\mathrm{ck}}}$ & $0,05 \sqrt{\mathrm{f}_{\mathrm{ck}}}$ & $0,3 \sqrt{\mathrm{f}_{\mathrm{ck}}}$ & $0,15 \sqrt{\mathrm{f}_{\mathrm{ck}}}$ \\
\hline
\end{tabular}

Os valores nas tabelas 2.1 e 2.2 são aplicados apenas nos estados de carregamento para os quais o concreto não é submetido a tração lateral.

\subsubsection{EUROCODE 2}

A tensão última de aderência deve ser tal que não ocorra nenhum deslizamento significativo devido às ações de serviço, e que haja uma segurança adequada contra a ruptura da aderência.

Nas condições de boa aderência, os valores de projeto para a tensão última de aderência $\tau_{\text {bu }}$ são dados na tabela 2.3. Nos outros casos, os valores da tabela 2.3 devem ser multiplicados por um coeficiente de 0,7 .

TABELA 2.3 - Valores de projeto da resistência de aderência para boas condições de aderência

- EUROCODE 2 (1992) -

\begin{tabular}{|c|c|c|c|c|c|c|c|c|c|}
\hline $\mathbf{f}_{\text {ck }}$ & $\mathbf{1 2}$ & $\mathbf{1 6}$ & $\mathbf{2 0}$ & $\mathbf{2 5}$ & $\mathbf{3 0}$ & $\mathbf{3 5}$ & $\mathbf{4 0}$ & $\mathbf{4 5}$ & $\mathbf{5 0}$ \\
\hline Barras lisas & 0,9 & 1,0 & 1,1 & 1,2 & 1,3 & 1,4 & 1,5 & 1,6 & 1,7 \\
\hline Barras de elevada aderência & 1,6 & 2,0 & 2,3 & 2,7 & 3,0 & 3,4 & 3,7 & 4,0 & 4,3 \\
\hline
\end{tabular}


Estes valores são derivados da seguinte formulação:

- Barras lisas:

$$
\tau_{\mathrm{bu}}=\left(\mathbf{0 , 3 6} \cdot \sqrt{\mathbf{f}_{\mathrm{ck}}}\right) / \gamma_{\mathrm{c}}
$$

- Barras nervuradas:

$$
\tau_{\text {bu }}=\left(2,25 . f_{\text {ctk } 0,05}\right) / \gamma_{c}
$$

Onde:

$\gamma_{c}=1,5$

$\mathbf{f}_{\mathbf{c k}}$ : resistência característica à compressão aos 28 dias medida em corpos-de-prova cúbicos

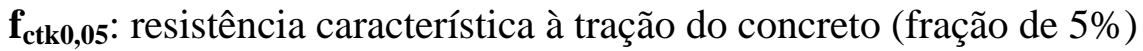

\subsubsection{NB-1/78 (NBR 6118)}

Segundo a NB-1/78 da ABNT, os trechos das barras em situação de boa aderência são aqueles que estão nas seguintes posições:

- com inclinação não inferior a $45^{\circ}$ sobre a horizontal;

- horizontais ou com inclinação menor que $45^{\circ}$ sobre a horizontal, desde que localizados no máximo $30 \mathrm{~cm}$ acima da face inferior da peça ou da junta de concretagem mais próxima, quando a altura $\mathbf{h} \leq \mathbf{6 0} \mathbf{c m}$, ou desde que localizados a mais de $30 \mathrm{~cm}$ abaixo da face superior ou da junta de concretagem mais próxima, quando $h>60 \mathrm{~cm}$.

Os trechos das barras em outras posições serão considerados em situação de aderência ruim.

Os valores de cálculo da resistência de aderência para situação de boa aderência são: 
- $\mathrm{Na}$ ancoragem e nas emendas por traspasse:

$$
\begin{aligned}
& \tau_{\text {bu }}=\mathbf{0 , 2 8} \sqrt{\mathbf{f}_{\text {cd }}} \text { para } \eta_{b} \leq \mathbf{1 , 0} \\
& \tau_{\text {bu }}=0,42 \sqrt[3]{\mathbf{f}_{\text {cd }}^{2}} \text { para } \eta_{b} \geq 1,5
\end{aligned}
$$

- Para deslizamento em peças fletidas:

$$
\begin{aligned}
\tau_{\text {bu }} & =\mathbf{0 , 5 1} \sqrt{\mathbf{f}_{\text {cd }}} \text { para } \eta_{b} \leq \mathbf{1 , 0} \\
\tau_{\text {bu }} & =\mathbf{0 , 7 4} \sqrt[3]{\mathbf{f}_{\text {cd }}^{2}} \text { para } \eta_{b} \geq \mathbf{1 , 5}
\end{aligned}
$$

Onde:

$\eta_{\mathbf{b}}$ : coeficiente de conformação superficial da barra

Para $\mathbf{1 , 0}<\eta_{\mathbf{b}}<\mathbf{1 , 5}$ : os valores de $\tau_{\mathbf{b u}}$ são interpolados linearmente.

No cálculo de $\tau_{\text {bu }}$ não se tomará, portanto, $\eta_{\mathbf{b}}$ maior que 1,5.

Em situação de aderência ruim, os valores de cálculo da resistência de aderência são os valores de $\tau_{\mathbf{b u}}$ indicados acima divididos por 1,5.

\subsection{DETERMINAÇÃO DA RESISTÊNCIA DE ADERÊNCIA}

O ensaio de arrancamento, normalizado pela RILEM-FIP-CEB (1973), tem a principal finalidade de determinar a resistência de aderência aço-concreto.

O modelo utilizado, indicado na figura 2.26, constitui um cubo de concreto com uma barra de aço no centro contendo um trecho aderente ao concreto e outro sem aderência para evitar a influência do confinamento causado pela placa de apoio do bloco.

No ensaio, a barra é tracionada do lado maior e o deslocamento relativo entre o aço e o concreto é medido na extremidade descarregada. 


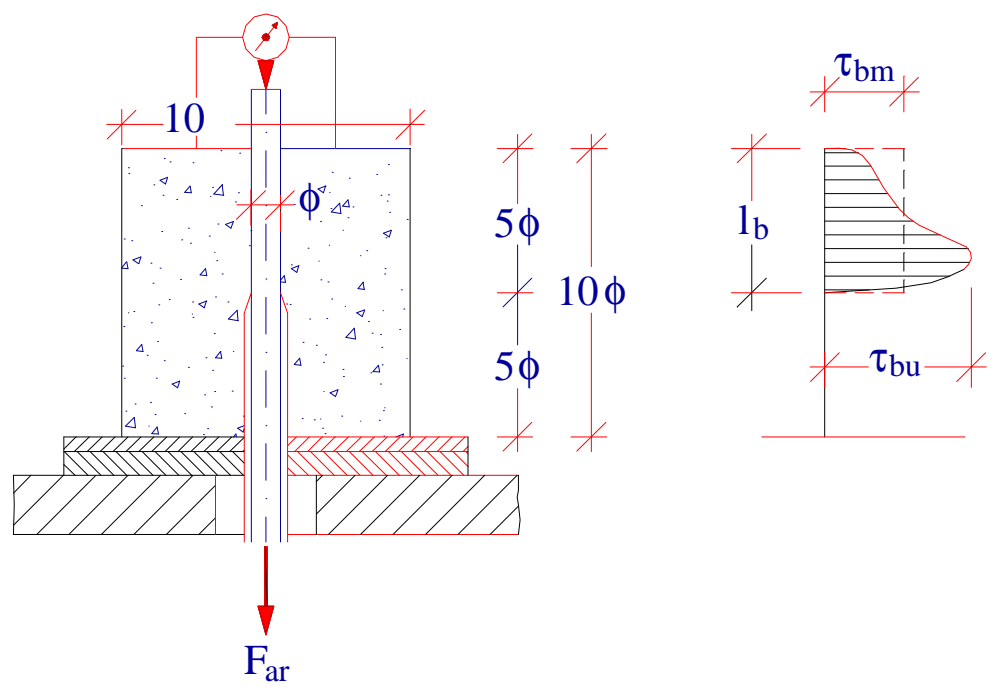

FIGURA 2.26 - Corpo-de-prova para o ensaio de arrancamento - RILEM-FIP-CEB (1973) -

Devido à dificuldade da medição da variação de tensão ao longo do comprimento de aderência e em vista das dimensões do modelo, os resultados dos ensaios de arrancamento são dados geralmente através de valores médios:

$$
\tau_{\mathrm{bm}}=\frac{\mathbf{F}_{\mathrm{ar}}}{\mathbf{u . \mathbf { l } _ { \mathrm { b } }}}
$$

O valor de cálculo da resistência de aderência $\tau_{1 \mathbf{R}}$ é definido como a tensão de aderência para a qual ocorre um deslocamento da extremidade livre da barra de 0,1 $\mathrm{mm}$ em relação ao concreto. Portanto, com a força $\mathbf{F}_{\mathbf{a r}}$ correspondente, tem-se:

$$
\tau_{1 \mathrm{R}}=\frac{\mathbf{F}_{\mathrm{ar}}(\mathbf{s}=\mathbf{0 , 1 \mathrm { mm } )}}{\mathbf{u} . \mathrm{l}_{\mathrm{b}}}
$$

Na realidade, a resistência de aderência efetiva $\left(\tau_{\mathbf{b u}}\right)$, especialmente devido ao engrenamento mecânico, é muito maior, atingindo até o dobro do valor acima, sendo que os deslocamentos vão até $1 \mathrm{~mm}$. Por questões de segurança, como há uma grande dispersão dos valores de aderência, recomenda-se para o dimensionamento um valor bastante afastado de $\tau_{\text {bu }}$. 


\section{ADERÊNCIA SOB AÇÕES CÍCLICAS}

Apesar de terem sido feitos alguns comentários sobre a aderência sob ações cíclicas anteriormente, neste capítulo, será dada uma ênfase no assunto.

\subsection{CLASSIFICAÇÃO DAS AÇÕES PARA ANÁlISE DA ADERÊNCIA}

A transferência de força de uma barra para o concreto é um fenômeno de grande complexidade, fortemente influenciado pela história do carregamento.

Existem dois tipos de carregamento nas estruturas: o estático, que atua permanentemente na estrutura, e o dinâmico, onde o tempo de atuação na estrutura varia. Em relação ao carregamento estático, existe o de longa duração, e o de curta duração ou monotônico, caracterizado por um parâmetro crescente, como deslocamento ou força. Dentro dos vários tipos de ações dinâmicas, estão situadas as ações cíclicas, caracterizadas por uma determinada amplitude de deslizamento ou tensão. A principal diferença entre as ações cíclicas e monotônicas, sob o ponto de vista da aderência, é que nas cíclicas a adesão é perdida após o primeiro ciclo, e a componente de atrito decresce com os ciclos.

O carregamento cíclico pode ser classificado de acordo com o número de ciclos e com tipo de tensão aplicada. 
Na primeira classificação, os elementos estruturais podem estar submetidos a um número relativamente baixo de ciclos (low-cycle) com carregamento elevado ao nível do estado limite último, característico, por exemplo de terremotos ou vento, ou a um grande número de ciclos (high-cycle), sob nível de carregamento de serviço e cuja ação resulta na fadiga da estrutura. Para esta última categoria, podemos citar o exemplo das pontes, estruturas offshore e estruturas que sustentam máquinas.

De acordo com o tipo de tensão aplicada, o carregamento cíclico pode ser repetido ou unidirecional (caso típico de carregamento de fadiga), ou alternado (característico de sismos).

As ações dinâmicas possuem diversas origens:

- Cargas móveis;

- Pontes rolantes;

- Ondas do mar;

- Pressões hidrostáticas variáveis;

- Sismos;

- Vento;

- Variações de temperatura e de umidade;

- Impacto

- Máquinas em operação.

\subsection{COMPORTAMENTO DA ADERÊNCIA SOB AÇÃO CÍCLICA}

Uma das principais características da ação cíclica é a deterioração progressiva da aderência que pode ser observada como um incremento no deslizamento. Devido a este processo de dano na ligação aço-concreto, a estrutura pode atingir a ruptura com níveis de tensão mais baixos que a tensão última monotônica. 


\subsubsection{AÇÃO REPETIDA (CÍCLICA UNIDIRECIONAL)}

LARANJEIRAS (1976) apresentou os resultados obtidos em uma investigação realizada no Laboratório Nacional de Engenharia Civil em Lisboa (Portugal), visando a identificação do fenômeno da aderência sob ações repetidas e de alguns parâmetros mais importantes como manutenção, repetição e história de carregamento.

O corpo-de-prova utilizado no ensaio foi o do tipo da figura 3.1 referido na literatura por double pull-out ou embedment bar test. Este modelo constitui um método mais simples de ensaio, pois dispensa o dispositivo necessário para a sustentação do corpo-de-prova do pull-out normal.

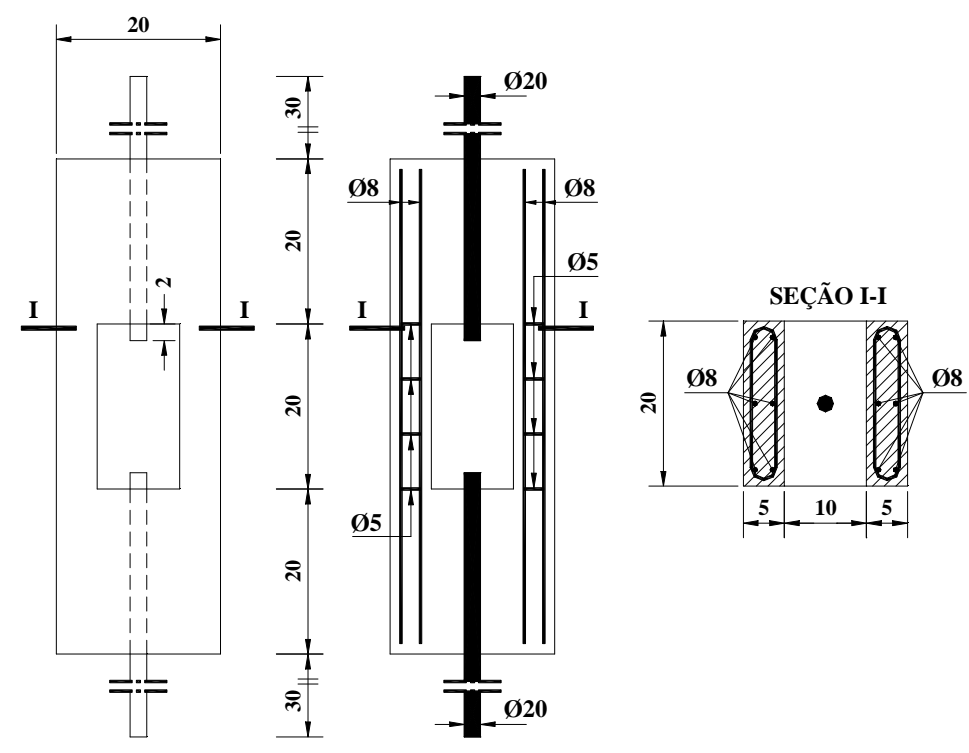

FIGURA 3.1 - Corpo-de-prova double pull-out - LARANJEIRAS (1976) -

Um dos corpos-de-prova foi ensaiado sob carregamento monotônico até a ruptura, os demais, sob carregamento repetido, obedecendo-se ao seguinte procedimento: elevação e subseqüente manutenção do carregamento em valor préfixado por um tempo suficiente para reduzir sensivelmente os efeitos dessa manutenção sobre os acréscimos de deslizamentos; em seguida, a aplicação de ciclos de carregamento repetido da ordem de $10^{5}$; por último, elevação do carregamento, 
em ensaio monotônico, a partir do valor superior já atingido, até arrancamento de uma das barras.

Os resultados indicaram que os deslizamentos crescem mais rapidamente com a manutenção do carregamento no início e mais lentamente com o passar do tempo, tendendo a estabilizar-se em um valor final. Esses acréscimos nos deslizamentos com o tempo de manutenção da força aplicada na barra são proporcionais à magnitude dessa força.

Outros fatores mostraram uma importante influência na análise do fenômeno, como a qualidade do concreto na região circundante à barra, a qual não é convenientemente caracterizada pelos ensaios de compressão em corpos-de-prova. Os resultados apresentaram algumas diferenças acentuadas no comportamento entre modelos diferentes, apesar de ensaiados sob as mesmas condições.

Em relação ao parâmetro de repetição de carregamento, os deslizamentos devido a uma força estática crescem progressivamente com a ação dinâmica dessa mesma força mais rapidamente nos primeiros ciclos, e com incrementos gradativamente menores à medida que o número de ciclos aumenta, tendendo a uma estabilização em um valor final. Para o mesmo número de repetições, esses acréscimos, em valores absolutos, são proporcionais à grandeza do limite superior da força aplicada na barra.

Apesar das mesmas influências qualitativamente da manutenção e repetição do carregamento no comportamento da aderência, os aumentos dos deslizamentos estabilizam-se em valores sensivelmente maiores, devido à ação dinâmica do carregamento.

Um importante fato observado nos ensaios em relação à história do carregamento foi que a repetição do carregamento altera a rigidez de aderência das barras, reduzindo-a ao nível do carregamento repetido, pelo aumento dos deslizamentos, e melhorando-a, para carregamento estático de valor imediatamente superior ao do carregamento repetido.

Nas recentes pesquisa sobre o problema em questão, BALÁZS (1991) mostrou os resultados experimentais de ensaios de arrancamento devido a ações repetidas e cíclicas alternadas. As principais variáveis analisadas foram: diâmetro da 
barra (diferentes áreas relativas das nervuras), comprimento de aderência e história do carregamento.

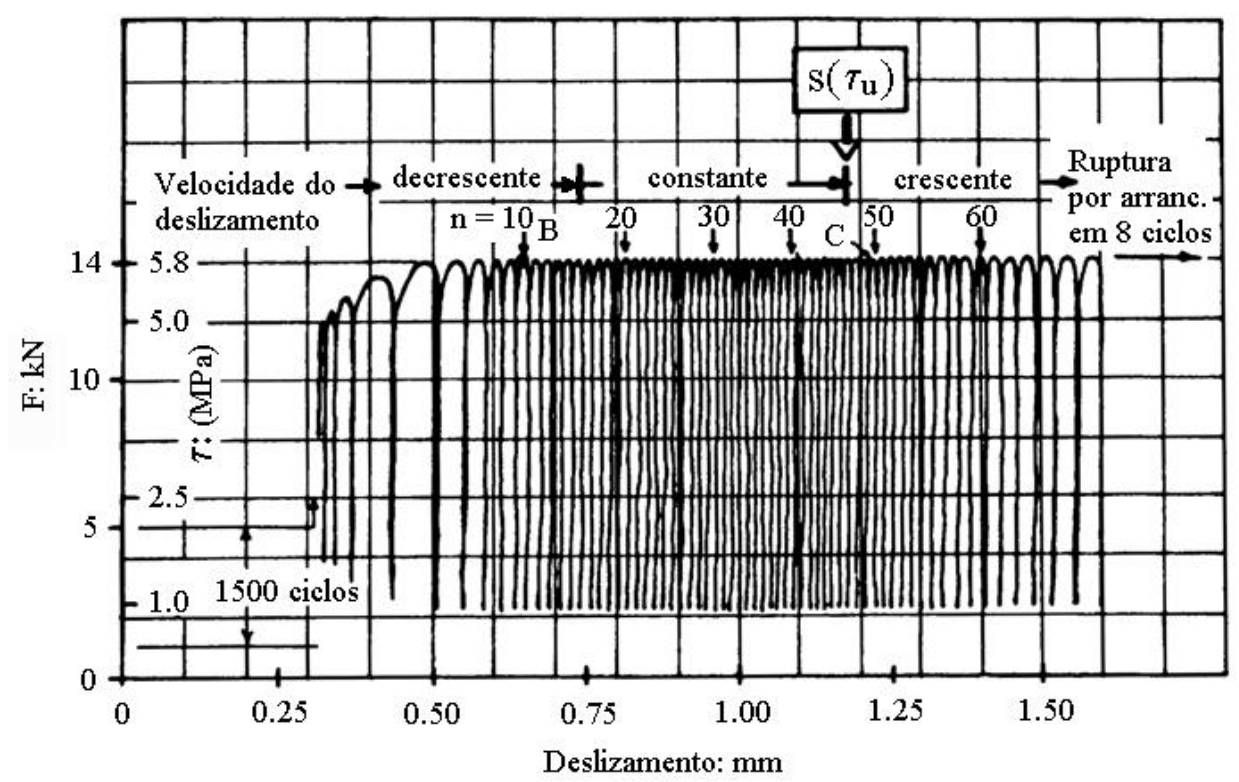

(a)

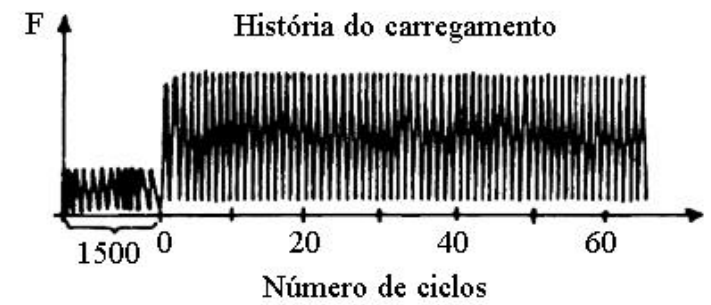

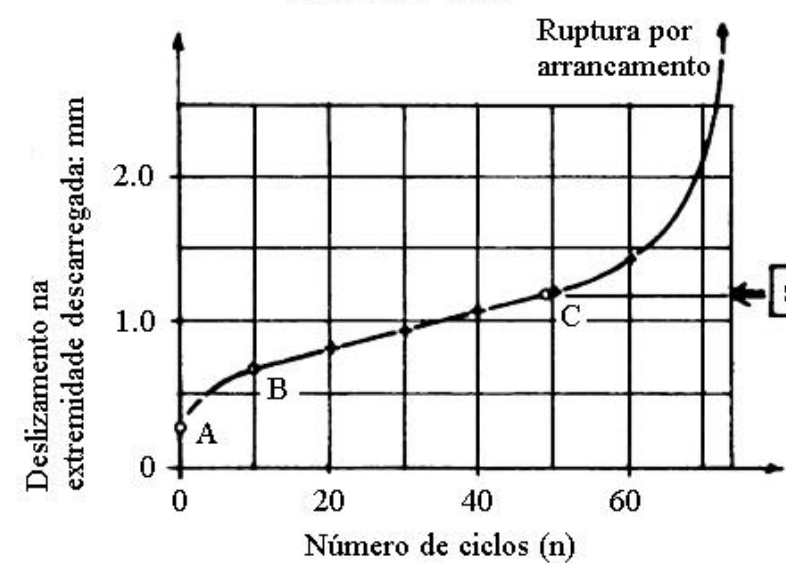

(b)

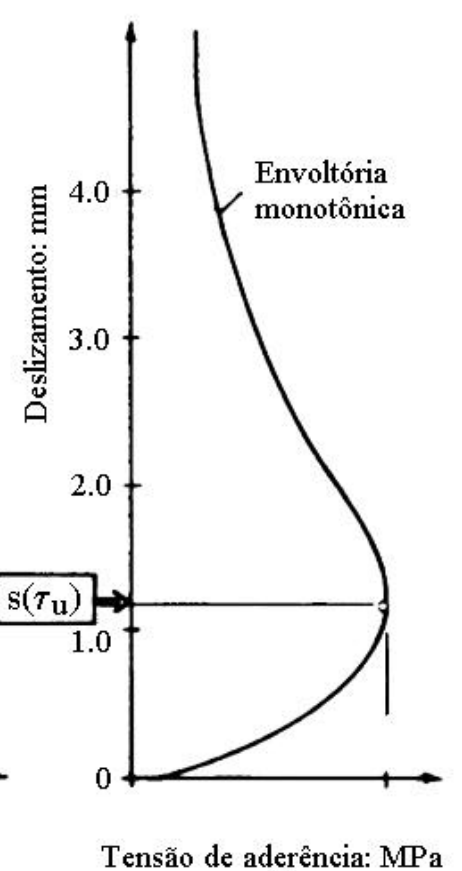

(c)

FIGURA 3.2 - Resultados experimentais do processo da fadiga da aderência devido ao carregamento repetido $\left(\mathrm{d}_{\mathrm{b}}=8 \mathrm{~mm}, \mathrm{f}_{\mathrm{y}}=400 \mathrm{MPa}, \mathrm{f}_{\mathrm{c}}{ }^{\prime}=16 \mathrm{MPa}, \mathrm{l}_{\mathrm{b}}=12 \mathrm{~d}_{\mathrm{b}}\right)$ :

(a) Diagrama força-deslizamento; (b) Diagrama deslizamento-número de ciclos;

(c) Diagrama monotônico tensão de aderência-deslizamento - BALÁZS (1991) - 
De acordo com a figura 3.2, existem três fases distintas no processo de fadiga da aderência sob carregamento repetido: Durante os ciclos iniciais, a velocidade de deslizamento é decrescente (primeira fase), em seguida, permanece constante (segunda fase) e depois cresce rapidamente até produzir a ruptura por arrancamento (terceira fase).

Em ensaios com amplitude constante e deslizamento ocorrendo nas duas extremidades da barra, a curva deslizamento versus número de ciclos contém três trechos: um côncavo, um linear e outro convexo, como indica a figura 3.2. Quando se ultrapassa $\mathbf{s}\left(\tau_{\mathbf{b u}}\right)$, ou seja, o deslizamento equivalente à resistência monotônica de aderência, com alguns ciclos adicionais ocorre a ruptura por arrancamento. Portanto, $\mathbf{s}\left(\tau_{\mathbf{b u}}\right)$ pode ser utilizado como um critério seguro para análise da ruptura por fadiga.

Nos ensaios de BALÁZS (1991), também se verificou que a história do carregamento tem uma influência significativa no deslizamento. Como ilustra a figura 3.3, um crescimento periódico da força repetida máxima produz uma velocidade de deslizamento maior na parte linear intermediária.

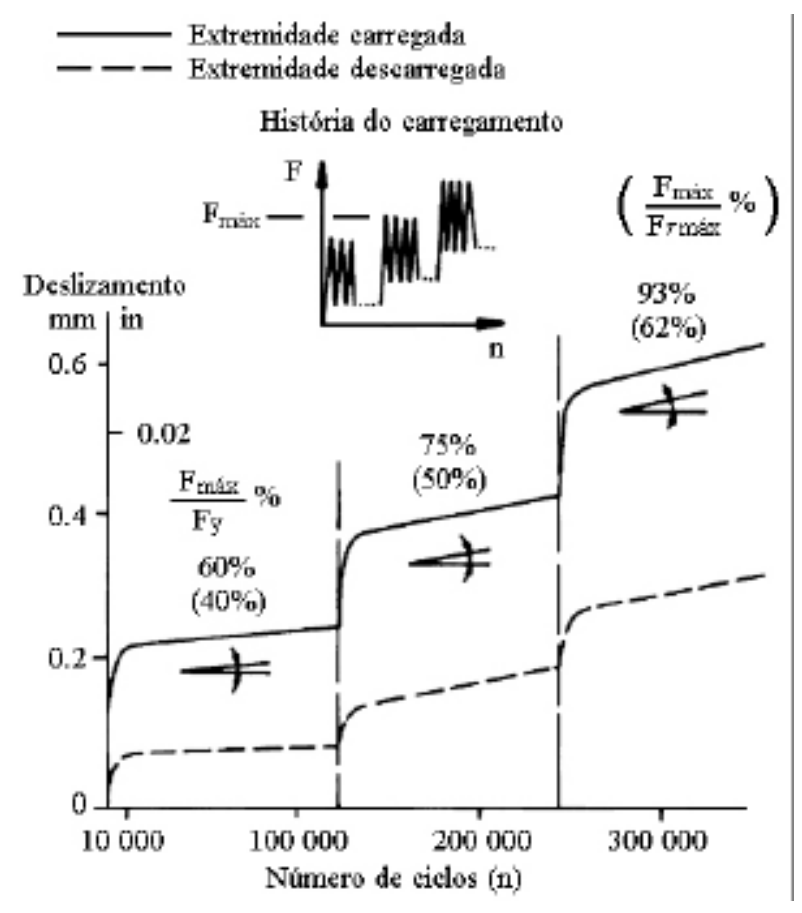

FIGURA 3.3 - Crescimento do deslizamento devido à força repetida crescente periodicamente $\left(\mathrm{d}_{\mathrm{b}}=8 \mathrm{~mm}, \mathrm{f}_{\mathrm{y}}=400 \mathrm{MPa}, \mathrm{f}_{\mathrm{c}}{ }^{\prime}=16 \mathrm{MPa}, \mathrm{l}_{\mathrm{b}}=12 \mathrm{~d}_{\mathrm{b}}\right)$ 
De acordo com a regra de Palmgren-Miner, o dano se acumula linearmente com o número de ciclos aplicado em um determinado nível de carregamento. $\mathrm{O}$ critério de ruptura é definido como:

$$
\sum_{i=1}^{k} \frac{n_{i}}{n_{\max i}}=1
$$

Onde:

$\mathbf{n}_{\mathbf{i}}$ : número de ciclos aplicados para um nível de carregamento $\mathbf{i}$

$\mathbf{n}_{\text {maxi: }}$ número de ciclos correspondente à ruptura para um nível de carregamento $\mathbf{i}$

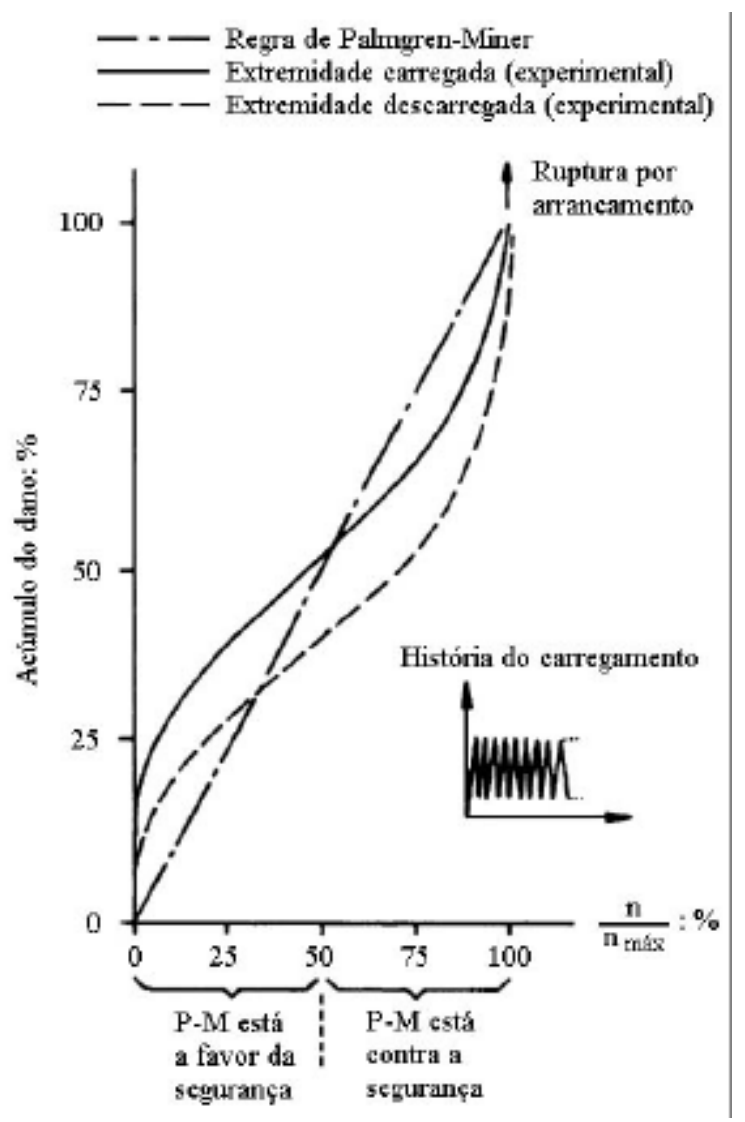

FIGURA 3.4 - Acúmulo do dano da aderência em relação à regra de Palmgren-Miner $\left(\mathrm{d}_{\mathrm{b}}=8 \mathrm{~mm}, \mathrm{f}_{\mathrm{y}}=400 \mathrm{MPa}, \mathrm{f}_{\mathrm{c}}{ }^{\prime}=16 \mathrm{MPa}, \mathrm{l}_{\mathrm{b}}=12 \mathrm{~d}_{\mathrm{b}}\right)$

- BALÁZS (1991) -

Outra conclusão de BALÁZS (1991) relacionada com o carregamento repetido, foi que a regra de Palmgren-Miner se mostrou inadequada para prever o acúmulo do dano da aderência por duas razões. Uma é que o acúmulo do dano da aderência é causado pelo crescimento progressivo de micro-fissuras e o esmagamento das bielas comprimidas perpendiculares às nervuras, indicado pelos 
deslizamentos crescentes nos ensaios. Entretanto, existem três diferentes fases na curva deslizamento versus número de ciclos em relação a regra do dano de Palmgren-Miner (figura 3.4). $\mathrm{O}$ dano da fadiga se acumula mais rápido que $\mathrm{o}$ previsto pela regra de Palmgren-Miner nas primeira e terceira fases, enquanto na segunda, a qual consiste de uma parte linear intermediária, o acúmulo do dano é mais lento. Outra razão é que a regra de Palmgren-Miner não considera o efeito da seqüência do carregamento, a qual influencia o número máximo de ciclos.

De acordo com BALÁZS et al (1993), as figuras 3.5 e 3.6 ilustram o comportamento do modelo sob carregamento repetido com amplitude constante e carregamento de longa duração, respectivamente. As curvas ao longo do tempo do deslizamento e do dano acumulado representado pela soma das amplitudes de emissão acústica apresentaram formas similares.

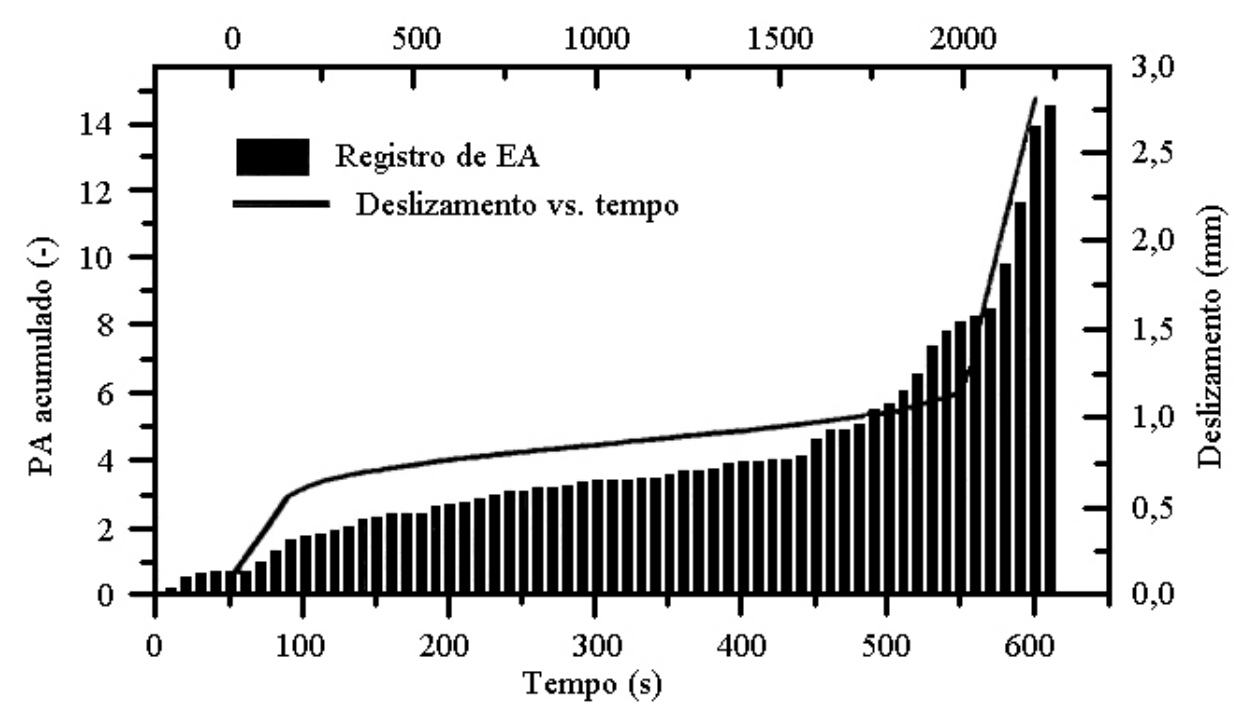

FIGURA 3.5 - PA acumulado e deslizamento versus tempo para carregamento repetido $\left(\phi 16, \alpha_{\mathrm{sb}}=0,065, \mathrm{f}_{\mathrm{y}}=500 \mathrm{MPa}, \mathrm{l}_{\mathrm{b}}=20 \mathrm{~mm}, \mathrm{f}_{\mathrm{c}}=35 \mathrm{MPa}\right)$

- BALÁZS (1993) -

KOCH \& BALÁZS (1993) realizaram ensaios de arrancamento em espécimes submetidos a ação repetida e de longa duração.

Os resultados relativos a ações de longa duração indicaram que quanto maior o nível do carregamento, maior o deslizamento inicial e o crescimento do deslizamento. 


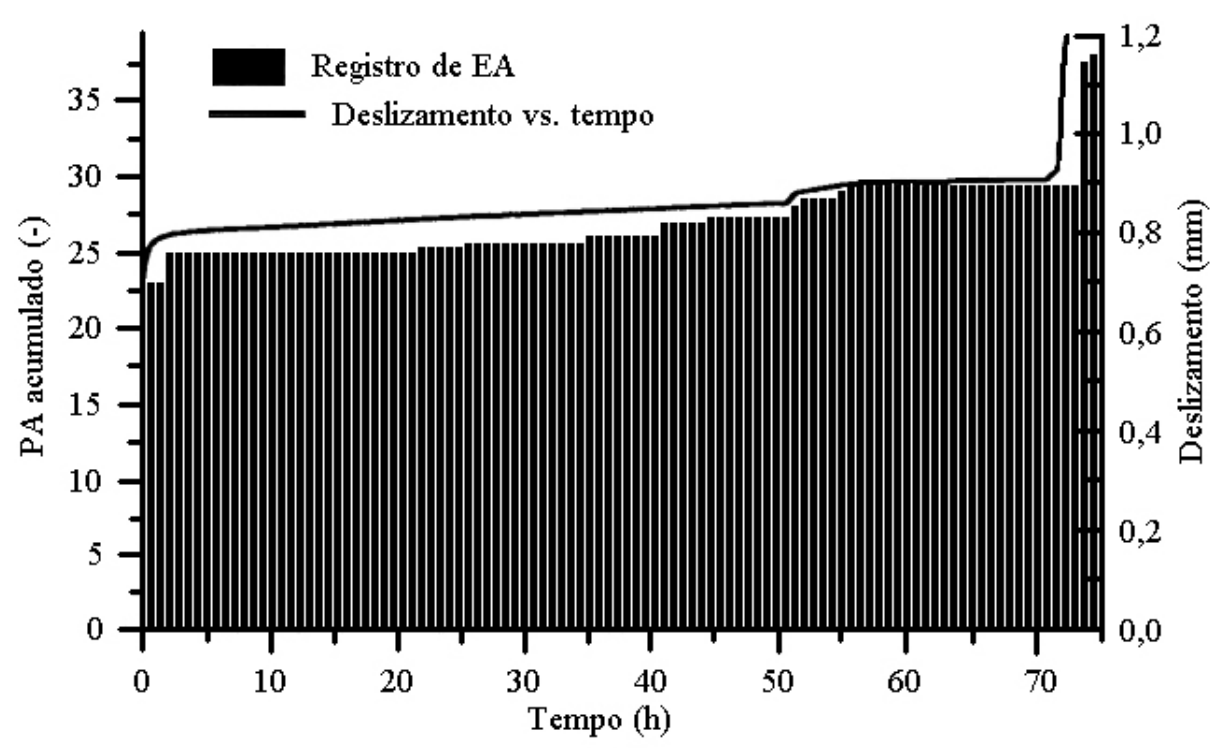

FIGURA 3.6 - PA acumulado e deslizamento versus tempo para carregamento de longa duração $\left(\phi 16, \alpha_{\mathrm{sb}}=0,065, \mathrm{f}_{\mathrm{y}}=500 \mathrm{MPa}, \mathrm{l}_{\mathrm{b}}=20 \mathrm{~mm}, \mathrm{f}_{\mathrm{c}}=35 \mathrm{MPa}\right)$ - BALÁZS (1993) -

Pela análise dos espécimes sob ação repetida, concluiu-se que quanto maior o nível do carregamento, menor a vida à fadiga ou o número de ciclos necessários para produzir um certo deslizamento.

Utilizando a proposta do CEB-FIP MC 1990 (1991) para a previsão do aumento do deslizamento em função da duração do carregamento ou número de ciclos, os diagramas relativos aos carregamentos de longa duração e repetido, em escala logarítmica, tiveram crescimento linear.

As curvas deslizamento versus duração do carregamento experimentais e as da proposta do CEB para diferentes níveis de carregamento de longa duração apresentam tendências semelhantes. Já para as ações repetidas, comparando as curvas deslizamento versus número de ciclos experimentais com as da proposta do CEB, como indica a figura 3.7 , podem ser observadas diferenças no percurso e inclinação dos diagramas. 


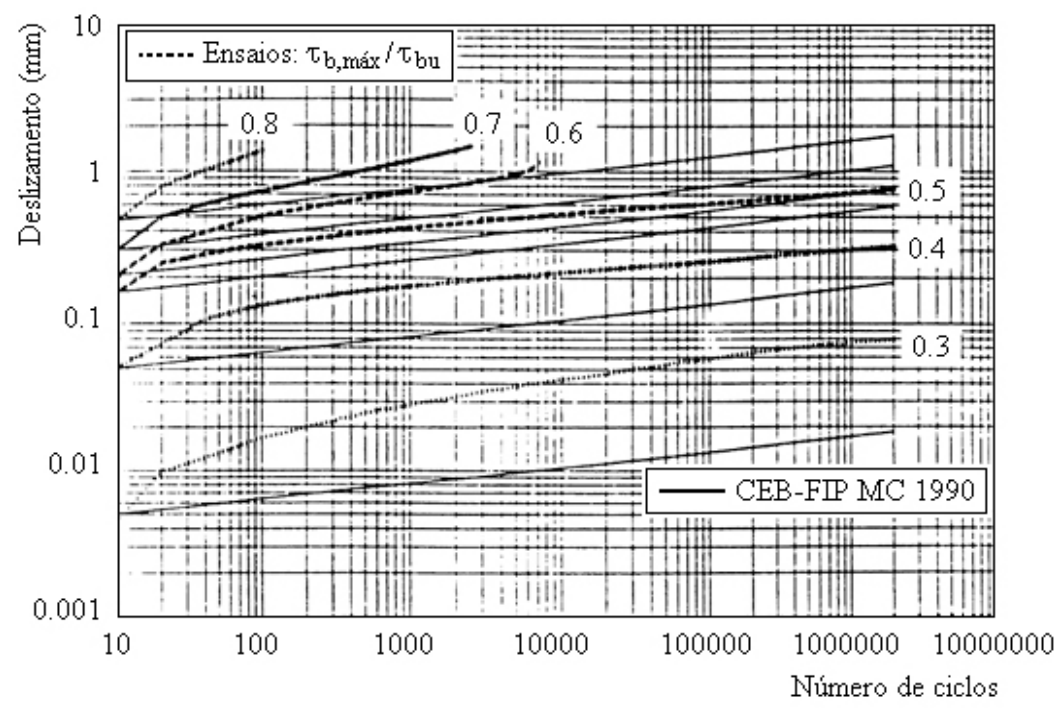

FIGURA 3.7 - Comparação dos resultados experimentais com o CEB-FIP MC 1990 para diferentes níveis de carregamento repetido

- KOCH \& BALÁZS (1993) -

Com base nas comparações dos resultados experimentais, REHM \& ELIGEHAUSEN $^{1}$ apud KOCH \& BALÁZS (1993) concluíram que a ação repetida pode ser considerada como um acelerador do tempo comparado com a ação de longa duração. Os comportamentos são semelhantes e o crescimento do deslizamento devido às ações de longa duração e repetidas pode ser expresso pela mesma forma matemática.

De acordo com os ensaios de arrancamento de REHM \& ELIGEHAUSEN ${ }^{1}$ apud CEB (1996) Bulletin d'Information n.230, se a ruptura por fadiga da aderência não ocorrer, a curva deslizamento versus número de ciclos em escala logarítmica é aproximadamente linear (figura 3.8), e os ciclos anteriores não influenciam negativamente o comportamento da aderência próximo do carregamento último, em comparação com a curva monotônica (figura 3.9).

\footnotetext{
${ }^{1}$ REHM, G.; ELIGEHAUSEN, R. (1979). Bond of ribbed bars under high-cycle repeated loads. $A C I$ Journal, v.76, n.2, p.297-309 apud KOCH \& BALÁZS (1993)
} 


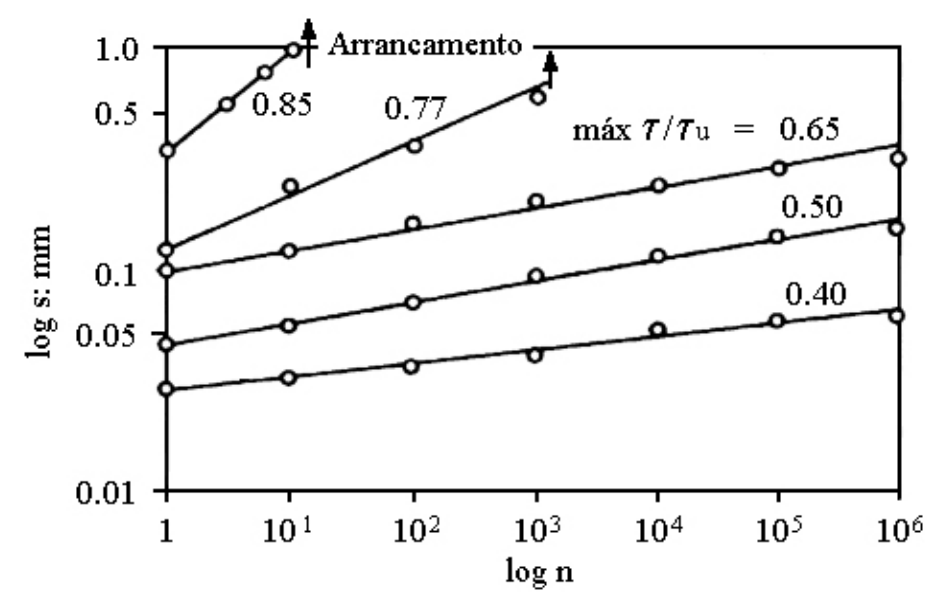

FIGURA 3.8 - Deslizamento na extremidade descarregada versus número de ciclos - REHM \& ELIGEHAUSEN apud CEB (1996) -

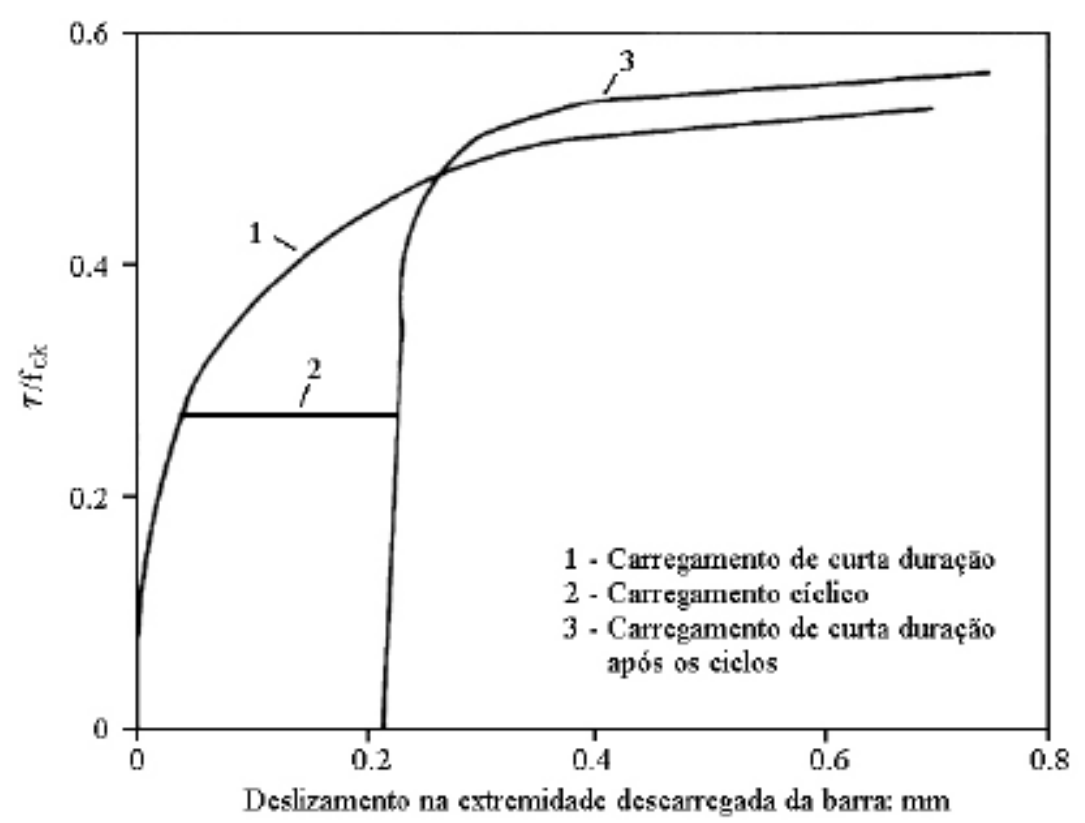

FIGURA 3.9 - Influência do carregamento repetido na resistência de aderência monotônica - REHM \& ELIGEHAUSEN apud CEB (1996) -

\subsubsection{AÇÃO CÍCLICA ALTERNADA}

Os ciclos de ações cíclicas alternadas produzem uma deterioração maior na resistência e rigidez de aderência que o mesmo número de ciclos de ações repetidas.

$\mathrm{Na}$ figura 3.10, é apresentada a relação cíclica alternada tensão de aderência versus deslizamento de acordo com o modelo conceitual de aderência proposto por 
TASSIOS (1979) para carregamento monotônico, onde os parâmetros e a sua importância são analisados.

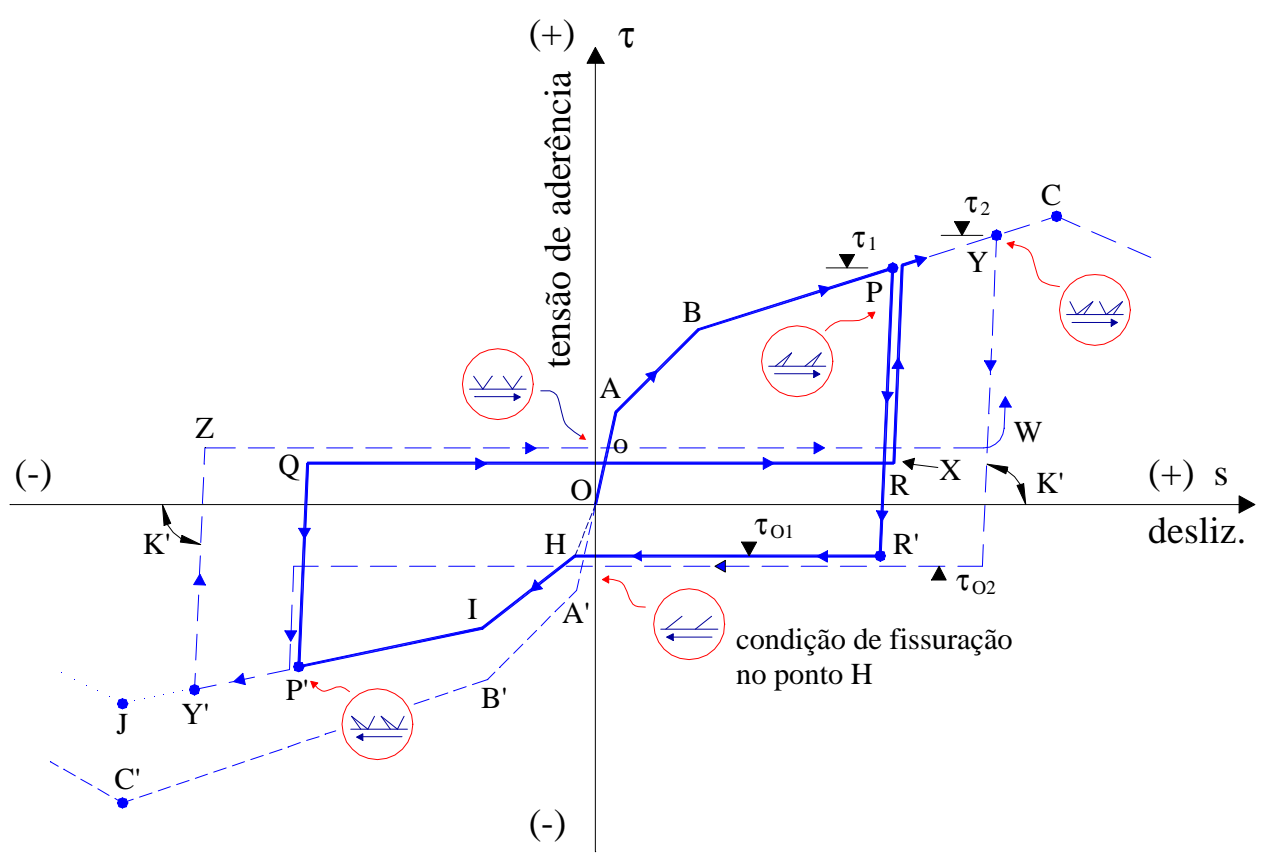

FIGURA 3.10 - Relação tensão de aderência versus deslizamento para carregamento cíclico alternado

- TASSIOS (1979) -

O trecho OP é referente ao comportamento da aderência monotônica apresentado no capítulo 2. Como primeira aproximação para a aderência cíclica alternada, o trecho de descarregamento $\mathbf{P R}$ possui a mesma inclinação da curva de carregamento $\mathbf{O} \tau_{\mathbf{0}}$. À medida que o deslizamento na direção contrária é imposto à armadura, uma tensão de aderência negativa $\tau_{\mathbf{0 1}}$ se desenvolverá. Esse comportamento negativo da aderência continua constante devido à hipótese da tensão normal $\sigma_{\mathbf{y}}$ permanecer inalterada. Neste caso, o ângulo $\beta$ indicado na figura 2.20 é $45^{\circ}$, tornando as componentes $\sigma_{\mathbf{y}}$ e $\tau_{1}$ de mesmo valor para manter o equilíbrio de força.

No comportamento negativo da aderência, alguns aspectos característicos podem ser observados no concreto envolvente. As fissuras transversais diagonais são fechadas gradualmente até o ponto $\mathbf{H}$, deixando o concreto "intacto" novamente. Entretanto, as fissuras de fendilhamento geradas no ponto $\mathbf{P}$ permanecem abertas devido à suposição da tensão normal $\sigma_{\mathbf{y}}$ permanecer constante. Com isto, o 
carregamento negativo não acompanha a curva $\mathrm{OA}^{\prime} \mathrm{B}^{\prime} \mathrm{C}^{\prime}$, havendo uma redução na resistência de aderência.

Com descarregamentos adicionais, o comportamento da aderência é semelhante ao anterior. Durante o recarregamento, a reação positiva $\tau_{\mathbf{Q}}$ permanece constante pelas mesmas razões vistas para $\tau_{\mathbf{0 1}}$, até o momento em que o deslizamento no início do ciclo é atingido. A partir deste ponto, são observados dois importantes fatos:

- As fissuras diagonais recuperam sua abertura inicial e se opõem a abertura adicional;

- As tensões devido ao engrenamento mecânico entre as saliências da barra começam a crescer novamente, contribuindo assim, para o crescimento das fissuras por fendilhamento ou para o esmagamento das bielas de compressão do concreto entre as nervuras.

Segundo ELIGEHAUSEN et al $^{1}$ apud CEB (1996), a degradação da aderência depende principalmente do deslizamento máximo nas duas direções de carregamento, da amplitude entre esses deslizamentos e do número de ciclos, como indica a figura 3.11. Se a tensão de aderência máxima durante os ciclos não exceder 70-80\% da resistência de aderência monotônica, a curva tensão de aderência versus deslizamento não é significativamente influenciada até 10 ciclos (figura 3.11(a)). A resistência de aderência no deslizamento máximo é deteriorada moderadamente com o número crescente de ciclos. Todavia, no caso das figuras 3.11(b) e (c), onde a tensão de aderência máxima ultrapassa $80 \%$ da resistência monotônica da ligação, o dano no comportamento da aderência torna-se muito mais significativo.

Devido às ações cíclicas alternadas, pelo modelo de aderência de Eligehausen et al, o trecho inicial da curva cíclica alternada tensão de aderência versus deslizamento acompanha a envoltória monotônica; todavia, o comportamento cíclico alternado da aderência é sensível ao nível do deslizamento no qual ocorre a inversão do carregamento. Três modelos qualitativos são propostos de acordo com a formação ou não de fissuras inclinadas.

${ }^{1}$ ELIGEHAUSEN, R. et al. (1983). Local bond stress-slip relationships of deformed bars under generalized excitations. Berkeley, University of California, Earthquake Engineering Research Center. (Report No. UCB/EERC 83-23). apud CEB (1996) 


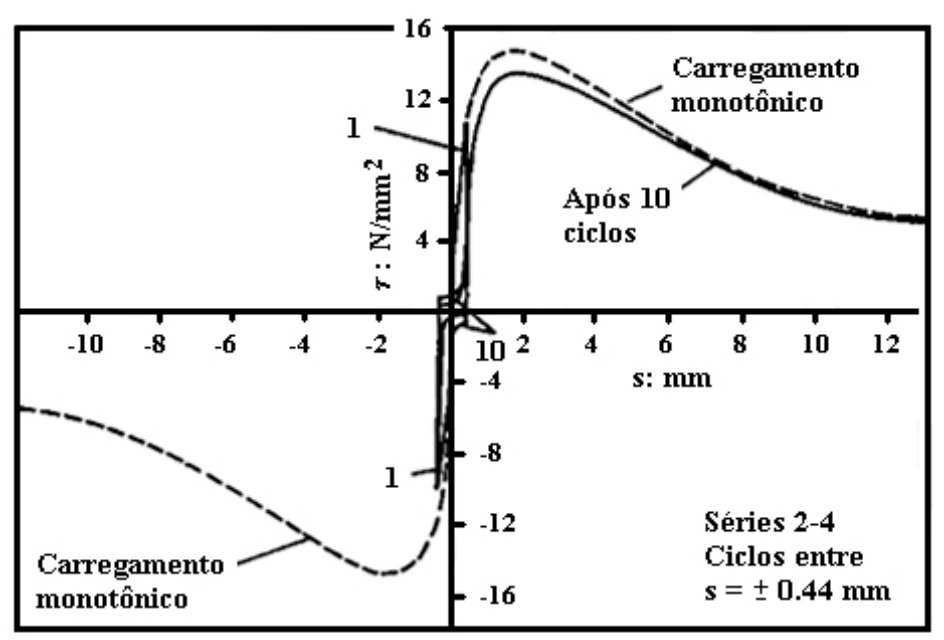

(a)

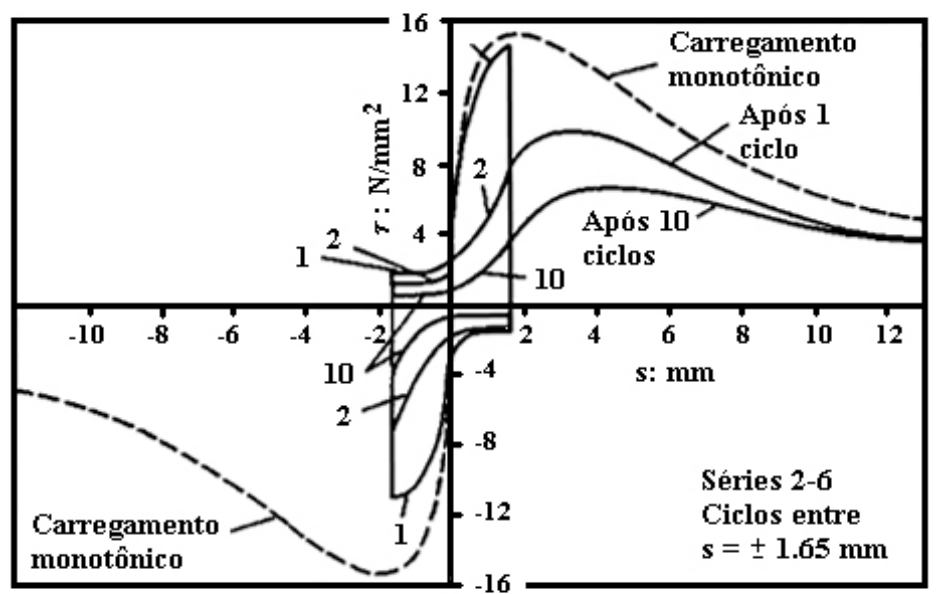

(b)

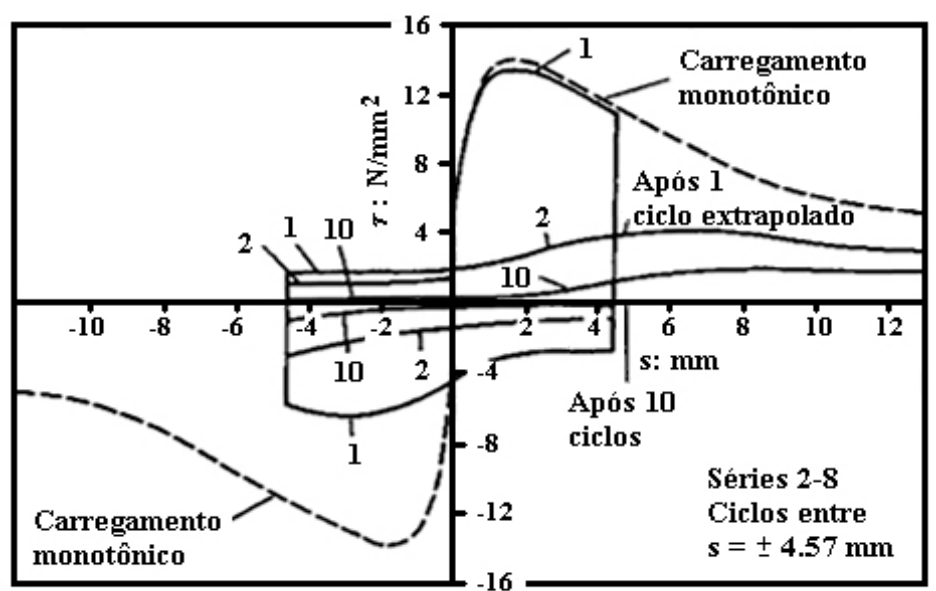

(c)

FIGURA 3.11 - Curvas tensão de aderência-deslizamento para diferentes amplitudes de deslizamentos

- ELIGEHAUSEN et al apud CEB (1996) -

No primeiro caso (figura 3.12(a)), fazendo a inversão do deslizamento em um valor arbitrário antes de surgir a fissuração inclinada, o trecho de descarregamento é 
extremamente rígido (trecho $\mathrm{AF}$ ), devido a apenas uma pequena parte do deslizamento ser causado pela deformação inelástica do concreto. Quando o deslizamento na direção contrária é imposto à barra, a aderência se desenvolve ao longo do trecho de atrito (trecho $\mathrm{FH}$ ), com uma inclinação insignificante, devido à superfície do concreto envolvente à barra ser lisa. Como as fissuras se fecham, a rigidez se torna pouco diferente da envoltória monotônica (ponto I). A partir deste nível, a curva de descarregamento IKL é muito semelhante à inicial AFH. A única diferença é que, devido à fissuração anterior e ao esmagamento do concreto na face das nervuras, o ponto onde as tensões de aderência começam a crescer novamente (ponto L) é deslocado para a direita da origem. O engrenamento entre as nervuras vai sendo mobilizado gradualmente até o ponto $\mathrm{M}$, a partir do qual a curva continua até a envoltória monotônica.

Se o descarregamento for feito após a formação das fissuras inclinadas (figura 3.12(b)), que corresponde ao segundo caso, e portanto próximo do deslizamento na tensão última de aderência, o trecho de descarregamento é semelhante ao primeiro caso até o ponto F. Como o dano é maior, a resistência de atrito mobilizada é um pouco mais elevada (ponto G). Com a inversão novamente do carregamento, o dente de concreto é pressionado pela nervura, com uma resistência menor devido às fissuras inclinadas. As fissuras de fendilhamento criadas no primeiro meio-ciclo são fechadas com uma tensão maior que a do primeiro caso (ponto $\mathrm{H}$ ), induzindo a uma formação precoce de fissuras de fendilhamento na direção oposta. Estas fissuras, combinadas com as fissuras inclinadas existentes ao longo da barra, resultam em uma envoltória reduzida (trecho HI) e em uma diminuição na capacidade de aderência na segunda direção (ponto I). Fazendo o descarregamento e recarregamento a partir deste nível (trecho IKLMN), a resistência e rigidez de aderência tornam-se reduzidas, devido a existir apenas uma pequena parte restante de concreto não esmagado entre as nervuras a ser "cortado". A resistência de aderência (ponto N) é substancialmente menor que a do ponto $\mathrm{C}$, e menor que a do ponto $\mathrm{I}$. 


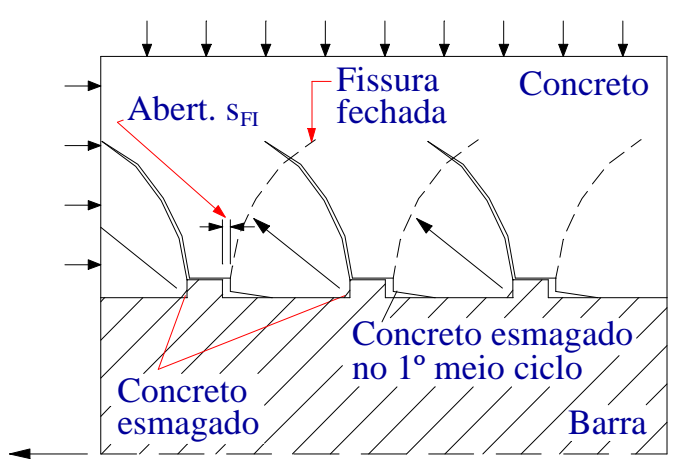

(a)

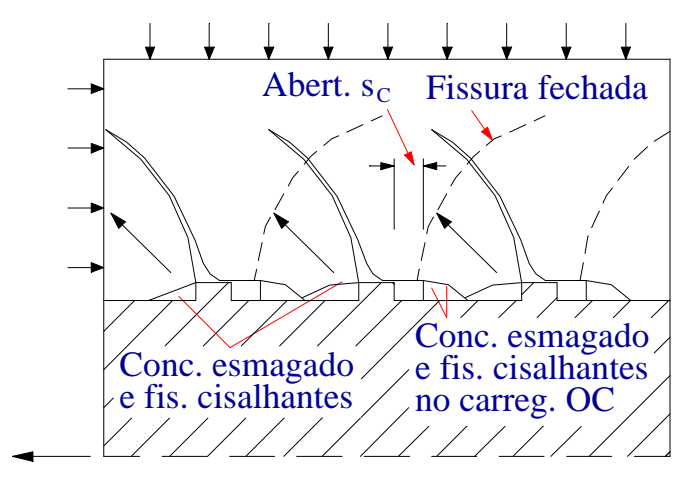

(b)
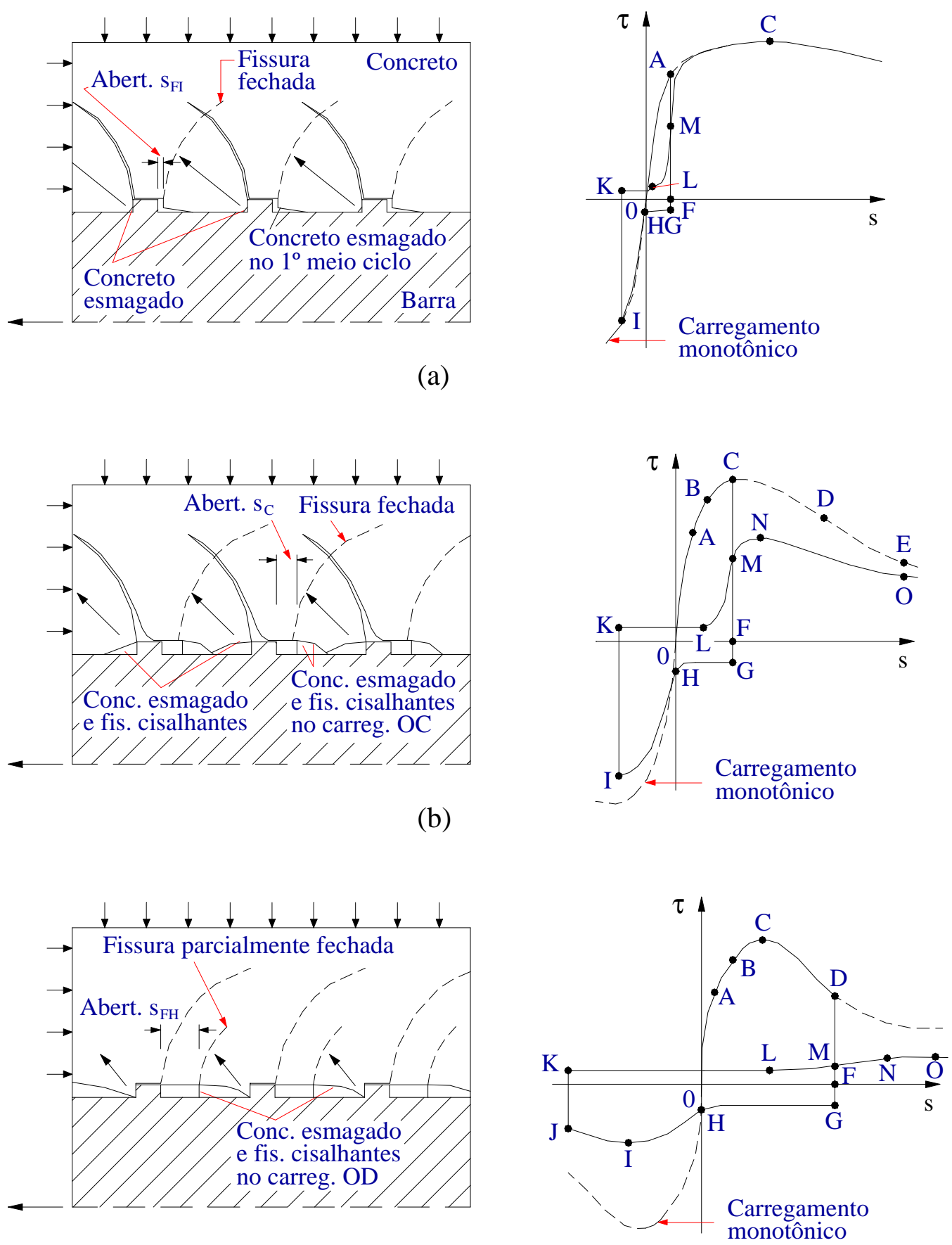

monotônico

(c)

FIGURA 3.12 - Mecanismo de aderência cíclica

- ELIGEHAUSEN et al apud CEB (1996) -

No terceiro caso, o descarregamento ocorre em um deslizamento muito maior que o correspondente à tensão última de aderência (ponto $\mathrm{C}$ ), sendo, portanto, a degradação muito maior (figura 3.12(c)), e a resistência de atrito (ponto G) muito mais elevada que os dois primeiros casos. Como as fissuras inclinadas se estendem 
ao longo de todo o concreto entre as nervuras, a parcela de força que pode ser transmitida por aderência é insignificante a partir da inversão do carregamento (trecho HIJ). O descarregamento e recarregamento na direção oposta (trecho JKLMN) resulta em uma deterioração significativa da capacidade de aderência, sendo a maior parte mobilizada pelo atrito, devido à grande perda da ancoragem mecânica.

Conforme HAWKINS et al (1982), observa-se pela figura 3.13, que a deterioração da aderência é crescente com o número de ciclos e se torna maior para inversões completas do deslizamento do que para meio-ciclos. Se os ciclos só produzem deslizamento em uma única direção, a deterioração da resistência de aderência não é tão significativa.

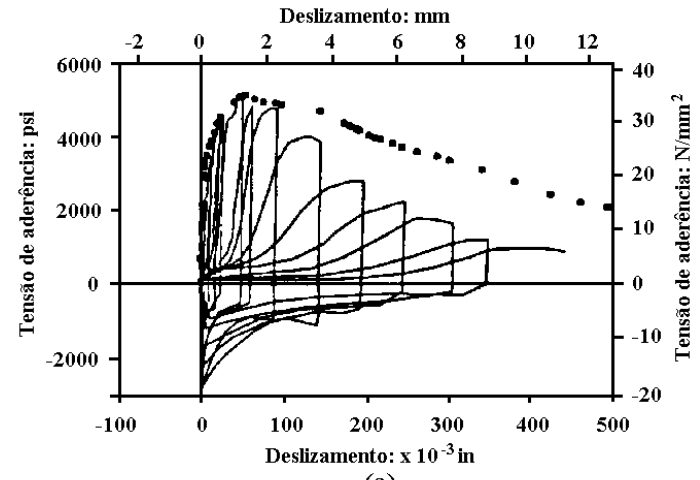

(a)

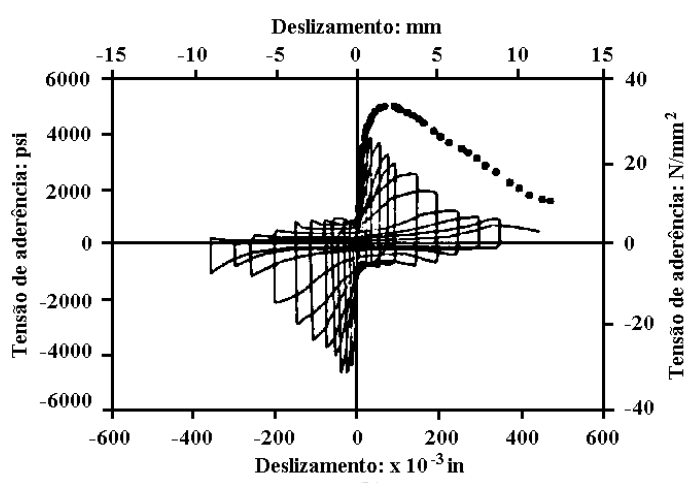

(b)

FIGURA 3.13 - Comparação das curvas tensão de aderência-deslizamento monotônica e cíclica allternada: (a) sem inversão de sinal do deslizamento; (b) com inversão de sinal do deslizamento

- HAWKINS et al (1982) -

A figura 3.14, de acordo com o ACI COMMITTEE 408 (1991), apresenta a relação tensão de aderência versus deslizamento de um elemento sob ação cíclica alternada de baixo-ciclo. A parte inicial da curva no primeiro ciclo acompanha a envoltória monotônica. Se o descarregamento for feito depois que a tensão de aderência exceder aproximadamente metade de seu valor último, um deslizamento residual significativo permanecerá na barra. Com o carregamento na direção inversa, a barra irá se deslocar inicialmente como um corpo rígido, mobilizando depois o atrito e o engrenamento mecânico. À medida que ciclos posteriores são aplicados, o concreto entre as nervuras vai sendo esmagado e cortado. 


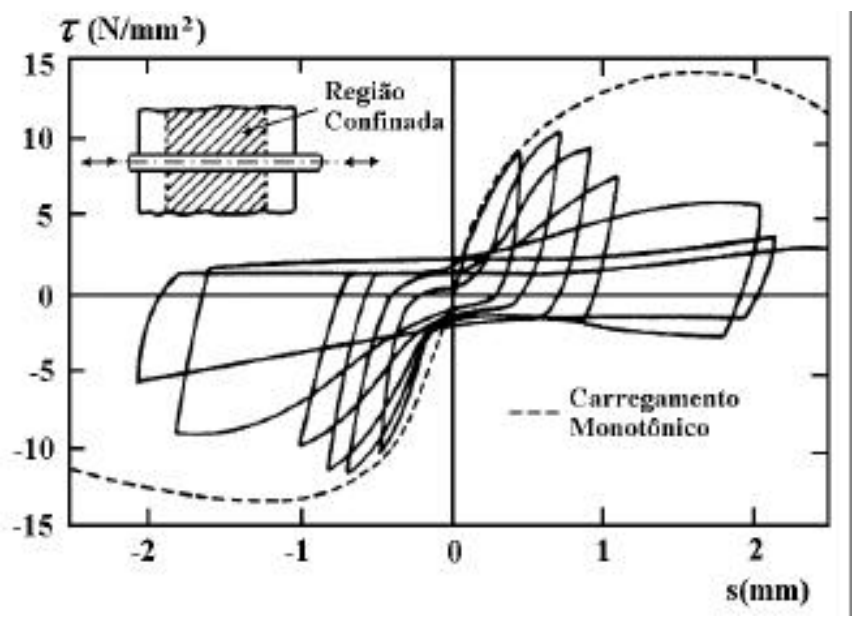

FIGURA 3.14 - Comportamento da aderência devido ao carregamento de baixo-ciclo - ACI COMMITTE 408 (1991) -

Para carregamento cíclico alternado, BALÁZS (1991) analisou a fadiga da aderência para ensaios com velocidade de deslizamento e força controlada.

Como indica a figura 3.15, ciclos com velocidade de deslizamento controlada produzem degradação da resistência de aderência máxima e da resistência de atrito.

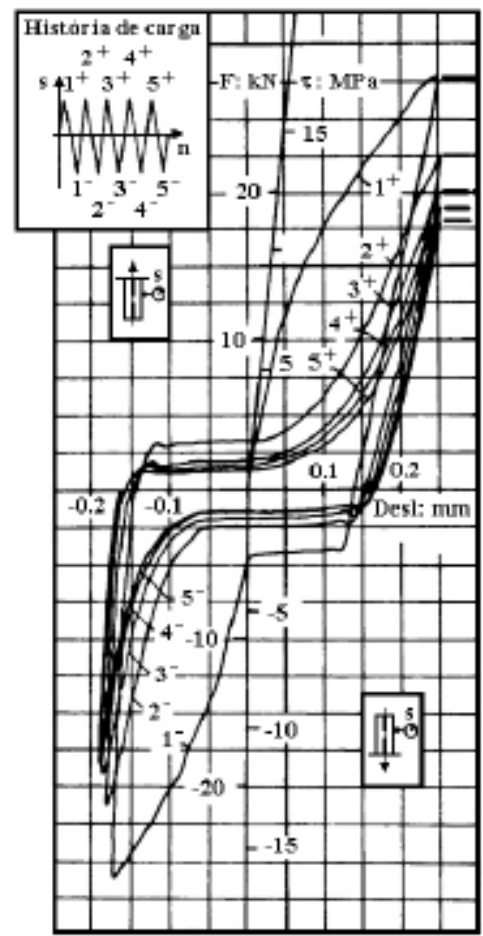

(a)

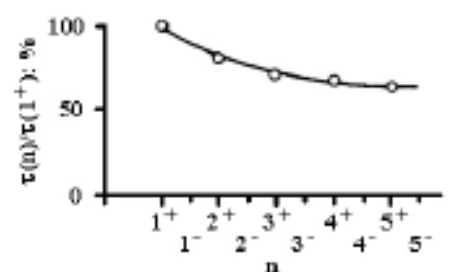

(b)

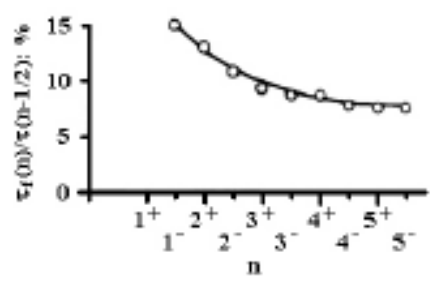

(c)

FIGURA 3.15 - Resultados experimentais com inversão de deslizamento controlado $\left(\mathrm{d}_{\mathrm{b}}=16\right.$ $\mathrm{mm}$ (barra nervurada), $\mathrm{f}_{\mathrm{y}}=400 \mathrm{MPa}, \mathrm{f}_{\mathrm{c}}{ }^{\prime}=25 \mathrm{MPa}, \mathrm{l}_{\mathrm{b}}=2 \mathrm{~d}_{\mathrm{b}}$ ): (a) curva força-deslizamento; (b) deterioração da tensão máxima de aderência; (c) deterioração da tensão máxima de atrito 
Já para os ciclos com velocidade de força controlada, o comportamento da aderência ilustrado na figura 3.16 foi caracterizado por um crescimento significativo no deslizamento, o qual ocasionou um dano expressivo no concreto envolvente à barra.

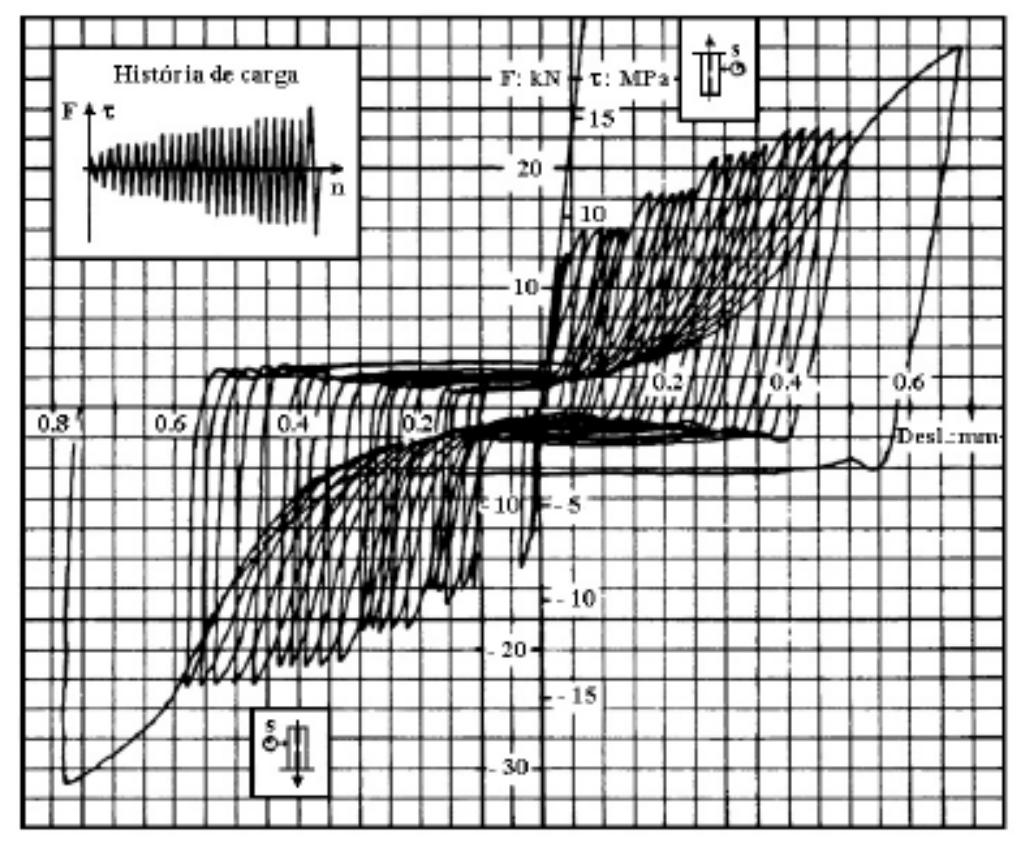

FIGURA 3.16 - Resultados experimentais com inversão de força controlada em quatro níveis diferentes de força $\left(\mathrm{d}_{\mathrm{b}}=16 \mathrm{~mm}\right.$ (barra nervurada), $\mathrm{f}_{\mathrm{y}}=400 \mathrm{MPa}, \mathrm{f}_{\mathrm{c}}{ }^{\prime}=25 \mathrm{MPa}, \mathrm{l}_{\mathrm{b}}=$ $\left.2 \mathrm{~d}_{\mathrm{b}}\right)$ : curva força-deslizamento - BALÁZSS (1991) -

De acordo com a figura 3.17, a qual mostra a deterioração da aderência devido a deslizamentos alternados crescentes, os trechos de carregamento para deslizamentos maiores indicam que há uma redução tanto da resistência de aderência $\left(\mathbf{K}_{\mathbf{2}} \tau_{\mathbf{b u}}\right)$ como do seu deslizamento correspondente $\left(\mathbf{K}_{\mathbf{3}} \mathbf{s}\left(\tau_{\mathbf{b u}}\right)\right)$. Estas reduções dependem basicamente da história de carregamento. 


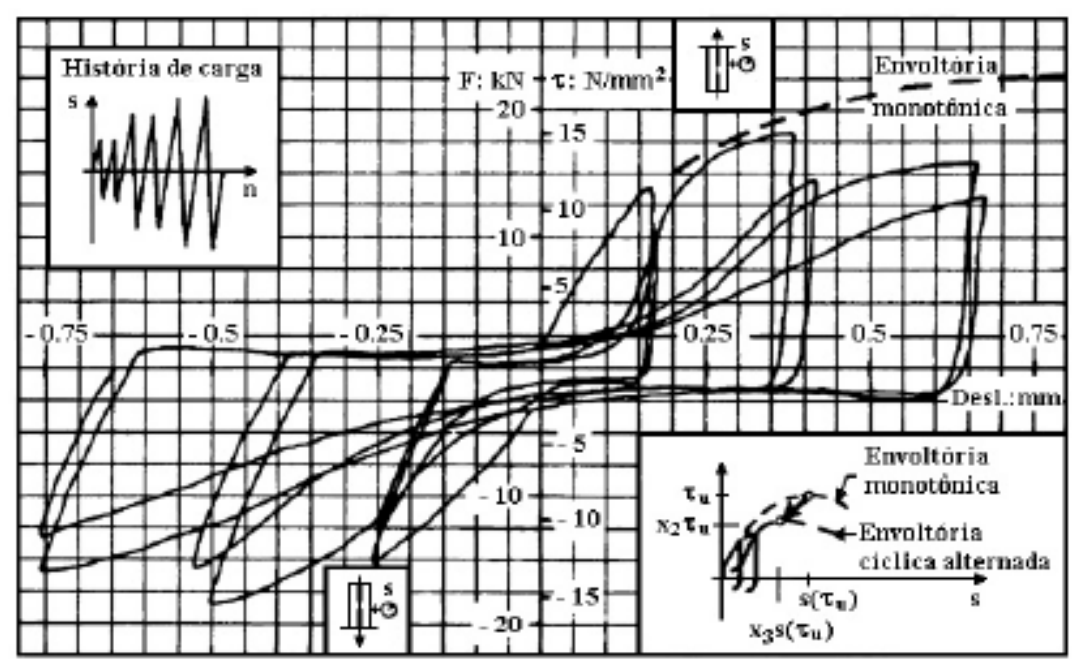

FIGURA 3.17 - Deterioração da aderência devido a deslizamento alternado crescente $\left(\mathrm{d}_{\mathrm{b}}=8\right.$ $\mathrm{mm}$ (barra nervurada), $\mathrm{f}_{\mathrm{y}}=400 \mathrm{MPa}, \mathrm{f}_{\mathrm{c}}{ }^{\prime}=25 \mathrm{MPa}, \mathrm{l}_{\mathrm{b}}=6 \mathrm{~d}_{\mathrm{b}}$ ) - BALÁZS (1991) -

\subsection{COMPORTAMENTO DA ADERÊNCIA EM SERVIÇO}

A investigação do comportamento da ancoragem sob ações cíclicas pode ser feita através de um outro ponto de vista, o qual não envolve a fadiga da ligação. Para ser feita uma análise do seu comportamento em serviço, considera-se o envelhecimento da aderência com a aplicação de carregamento cíclico e posterior carregamento estático para efeito de comparação com a aderência intacta.

Nesta linha de pesquisa, VALLE (1994) fez um estudo sobre o comportamento da aderência entre a armadura e o concreto sob ações repetidas através do ensaio das quatro barras, no qual a barra central é tracionada e o cilindro de concreto permanece imóvel pela força de reação exercida pelas três barras dispostas nos vértices de um triângulo, como indica a figura 3.18.

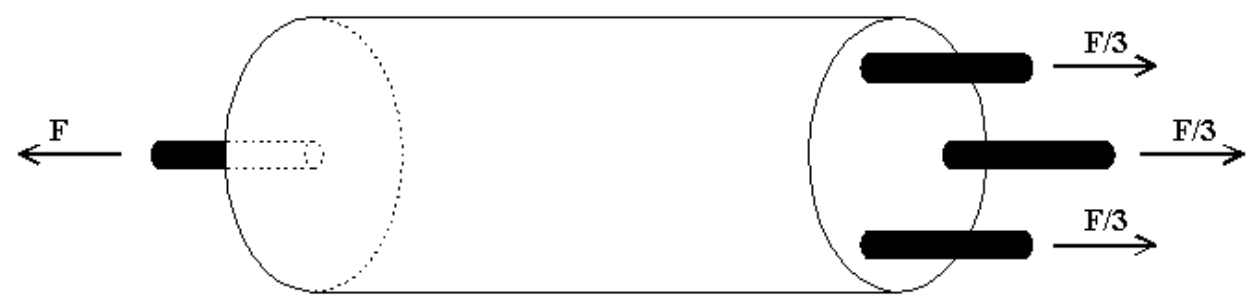

FIGURA 3.18 - Corpo-de-prova do ensaio das quatro barras - VALLE (1994) - 
As variáveis analisadas nos ensaios foram a distância entre a barra central e as barras que servem de suporte ao modelo, o comprimento de aderência da barra central e o carregamento estático ou repetido.

O principal objetivo da investigação experimental foi comparar o comportamento da ancoragem em serviço com a ancoragem intacta dos primeiros carregamentos. O método adotado para o envelhecimento da ligação foi a aplicação de um carregamento repetido com intensidade e número de ciclos que não conduzissem à ruptura da aderência.

De acordo com os resultados dos ensaios, verificou-se que o carregamento repetido prévio ocasionou um acréscimo no valor de $\tau_{\mathbf{b}, \mathbf{m a ́ x}}$, tensão máxima de aderência associada à ruptura local da ligação, $\tau_{\mathbf{b}, \text { rup }}$, tensão de aderência de ruptura na qual a armadura perde a capacidade de ancoragem, e nos deslizamentos registrados na ruptura da ancoragem. A justificativa para tal fato é que, quando submetido ao carregamento repetido, além da ruptura das parcelas da adesão e do atrito, a mobilização do engrenamento mecânico entre o concreto e a armadura iniciou o processo de pulverização das saliências de concreto. A existência deste concreto compactado, quando da aplicação do carregamento estático, possibilitou o surgimento de tensões de aderência mais elevadas. Já os valores dos deslizamentos maiores são devido ao deslizamento residual ocasionado pela ação repetida.

Devido ao carregamento repetido prévio, ocorreu uma diminuição da tensão de aderência uniforme, $\tau_{\mathbf{b} \text {,unif }}$ o que constatou o decréscimo da capacidade última de ancoragem, antecipando a ruptura global da aderência. Tal fenômeno é justificado pelo fato de que a ação repetida causa a ruptura dos pontos de ligação mais frágeis, ocasionando uma propagação mais rápida das rupturas locais.

\subsection{COMPORTAMENTO DE NÓS DE PÓRTICOS SOB AÇÃO CÍCLICA}

No campo inelástico e particularmente, tratando-se de ações cíclicas de elevada intensidade (ações sísmicas), existe uma perda progressiva de aderência entre a armadura e o concreto principalmente nos nós viga-pilar, podendo ocasionar a 
ruptura da estrutura. Além disso, a armadura se deforma significativamente no escoamento, induzindo ao desenvolvimento de fissuras ao longo da viga, as quais juntas com as da interface viga-pilar causam uma grande rotação relativa entre estes dois elementos.

Na figura 3.19, é ilustrado o mecanismo de transmissão de forças ao longo do núcleo de nós internos, antes e depois da fissuração das vigas, conforme PAULAY et $\mathrm{al}^{1}$ apud TASSIOS (1979). Inicialmente, as forças de compressão da viga e do pilar que atuam na região de compressão não fissurada são diretamente transmitidas de canto a canto através do núcleo do nó. As tensões diagonais de compressão relativamente pequenas também se desenvolvem nesta área, devido à aderência ao longo das barras. Após a formação de grandes fissuras nas interfaces verticais do nó, devido à atuação do carregamento cíclico, as forças de compressão horizontais da viga são transmitidas pela armadura de compressão, tal que $\mathbf{C}_{\mathbf{s}}=\mathbf{T}_{\mathrm{s}}$. Devido ao aumento das tensões de aderência em um certo trecho, denominado na literatura de yield penetration, a transmissão das forças de compressão de canto a canto não é mais possível; portanto, a combinação da força de compressão do pilar com as forças de aderência induzidas pelas barras horizontais resulta em forças de compressão diagonais direcionadas para os pontos $\mathbf{B}$ e $\mathbf{B}^{\prime}$, como apresenta a figura 3.19(b). Paralelamente, forças de compressão diagonais significativas são ocasionadas pelas elevadas tensões de aderência concentradas $\left(\tau_{\mathbf{u}}\right)$, as quais são direcionadas para os pontos A e $\mathbf{A}^{\prime}$ na figura 3.19(b), onde o equilíbrio se torna impossível, a não ser que existam ganchos horizontais.

\footnotetext{
1 PAULAY; PARK; PRIESTLEY (1978). R.C. beam-column joints under seismic actions. ACI
} Journal, Nov. apud TASSIOS (1979) 


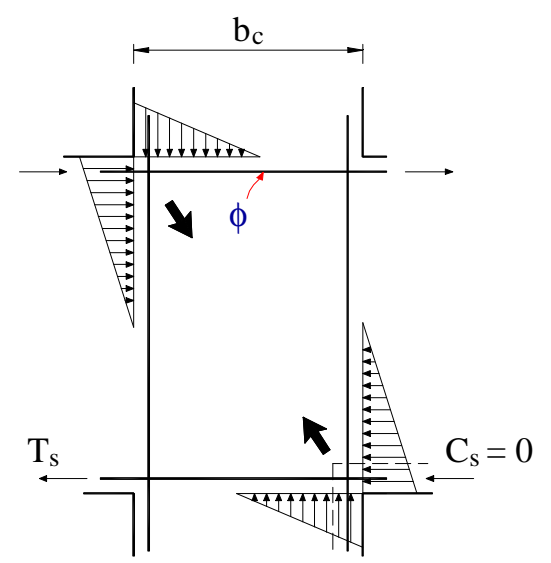

tensão de aderência

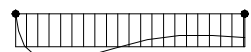

$$
\tau_{\mathrm{o}} \approx \frac{\mathrm{f} \mathrm{y}}{\mathrm{bc}} \cdot \frac{\phi}{4}
$$

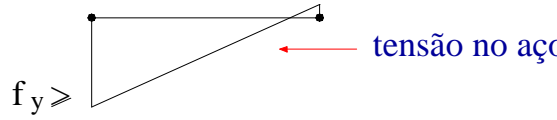

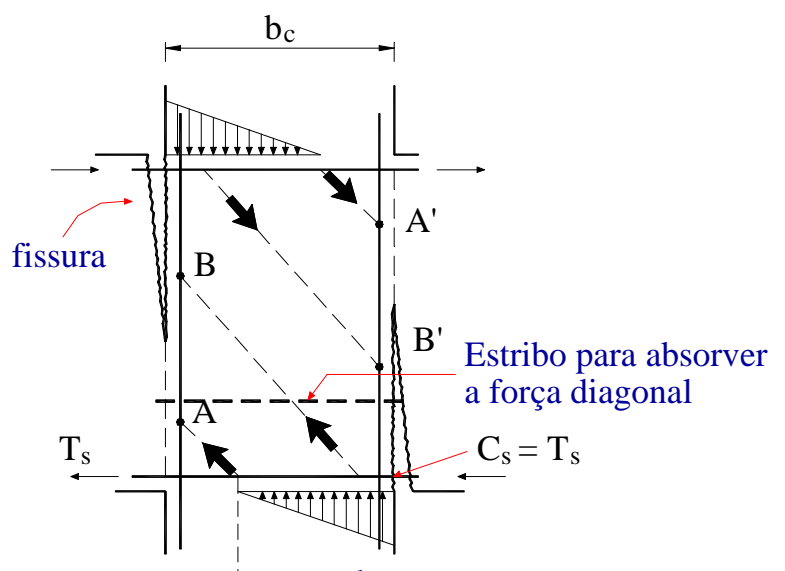

tensão de aderência

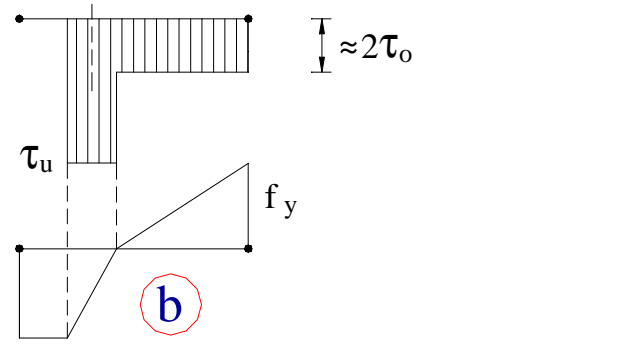

FIGURA 3.19 - Transmissão de forças através do: (a) núcleo de um nó intacto; (b) núcleo de um nó após a perda de aderência em um certo trecho

- TASSIOS (1979) -

De acordo com POPOV (1984), em seus estudos sobre estruturas submetidas a carregamento sísmico, a ruptura de tais estruturas ocorre fundamentalmente devido ao arrancamento da armadura principal dos elementos ou nós internos.

Através de resultados de análises elásticas por elementos finitos, foi feita uma explicação analítica para o fenômeno da aderência. Na figura 3.20, são apresentadas as tensões principais calculadas para um deslocamento arbitrário da barra de $1,3 \times 10^{-3}$ para a direita. As fissuras radiais inclinadas surgem perpendicularmente às tensões principais de tração quando estas ultrapassam a resistência do concreto à tração. A presença da componente de tensão radial provoca, ainda, uma pressão no concreto envolvente, podendo ocasionar fissuras de fendilhamento. 


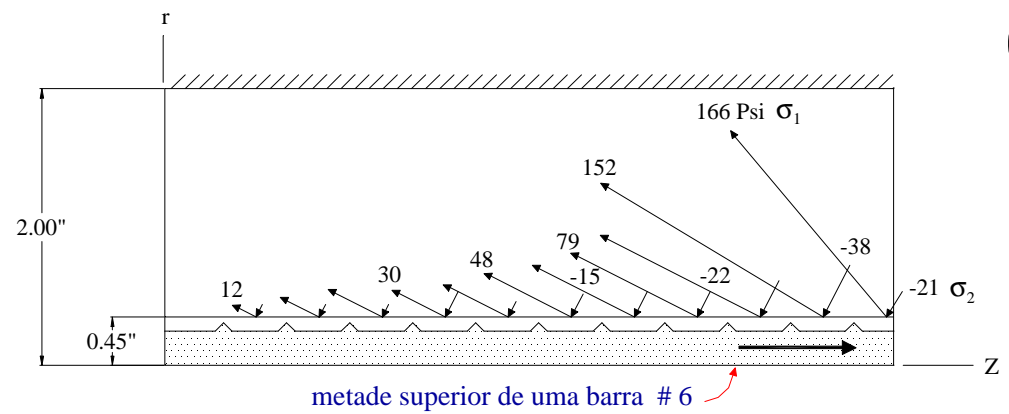

(a)

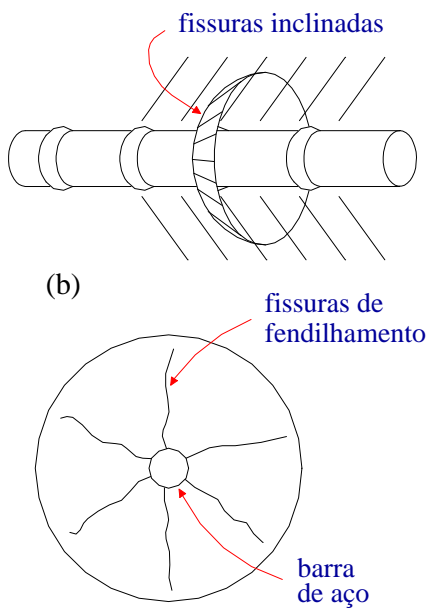

(c)

FIGURA 3.20 - (a) Análise elástica por elementos finitos do arrancamento de uma barra com indicação das tensões principais axissimétricas em um raio de 0,45 " ocasionadas por um deslocamento aplicado na barra de 0,00005 " para a direita; (b) Fissuras inclinadas normais às tensões de tração; (c) Fissuras de fendilhamento devido à pressão normal atuante na barra - POPOV (1984) -

Com o objetivo de reduzir a complexidade e os custos dos modelos para a análise da deterioração da aderência em pórticos rígidos, dois tipos de ensaios foram realizados na Universidade da Califórnia, Berkeley: um com grande comprimento de aderência e outro com pequeno comprimento.

No primeiro tipo, ensaiou-se um modelo de pilar com concreto confinado por estribos e uma barra simulando uma das armaduras principais da viga, como indica a figura 3.21 .

$\mathrm{Na}$ relação tensão de aderência versus deslizamento para barras longas mostrada na figura 3.22, apresenta-se a situação mais desfavorável encontrada em nós viga-pilar, que ocorre quando forças de igual intensidade e mesmo sentido são aplicadas ciclicamente em ambas as extremidades da barra. 


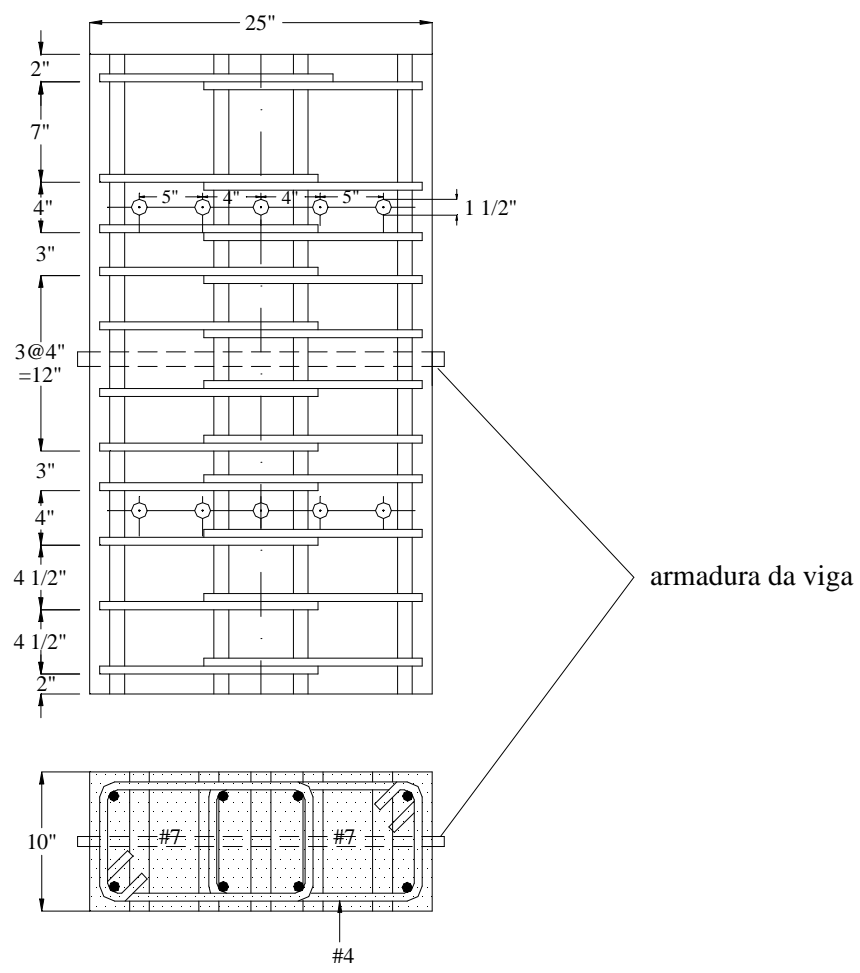

FIGURA 3.21 - Núcleo típico de pilar para análise da ancoragem de uma barra com comprimento longo

- POPOV (1984) -

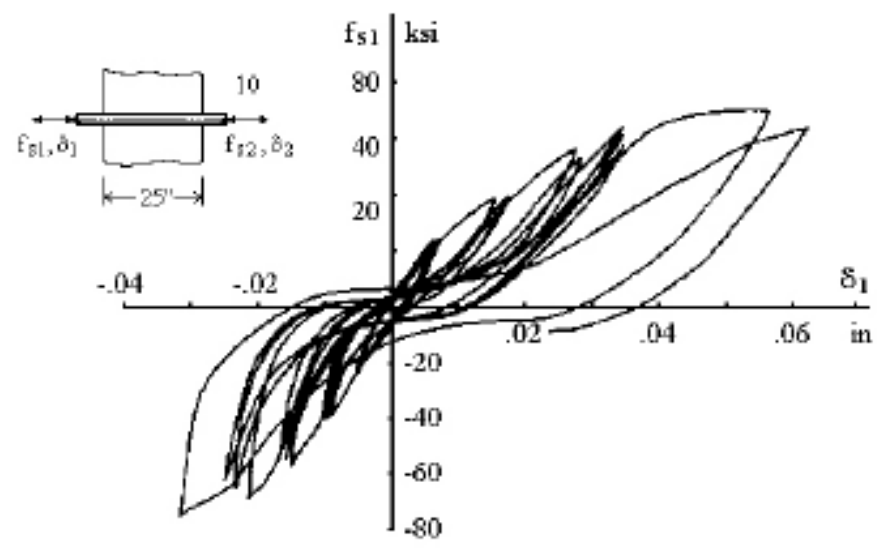

FIGURA 3.22 - Experimentos cíclicos alternados com barra \#10 para forças iguais aplicadas simultaneamente em ambas as extremidades da barra - POPOV (1984) -

Para ensaios com barras curtas, o comprimento de aderência foi limitado a 5 vezes o diâmetro da barra, como ilustra a figura 3.23, considerando-se assim, a tensão média de aderência calculada como representativa da tensão de aderência local. 


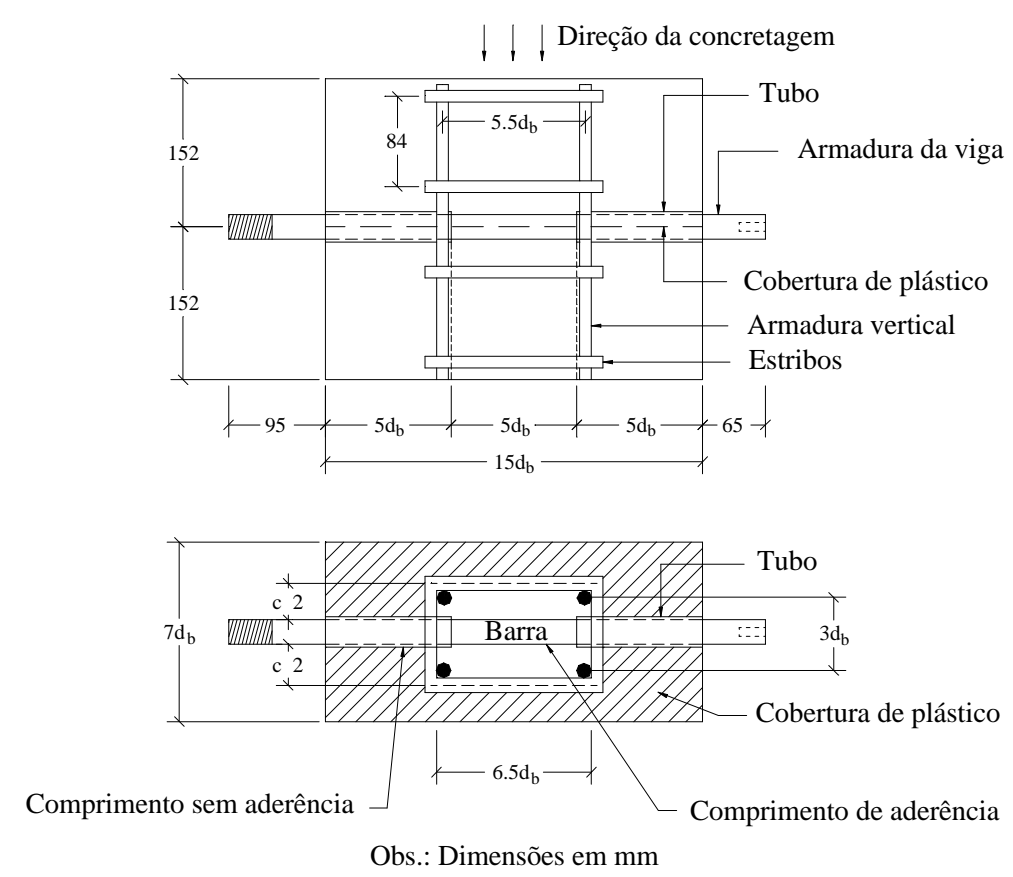

FIGURA 3.23 - Modelo do ensaio para determinação do comportamento local tensão de aderência-deslizamento em concreto confinado

- POPOV (1984) -

Na figura 3.24, é apresentado um diagrama representativo da tensão média de aderência local versus deslizamento para uma barra reta (figura 3.23). Alguns aspectos podem ser analisados neste diagrama. Primeiro, as curvas monotônicas na tração e compressão têm formas semelhantes. Segundo, neste ensaio particular sob elevado carregamento cíclico alternado $\left(\mathrm{s}_{\mathrm{o}}= \pm 1,65 \mathrm{~mm}\right)$, observa-se uma significativa deterioração da aderência durante a primeira inversão do carregamento. Terceiro, após um ciclo completo, a capacidade de aderência da barra não alcança a curva monotônica. Além disso, o dano da aderência continua conforme a aplicação do carregamento cíclico alternado. Por último, para deslizamentos muito grandes, a tensão média de aderência permanece aproximadamente constante, o que pode ser associado à força de atrito interna. 


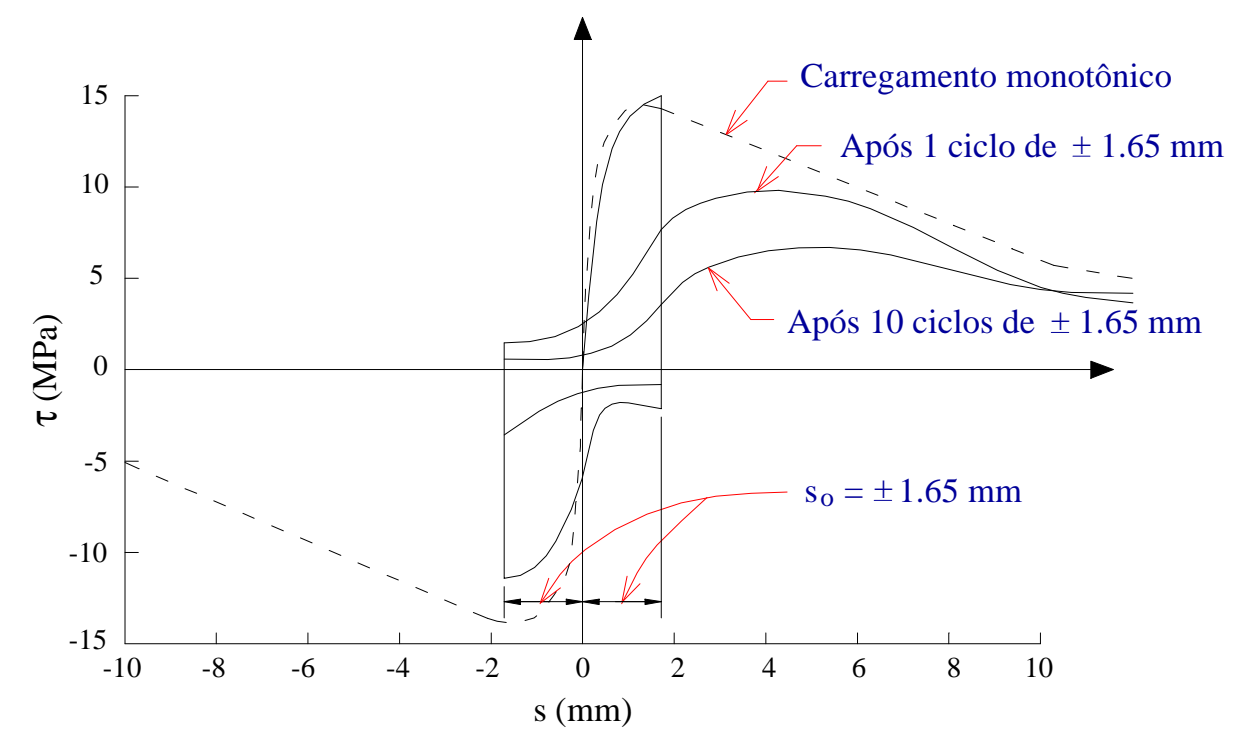

FIGURA 3.24 - Curva cíclica alternada experimental tensão de aderência-deslizamento para uma barra \#8 - adaptada de POPOV (1984) -

Com o objetivo de analisar de uma maneira mais simples o comportamento dos nós viga-pilar sob ações cíclicas alternadas, MORITA et al (1992) utilizaram um novo método experimental que consiste apenas de uma parte do nó representando a região da ligação, como indica a figura 3.25.

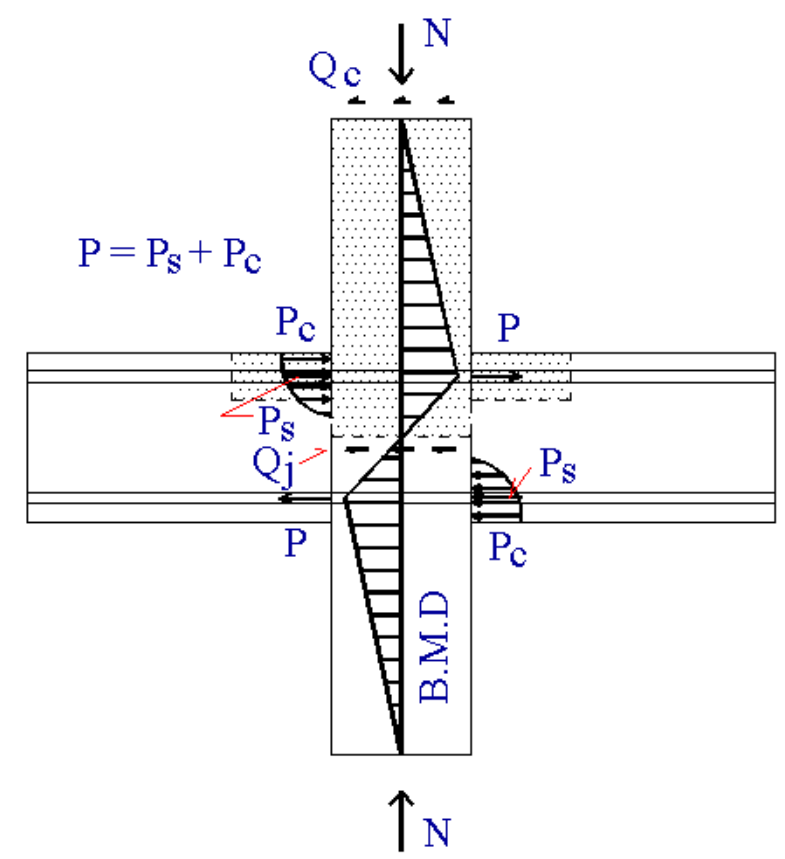

FIGURA 3.25 - Porção sombreada simulando o nó viga-pilar - MORITA et al (1992) - 
As variáveis analisadas no ensaio foram: largura da coluna, diâmetro da armadura da viga, tensão de escoamento da armadura da viga, resistência à compressão do concreto e relação entre a tensão axial no pilar e a resistência do concreto.

A figura 3.26 ilustra o tipo de fissuração de um modelo que rompeu por aderência, o qual apresenta as fissuras longitudinais.

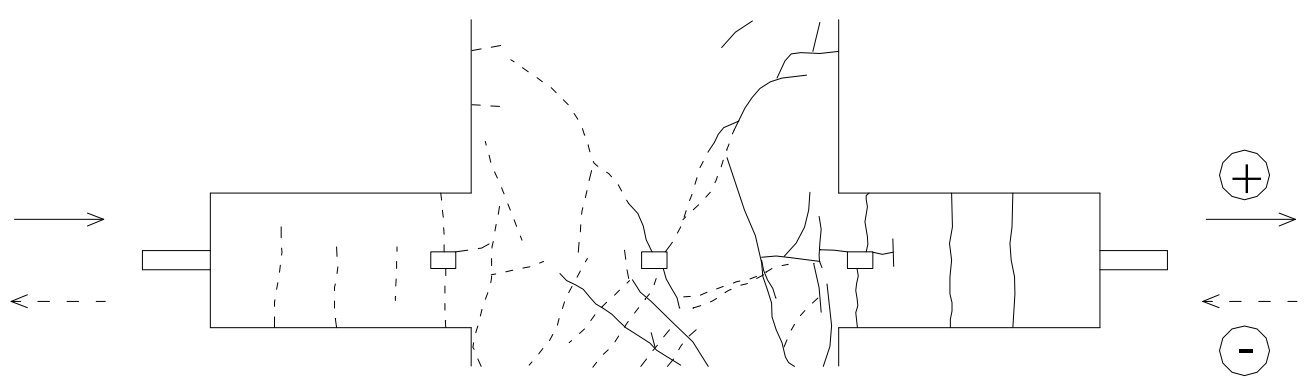

FIGURA 3.26 - Tipo de fissuração observada no modelo $n^{0} 5$ que rompeu por aderência - MORITA et al (1992) -

A relação força aplicada versus deslizamento de um modelo que rompeu por aderência após diversos ciclos alternados posteriores ao escoamento é apresentada na figura 3.27. O deslizamento interno (para a direção do carregamento) de uma face do pilar é muito pequeno em comparação com o deslocamento externo (para a direção contrária de carregamento) na mesma face antes da degradação da aderência. Para a seção central, foram observados deslizamentos de mesma magnitude em ambas as direções de carregamento. À medida que os ciclos progridem, o deslizamento continua crescendo gradualmente, até a total ruptura da aderência.

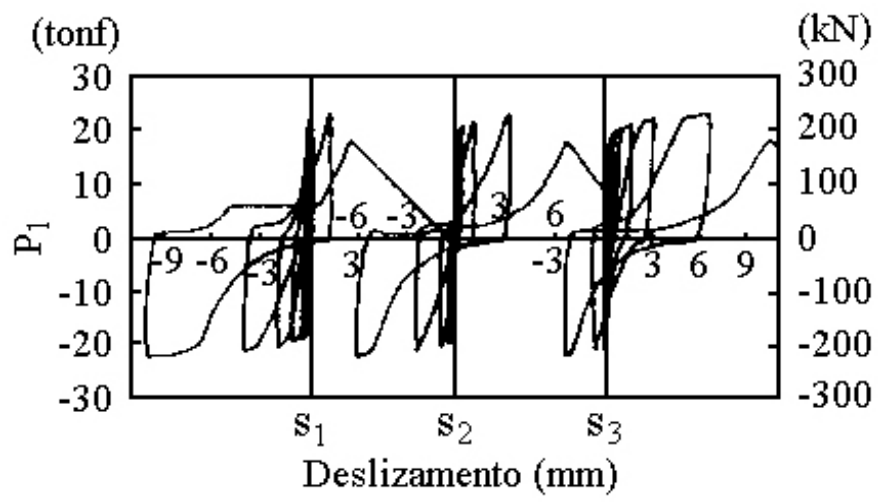

FIGURA 3.27 - Curvas força-deslizamento do modelo $n^{\circ} 6$ que rompeu por aderência - MORITA et al (1992) - 
Através dos resultados dos ensaios de MORITA et al (1992), ficou comprovado que um aumento da resistência do concreto, da força axial do pilar ou da relação entre a profundidade do pilar e o diâmetro da barra da viga induz a maior capacidade de aderência e maior rigidez nas curvas tensão de aderência versus deslizamento. Também se pode aumentar a resistência de aderência do nó com o decréscimo da tensão de escoamento da armadura da viga.

\subsection{ANÁliSE dAS AÇÕES CÍCLICAS SOB O PONTO DE VISTA DA FADIGA DO CONCRETO}

LARANJEIRAS (1990) apresentou um estado-da-arte resumido sobre a fadiga das estruturas de concreto, visando identificar fatores relevantes e diretrizes para o projeto estrutural. Este estudo enfoca ainda conclusões extraídas de observações de danos em estruturas, tendo a fadiga como causa importante destes danos. Os principais pontos desse estudo são resumidos a seguir.

A fadiga, fenômeno associado às ações dinâmicas repetidas, pode ser definida como o processo de modificações progressivas e permanentes da estrutura de um material submetido a tensões repetidas. Estas alterações podem ser danosas, resultando em aumento progressivo de fissuras internas, podendo evoluir a eventuais fraturas do material, caso a repetição seja suficientemente grande. A intensidade da fadiga está estreitamente relacionada às propriedades dos seus materiais componentes, que neste caso, tratam-se do aço, do concreto e da ligação entre eles.

No comportamento em serviço das estruturas, esses efeitos desfavoráveis das ações repetidas são observados através da formação prematura de fissuras, aumento da própria fissuração e no incremento de deformações.

Sob ações cíclicas, o concreto pode apresentar fissuração excessiva e romper após grande número de ciclos, mesmo com um nível do carregamento menor do que o equivalente à sua resistência estática. Portanto, a resistência de ruptura à fadiga do concreto pode ser expressa como uma fração da resistência estática para um determinado número de ciclos. $\mathrm{O}$ concreto caracteriza-se por não possuir um limite 
de resistência à fadiga, ou seja, um valor de tensão abaixo do qual a vida (número de ciclos) seria infinita.

Ao contrário dos metais, a ruptura à fadiga do concreto apresenta uma natureza dúctil, devido ao fato de ocorrerem deformações e microfissuração bem maiores que as decorrentes da ruptura estática.

De fato, os carregamentos que provocam a fadiga dos elementos estruturais de concreto armado têm uma influência mais significativa no comportamento em serviço do que na ruptura, no qual podem ser identificados os principais efeitos:

- Fissuração excessiva, ocasionando maiores danos devido à corrosão das armaduras;

- Deformações excessivas;

- Redução localizada da rigidez estrutural, diminuindo a durabilidade da estrutura.

Portanto, a fadiga além de ser verificada no estado limite último, para evitar a ruína da armadura e do concreto, deve ser estendida ao estado limite de utilização, para controlar seus efeitos adicionais danosos nas deformações e fissuração excessivas.

\subsubsection{TEORIA DO DANO}

A ruptura à fadiga nas estruturas é originada do acúmulo do dano proveniente de vários ciclos de carregamento, com diferentes freqüências e amplitudes. O dano é caracterizado pela degradação local progressiva irreversível do material, conseqüente à evolução de fissuração, desde a escala microscópica até a ruptura de um volume considerável.

Segundo DRIEMEIER (1995), o dano não está relacionado diretamente com a perda de rigidez do material, mas com a diminuição da vida à fadiga. No modelo linear do dano proposto por Palmgren-Miner, o dano é definido como proporcional à relação de ciclos $\mathbf{n}_{\mathbf{i}} / \mathbf{N}_{\mathbf{i}}$, onde $\mathbf{n}_{\mathbf{i}}$ é o número de ciclos de carregamento realizados durante um certo período de análise, e $\mathbf{N}_{\mathbf{i}}$ é o número de ciclos correspondente à ruptura para um mesmo nível de carregamento. Esta relação é também chamada de 
vida relativa à fadiga. Logo, admite-se que a ruptura ocorra quando a soma das vidas relativas é igual a unidade.

Apesar da regra de Palmgren-Miner não considerar a influência da seqüência do carregamento, da não-linearidade do acúmulo do dano, das tensões residuais e outros efeitos, e considerando a complexidade de outras teorias, esse modelo, para questões práticas, ainda constitui a melhor forma de previsão de ruptura para ações cíclicas, tanto em metais quanto em concreto.

Nas pesquisas sobre fadiga, DRIEMEIER (1995) apresentou um modelo constitutivo não-linear baseado na mecânica do dano contínuo, com extensão para o caso de ação cíclica, e a implementação numérica desse em combinação com o método dos elementos finitos. Esse modelo considera a aderência perfeita entre os nós dos elementos, que podem ser de chapa e/ou de barra. Os resultados numéricos foram comparados através de três exemplos de vigas de concreto armado, um com resultados teóricos e os outros dois com dados experimentais, ambos disponíveis da literatura, e apresentaram, de modo geral, uma boa concordância entre eles.

\subsubsection{INFLUÊNCIA DAS AÇÕES CÍCLICAS NAS FLECHAS DE VIGAS DE CONCRETO ARMADO}

A fluência cíclica pode ser definida como a deformação inelástica adicional à fluência estática, causada pela atuação do carregamento cíclico na estrutura. Esse fenômeno, de natureza complexa, vem sendo investigado por alguns pesquisadores.

As normas atuais como a NBR-6118/78 (NB-1/78 - Projeto e Execução de Estruturas de Concreto Armado), a NBR-7187/87 (Projeto e Execução de Pontes de Concreto Armado e Protendido), a Norma Americana ACI 318/83, a Norma Inglesa BSI-8110: Part 2: 1985 não apresentam recomendações sobre a evolução dos deslocamentos nas estruturas submetidas a ações cíclicas. Apenas o CEB-FIP MC 1990 enfoca essa questão com o uso de uma expressão que é baseada em investigações experimentais. A falta de recomendações nas normas para prever essa flecha adicional que ocorre nas estruturas pode levar a mesma à ocorrência de um estado limite, seja de ruptura ou de utilização. 
Portanto, com o objetivo de mostrar a importância do fenômeno da fluência cíclica, BRAGUIM (1995) realizou uma investigação experimental em vigas de concreto superarmadas e normalmente armadas sob ações cíclicas de serviço. Para comparar a ordem de grandeza do acréscimo do deslocamento devido ao carregamento cíclico, com o acréscimo proveniente da deformação lenta, também foram executados ensaios com carregamento permanente em modelos de vigas com propriedades semelhantes às daquelas submetidas ao carregamento cíclico.

Além dos estudos experimentais, foi feita uma modelagem empírica e numérica com as vigas ensaiadas com carregamento cíclico, sendo a primeira com a utilização dos modelos disponíveis na literatura e a segunda utilizando a implementação numérica desenvolvida por DRIEMEIER (1995).

De acordo com a figura 3.28, apesar de algumas diferenças entre os modelos teóricos utilizados e os resultados experimentais, fica comprovada a mesma tendência entre as curvas de crescimento da flecha com aumento no número de ciclos.

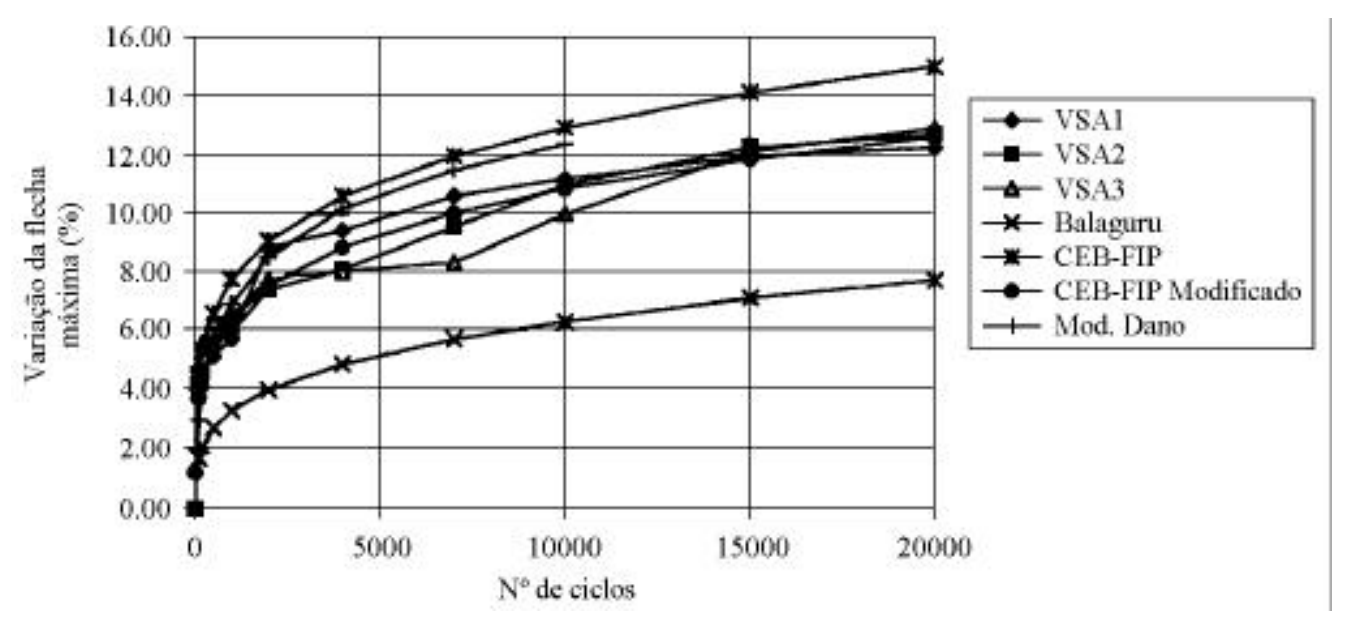

FIGURA 3.28 - Variação da flecha máxima versus número de ciclos para as vigas VSA - BRAGUIM (1995) -

Pode-se notar ainda pelos resultados comparados por BRAGUIM (1995), que a evolução da flecha devido ao carregamento cíclico é da mesma ordem de grandeza da deformação lenta devido ao carregamento permanente. Torna-se evidente, assim, que a mesma importância dada ao fenômeno da deformação lenta deve ser atribuída à "fluência cíclica". O efeito das ações cíclicas talvez possa ser considerado no próprio cálculo da deformação lenta, somando-se as ações permanentes com pelo menos uma parcela das ações acidentais. 
$\mathrm{KOH}$ et al (1997) desenvolveram um método computacional para calcular flechas em vigas de concreto armado submetidas a carregamento repetido, utilizando o modelo semi-empírico constitutivo de Bazant e Panula (BP), disponível na literatura, que considera os efeitos da retração, da fluência básica, por secagem e cíclica.

Para verificar a precisão do procedimento numérico, foram utilizados os resultados experimentais de vigas ensaiadas por Sparks \& Menzies e Snowdon, as quais eram simplesmente apoiadas com a força aplicada no meio do vão. O modelo também foi comparado com o método de Lovegrove \& Salah (LS) e de Balaguru \& Shah (BS), encontrados na literatura.

Conforme os resultados de $\mathrm{KOH}$ et al (1997), o crescimento na flecha das vigas observado é devido aos seguintes fatos:

- Para a mesma duração total de tempo, uma freqüência de carregamento maior implica em um número de ciclos maior e, conseqüentemente, uma fluência cíclica mais significativa.

- Quanto maior o fator água/cimento ou a relação cimento/agregado, maior o efeito da fluência cíclica.

- No início do carregamento, a viga carregada com idade maior apresenta uma flecha maior devido à deformação por retração maior. À medida que o carregamento continua, a flecha da viga carregada com uma idade menor é gradualmente crescente e excede a da viga carregada na idade maior. Isto ocorre devido à fluência se desenvolver mais rapidamente nas vigas carregadas em uma idade menor.

- Uma umidade relativa do ambiente menor induz mais à fluência por secagem.

Os resultados numéricos obtidos pelo modelo de $\mathrm{KOH}$ et al (1997), por considerarem os parâmetros acima, apresentaram a melhor concordância com os dados experimentais, comparados com os outros dois métodos. 


\section{INVESTIGACCÃO
EXPERIMENTAL DA ADERÊNCIA}

\subsection{CONSIDERAÇÕES INICIAIS}

A investigação experimental do comportamento da aderência foi feita por ensaios de arrancamento padronizados pela RILEM-FIP-CEB (1973) com adaptação do modelo cúbico padrão para um modelo cilíndrico, o qual apresenta um melhor comportamento.

O planejamento inicial desse estudo consistiu de uma pesquisa bibliográfica para a definição das principais variáveis que influenciam no comportamento da aderência. Após a identificação desses parâmetros, alguns deles foram escolhidos com o objetivo de analisar a sua influência na aderência, por meio dos ensaios e da modelagem numérica. Os parâmetros escolhidos foram:

- Diâmetro da armadura $(\phi=\mathbf{1 0 . 0} \mathbf{~ m m}$ e $\phi=\mathbf{2 0 . 0} \mathbf{~ m m})$;

- Tipo de carregamento (monotônico e repetido);

- Amplitude do carregamento repetido ( $\tau_{\operatorname{máx}}$ e $\left.\tau_{\text {mín }}\right)$.

Os modelos estudados foram denominados de PT (Pull-Out Test) acompanhados por dois números, a letra $\mathbf{M}$ (monotônico) ou $\mathbf{R}$ (repetido), os quais indicam a série, o número e o tipo do carregamento, respectivamente, da seguinte maneira:

\section{PT10-1R}

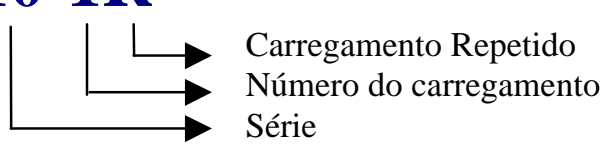


Os modelos PT10-Mpil-a e PT10-Mpil-b foram ensaiados com a finalidade de se observar o comportamento do ensaio de arrancamento para ação monotônica e o funcionamento do dispositivo e da instrumentação utilizados. O modelo PT10-Mref serviu de referência para o PT10-Rpil, sendo este o protótipo piloto para carregamento repetido.

A primeira série (número 10) constituiu ensaios para armadura de $10 \mathrm{~mm}$ e a segunda (número 20) para armadura de $20 \mathrm{~mm}$. O número do carregamento pode ser 1 a 4 para ação repetida conforme a tabela 4.1. Alguns modelos das séries foram ensaiados em duas amostras (a e b), de forma a se obter uma média dos resultados.

O resumo das características gerais de cada modelo são apresentadas na tabela 4.1.

TABELA 4.1 - Resumo das características gerais dos modelos

\begin{tabular}{|c|c|c|c|c|c||}
\hline Modelo & $\phi(\mathbf{m m})$ & $\begin{array}{c}\text { Número do } \\
\text { carregamento }\end{array}$ & $\begin{array}{c}\text { Tipo de } \\
\text { carregamento }\end{array}$ & $\begin{array}{c}\text { Número } \\
\text { de ciclos }\end{array}$ & $\begin{array}{c}\text { Amplitude de } \\
\text { carregamento }\end{array}$ \\
\hline PT10-Mpil-a & 10 & - & Monotônico & - & - \\
\hline PT10-Mpil-b & 10 & - & Monotônico & - & - \\
\hline PT10-Mref & 10 & - & Monotônico & - & - \\
\hline PT10-Rpil & 10 & - & Repetido & 50 & $60 \% \tau_{\mathrm{bu}}$ \\
\hline PT10-Ma & 10 & - & Monotônico & - & - \\
\hline PT10-Mb & 10 & - & Monotônico & - & - \\
\hline PT10-1Ra & 10 & 1 & Repetido & 30 & $60 \% \tau_{\mathrm{bu}}$ \\
\hline PT10-1Rb & 10 & 1 & Repetido & 30 & $60 \% \tau_{\mathrm{bu}}$ \\
\hline PT10-2Ra & 10 & 2 & Repetido & 30 & $80 \% \tau_{\mathrm{bu}}$ \\
\hline PT10-2Rb & 10 & 2 & Repetido & 30 & $80 \% \tau_{\mathrm{bu}}$ \\
\hline PT20-Ma & 20 & - & Monotônico & - & - \\
\hline PT20-Mb & 20 & - & Monotônico & - & - \\
\hline PT20-1R & 20 & 1 & Repetido & 30 & $60 \% \tau_{\mathrm{bu}}$ \\
\hline PT20-2R & 20 & 2 & Repetido & 30 & $80 \% \tau_{\mathrm{bu}}$ \\
\hline PT20-3R & 20 & 3 & Repetido & 130 & $80 \% \tau_{\mathrm{bu}}$ \\
\hline PT20-4R & 20 & 4 & Repetido & 50 & $90 \% \tau_{\mathrm{bu}}$ \\
\hline
\end{tabular}

Um dos objetivos iniciais do ensaio era avaliar a distribuição das tensões de aderência ao longo da barra e a influência do comprimento de aderência; entretanto 
como é apresentado mais adiante, isso não foi possível. Portanto, dos ensaios foi obtida apenas a capacidade resistente da ligação com a uniformização das tensões ao longo do pequeno trecho aderente do modelo.

A seguir, será apresentada a metodologia empregada na moldagem dos modelos e nos ensaios.

\subsection{PROGRAMA EXPERIMENTAL}

Na investigação experimental, alguns setores da Escola de Engenharia de São Carlos estiveram envolvidos.

Os ensaios de caracterização da areia e brita foram realizados no Laboratório de Construção Civil (Departamento de Arquitetura e Urbanismo). No Laboratório de Mecânica das Rochas (Departamento de Geotecnia), os modelos foram cortados ao meio para a visualização da forma de ruptura da ligação. Na marcenaria, foram confeccionados os dispositivos de madeira para a montagem das fôrmas dos modelos. A placa de apoio e as hastes para a realização do ensaio de arrancamento foram confeccionados na Oficina Mecânica (Departamento de Engenharia Mecânica). Os ensaios de caracterização do concreto e do aço e de arrancamento foram realizados no Laboratório de Estruturas (Departamento de Engenharia de Estruturas).

O programa experimental foi dividido nas seguintes etapas:

- ensaios preliminares de caracterização dos materiais;

- estudo de dosagem dos materiais, para obtenção de um traço para concreto com resistência média à compressão de $30 \mathrm{MPa}$ aos 28 dias;

- ensaios piloto, para determinação das dimensões e instrumentação do modelo, verificação do funcionamento do dispositivo de ensaio e estabelecimento do procedimento de aplicação do carregamento repetido;

- ensaios de arrancamento nos modelos definidos a partir dos ensaios piloto;

- caracterização do concreto, simultaneamente às duas etapas anteriores;

- caracterização do aço. 


\subsection{MATERIAIS UTILIZADOS NA CONFECÇÃO DO CONCRETO}

Na confecção do concreto, foi utilizado o Cimento Portland Comum CPIIF32 da marca ITAÚ, cuja massa específica foi fornecida pelo fabricante, conforme a NBR 6474/84.

A água empregada na mistura é proveniente da rede pública de abastecimento de São Carlos.

O agregado miúdo consiste em uma areia quartzosa, proveniente do Rio Mogi - Município de Rincão com composição granulométrica apresentada na tabela 4.2.

TABELA 4.2 - Análise granulométrica do agregado miúdo (NBR 7217/87)

\begin{tabular}{|c|c|c|c|c|c|c|}
\hline \multirow[t]{2}{*}{ Peneira (mm) } & \multicolumn{2}{|c|}{ Material retido (g) } & \multicolumn{2}{|c|}{$\%$ retida } & \multicolumn{2}{|c|}{$\%$ retida acumulada } \\
\hline & $\mathrm{M}_{1}$ & $\mathrm{M}_{2}$ & $\mathrm{M}_{1}$ & $\mathrm{M}_{2}$ & $\mathrm{M}_{1}$ & $\mathrm{M}_{2}$ \\
\hline 9,5 & 0,0 & 0,0 & 0,0 & 0,0 & 0,0 & 0,0 \\
\hline 6,3 & 3,1 & 0,6 & 0,6 & 0,1 & 0,6 & 0,1 \\
\hline 4,8 & 0,7 & 1,1 & 0,1 & 0,2 & 0,7 & 0,3 \\
\hline 2,4 & 7,0 & 9,0 & 1,4 & 1,8 & 2,1 & 2,1 \\
\hline 1,2 & 32,6 & 37,7 & 6,5 & 7,6 & 8,7 & 9,7 \\
\hline 0,6 & 95,0 & 105,4 & 19,0 & 21,1 & 27,7 & 30,8 \\
\hline 0,3 & 222,5 & 222,4 & 44,5 & 44,6 & 72,2 & 75,4 \\
\hline 0,15 & 132,5 & 117,8 & 26,5 & 23,6 & 98,7 & 99,0 \\
\hline Fundo & 6,6 & 4,9 & 1,3 & 1,0 & 100,0 & 100,0 \\
\hline \multicolumn{5}{|c|}{ Dimensão máxima característica } & \multicolumn{2}{|c|}{$2,4 \mathrm{~mm}$} \\
\hline \multicolumn{5}{|c|}{ Módulo de finura médio } & \multicolumn{2}{|c|}{2,14} \\
\hline
\end{tabular}

Obs.: $M_{1}$ e $M_{2}$ correspondem às amostras 1 e 2 respectivamente

O agregrado graúdo, de origem basáltica, foi retirado da Pedreira Morada do

Sol - Município de Araraquara, cuja análise granulométrica é indicada na tabela 4.3. 
TABELA 4.3 - Análise granulométrica do agregado graúdo (NBR 7217/87)

\begin{tabular}{|c|c|c|c|c|c|c|}
\hline \multirow[t]{2}{*}{ Peneira (mm) } & \multicolumn{2}{|c|}{ Material retido $(\mathrm{g})$} & \multicolumn{2}{|c|}{$\%$ retida } & \multicolumn{2}{|c|}{$\%$ retida acumulada } \\
\hline & $\mathrm{M}_{1}$ & $\mathrm{M}_{2}$ & $\mathrm{M}_{1}$ & $\mathrm{M}_{2}$ & $\mathrm{M}_{1}$ & $\mathrm{M}_{2}$ \\
\hline 25 & 0,0 & 0,0 & 0,0 & 0,0 & 0,0 & 0,0 \\
\hline 19 & 0,0 & 0,0 & 0,0 & 0,0 & 0,0 & 0,0 \\
\hline 12,5 & 1230,0 & 1230,0 & 14,0 & 14,0 & 14,0 & 14,0 \\
\hline 9,5 & 5140,0 & 5140,0 & 58,5 & 58,5 & 72,5 & 72,5 \\
\hline 6,3 & 3180,0 & 3180,0 & 36,2 & 36,2 & 108,7 & 108,7 \\
\hline 4,8 & 330,0 & 330,0 & 3,8 & 3,8 & 112,5 & 112,5 \\
\hline 2,4 & 80,0 & 80,0 & 0,9 & 0,9 & 113,4 & 113,4 \\
\hline 1,2 & 60,0 & 60,0 & 0,7 & 0,7 & 114,1 & 114,1 \\
\hline Fundo & 0,0 & 0,0 & 0,0 & 0,0 & 114,1 & 114,1 \\
\hline \multicolumn{5}{|c|}{ Dimensão máxima característica } & \multicolumn{2}{|c|}{$19 \mathrm{~mm}$} \\
\hline \multicolumn{5}{|c|}{ Módulo de finura médio } & \multicolumn{2}{|c|}{7,54} \\
\hline
\end{tabular}

Obs.: $M_{1}$ e $M_{2}$ correspondem às amostras 1 e 2 respectivamente

As principais características dos materiais utilizados na confecção do concreto são dadas na tabela 4.4.

TABELA 4.4 - Características dos materiais utilizados no concreto

\begin{tabular}{|c|c|}
\hline Material & Características \\
\hline Areia fina & $\begin{array}{l}\text { Módulo de finura: M.F. }=2,14 \\
\text { Massa unitária: } 1,497 \mathrm{~g} / \mathrm{cm}^{3} \\
\text { Massa específica: } 2,584 \mathrm{~g} / \mathrm{cm}^{3}\end{array}$ \\
\hline Brita & $\begin{array}{l}\text { Módulo de finura: M.F. }=7,54 \\
\text { Massa unitária: } 1,388 \mathrm{~g} / \mathrm{cm}^{3} \\
\text { Massa específica: } 2,963 \mathrm{~g} / \mathrm{cm}^{3}\end{array}$ \\
\hline Cimento & $\begin{array}{c}\text { CPII F-32 ITAÚ } \\
\text { Massa específica: } 3,1 \mathrm{~g} / \mathrm{cm}^{3}\end{array}$ \\
\hline
\end{tabular}

\section{Obs.: normas utilizadas:}

NBR 7251/82 - Agregado em estado solto - Determinação da massa unitária NBR 7211/83 - Agregado para concreto

NBR 9776/87 - Agregados - Determinação da massa específica de agregados miúdos por meio do frasco de Chapman 


\subsection{DOSAGEM DOS MATERIAIS}

O programa experimental se iniciou com um estudo de dosagem para a determinação da resistência à compressão do concreto em uma faixa de $30 \mathrm{MPa}$ aos 28 dias. O traço inicial, obtido no Laboratório de Construção Civil da Escola de Engenharia de São Carlos - EESC/USP, apresentou resultados de resistência e trabalhabilidade satisfatórios.

O consumo dos materiais utilizados na confecção do concreto com resistência média de $30 \mathrm{MPa}$ aos 28 dias com o respectivo traço em massa é apresentado na tabela 4.5.

TABELA 4.5 - Consumo dos materiais utilizados na confecção do concreto

\begin{tabular}{|c|c||}
\hline Material & Consumo por $\mathbf{~ m}^{\mathbf{3}}$ de concreto \\
\hline Cimento CP II F-32 & $392 \mathrm{~kg}$ \\
\hline Areia & $902 \mathrm{~kg}$ \\
\hline Brita & $862 \mathrm{~kg}$ \\
\hline Água & $227 \mathrm{~kg}$ \\
\hline \multicolumn{2}{|c|}{ Traço em massa: $1: 2,3: 2,2: 0,58$} \\
\hline
\end{tabular}

\subsection{CONFECÇÃO E CARACTERIZAÇÃO DO CONCRETO}

A confecção do concreto foi feita em uma betoneira basculante, com a seguinte seqüência de mistura dos componentes: brita, areia, cimento e água. $\mathrm{Na}$ figura 4.1, é ilustrado o concreto fabricado in loco após a mistura dos seus componentes, onde pode ser observado que a sua trabalhabilidade foi consideravelmente grande, facilitando a concretagem dos modelos.

Os modelos foram moldados na posição vertical em duas camadas com o adensamento realizado na mesa vibratória, conforme ilustra a figura 4.2. 


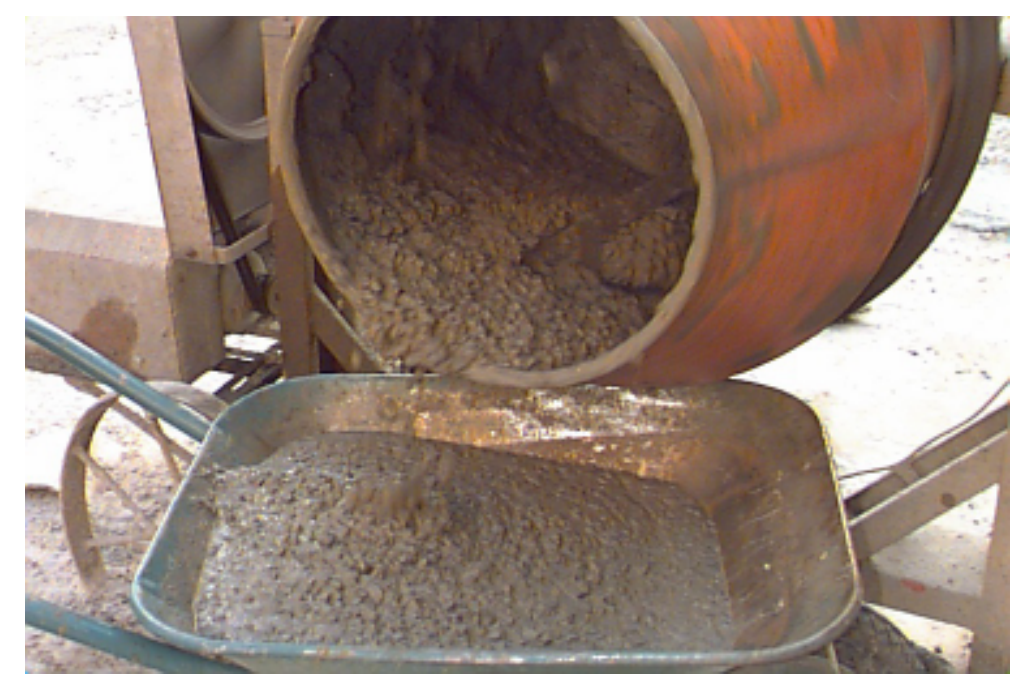

FIGURA 4.1 - Materiais na betoneira após a mistura

A medida da trabalhabilidade do concreto foi feita através do ensaio do tronco de cone (Slump Test) conforme a NBR 7223/82 ${ }^{1}$.

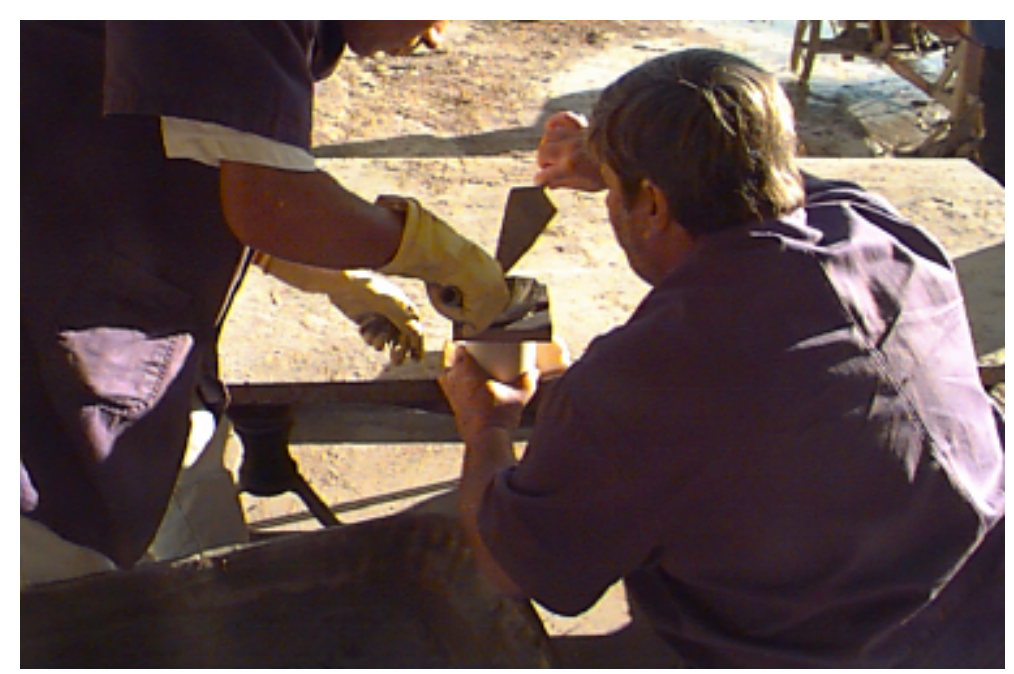

FIGURA 4.2 - Moldagem dos modelos

Para a determinação da resistência à compressão, à tração e do comportamento tensão-deformação do concreto, foram utilizados corpos-de-prova cilíndricos de $10 \mathrm{~cm}$ x $20 \mathrm{~cm}$. Sua moldagem pode ser vista pela figura 4.3, na qual foi utilizada uma mesa vibratória para o adensamento. A resistência à compressão e à

\footnotetext{
${ }^{1}$ NBR 7223 (1982). Determinação da consistência do concreto pelo abatimento do tronco de cone Ensaio de abatimento.
} 
tração do concreto foi determinada segundo as normas NBR 5739/80 ${ }^{1}$ e NBR $7222 / 83^{2}$.

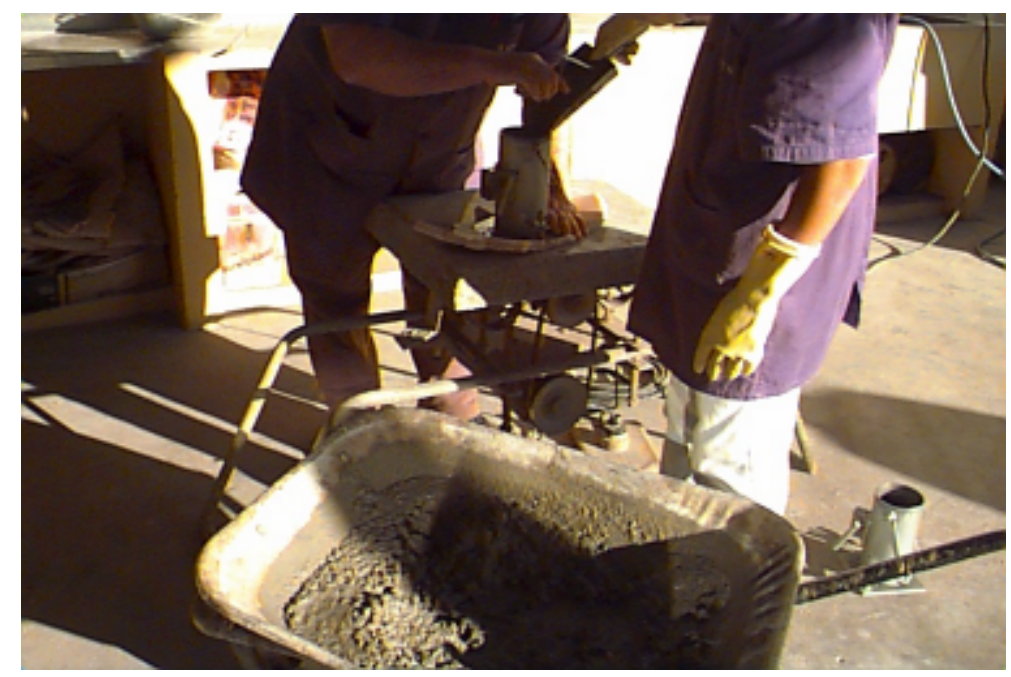

FIGURA 4.3 - Moldagem dos corpos-de-prova cilíndricos $10 \mathrm{~cm}$ x $20 \mathrm{~cm}$

O comportamento tensão-deformação do concreto foi determinado por ensaios de compressão em corpos-de-prova cilíndricos, conforme as prescrições da NBR 8522/84 ${ }^{3}$, com dois extensômetros colados à meia altura do modelo, como indica a figura 4.4. Do diagrama resultante, foi extraído o módulo de deformação longitudinal do concreto.

Os modelos e os corpos-de-prova foram curados até o dia do ensaio em um tanque d'água.

Os valores do slump para cada concretagem, da resistência à compressão, à tração e do módulo de elasticidade dos modelos são apresentados na tabela 6.1 do capítulo 6.

\footnotetext{
${ }^{1}$ NBR 5739 (1980). Ensaio de compressão de corpos-de-prova cilíndricos de concreto.

${ }^{2}$ NBR 7222 (1983). Argamassas e concretos - Determinação da resistência à tração por compressão diametral de corpos-de-prova cilíndricos.

${ }^{3}$ NBR 8522 (1984). Concreto - Determinação do módulo de deformação estática e diagrama tensãodeformação.
} 


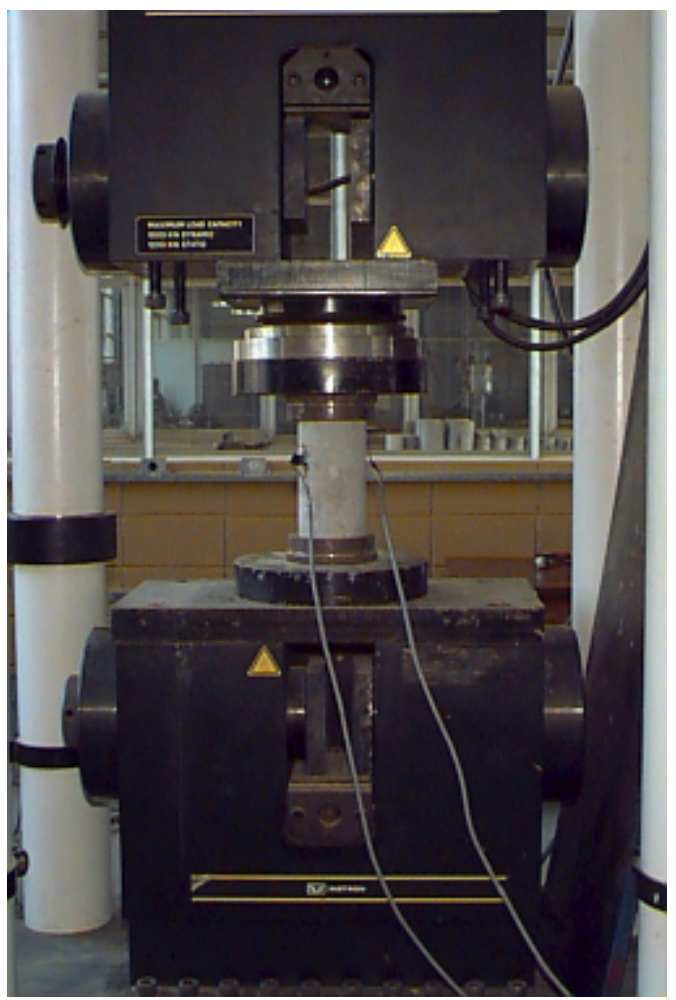

FIGURA 4.4 - Ensaio de módulo de elasticidade com CPs $10 \mathrm{~cm}$ x $20 \mathrm{~cm}$

\subsubsection{RESISTÊNCIA À COMPRESSÃO}

De acordo com METHA \& MONTEIRO (1994), a resistência à compressão é definida como a propriedade geralmente especificada no projeto de estruturas de concreto por ser relativamente fácil de ser ensaiada em relação à maioria das propriedades.

Embora na prática o concreto seja submetido simultaneamente a uma combinação de esforços de compressão, de cisalhamento e de tração, em uma ou mais direções, os ensaios de compressão uniaxial são de mais fácil execução. Portanto, o índice geral da resistência do concreto aceito universalmente é determinado através do ensaio padrão de compressão axial aos 28 dias.

Para a obtenção da resistência média $\mathbf{f}_{\mathbf{c m}}$, é necessário multiplicar os resultados obtidos dos ensaios dos corpos-de-prova por uma coeficiente de modificação, resultante do produto de três outros: 


$$
\mathbf{k}_{\text {mod }}=\mathbf{k}_{\bmod , \mathbf{1}} \cdot \mathbf{k}_{\bmod , 2} \cdot \mathbf{k}_{\bmod , 3}
$$

Onde:

$\mathbf{k}_{\text {mod,1 }}$ : considera o acréscimo de resistência do concreto após os 28 dias de idade. Segundo FUSCO (1995), este coeficiente é igual a 1,2 nos estados limites últimos de solicitações normais.

$\mathbf{k}_{\mathbf{m o d}, 2}$ : leva em conta a influência das dimensões do corpo-de-prova. A resistência medida em corpos-de-prova de tamanho maior é menor, por haver menos influência do atrito entre o corpo-de-prova e os pratos na prensa de ensaio. Para corpos-deprova cilíndricos $15 \mathrm{~cm}$ x $30 \mathrm{~cm}$, este coeficiente é adotado como 0,95. Quando se trata de corpos-de-prova $10 \mathrm{~cm}$ x $20 \mathrm{~cm}$, tal coeficiente é reduzido para 0,90 $(0,95 \mathrm{x}$ 0,95), considerando assim a influência do aumento de resistência do CP $10 \mathrm{~cm}$ x 20 $\mathrm{cm}$ em relação ao $\mathrm{CP} 15 \mathrm{~cm}$ x $30 \mathrm{~cm}$.

$\mathbf{k}_{\text {mod,3: }}$ considera o efeito deletério da ação de ações de longa duração. Este coeficiente pode ser considerado igual a 0,75 nos estados limites últimos de solicitações normais, conforme FUSCO (1995).

Portanto, para as condições de ensaio realizado aos 28 dias, em CP $10 \mathrm{~cm} \mathrm{x}$ $20 \mathrm{~cm}$ e sob carregamento de curta duração:

$$
\begin{gathered}
k_{\text {mod }}=1 \times 0,90 \times 1=0,90 \\
f_{\mathrm{cm}}=0,9 . f_{\mathrm{c}}
\end{gathered}
$$

\subsubsection{RESISTÊNCIA À TRAÇÃO}

O concreto caracteriza-se por ter um comportamento de ruptura relativamente frágil sob tensões de tração. Portanto, torna-se importante conhecer a resistência à tração do concreto para a avaliação do seu comportamento quanto à fissuração.

A resistência à tração do concreto pode ser determinada através de três ensaios: resistência à tração direta, resistência à compressão diametral e resistência de tração por flexão com carregamento nos terços de vão.

Nos ensaios de tração por compressão diametral, realizados neste trabalho, os cilindros de concreto $10 \mathrm{~cm}$ x $20 \mathrm{~cm}$ são submetidos a carregamento de compressão 
ao longo de duas linhas axiais, as quais são diametralmente opostas. O carregamento é aplicado continuamente a uma velocidade constante dentro de um intervalo de tensão de ruptura à tração de 0,7 a 1,4 $\mathrm{MPa}$, até a ruptura do corpo-de-prova. A tensão de compressão produz uma tensão transversal que é uniforme ao longo do diâmetro vertical.

Como o plano de fratura imposto pelo arranjo do ensaio de compressão diametral não se constitui obrigatoriamente no plano de menor resistência, os resultados desse ensaio, conforme LOBO CARNEIRO ${ }^{1}$ apud FUSCO (1995), são sistematicamente maiores que os do ensaio de tração pura. Portanto, a resistência à tração do ensaio de compressão diametral é multiplicada por 0,85 .

$$
\mathbf{f}_{\mathrm{tm}}=\mathbf{0 , 8 5 . \mathbf { f } _ { \mathrm { t } }}
$$

\subsubsection{COMPORTAMENTO TENSÃO-DEFORMAÇÃO}

Observando-se as curvas típicas tensão-deformação $(\sigma-\varepsilon)$ para o agregado, a pasta endurecida e o concreto sob compressão uniaxial na figura 4.5(a), o concreto apresenta um comportamento não elástico compreendido entre o diagrama do agregado e o da pasta de cimento. Nem a deformação sob carregamento instantâneo de um corpo-de-prova de concreto é diretamente proporcional à tensão aplicada, nem esta é totalmente recuperada após o descarregamento.

A curva tensão-deformação do concreto na figura 4.5(b) apresenta um trecho linear elástico até aproximadamente $30 \%$ da resistência final $\left(\mathbf{f}_{\mathbf{c}}{ }^{\prime}\right)$ porque sob carregamento rápido as microfissuras na zona de transição permanecem estáveis. Para tensões acima deste ponto, até cerca de $50 \%$ de $\mathbf{f}_{\mathbf{c}}{ }^{\prime}$, na medida em que a tensão aumenta, as microfissuras da zona de transição começam a aumentar em comprimento, largura e número. Entretanto, pode-se admitir que exista um sistema estável de microfissuras na zona de transição, devido à fissuração na matriz ser considerada ainda desprezível. A partir de 50 a $60 \%$ de $\mathbf{f}_{\mathbf{c}}{ }^{\prime}$, começam a formar-se

\footnotetext{
${ }^{1}$ LOBO CARNEIRO, F.L. (1949). Résistence à la traction des bétons. Rio de Janeiro, Instituto Nacional de Tecnologia.
} 
fissuras na matriz. Com o aumento adicional da tensão até cerca de $75 \%$ de $\mathbf{f}_{\mathbf{c}}$, não só o sistema de fissuras na zona de transição torna-se instável, mas também a proliferação e propagação de fissuras na matriz aumenta, fazendo com que a curva tensão-deformação incline-se consideravelmente em direção à horizontal. Acima de 75 a $80 \%$ de $\mathbf{f}_{\mathbf{c}}$ ', a taxa de liberação de energia de deformação parece atingir o nível crítico necessário para o crescimento espontâneo das fissuras sob tensão constante e o material se deforma até o colapso. Em resumo, acima de $\mathbf{7 5 \%}$ de $\mathbf{f}_{\mathbf{c}}{ }^{\prime}$, com o aumento da tensão, desenvolvem-se deformações muito grandes, indicando que o sistema de fissuras depois muda bruscamente de declividade (torna-se quase horizontal no topo) e finalmente desce, até o corpo-de-prova sofrer ruptura.

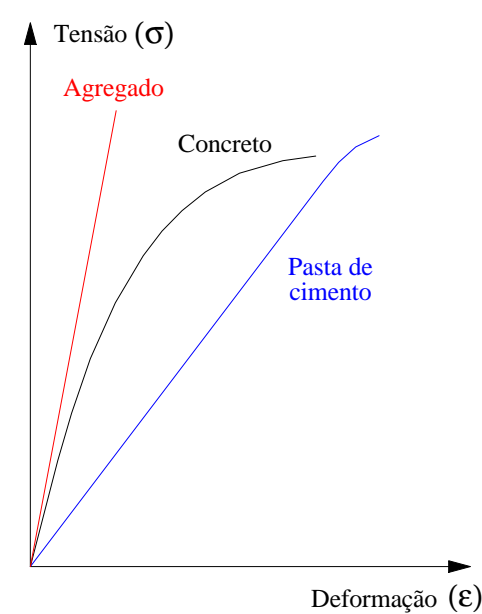

(a)

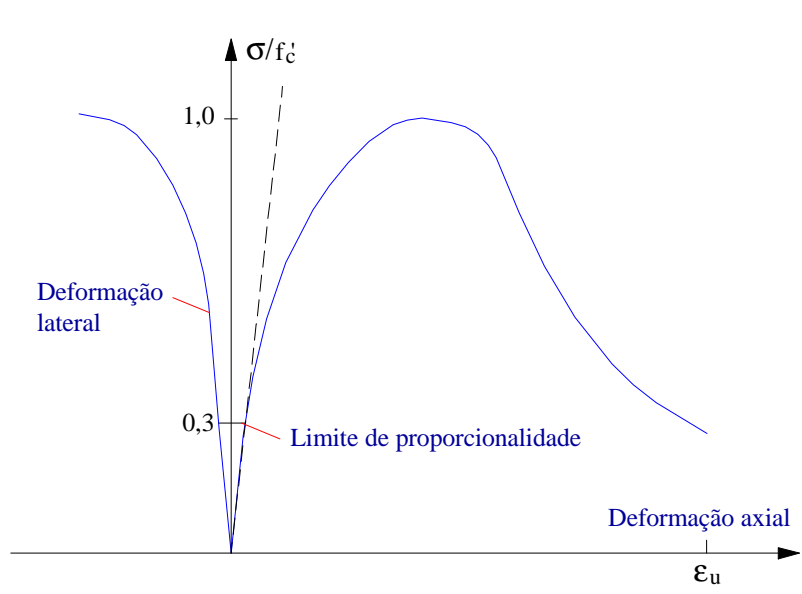

(b)

FIGURA 4.5 - (a) Comportamentos típicos tensão-deformação de pasta de cimento, agregado e concreto; (b) Curva tensão-deformação do concreto

\subsubsection{MÓDULO DE DEFORMAÇÃO LONGITUDINAL}

O módulo de deformação estático para um material sob tração ou compressão é dado pela declividade da curva $\sigma-\varepsilon$ para concreto sob carregamento uniaxial. Uma vez que a curva para o concreto é não linear, existem três métodos para calcular o módulo:

- Módulo tangente: declividade de uma reta tangente à curva $\boldsymbol{\sigma}-\boldsymbol{\varepsilon}$ em qualquer ponto da mesma. 
- Módulo secante: declividade de uma reta traçada da origem a um ponto da curva correspondendo a $40 \%$ da tensão de ruptura.

- Módulo corda: declividade de uma reta traçada entre dois pontos da curva $\boldsymbol{\sigma}-\boldsymbol{\varepsilon}$. Comparado ao módulo secante, ao invés de partir da origem, a linha é traçada de um ponto representando uma deformação longitudinal de $50 \mu \mathrm{m} / \mathrm{m}$ ao ponto correspondente a $40 \%$ da tensão última.

Neste trabalho, foi utilizado o módulo de deformação secante obtido a partir das curvas tensão-deformação.

\subsubsection{COEFICIENTE DE POISSON}

Para um material sujeito à força axial simples, a razão entre a deformação lateral e a deformação axial dentro do intervalo elástico é definida como coeficiente de Poisson $\left(v_{\mathbf{c}}\right)$.

No concreto, os valores do coeficiente de Poisson geralmente variam entre 0,15 e 0,20 . Não parece haver relação consistente entre o coeficiente de Poisson e características do concreto tais como relação água/cimento, tempo de cura e granulometria do agregado. Entretanto, o coeficiente de Poisson é geralmente menor em concreto de alta resistência e maior para concreto saturado e concreto carregado dinamicamente.

Neste trabalho, o coeficiente de Poisson $\left(v_{c}\right)$ adotado para o concreto foi de 0,20 .

\subsection{CARACTERIZAÇÃO DO AÇO}

A armadura utilizada no concreto armado caracteriza-se principalmente por resistir às grandes forças de tração com um patamar de escoamento bem definido. Torna-se importante, então, determinar as propriedades mecânicas que definem o comportamento estrutural do aço sob esforços de tração. 
A caracterização do aço foi feita através do ensaio de um corpo-de-prova da barra sob esforço de tração até a ruptura na máquina INSTRON, segundo a NBR 6152/92 ${ }^{1}$. Para cada diâmetro utilizado, foram ensaiados três corpos-de-prova. Na figura 4.6, é ilustrado o ensaio da armadura, onde as extremidades desta são presas pelas garras da máquina. As deformações na região central da amostra medidas através de um extensômetro foram registradas em intervalos discretos muito pequenos. O ensaio foi realizado com uma velocidade de deformação controlada de $0,20 \% / \mathrm{min}$.

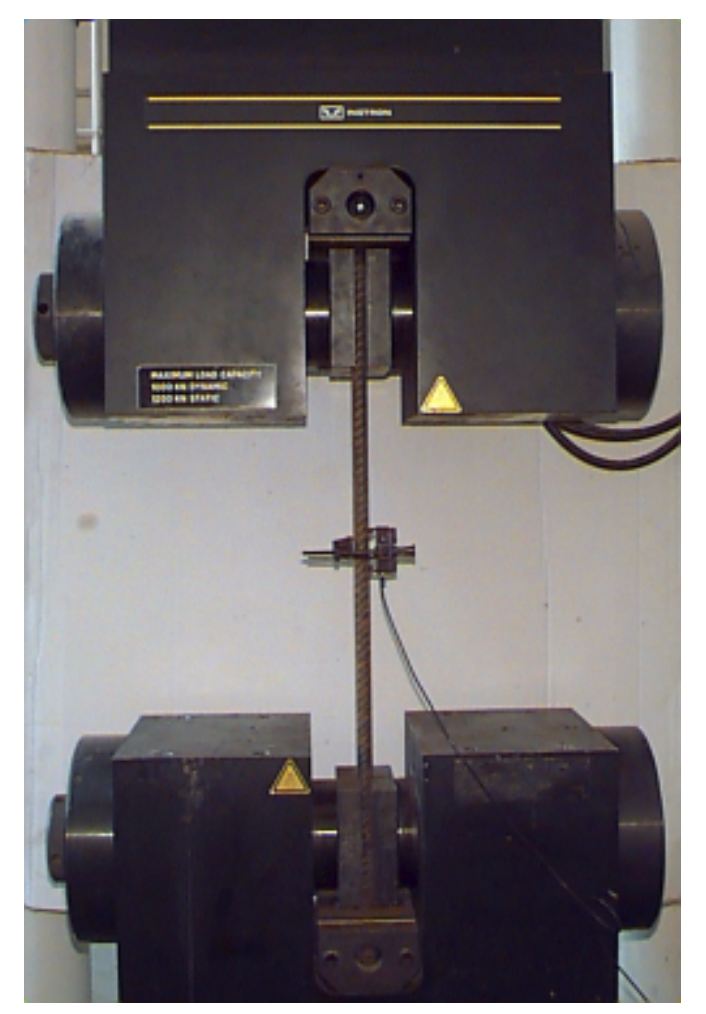

FIGURA 4.6 - Ensaio da armadura sob tração

Para a determinação da seção inicial da armadura, esta foi pesada e seu comprimento foi medido. Logo, as tensões foram calculadas a partir da divisão da força pela seção inicial do corpo-de-prova, a qualquer instante do ensaio.

A partir do diagrama tensão-deformação da armadura sob tração, podem ser determinados os principais valores que definem as suas propriedades mecânicas.

\footnotetext{
${ }^{1}$ NBR 6152 (1992). Materiais metálicos - Determinação das propriedades mecânicas à tração.
} 
A figura 4.7 ilustra as três fases distintas da relação tensão-deformação do aço: fase elástica, fase plástica e fase de ruptura.

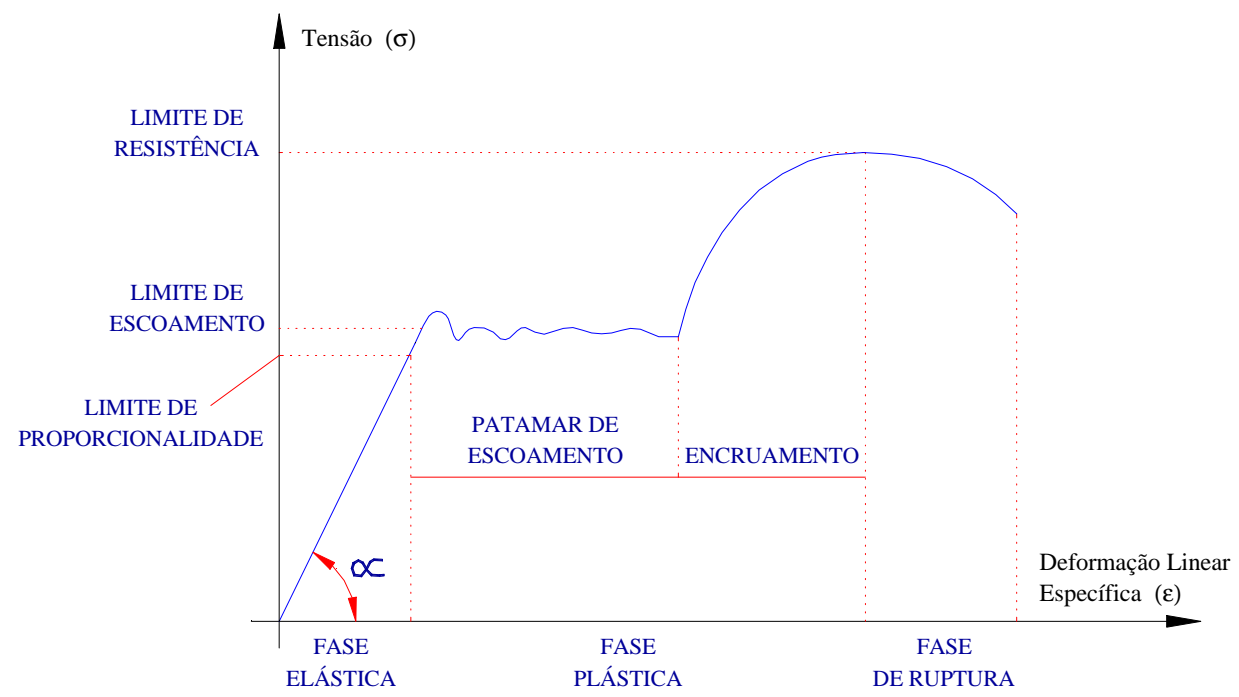

FIGURA 4.7 - Diagrama tensão-deformação do aço

Dentro dos limites da fase elástica, o comportamento da armadura segue a lei de Hooke, ou seja, a deformação é proporcional ao esforço aplicado. A constante de proporcionalidade que define esse trecho retilíneo do diagrama é denominado de módulo de elasticidade.

Ultrapassado o limite de proporcionalidade, surge a fase plástica (patamar de escoamento), onde ocorrem deformações crescentes sem variação da tensão. Esse valor constante da tensão é denominado de limite de escoamento.

Existem três tipos de limite de escoamento:

- Limite superior $\left(\sigma \mathbf{e}_{\mathrm{s}}\right)$ ou $\left(\mathbf{L E} \mathbf{E}_{\mathbf{s}}\right)$ ou $(\boldsymbol{\sigma e})$ ou $(\mathbf{L E})$

Corresponde ao valor da tensão convencional no ponto onde se inicia o escoamento, ou valor da tensão convencional no primeiro valor máximo obtido durante o escoamento, máximo este que pode ser igual ou não aos outros máximos que possam ser observados durante o escoamento, indicados na figura 4.8(a), (b) e (c). Este valor é denominado comumente de limite de escoamento.

- Limite inferior $\left(\boldsymbol{\sigma} \mathbf{e}_{\mathbf{i}}\right)$ ou $\left(\mathbf{L E}_{\mathbf{i}}\right)$

Consiste no menor valor da tensão convencional durante o escoamento, não se computando o efeito transitório inicial que se possa produzir, como é ilustrado na figura 4.8(a), (b) e (c). 
- Limite convencional $\left(\sigma \mathbf{e}_{\mathbf{x}}\right)$ ou $\left(\mathbf{L E}_{\mathbf{x}}\right)$

Eqüivale à tensão convencional que produz uma percentagem especificada $\mathbf{x}$ de alongamento não-elástico, sob força aplicada, como apresenta a figura 4.8(d). O valor $\mathbf{x}$ da percentagem especificada deve ser indicado na especificação de cada material. A determinação desse limite de escoamento convencional é conveniente para materiais que não apresentam patamar no diagrama tensão-deformação.

Para a barra de aço do ensaio, o limite de escoamento considerado foi o superior.

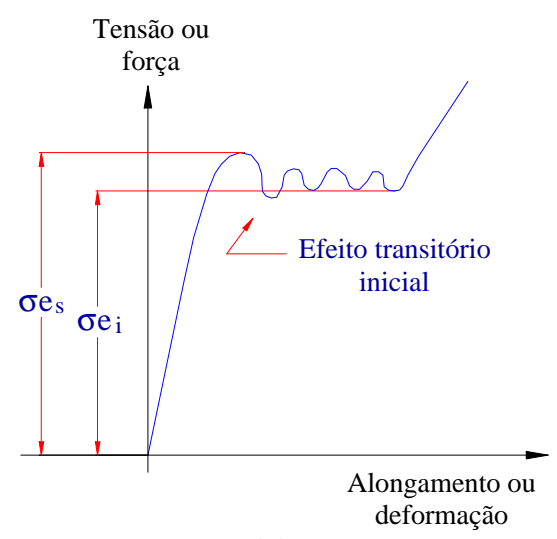

(a)

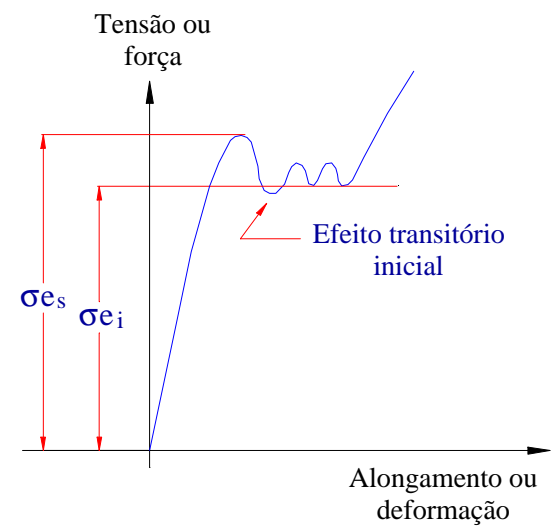

(c)

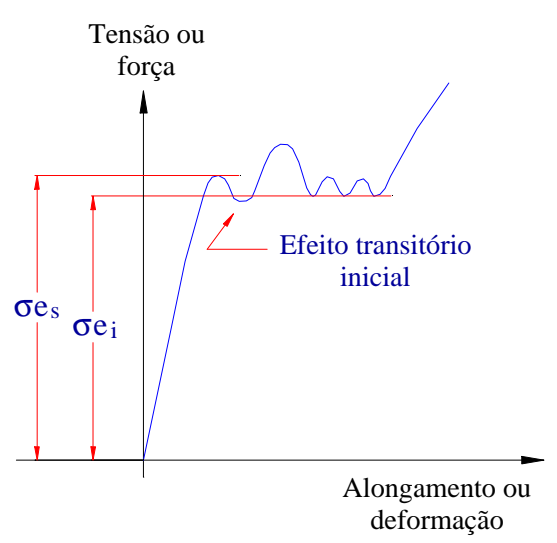

(b)

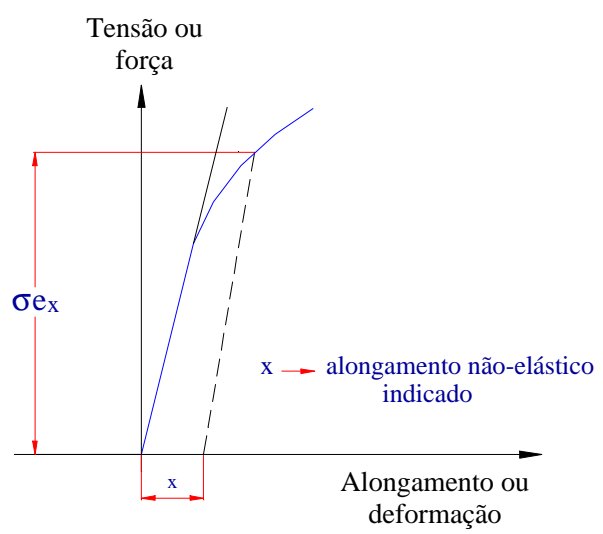

(d)

FIGURA 4.8 - Tipos de limite de escoamento

Após o escoamento, ainda na fase plástica, a estrutura interna do aço se rearranja e o material passa pelo encruamento, onde a variação da tensão com a deformação é não-linear. O valor máximo da tensão é chamado de limite de resistência do aço, que corresponde à capacidade máxima da armadura sob tração.

O coeficiente de Poisson $\left(\boldsymbol{v}_{\mathbf{s}}\right)$ adotado para o aço foi de 0,30 . 
Os valores correspondentes à caracterização do aço estão indicados na tabela 6.2 do capítulo 6 .

\subsection{INSTRUMENTOS E EQUIPAMENTOS UTILIZADOS}

Os instrumentos e equipamentos de medição utilizados nos ensaios piloto e nos ensaios dos modelos estão indicados na tabela 4.6.

TABELA 4.6 - Instrumentos utilizados nos ensaios

\begin{tabular}{|c|c|c|c|c|}
\hline Instrumento & Tipo & Finalidade & Marca & Características \\
\hline $\begin{array}{c}\text { sistema de } \\
\text { aquisição de } \\
\text { dados por } \\
\text { extensometria }\end{array}$ & $\begin{array}{c}\text { SYSTEM } 5000 \\
\text { PROGRAM } \\
\text { POWER-UP }\end{array}$ & $\begin{array}{c}\text { coleta e } \\
\text { gravaçãa } \\
\text { automática de } \\
\text { dados }\end{array}$ & $\begin{array}{l}\text { MEASUREMENTS } \\
\text { GROUP }\end{array}$ & - \\
\hline $\begin{array}{l}\text { extensômetros } \\
\text { elétricos de } \\
\text { resistência }\end{array}$ & KFG-5-C1-11 & $\begin{array}{c}\text { medição das } \\
\text { deformações do } \\
\text { aço no ensaio } \\
\text { piloto }\end{array}$ & KYOWA & $\mathrm{GF}=2,12$ \\
\hline $\begin{array}{l}\text { extensômetros } \\
\text { elétricos de } \\
\text { resistência }\end{array}$ & KFG-10-C1-11 & $\begin{array}{l}\text { medição de } \\
\text { deformação no } \\
\text { concreto }\end{array}$ & KYOWA & $\mathrm{GF}=2,11$ \\
\hline $\begin{array}{l}\text { transdutores de } \\
\text { deslocamento }\end{array}$ & DT-10D & $\begin{array}{c}\text { medição de } \\
\text { deslocamentos }\end{array}$ & KYOWA & $\begin{array}{c}\text { base }=10 \mathrm{~mm} \\
\text { resolução = } \\
0,003 \mathrm{~mm}\end{array}$ \\
\hline $\begin{array}{l}\text { transdutor de } \\
\text { deslocamento }\end{array}$ & $\begin{array}{l}\text { CAT NO } \\
2630-201\end{array}$ & $\begin{array}{c}\text { medição de } \\
\text { deformação no } \\
\text { aço }\end{array}$ & INSTRON & $\mathrm{L}_{\mathrm{o}}=50 \mathrm{~mm}$ \\
\hline $\begin{array}{c}\text { máquina } \\
\text { hidráulica } \\
\text { automática }\end{array}$ & $\begin{array}{c}\text { modelo } \\
\text { Autotest } 2000\end{array}$ & $\begin{array}{l}\text { ensaio dos } \\
\text { corpos-de- } \\
\text { prova de } \\
\text { concreto }\end{array}$ & ELE & controle de força \\
\hline $\begin{array}{l}\text { máquina de } \\
\text { ensaio servo- } \\
\text { hidráulica, } \\
\text { com controle } \\
\text { digital por } \\
\text { computador }\end{array}$ & modelo 8506 & $\begin{array}{l}\text { aplicação da } \\
\text { força do } \\
\text { ensaio de } \\
\text { arrancamento }\end{array}$ & INSTRON & $\begin{array}{c}\text { controle de } \\
\text { deslocamento do } \\
\text { pistão }\end{array}$ \\
\hline
\end{tabular}

$\mathrm{Na}$ figura 4.9, ilustra-se a máquina universal INSTRON, a qual realiza ensaios com controle de força, deslocamento e deformação. Os ensaios de 
arrancamento foram executados com controle de deslocamento, permitindo assim analisar o ramo descendente após o modelo atingir a ruptura da ligação.

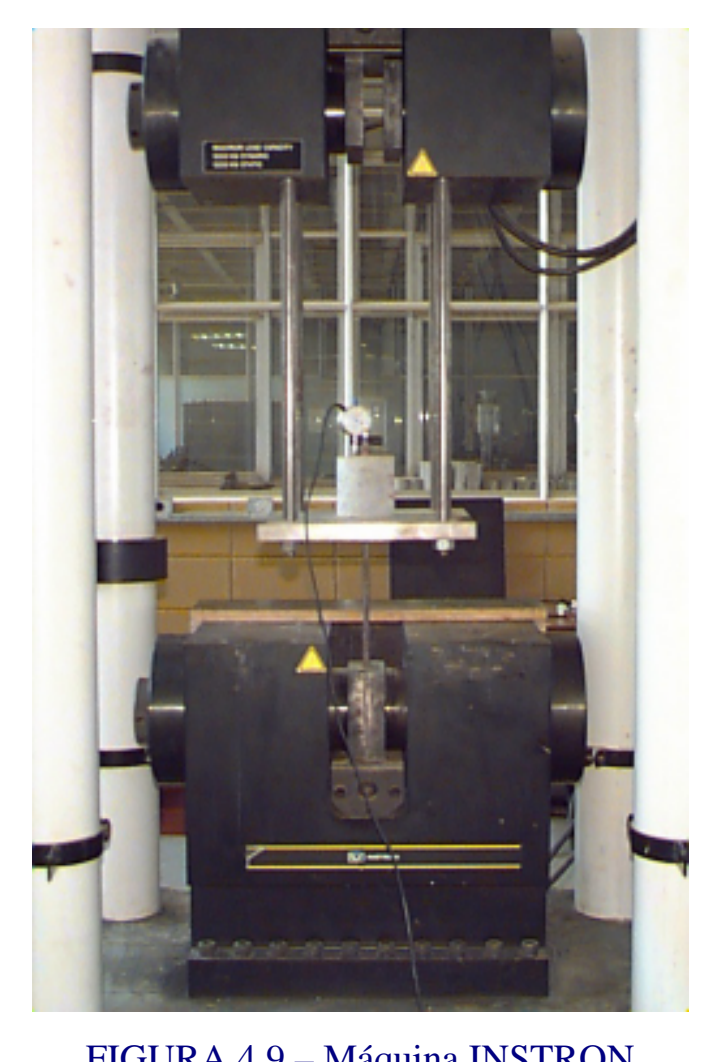

O dispositivo de ensaio constituía de uma placa apoiando o concreto com um furo central onde a barra é inserida, sendo esta presa à garra da máquina INSTRON. A placa de apoio é presa por quatro hastes, as quais são rosqueadas na máquina.

A instrumentação utilizada nos ensaios foi um transdutor de deslocamento no topo da barra (a $5 \mathrm{~cm}$ da extremidade do bloco) com a base no concreto. Além desse transdutor de deslocamento, nos ensaios piloto, foram utilizados extensômetros colados na barra de aço.

A figura 4.10 ilustra o dispositivo de ensaio e a instrumentação utilizada. 


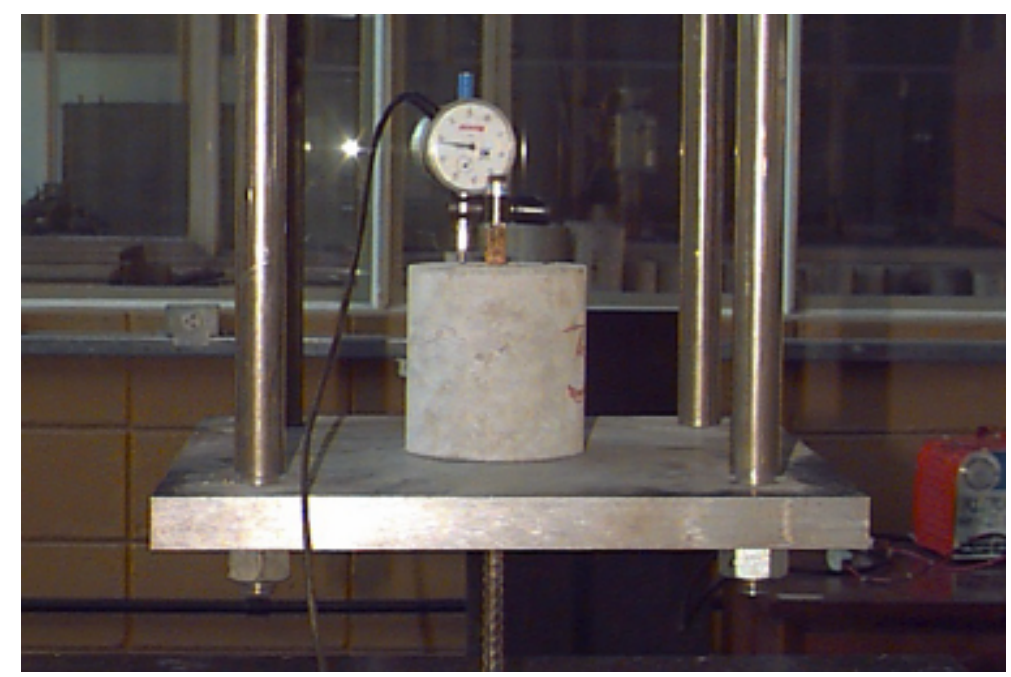

FIGURA 4.10 - Detalhe do dispositivo e da instrumentação do ensaio

\subsection{PROCEDIMENTO DE ENSAIO}

Os ensaios de arrancamento foram executados aos 28 dias de idade do concreto. A aplicação da força de tração na barra, a qual é presa pela garra da máquina, foi feita de modo que as hastes que prendem a placa de apoio do bloco são movidas junto com o pistão, sendo a reação transmitida pela placa ao concreto.

Antes da realização dos ensaios, foi feita a aplicação de uma força de aproximadamente $10 \%$ da força última, com o objetivo de verificar o funcionamento dos instrumentos. $\mathrm{O}$ ensaios da série 10 foram realizados com velocidade de deslocamento do pistão de $0,01 \mathrm{~mm} / \mathrm{s}$ e os da série 20 com $0,02 \mathrm{~mm} / \mathrm{s}$, registrando-se os valores medidos discretamente em pequenos intervalos de tempo.

Os resultados obtidos de cada modelo serão apresentados e analisados no capítulo 6.

\subsection{ENSAIO PILOTO COM EXTENSÔMETRO}

Antes da execução dos ensaios e definição dos parâmetros dos modelos, foi necessário realizar o ensaio piloto. As fôrmas dos dois modelos piloto são ilustradas na figura 4.11 . 


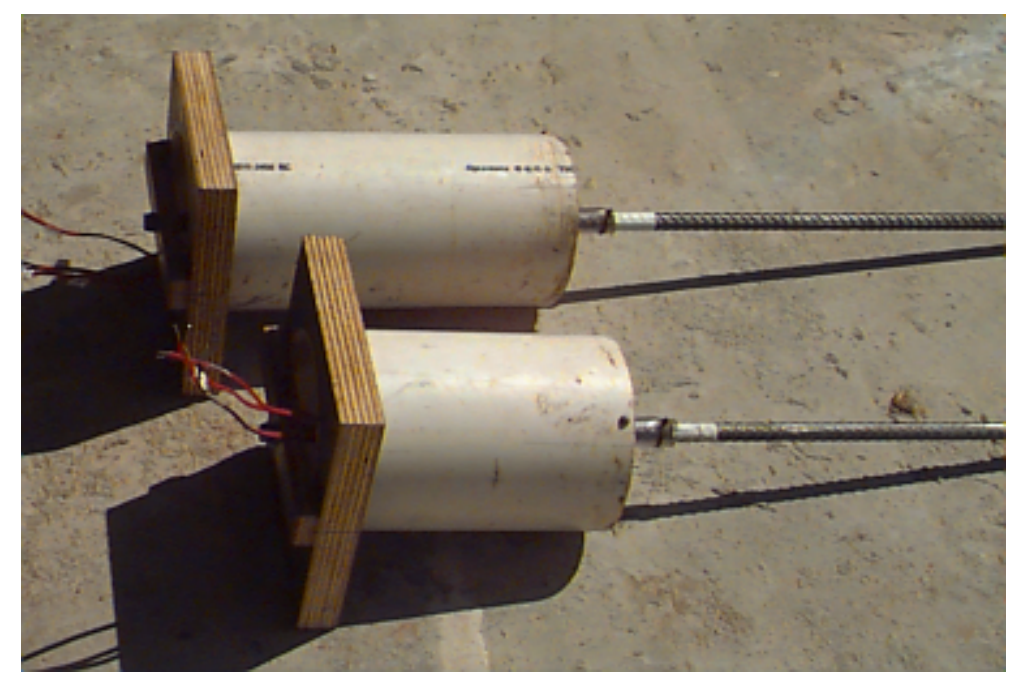

FIGURA 4.11 - Fôrmas dos modelos piloto 1 e 2

A armadura dos dois modelos foi instrumentada de acordo com a figura 4.12, com o objetivo de avaliar a distribuição das tensões de aderência. No modelo piloto 1 , os extensômetros foram colados no comprimento de aderência $\mathbf{l}_{\mathbf{b}}=\mathbf{1 0} \phi(10 \mathrm{~cm})$ e protegidos com fita isolante, de forma que este foi reduzido para 2,5 cm, com a área central de $\mathbf{l}_{\mathbf{b}}$ totalmente sem aderência. No modelo piloto 2 , foi acrescentado a $\mathbf{l}_{\mathbf{b}} 6$ $\mathrm{cm}$, pois $2 \mathrm{~cm}$ equivale à proteção de cada extensômetro; entretanto, o isolamento foi maior que o previsto, de tal maneira que $\mathbf{l}_{\mathbf{b}}$ foi reduzido para $8,5 \mathrm{~cm}$. Além dessa instrumentação, em cima da barra, foi colocado um transdutor de deslocamento, com a finalidade de medir o deslocamento da barra.

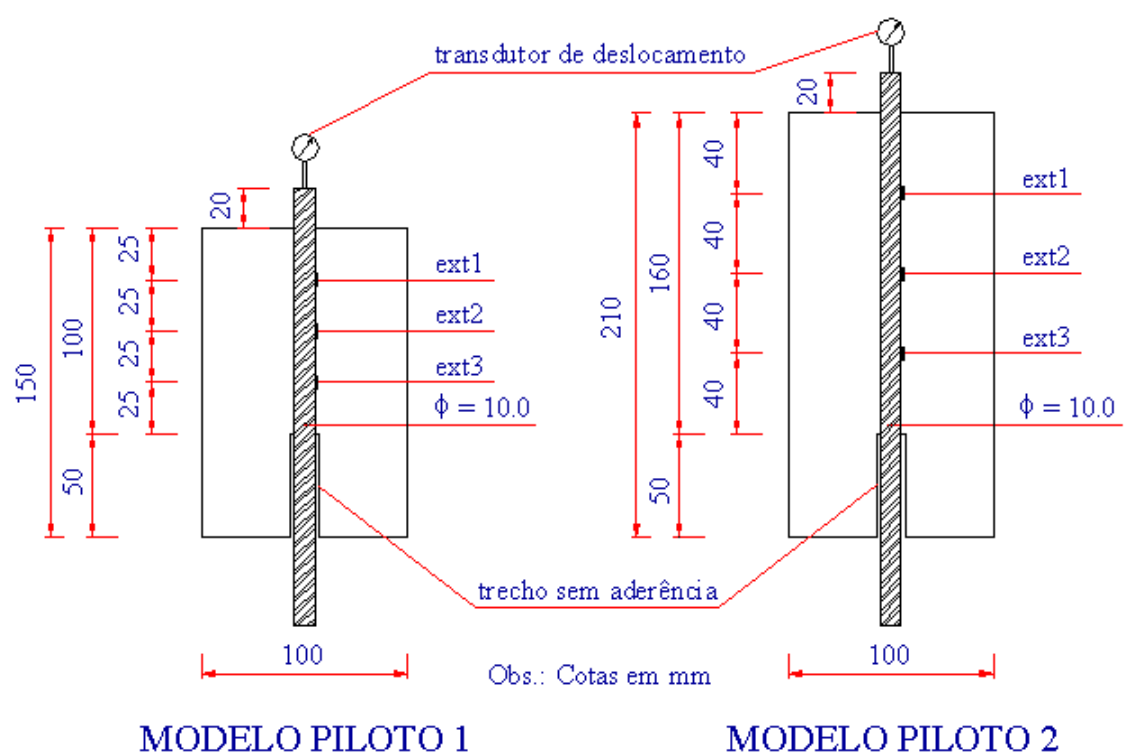

FIGURA 4.12 - Instrumentação da armadura dos modelos piloto 1 e 2 
$\mathrm{Na}$ figura 4.13, é ilustrada a visualização da ruptura da ligação do modelo piloto 2 e degradação da aderência ocasionada pelos extensômetros na armadura dos modelos piloto 1 e 2 .

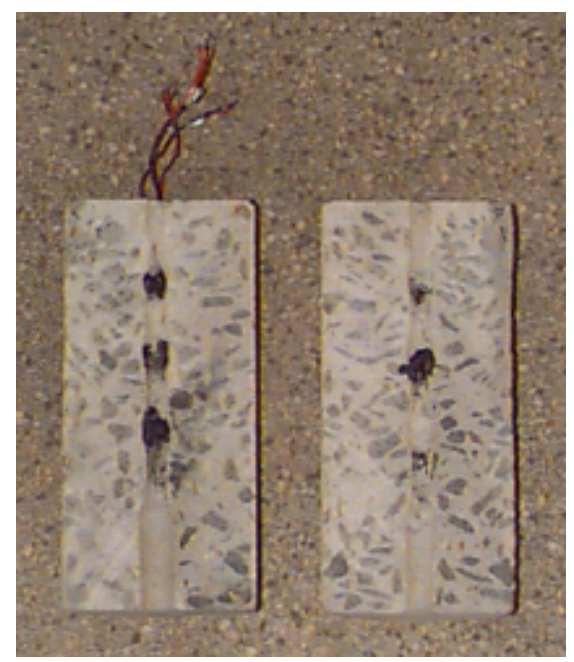

(a)

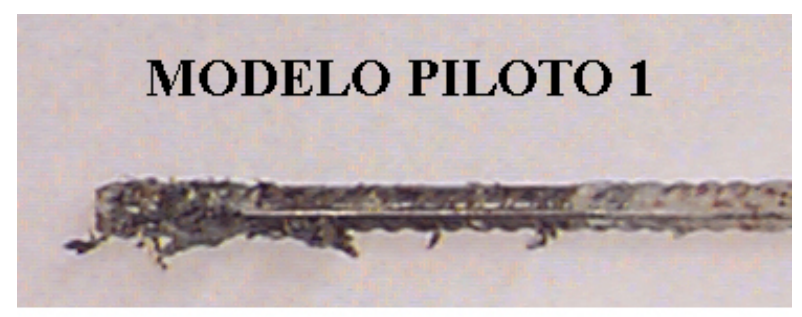

\section{MODELO PILOTO 2}

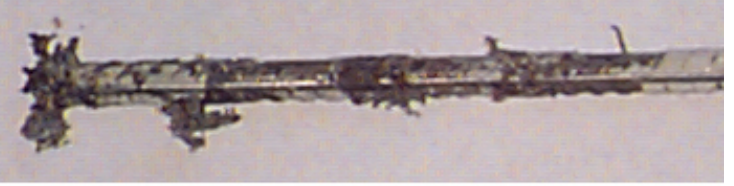

(b)

FIGURA 4.13 - (a) Ruptura do modelo piloto 2; (b) Degradação da aderência pelos extensômetros na armadura dos modelos piloto 1 e 2

Inicialmente, pretendia-se avaliar a distribuição das tensões de aderência ao longo do comprimento de aderência e a influência deste no comportamento da ligação. Entretanto, com esses ensaios piloto, concluiu-se que não é possível obter resultados coerentes, devido à degradação na aderência causada pelo isolamento dos extensômetros. Portanto, para os modelos seguintes, a instrumentação foi excluída, permanecendo o comprimento de aderência padrão $\mathbf{l}_{\mathbf{b}}$ igual a $5 \phi$, o que, como já foi visto, implica na consideração de uma tensão de aderência uniforme neste trecho.

SCOTT et al (1999) apresentaram um estudo sobre os mecanismos intrínsecos do comportamento de nós de pórtico com as armaduras do pilar e da viga principal instrumentadas internamente com extensômetros elétricos de resistência, obtendo-se assim as distribuições das tensões de aderência e deformações na barra. A técnica utilizada evitou a degradação da aderência entre as barras e o concreto envolvente, pois os extensômetros foram colocados em um duto central inserido longitudinalmente no centro da armadura. Essa técnica teve considerável desenvolvimento na Durham University, onde tem sido bastante utilizada. 


\subsection{ENSAIO DOS MODELOS}

Na figura 4.14, são ilustradas as fôrmas dos modelos das séries 10 e 20.

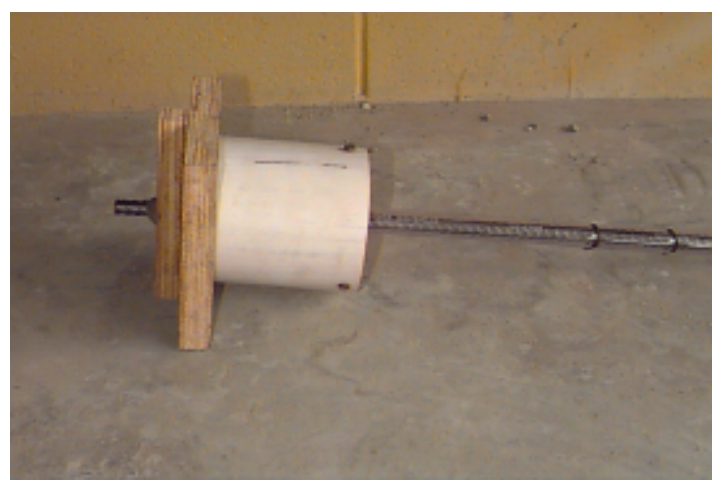

(a)

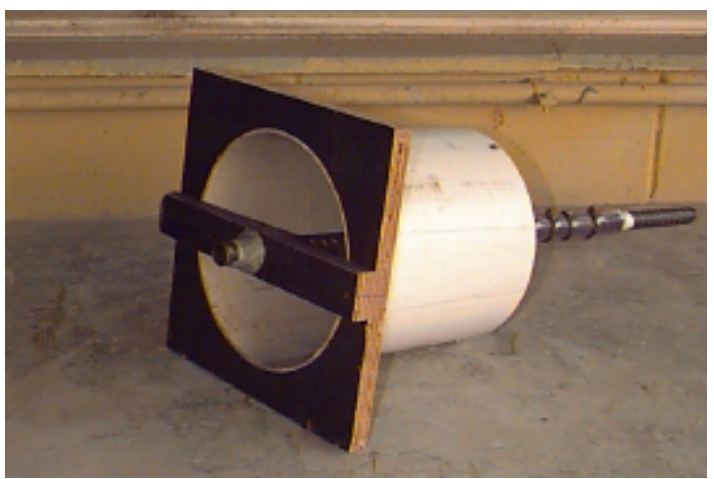

(b)

FIGURA 4.14 - Fôrmas dos modelos: (a) Série 10; (b) Série 20

O detalhe da fôrma do modelo cilíndrico adaptado do ensaio padrão de arrancamento segundo a RILEM-FIP-CEB (1973) pode ser visualizado na figura 4.15. Para evitar a influência das tensões de compressão ocasionadas pela placa de apoio, foi colocada uma mangueira de plástico no trecho não aderente e retirada durante a desfôrma do modelo. O sarrafo fixado no gabarito teve a finalidade de servir como um balizador da barra de aço.

Os ensaios foram executados em duas etapas. Na primeira etapa, realizou-se o ensaio de modelos piloto monotônicos e repetidos. Na segunda etapa, foram ensaiados dois modelos monotônicos para se ter uma média da força última e os modelos com carregamento repetido a partir de uma parcela desse valor médio.

Existem duas formas de execução do ensaio de arrancamento sob ação repetida: em uma, aplica-se a amplitude de força até o arrancamento total da barra; na outra, aplica-se um determinado número de ciclos e a partir daí, leva-se a armadura à ruptura monotônica. Como um dos objetivos dessa pesquisa é avaliar a redução da tensão última de aderência e devido ao tempo de ensaio relativamente grande para o arrancamento total da barra, optou-se pela segunda opção. 


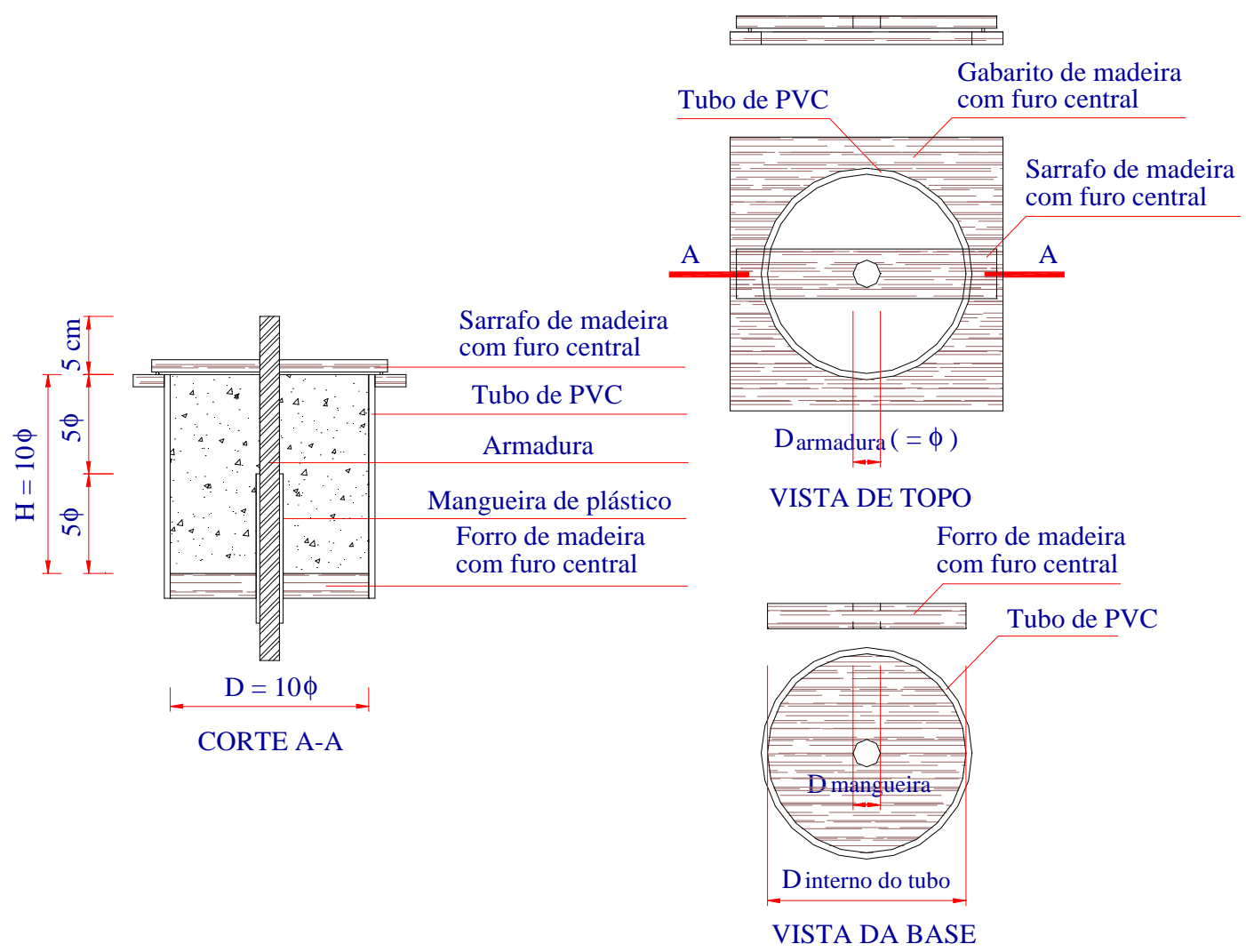

FIGURA 4.15 - Detalhe da fôrma dos modelos

Devido a alguns problemas relativos a máquina de ensaio, alguns modelos ensaiados com carregamento repetido foram perdidos, sendo necessário mudar o procedimento de aplicação do carregamento. O controle automático da amplitude do carregamento da máquina INSTRON não apresenta precisão na aplicação de forças repetidas de pequena intensidade à baixa freqüência. Portanto, para os modelos seguintes, a aplicação do carregamento repetido foi feita manualmente com a mesma velocidade do carregamento monotônico, sendo o nível mínimo do pré-carregamento igual a $0,5 \mathrm{kN}$. Foi aplicado um determinado número de ciclos em cada modelo de ensaio repetido; após isso, ensaiou-se o modelo monotonicamente, para a comparação dos resultados com o modelo monotônico de referência. 


\subsection{CONSIDERAÇÕES INICIAIS}

Além do estudo experimental, uma análise teórica da aderência foi realizada através de modelos numéricos representando os ensaios de arrancamento. Os resultados obtidos na investigação experimental foram utilizados como parâmetros de avaliação e calibragem do modelo numérico.

O comportamento da aderência cíclica não foi possível de ser analisado no Ansys porque, quando do descarregamento da força repetida, o deslizamento residual tornou-se nulo, impossibilitando, portanto, essa análise.

Outra tentativa foi feita no programa computacional desenvolvido por DRIEMEIER (1995) com uma extensão do modelo de dano de Mazars para carregamento cíclico. Entretanto, esse programa considera a aderência perfeita entre os nós dos elementos de concreto e aço, e o seu modelo de dano para o comportamento do material não considera deformações residuais, como ilustra a figura 5.1, o que gerou no primeiro ciclo um dano muito elevado nos elementos próximos da ligação no modelo de arrancamento, ocasionando um erro numérico no programa. 


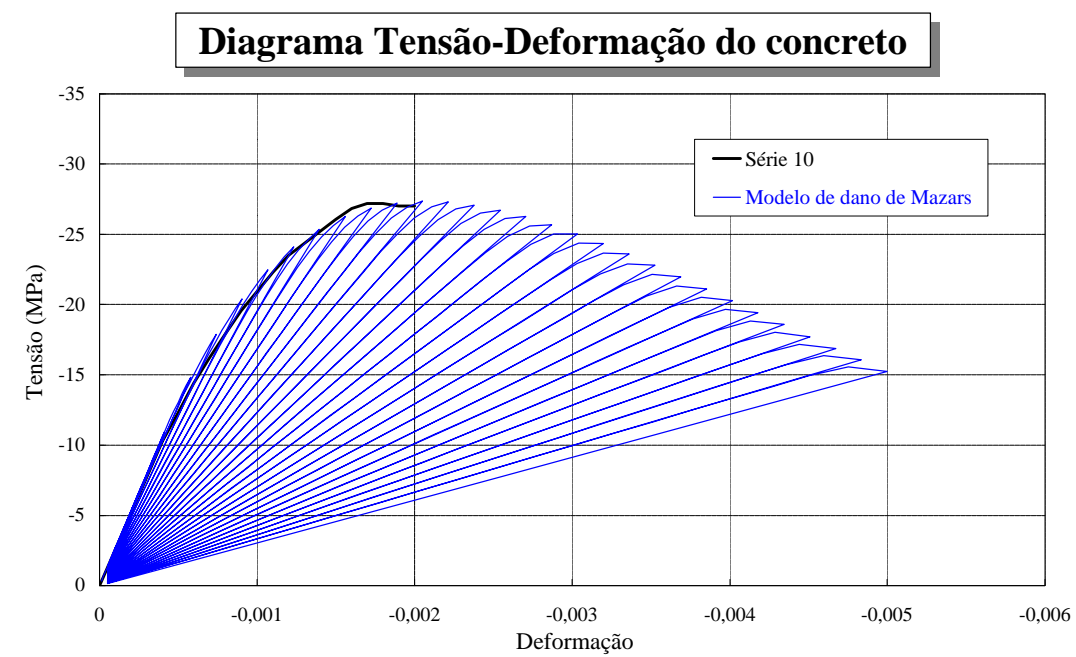

FIGURA 5.1 - Calibragem dos parâmetros do material com o modelo de dano de Mazars para carregamento cíclico

Para a modelagem numérica da aderência monotônica, foi utilizado o programa computacional Ansys ${ }^{1}$, baseado no método dos elementos finitos.

De acordo com os resultados experimentais, a destruição da ligação açoconcreto não ocorre no contato entre os dois materiais, mas sim pela ruptura do concreto ao cisalhamento entre as nervuras, como indica a figura 5.2.

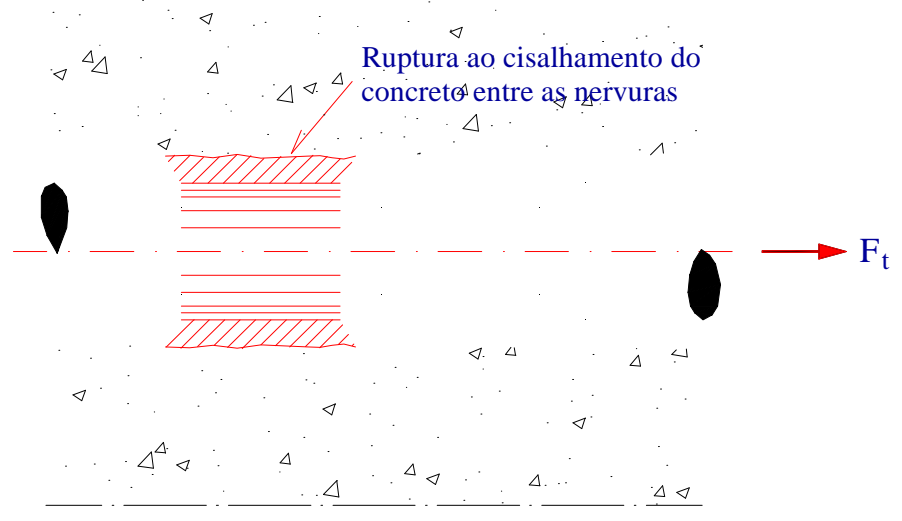

FIGURA 5.2 - Ruptura ao cisalhamento do concreto entre as nervuras

A ruptura da ligação pode ser representada de duas maneiras:

- Modelagem da barra nervurada, sem o elemento de contato, considerando a nãolinearidade do concreto e o comportamento elástico-linear do aço. Neste caso, pode-

\footnotetext{
${ }^{1}$ Ansys release 5.5 - Engineering Analysis System
} 
se colocar o elemento de contato na parte da nervura que tende a descolar do concreto para auxiliar na convergência;

- Modelagem da barra lisa com diâmetro igual ao da nervura, com o elemento de contato e considerando-se o comportamento elástico-linear do concreto e do aço.

Devido às dificuldades de convergência, quando da consideração da não linearidade física do concreto, a primeira modelagem não foi realizada.

A análise do problema da ligação foi feita então, de acordo com a segunda opção, utilizando-se elementos bidimensionais e tridimensionais. O modelo utilizado foi o da série 10 .

\subsection{SINGULARIDADES DO CONTATO NO ANSYS}

Os problemas de contato envolvem a não-linearidade geométrica da estrutura, apresentando, portanto, algumas dificuldades para a sua resolução. Dependendo do carregamento, material, condições de contorno e outros fatores, determinadas regiões do modelo podem entrar ou sair do contato bruscamente. Além disso, a maioria desses problemas precisam considerar o atrito, o qual é calculado de acordo com algumas regras e modelos, todos não-lineares. O comportamento do atrito pode dificultar a convergência da solução.

O contato pode ser classificado em rígido-flexível e flexível-flexível. Nos problemas de contato rígido-flexível, uma ou mais das superfícies em contato são tratadas como rígidas, isto é, possui uma rigidez relativa ao corpo deformável em contato muito maior. Um exemplo deste caso é o contato aço-concreto no ensaio de arrancamento, trabalho dessa dissertação, onde o concreto apresenta um deslocamento muito maior em relação à armadura, permanecendo esta praticamente imóvel. No contato flexível-flexível, todos os corpos em contato são deformáveis, ou seja, possuem rigidezes similares. Para tal classe, o contato de uma chapa parafusada pode ser citada como exemplo.

A análise do contato pode ser feita através de três formas: nó-nó, nósuperfície e superfície-superfície. Se uma das partes de interação é um ponto, a componente correspondente do modelo é um nó. Se uma das partes de interação é 
uma superfície, a componente correspondente do modelo é um elemento. O método dos elementos finitos reconhece possíveis pares de contato através da presença de elementos de contato específicos, que revestem as partes do modelo que estão sendo analisadas para interação. O contato aço-concreto do ensaio de arrancamento é considerado um problema de superfície-superfície.

Os elementos de superfície-superfície possuem algumas vantagens em relação aos de nó-superfície, como:

- permitem elementos de alta e baixa ordem na superfície, isto é, elementos com nós de extremidade e intermediários;

- permitem grandes deformações, com um deslizamento e atrito significativos. Uma matriz de rigidez consistente é calculada, e os elementos permitem a utilização da opção de uma matriz de rigidez assimétrica;

- fornecem melhores resultados no caso de pressão normal e tensões de atrito;

- não existem restrições quanto à forma da superfície rígida. As descontinuidades da superfície podem ser físicas ou devido à discretização do modelo;

- exigem uma menor quantidade de elementos que os de nó-superfície.

No contato superfície-superfície, os elementos do corpo deformável são denominados elementos "de contato", e os elementos do corpo rígido são chamados "rígidos".

O contato ainda pode ser classificado como assimétrico e simétrico. O contato assimétrico é definido com todos os elementos "de contato" em uma superfície e todos os elementos "rígidos" em outra. Esta é a maneira mais eficiente de modelagem do contato superfície-superfície. Entretanto, em algumas circunstâncias do contato assimétrico, não é possível resolver o problema satisfatoriamente. Em tais casos, cada superfície pode ser designada tanto de "rígida" como "de contato". Duas séries de pares de contato podem ser geradas entre as superfícies em contato ou apenas um par de contato, como o exemplo de modelos que entram em contato com eles mesmos. Este caso é conhecido como contato simétrico, o qual é menos eficiente que o assimétrico. Entretanto, muitas análises exigem seu uso, como por exemplo para reduzir a penetração de uma superfície na outra. O problema do contato no ensaio de arrancamento é classificado como assimétrico. 
Após a definição do tipo de problema e dos elementos que serão utilizados para melhor representá-lo, é necessário atribuir valores adequados para as "constantes reais" (real constants). Tanto a superfície "de contato" como a "rígida" devem possuir as mesmas "constantes reais".

No modelo de atrito Coulomb, duas superfícies inicialmente em contato irão deslizar uma em relação à outra a partir do momento em que uma certa tensão cisalhante for atingida. Na figura 5.3, pode ser visualizado o modelo de atrito Coulomb. A tensão cisalhante equivalente $\tau$ é definida como uma parcela da pressão de contato $\mathbf{p}$, onde a constante de relação entre esses dois fatores é o coeficiente de atrito $\mu$.

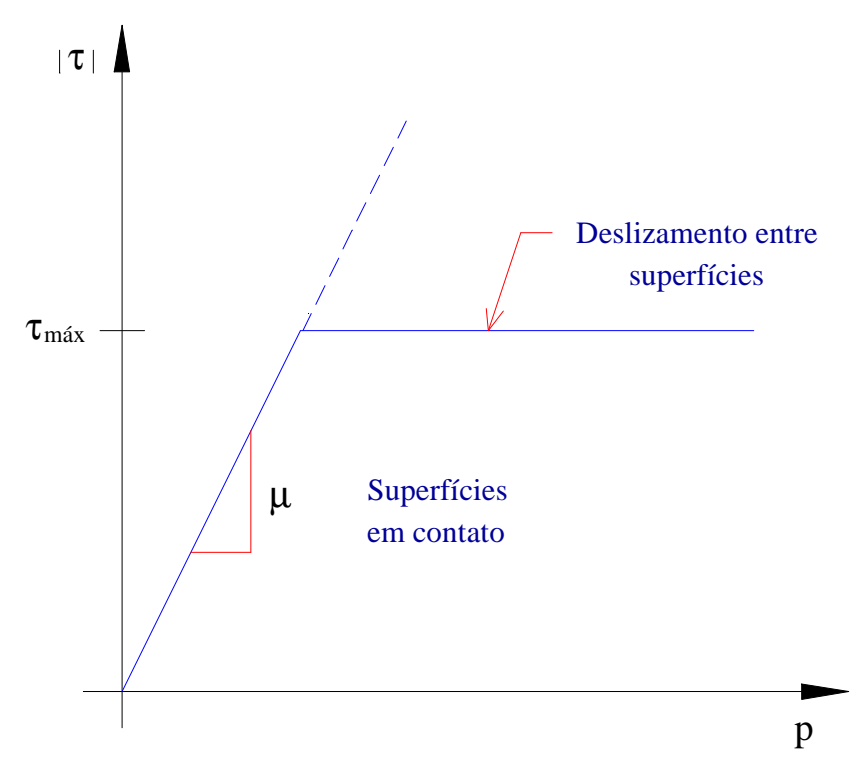

FIGURA 5.3 - Modelo de atrito para o contato superfície-superfície

\subsection{PARÂMETROS PARA MODELAGEM DO MODELO}

Os parâmetros do material utilizados relativos à série 10, são listados a seguir:

- Concreto:

$$
\mathbf{E}_{\mathrm{cm}}=25678 \mathrm{MPa}
$$$$
v_{c}=\mathbf{0 , 2}
$$

- Aço:

$$
\begin{gathered}
E_{\mathrm{sm}}=207167 \mathrm{MPa} ; \\
v_{\mathrm{s}}=0,3
\end{gathered}
$$

- Contato:

$$
\mu=0,4
$$


No modelo numérico, aplicou-se a força última experimental média $\left(\mathbf{F}_{\mathbf{u}}\right)$ da série 10 de 19,46 kN uniformemente distribuída na base dos elementos de concreto em 20 incrementos de carregamento.

Para a calibragem dos resultados experimentais, foi necessário ajustar a constante real $\mathbf{F K N}$, a qual define a rigidez de contato, de modo que o deslizamento último $\left(\mathbf{s}_{\mathbf{u}}\right)$ fosse $1,25 \mathrm{~mm}$. A constante real TAUMAX foi considerada igual ao valor da resistência de aderência convencional $\tau_{1 \mathrm{R}}=4,23 \mathrm{MPa}$.

\subsection{ELEMENTOS FINITOS UTILIZADOS}

\subsubsection{PLANE42}

O elemento finito PLANE42 é usado para a modelagem bidimensional (estado plano de tensão ou deformação) de estruturas sólidas. Ele é definido por quatro nós, tendo dois graus de liberdade cada um: translações nas direções nodais $\mathbf{x}$ e $\mathbf{y}$, como indica a figura 5.4. Ele permite plasticidade, fluência, rigidez à tração, grandes deflexões e deformações.

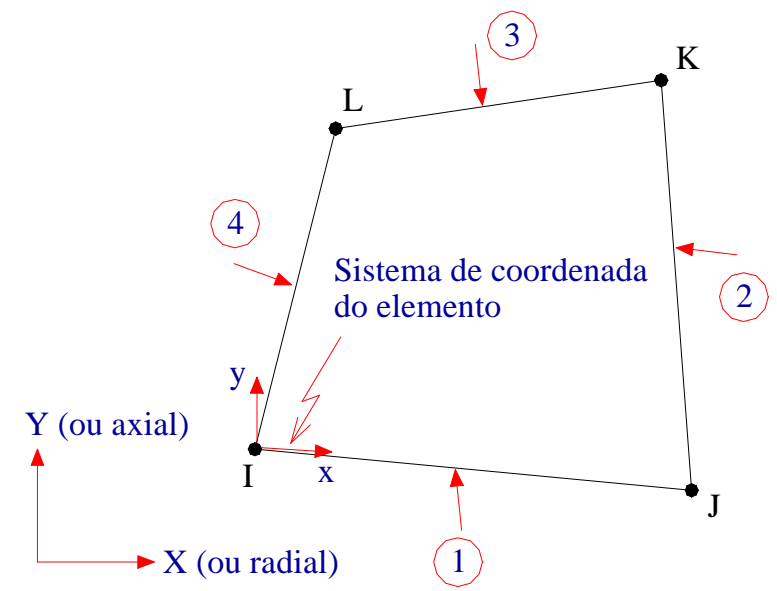

FIGURA 5.4 - Elemento finito PLANE42 


\subsubsection{CONTA171}

O elemento finito CONTA171 é usado para representar o contato e deslizamento entre a superfície "rígida" (TARGE169) e a superfície deformável, definida por esse elemento. Possui dois graus de liberdade em cada nó: translações nas direções nodais $\mathbf{x}$ e $\mathbf{y}$. As características geométricas desse elemento são as mesmas da face dos elementos sólidos, de casca, ou de barra a qual está ligado, como mostra a figura 5.5 .

Superfície do elemento TARGE169

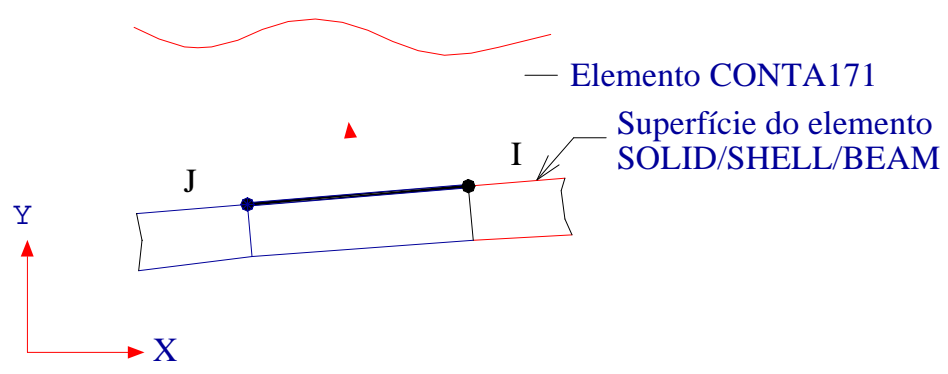

FIGURA 5.5 - Elemento finito CONTA171

\subsubsection{TARGE169}

O elemento finito TARGE169 é utilizado para representar várias superfícies "rígidas" bidimensionais associadas com os elementos "de contato", definidos pelo CONTA171. Os elementos de contato revestem os elementos sólidos descrevendo o contorno do corpo deformável e estão potencialmente ligados à superfície "rígida". Tal superfície é discretizada por uma série de elementos TARGE169, formando par com a superfície "de contato" associada através de uma mesma constante. Possui dois graus de liberdade em cada nó: translações nas direções nodais $\mathbf{x}$ e $\mathbf{y}$. As direções dos vetores normais às superfícies dos elementos CONTA171 e TARGE169 devem estar em sentido contrário conforme a figura 5.6. 
Elemento TARGE169

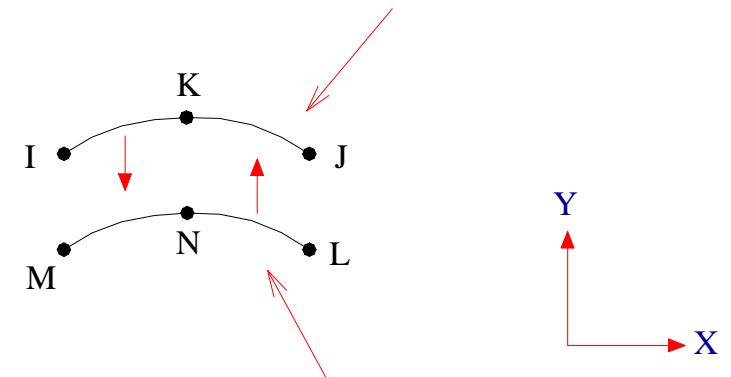

Elemento CONTA171

FIGURA 5.6 - Elemento finito TARGE169

\subsubsection{SOLID65}

O elemento finito SOLID65 é usado para a modelagem tridimensional de materiais sólidos como o concreto com ou sem armadura. Esse elemento permite fissuração na tração, esmagamento na compressão, deformação plástica e fluência. É definido por oito nós tendo três graus de liberdade cada um: translações nas direções nodais $\mathbf{x}, \mathbf{y}$ e $\mathbf{z}$, como ilustra a figura 5.7. A característica mais importante desse elemento é a não-linearidade física.

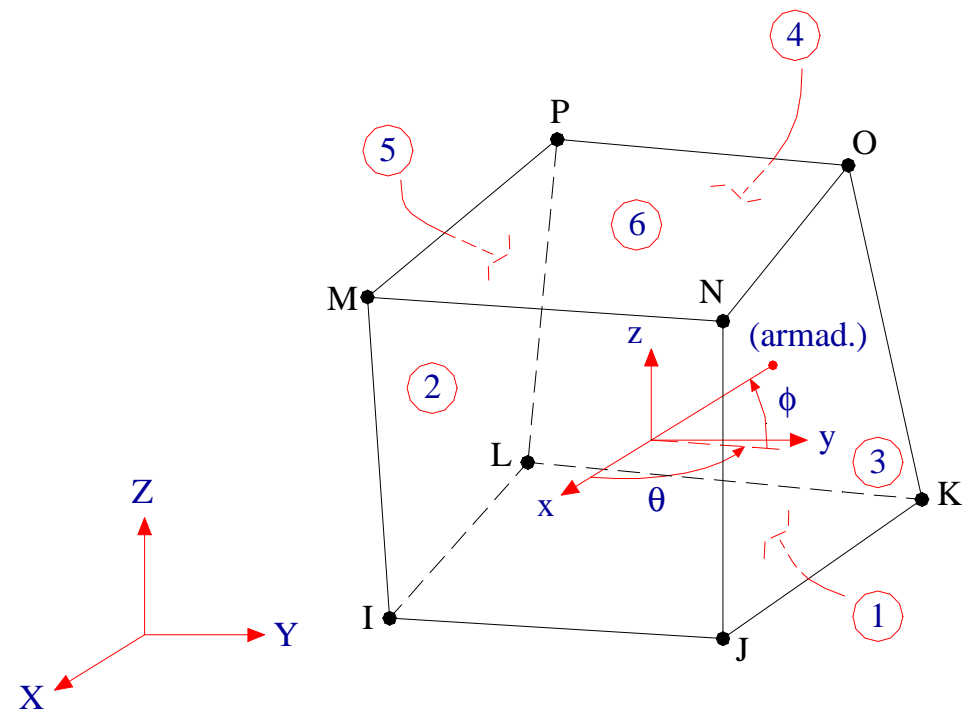

FIGURA 5.7 - Elemento finito SOLID65 


\subsubsection{SOLID45}

O elemento finito SOLID45 é utilizado para a modelagem tridimensional de materiais sólidos. É definido por oito nós tendo três graus de liberdade cada um: translações nas direções nodais $\mathbf{x}, \mathbf{y}$ e $\mathbf{z}$, como indica a figura 5.8. Esse elemento permite plasticidade, fluência, dilatação térmica, rigidez à tração, grandes deflexões e deformações.

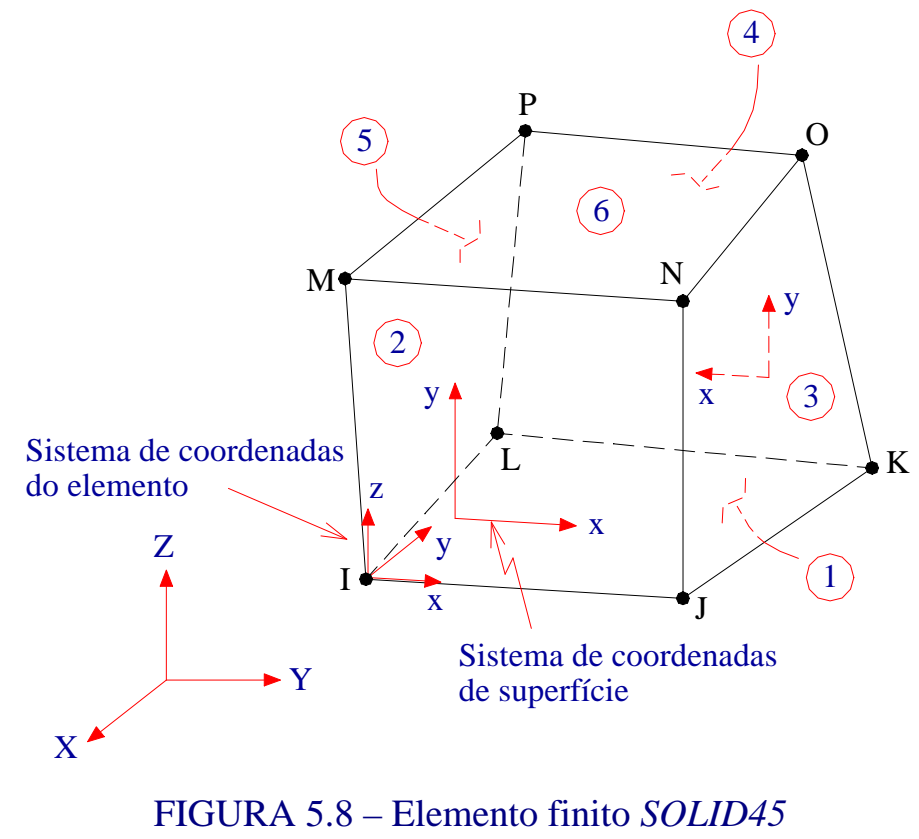

\subsubsection{CONTA173}

O elemento finito CONTA173 é usado para representar o contato e deslizamento entre a superfície "rígida" (TARGE170) e a superfície deformável, definida por esse elemento. Possui três graus de liberdade em cada nó: translações nas direções nodais $\mathbf{x}, \mathbf{y}$ e $\mathbf{z}$. As características geométricas desse elemento são as mesmas da face dos elementos sólidos a qual está ligado, como mostra a figura 5.9. 


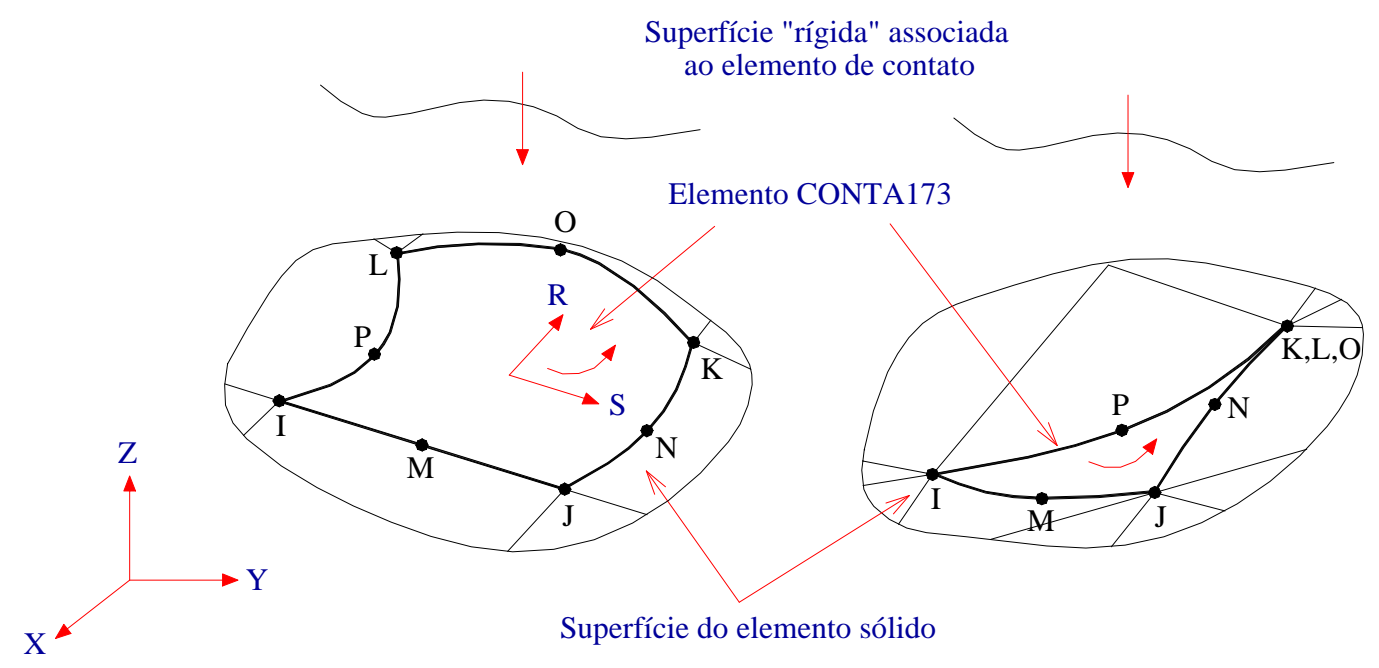

FIGURA 5.9 - Elemento finito CONTA173

\subsubsection{TARGE170}

O elemento finito TARGE170 é utilizado para representar várias superfícies "rígidas" tridimensionais associadas com os elementos "de contato", os quais neste trabalho são definidos pelo CONTA173. Os elementos de contato revestem os elementos sólidos descrevendo o contorno do corpo deformável e estão potencialmente ligados à superfície "rígida". Tal superfície é discretizada por uma série de elementos TARGE170, formando par com a superfície "de contato" associada através de uma mesma constante, que no caso desses elementos, é a resistência de atrito. Possui três graus de liberdade em cada nó: translações nas direções nodais $\mathbf{x}, \mathbf{y}$ e $\mathbf{z}$. As direções dos vetores normais às superfícies dos elementos CONTA173 e TARGE170 devem estar em sentido contrário conforme a figura 5.10 . 


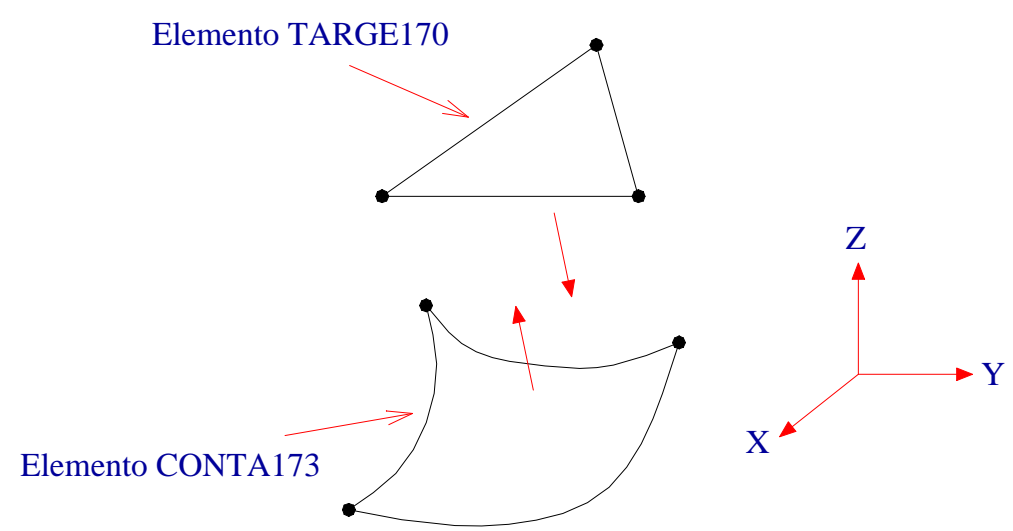

FIGURA 5.10 - Elemento finito TARGE170

\subsection{ANÁLISE NUMÉRICA}

\subsubsection{MODELO BIDIMENSIONAL COM A BARRA LISA (PT10-2D)}

A modelagem bidimensional do modelo PT10-2D foi feita no estado plano de tensões, desconsiderando portanto, a tensão na direção perpendicular ao plano .

$\mathrm{Na}$ figura 5.11, são ilustradas a discretização e as condições de contorno adotadas para o modelo PT10-2D, onde a armadura permanece fixa em uma extremidade representando a garra da máquina, e a força é aplicada uniformemente distribuída na base do concreto, representando a placa de apoio que a empurra no ensaio. Para esse modelo, foram colocadas restrições horizontais nos nós laterais do concreto, com o objetivo de evitar a rotação do concreto. 


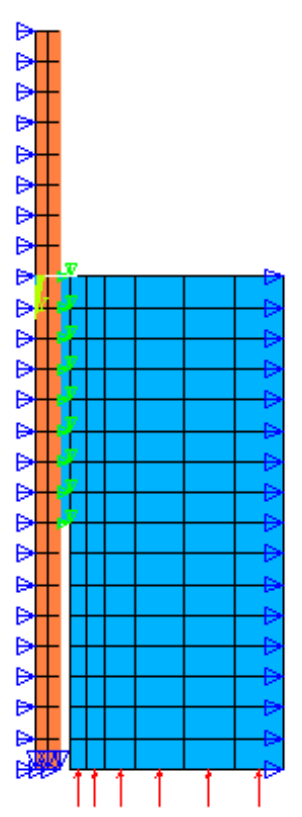

FIGURA 5.11 - Modelo PT10-2D

Foram utilizados os seguintes elementos:

- PLANE42 2-D Structural Solid, para o aço e o concreto;

- CONTA171 2-D Surface-to-Surface Contact Element para a área de contato do concreto;

- TARGE169 3-D Target Segment para a área de contato do aço.

\subsubsection{MODELO TRIDIMENSIONAL COM A BARRA LISA (PT10-3D)}

Para a construção do modelo PT10-3D, procurou-se adotar uma discretização que não interferisse na convergência e não tivesse um custo computacional muito grande. As condições de contorno foram semelhantes à da modelagem bidimensional.

A discretização e as condições de contorno adotadas para o modelo PT10-3D são ilustradas na figura 5.12. 

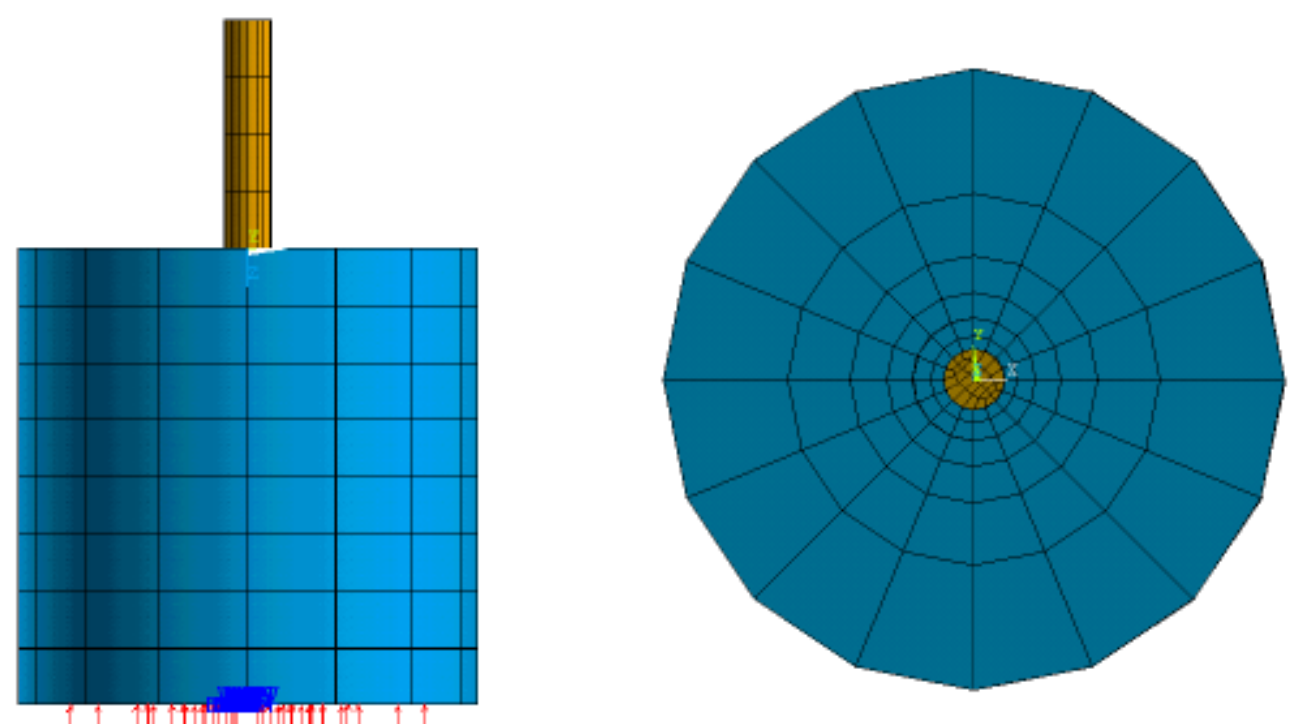

FIGURA 5.12 - Modelo PT10-3D

Foram utilizados quatros tipos de elementos finitos:

- SOLID65 3-D Reinforced Concrete Solid para representar o concreto;

- SOLID45 3-D Structural Solid para representar a barra de aço;

- CONTA173 3-D Surface-to-Surface Contact Element para representar a área de contato do concreto;

- TARGE170 3-D Target Segment para representar a área de contato do aço. 


\section{APRESENTAÇÃO E ANÁLISE DOS RESULTADOS}

Este capítulo apresenta os resultados da investigação experimental, da modelagem numérica e valores teóricos de normas, juntamente com sua análise.

\subsection{RUPTURA DOS MODELOS}

Todos os modelos ensaiados apresentaram ruptura por arrancamento da barra, com degradação do concreto entre as nervuras, conforme indica a figura 6.1(a). Como já foi mencionado anteriormente, este tipo de ruptura está relacionado com o confinamento da barra ocasionado pelo concreto, evitando assim, o fendilhamento do cobrimento. Na figura 6.1(b), pode ser visualizado o corte de um dos modelos, ilustrando o orifício perfeito causado pelo arrancamento da barra. Pode ser observado que não ocorreu nenhuma fissura de fendilhamento, comprovando que todos os modelos estavam sob a ação do confinamento do concreto. 


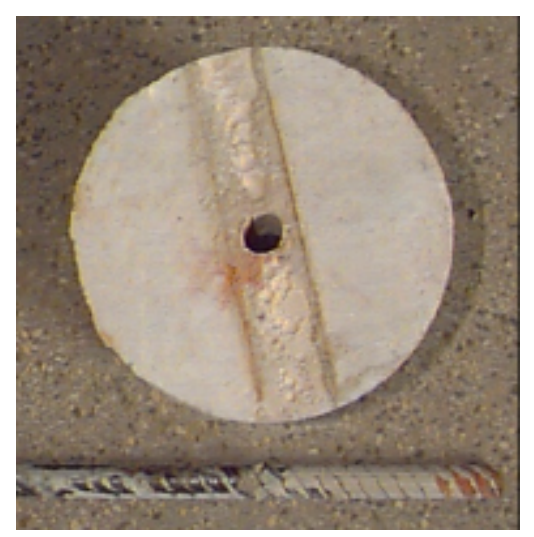

(a)

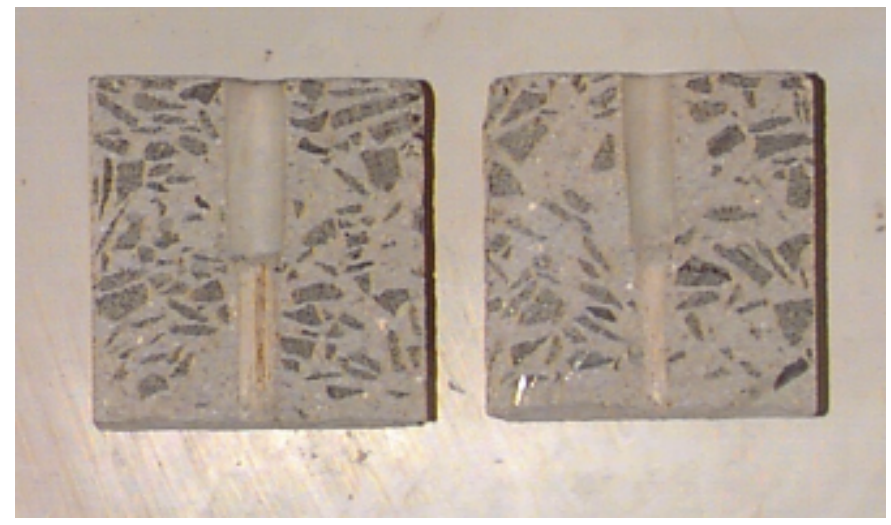

(b)

FIGURA 6.1 - (a) Ruptura por arrancamento de um modelo; (b) Corte de um modelo

\subsection{CARACTERIZAÇÃO DO CONCRETO E DO AÇO}

Como já foi mencionado no capítulo 2, as propriedades físicas e mecânicas dos materiais e de seus constituintes, entre outras, tem grande influência na resistência da ligação. Os resultados da caracterização dos materiais utilizados no concreto foram apresentados no capítulo 4. Nas tabelas 6.1 e 6.2, estão indicadas as informações relativas à caracterização do concreto e do aço, respectivamente.

TABELA 6.1 - Caracterização do concreto

\begin{tabular}{||c|c|c|c|c|c|c|c||}
\cline { 2 - 8 } \multicolumn{1}{c|}{} & Modelo & $\begin{array}{c}\text { slump } \\
(\mathbf{c m})\end{array}$ & $\begin{array}{c}\mathbf{f}_{\mathbf{c}} \\
(\mathbf{M P a})\end{array}$ & $\begin{array}{c}\mathbf{f}_{\mathbf{c m}} \\
(\mathbf{M P a})\end{array}$ & $\begin{array}{c}\mathbf{f}_{\mathbf{t}} \\
(\mathbf{M P a})\end{array}$ & $\begin{array}{c}\mathbf{f}_{\mathbf{t m}} \\
(\mathbf{M P a})\end{array}$ & $\begin{array}{c}\mathbf{E}_{\mathbf{c}} \\
(\mathbf{M P a})\end{array}$ \\
\cline { 2 - 8 } & PT10-Mon-a & 18,6 & 29,74 & 26,77 & 2,54 & 2,16 & 28404 \\
\cline { 2 - 8 } & PT10-Mon-b & 18,6 & 29,74 & 26,77 & 2,54 & 2,16 & 28404 \\
\cline { 2 - 8 } \multicolumn{1}{c|}{} & PT10-Mref & 14,7 & 34,54 & 31,09 & 3,27 & 2,78 & 29123 \\
\cline { 2 - 8 } & PT10-Rpiloto & 14,7 & 34,54 & 31,09 & 3,27 & 2,78 & 29123 \\
\hline $\mathbf{S}$ & PT10-Ma & 15,7 & 30,52 & 27,47 & 2,51 & 2,13 & 25678 \\
\hline $\mathbf{E}$ & PT10-Mb & 15,7 & 30,52 & 27,47 & 2,51 & 2,13 & 25678 \\
\hline $\mathbf{R}$ & PT10-1Ra & 15,7 & 30,52 & 27,47 & 2,51 & 2,13 & 25678 \\
\hline $\mathbf{I}$ & PT10-1Rb & 15,7 & 30,52 & 27,47 & 2,51 & 2,13 & 25678 \\
\hline $\mathbf{E}$ & PT10-2Ra & 15,7 & 30,52 & 27,47 & 2,51 & 2,13 & 25678 \\
\hline $\mathbf{1 0}$ & PT10-2Rb & 15,7 & 30,52 & 27,47 & 2,51 & 2,13 & 25678 \\
\hline $\mathbf{S}$ & PT20-Ma & 19,5 & 31,10 & 27,99 & 3,21 & 2,73 & 30447 \\
\hline$\hat{\mathbf{E}}$ & PT20-Mb & 19,5 & 31,10 & 27,99 & 3,21 & 2,73 & 30447 \\
\hline $\mathbf{R}$ & PT20-1R & 19,5 & 31,10 & 27,99 & 3,21 & 2,73 & 30447 \\
\hline I & PT20-2R & 19,5 & 31,10 & 27,99 & 3,21 & 2,73 & 30447 \\
\hline $\mathbf{E}$ & PT20-3R & 19,5 & 31,10 & 27,99 & 3,21 & 2,73 & 30447 \\
\hline $\mathbf{2 0}$ & PT20-4R & 19,5 & 31,10 & 27,99 & 3,21 & 2,73 & 30447 \\
\hline
\end{tabular}


TABELA 6.2 - Caracterização do aço

\begin{tabular}{|c|c|c|c||}
\hline Diâmetro & $\mathbf{E}_{\mathbf{s}}(\mathbf{M P a})$ & $\mathbf{f}_{\mathbf{y}}(\mathbf{M P a})$ & $\sigma_{\mathrm{t}}(\mathbf{M P a})$ \\
\hline$\phi=10 \mathrm{~mm}$ & 207167 & 696 & 852 \\
\hline$\phi=20 \mathrm{~mm}$ & 206533 & 621 & 727 \\
\hline
\end{tabular}

O comportamento tensão-deformação do concreto e do aço é ilustrado nas figuras 6.2 e 6.3, respectivamente. O diagrama relativo ao aço é aproximado, considerando-se o patamar de escoamento horizontal, apesar de no ensaio, este ter apresentado uma inclinação desprezível.

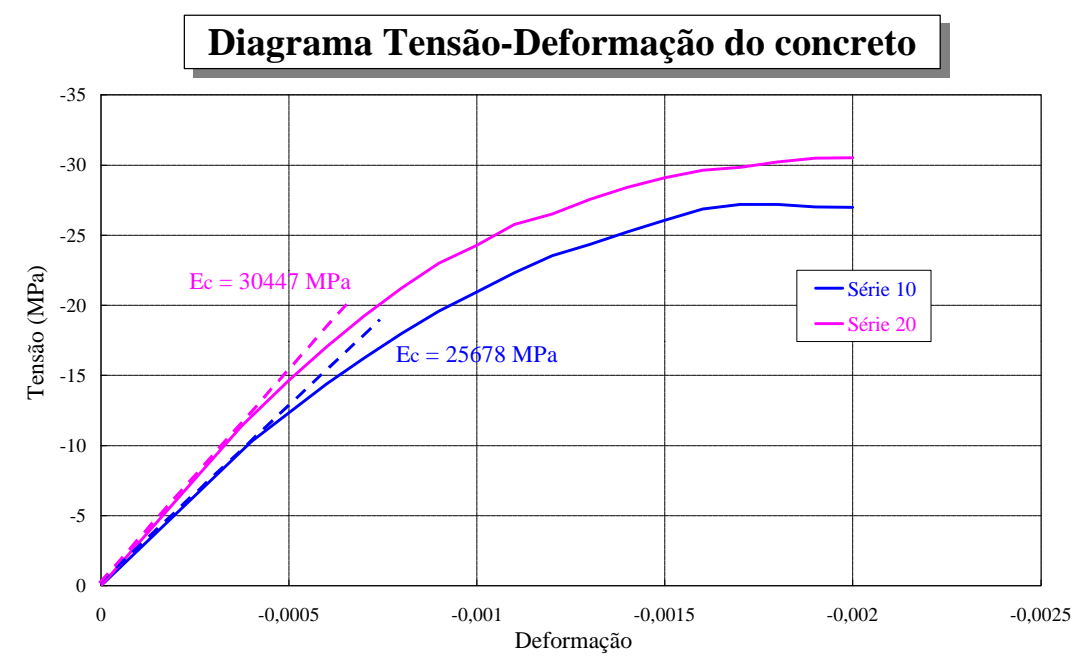

FIGURA 6.2 - Diagrama tensão-deformação do concreto

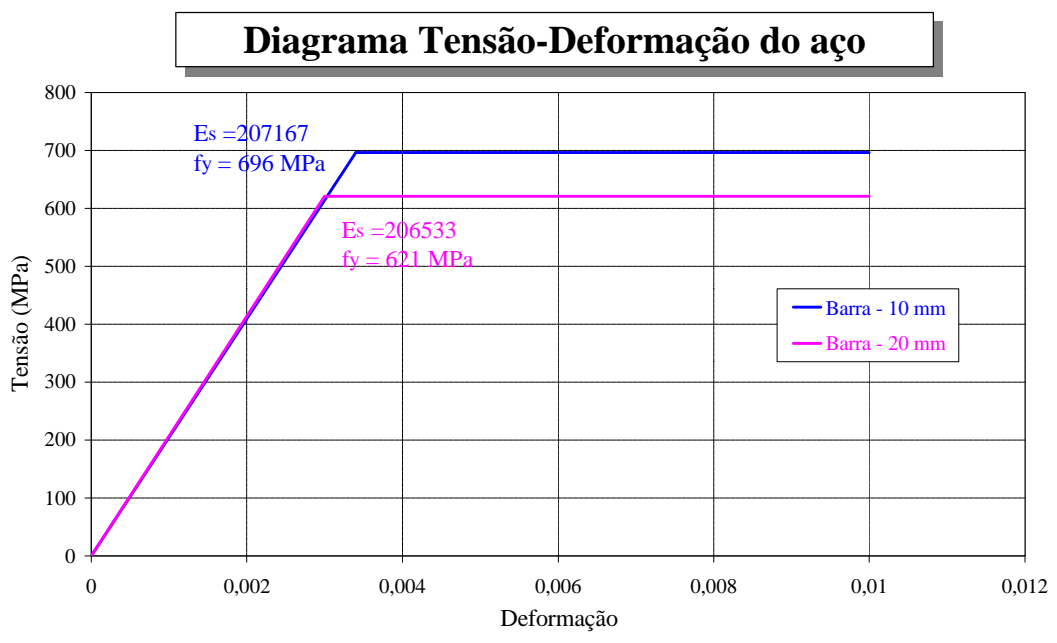

FIGURA 6.3 - Diagrama tensão-deformação do aço 


\subsection{COMPORTAMENTO MONOTÔNICO DA ADERÊNCIA}

Nos itens a seguir, serão apresentados os resultados dos ensaios monotônicos de arrancamento. Em todos os modelos monotônicos e repetidos, a tensão de aderência é calculada como um valor médio, considerando-se a distribuição uniforme da força aplicada ao longo da área de contato aço-concreto, a qual é função do diâmetro nominal da barra e do comprimento de ancoragem.

\subsubsection{MODELOS PILOTO}

Na figura 6.4, são apresentadas as curvas experimentais tensão de aderência versus deslizamento dos modelos PT10-Mpil-a e PT10-Mpil-b, plotadas juntamente com a média e a relação proposta pelo CEB-FIP MC90. Em relação à resistência de aderência para efeitos de cálculo $\left(\tau_{\mathbf{1}}\right)$, os dois modelos apresentaram resultados bastante próximos um do outro, sendo, porém este valor superestimado pelo CEBFIP MC90. Já os valores da tensão de aderência última $\left(\tau_{\mathbf{b u}}\right)$ tiveram uma pequena diferença; entretanto, seu valor médio ficou bem próximo do resultado do CEB-FIP MC90, com uma diferença de 2,55\%. Portanto, foram ensaiados dois modelos com força monotônica para se obter uma média da tensão última de aderência.

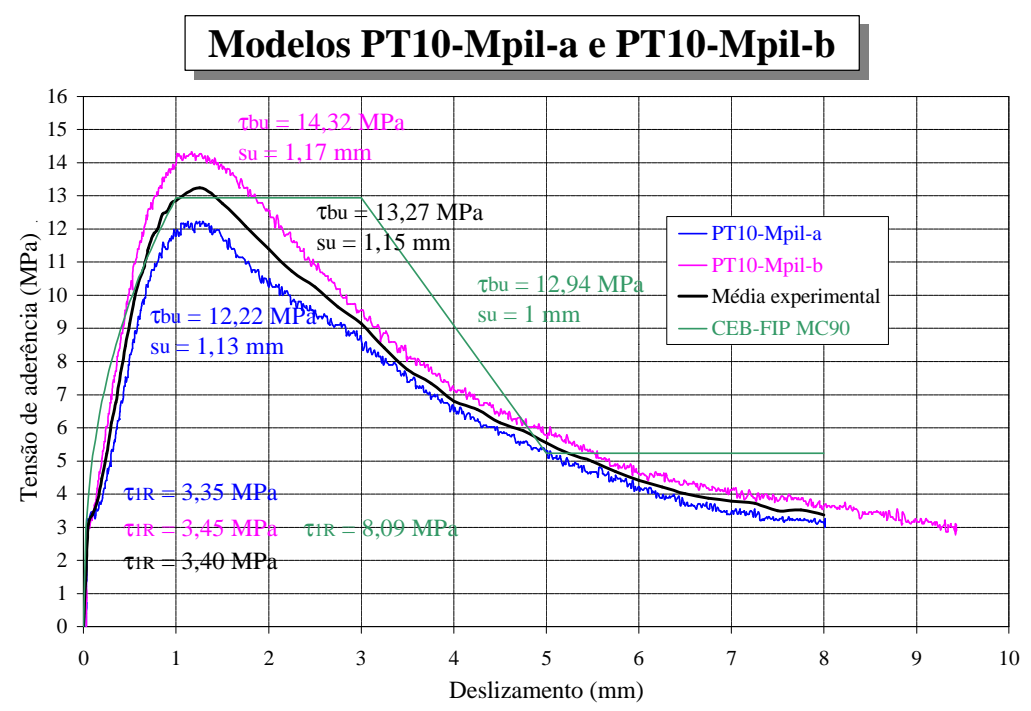

FIGURA 6.4 - Curva monotônica tensão de aderência-deslizamento dos modelos PT10-Mpil-a e PT10-Mpil-b 


\subsubsection{SÉRIES 10 E 20}

O comportamento da ligação dos modelos monotônicos da série 10 e 20, ilustrado na figuras 6.5 e 6.6, respectivamente, constitui de três fases:

- $\quad \mathbf{0} \leq \mathbf{s} \leq \mathbf{0 , 1 m m}$ : aderência inicial devido à adesão, até a ruptura convencional da ligação $\left(\tau_{\mathbf{1 R}}\right)$, correspondente ao deslizamento de $0,1 \mathrm{~mm}$. Neste trecho elástico linear, as deformações dos dois materiais são admitidas iguais e não há formação de fissuras;

- $\quad \mathbf{0 , 1 m m} \leq \mathbf{s} \leq \mathbf{s}_{\mathbf{u}}$ : mobilização da aderência por atrito e a mecânica, até atingir a ruptura efetiva da ligação $\left(\tau_{\mathbf{b u}}\right)$. As fissuras "cisalhantes" formadas pelo esmagamento do concreto próximo às nervuras se propagam ao longo de um comprimento considerável ocasionando o corte parcial do concreto entre as nervuras.

- $\mathbf{s}_{\mathbf{u}} \leq \mathbf{s} \leq \mathbf{s}_{\lim }$ : processo desencadeado pelo atrito concreto-concreto e travamento entre o concreto e as nervuras, que só foi possível devido às condições de ensaio de deslocamento controlado. Nesta fase, ocorre um decréscimo brusco da curva, a qual finaliza no deslizamento limite medido pelo transdutor de deslocamento $\left(\mathbf{s}_{\mathbf{l i m}}\right)$, caracterizando o arrancamento total da barra. A tensão residual, quando a curva se torna praticamente horizontal, não foi possível de ser capturada, devido ao término da medição do transdutor de deslocamento.

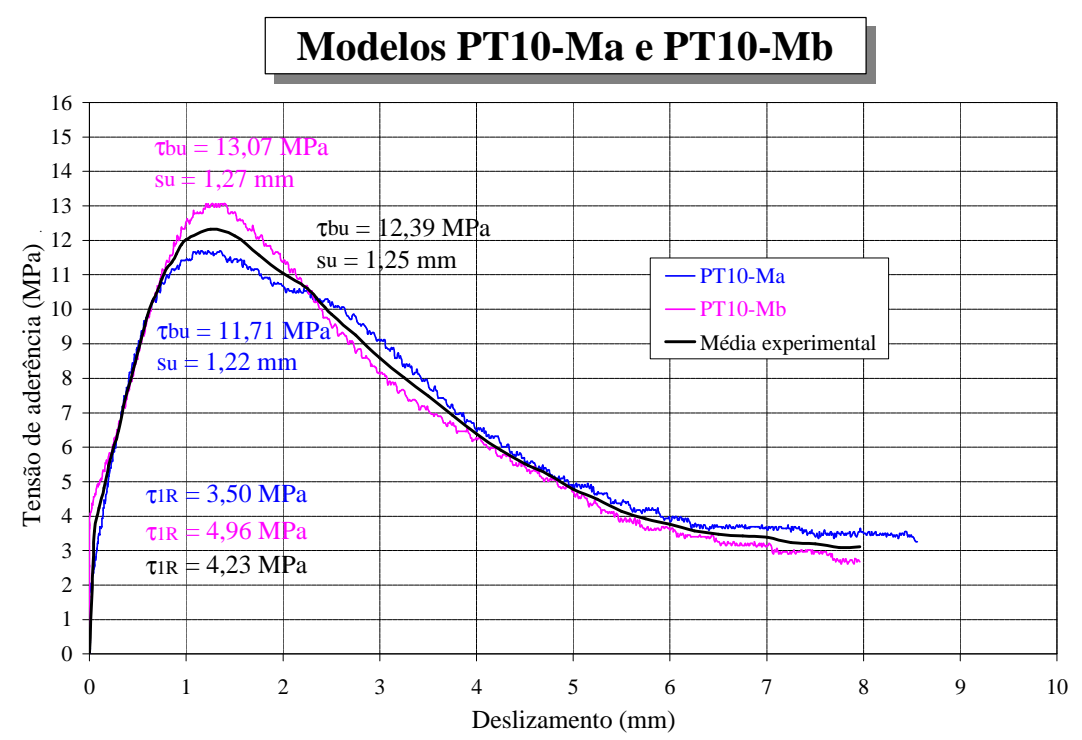

FIGURA 6.5 - Curva monotônica tensão de aderência-deslizamento dos modelos PT10-Ma e PT10-Mb 


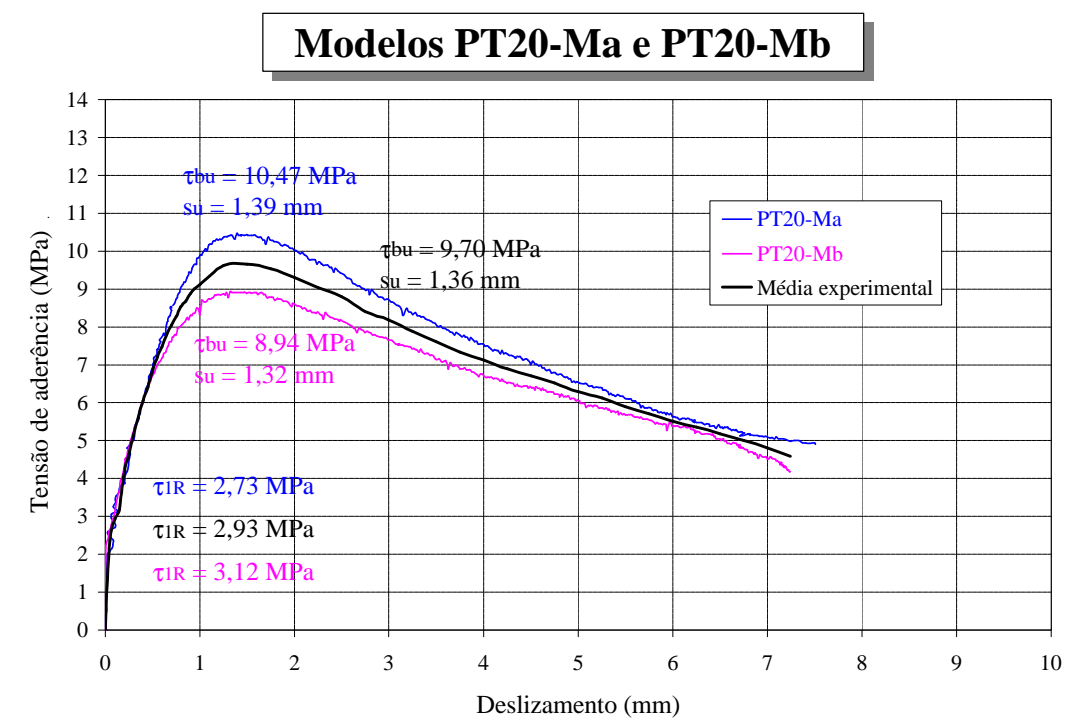

FIGURA 6.6 - Curva monotônica tensão de aderência-deslizamento dos modelos PT20-Ma e PT20-Mb

Essas três fases do processo da aderência podem ser melhor visualizadas na figura 6.7 .

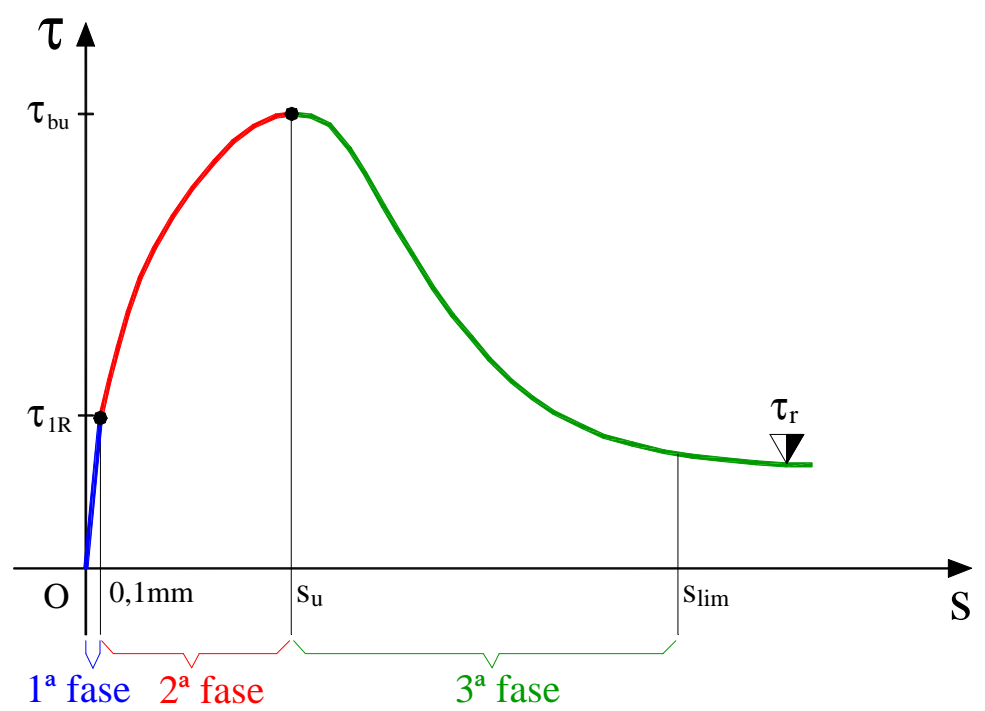

FIGURA 6.7 - Digrama representativo das fases do comportamento da aderência dos ensaios monotônicos

Observando-se as duas curvas médias da figura 6.8, os modelos da série 10 apresentaram um melhor comportamento de aderência que os modelos da série 20, tanto em relação à resistência convencional da ligação $\left(\tau_{1 \mathbf{R}}\right)$ como em relação à tensão última de aderência $\left(\tau_{\mathbf{b u}}\right)$, apesar da força de arrancamento ter sido menor. Já 
em relação ao ramo descendente da curva, os modelos da série 20 tiveram um comportamento melhor através da inclinação menor da curva, sendo, portanto, mais dúcteis.

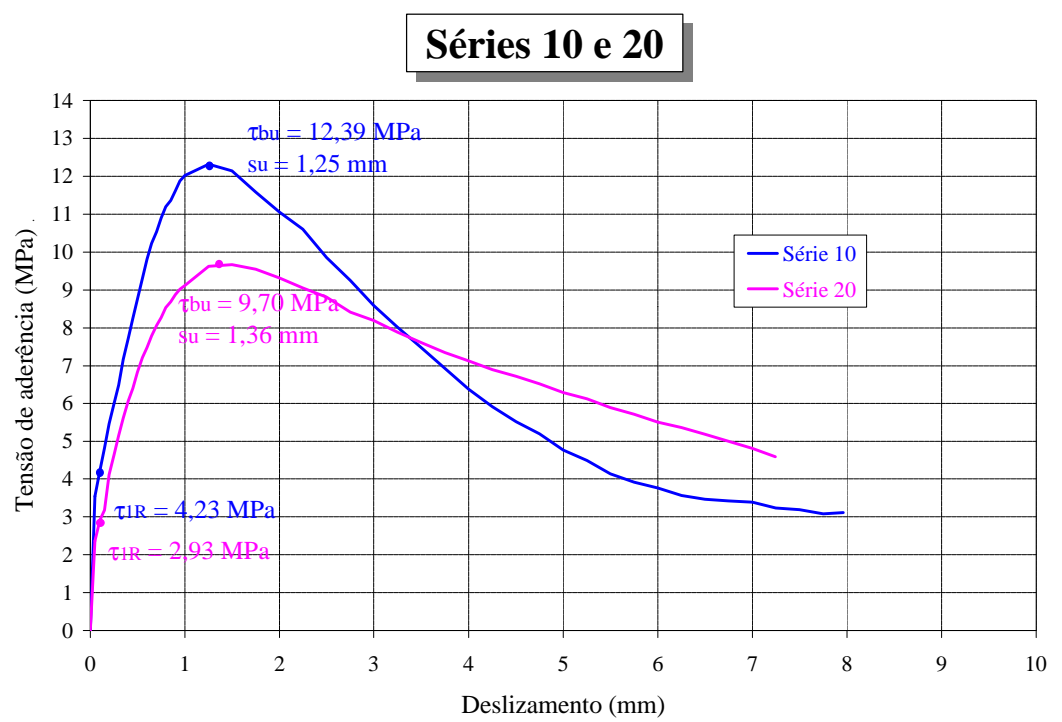

FIGURA 6.8 - Curva média dos modelos das séries 10 e 20

\subsection{CÁlCULO DA RESISTÊNCIA DE ADERÊNCIA SEGUNDO AS NORMAS}

Diante da falta de uma relação tensão de aderência versus deslizamento, com exceção do CEB-FIP MC 1990, foi calculada para as outras normas apenas a resistência de aderência equivalente ao deslizamento de $0,1 \mathrm{~mm}$. Os valores foram calculados para condições de aderência boas e ruins.

\subsubsection{CEB-FIP MC 1990}

Os parâmetros da relação tensão de aderência versus deslizamento foram definidos a partir das quarta e quinta colunas da tabela 2.1, pois no ensaio de arrancamento o concreto está confinado. 
- Série 10

Condições de aderência boas (situação 1):

$$
\begin{aligned}
& s_{1}=1 \mathrm{~mm} ; \quad s_{2}=3 \mathrm{~mm} ; \quad s_{3}=5 \mathrm{~mm} ; \quad \alpha=0,4 ; \quad \tau_{\text {máx }}=2,5 \sqrt{27,47}=13,10 \mathrm{MPa} ; \\
& \tau_{\mathrm{f}}=0,4 \times 13,10=5,24 \mathrm{MPa} \\
& \tau=13,10(s)^{0,4} \quad 0 \leq s \leq s_{1} \\
& \tau=13,10 \quad s_{1}<s \leq s_{2} \\
& \tau=2,62(s-3) \quad s_{2}<s \leq s_{3} \\
& \tau=\mathbf{5 , 2 4} \quad \mathbf{s}_{\mathbf{3}}<\mathbf{s} \\
& \tau_{1 \mathrm{R}}=13,10 .(0,1)^{0,4} \quad \therefore \tau_{1 \mathrm{R}}=5,22 \mathrm{MPa}
\end{aligned}
$$

Condições de aderência ruins (situação 2):

$$
\begin{array}{lc}
\mathrm{s}_{1}=1 \mathrm{~mm} ; \quad \mathrm{s}_{2}=3 \mathrm{~mm} ; \quad \mathrm{s}_{3}=5 \mathrm{~mm} ; \quad \alpha=0,4 ; \quad \tau_{\text {máx }}=1,25 \sqrt{27,47}=6,55 \mathrm{MPa} ; \\
\begin{array}{lc}
\tau_{\mathrm{f}}=0,4 \times 6,55=2,62 \mathrm{MPa} & \\
\tau=6,55(\mathrm{~s})^{0,4} & 0 \leq \mathrm{s} \leq \mathrm{s}_{1} \\
\tau=6,55 & \mathrm{~s}_{1}<\mathrm{s} \leq \mathrm{s}_{2} \\
\tau=1,31(\mathrm{~s}-3) & \mathrm{s}_{2}<\mathrm{s} \leq \mathrm{s}_{3} \\
\tau=2,62 & \mathrm{~s}_{3}<\mathrm{s} \\
\tau_{1 \mathrm{R}}=6,55 .(0,1)^{0,4} \quad \therefore \quad \tau_{1 \mathrm{R}}=2,61 \mathrm{MPa}
\end{array}
\end{array}
$$

- Série 20

Condições de aderência boas (situação 1):

$$
\begin{array}{lc}
\mathrm{s}_{1}=1 \mathrm{~mm} ; \quad \mathrm{s}_{2}=3 \mathrm{~mm} ; \quad \mathrm{s}_{3}=7 \mathrm{~mm} ; \quad \alpha=0,4 ; \quad \tau_{\text {máx }}=2,5 \sqrt{28,00}=13,23 \mathrm{MPa} ; \\
\begin{array}{lc}
\tau_{\mathrm{f}}=0,4 \times 13,23=5,29 \mathrm{MPa} & 0 \leq \mathrm{s} \leq \mathrm{s}_{1} \\
\tau=13,23(\mathrm{~s})^{0,4} & \mathrm{~s}_{1}<\mathrm{s} \leq \mathrm{s}_{2} \\
\tau=13,23 & \mathrm{~s}_{2}<\mathrm{s} \leq \mathrm{s}_{3} \\
\tau=1,323(\mathrm{~s}-3) & \mathrm{s}_{3}<\mathrm{s} \\
\tau=5,29 & \therefore \tau_{1 \mathrm{R}}=5,27 \mathrm{MPa}
\end{array}
\end{array}
$$


Condições de aderência ruins (situação 2):

$$
\begin{aligned}
& s_{1}=1 \mathrm{~mm} ; \quad s_{2}=3 \mathrm{~mm} ; \quad s_{3}=7 \mathrm{~mm} ; \quad \alpha=0,4 ; \quad \tau_{\text {máx }}=1,25 \sqrt{28,00}=6,61 \mathrm{MPa} ; \\
& \tau_{\mathrm{f}}=0,4 \times 6,61=2,64 \mathrm{MPa} \\
& \tau=6,61(s)^{0,4} \quad 0 \leq s \leq s_{1} \\
& \tau=6,61 \quad s_{1}<s \leq s_{2} \\
& \tau=0,661(s-3) \quad s_{2}<s \leq s_{3} \\
& \tau=2,64 \\
& \tau_{1 \mathrm{R}}=6,61 .(0,1)^{0,4} \quad \therefore \tau_{1 \mathrm{R}}=2,63 \mathrm{MPa}
\end{aligned}
$$

\subsubsection{EUROCODE 2}

Como as barras são nervuradas, o cálculo da resistência de aderência foi feita segundo a equação 2.11. Entretanto, o coeficiente de segurança $\gamma_{c}$ é igual à unidade, que é equivalente a situação real.

- Série 10

Condições de aderência boas (situação 1):

$\mathbf{f}_{\mathrm{ctm}}=2,13 \mathrm{MPa}$

$\tau_{1 \mathrm{R}}=2,25 . \mathrm{f}_{\mathrm{ctm}} \quad \therefore \tau_{1 \mathrm{R}}=4,79 \mathrm{MPa}$

Condições de aderência ruins (situação 2):

$\tau_{1 \mathrm{R}}=4,79 \times 0,7 \mathrm{MPa} \quad \therefore \tau_{1 \mathrm{R}}=3,35 \mathrm{MPa}$

- Série 20

Condições de aderência boas (situação 1):

$\mathbf{f}_{\mathrm{ctm}}=2,73 \mathrm{MPa}$

$\tau_{1 \mathrm{R}}=2,25 . \mathrm{f}_{\mathrm{ctm}} \quad \therefore \tau_{1 \mathrm{R}}=6,14 \mathrm{MPa}$

Condições de aderência ruins (situação 2):

$\tau_{1 \mathrm{R}}=6,14 \times 0,7 \mathrm{MPa} \quad \therefore \tau_{1 \mathrm{R}}=4,30 \mathrm{MPa}$ 


\subsubsection{NB-1/78 (NBR 6118)}

A resistência de aderência é calculada segundo a equação 2.2. A resistência de cálculo à compressão $\mathbf{f}_{\mathbf{c d}}$ foi considerada igual à resistência média à compressão $\mathbf{f}_{\mathrm{cm}}$, equivalente a situação real.

- Série 10

Condições de aderência boas (situação 1):

$\mathbf{f}_{\mathrm{cm}}=27,47 \mathrm{MPa}$

$\tau_{1 \mathrm{R}}=0,42 \sqrt[3]{\mathrm{f}_{\mathrm{cm}}{ }^{2}} \quad \therefore \tau_{1 \mathrm{R}}=3,82 \mathrm{MPa}$

Condições de aderência ruins (situação 2):

$\tau_{1 \mathrm{R}}=3,82 / 1,5 \quad \therefore \tau_{1 \mathrm{R}}=2,55 \mathrm{MPa}$

- Série 20

Condições de aderência boas (situação 1):

$\mathbf{f}_{\mathrm{cm}}=28,00 \mathrm{MPa}$

$\tau_{\mathrm{br}}=0,42 \sqrt[3]{\mathbf{f}_{\mathrm{cm}}{ }^{2}} \quad \therefore \tau_{\mathrm{br}}=3,87 \mathrm{MPa}$

Condições de aderência ruins (situação 2):

$\tau_{1 \mathrm{R}}=3,87 / 1,5 \quad \therefore \tau_{1 \mathrm{R}}=2,58 \mathrm{MPa}$

\subsection{COMPARAÇÃO DA ADERÊNCIA MONOTÔNICA EXPERIMENTAL COM OS VALORES DE NORMAS}

A resistência convencional de ligação $\left(\tau_{1 \mathbf{R}}\right)$, a resistência de aderência efetiva $\left(\tau_{\mathbf{b u}}\right)$ com seu respectivo deslizamento $\left(\mathbf{s}_{\mathbf{u}}\right)$, relativas aos ensaios e aos valores de norma, e a diferença percentual entre eles para as situações 1 e 2 são mostrados na tabela 6.3. Na comparação da figura 6.9, a diferença entre esses valores pode ser melhor visualizada. Nas figuras 6.10. e 6.11, é apresentada a comparação do comportamento global do ensaio com a curva do CEB-FIP MC90. 
TABELA 6.3 - Comparação dos valores de $\tau_{\mathbf{1 R}}, \tau_{\mathbf{b u}}$ e $\mathbf{s}_{\mathbf{u}}$ experimentais com os propostos pelas normas

\begin{tabular}{|c|c|c|c|c|c|c|c|c|c|c|c|}
\hline & \multicolumn{2}{|c|}{$\tau_{1 \mathrm{R}}(\mathbf{M P a})$} & \multicolumn{2}{|c|}{ Dif. (\%) } & \multicolumn{2}{|c|}{$\tau_{\mathrm{bu}}(\mathbf{M P a})$} & \multicolumn{2}{|c|}{ Dif. (\%) } & \multirow{2}{*}{$\begin{array}{c}\begin{array}{c}\mathbf{s}_{\mathbf{u}} \\
(\mathbf{m m})\end{array} \\
\end{array}$} & \multirow{2}{*}{$\begin{array}{l}\text { Dif. } \\
(\%)\end{array}$} \\
\hline & & sit. 1 & sit. 2 & sit. 1 & sit. 2 & sit. 1 & sit. 2 & sit. 1 & sit. 2 & & \\
\hline $\begin{array}{l}\mathbf{S} \\
\mathbf{E}\end{array}$ & $\begin{array}{c}\text { Média } \\
\text { Experimental }\end{array}$ & \multicolumn{2}{|c|}{4,23} & \multicolumn{2}{|c|}{ - } & \multicolumn{2}{|c|}{12,39} & \multicolumn{2}{|c|}{-} & 1,25 & - \\
\hline $\mathbf{R}$ & CEB-FIP MC90 & 5,22 & 2,61 & $-23,40$ & 38,30 & 13,10 & 6,55 & $-5,73$ & 47,13 & 1 & 20,00 \\
\hline $\mathbf{I}$ & EUROCODE 2 & 4,79 & 3,35 & $-13,24$ & 20,80 & - & - & - & - & - & - \\
\hline 10 & NB-1/78 & 3,82 & 2,55 & 9,69 & 39,72 & - & - & - & - & - & - \\
\hline $\begin{array}{l}\mathbf{S} \\
\hat{\mathbf{E}}\end{array}$ & $\begin{array}{c}\text { Média } \\
\text { Experimental }\end{array}$ & \multicolumn{2}{|c|}{2,93} & \multicolumn{2}{|c|}{ 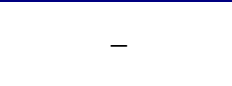 } & \multicolumn{2}{|c|}{9,70} & \multicolumn{2}{|c|}{-} & 1,36 & - \\
\hline $\mathbf{R}$ & CEB-FIP MC90 & 5,27 & 2,63 & $-79,86$ & 10,24 & 13,23 & 6,61 & $-36,39$ & 31,86 & 1 & 26,47 \\
\hline $\mathbf{F}$ & EUROCODE 2 & 6,14 & 4,30 & $-109,56$ & $-46,76$ & - & - & - & - & - & - \\
\hline 20 & NB-1/78 & 3,87 & 2,58 & $-32,08$ & 11,95 & - & - & - & - & - & - \\
\hline
\end{tabular}

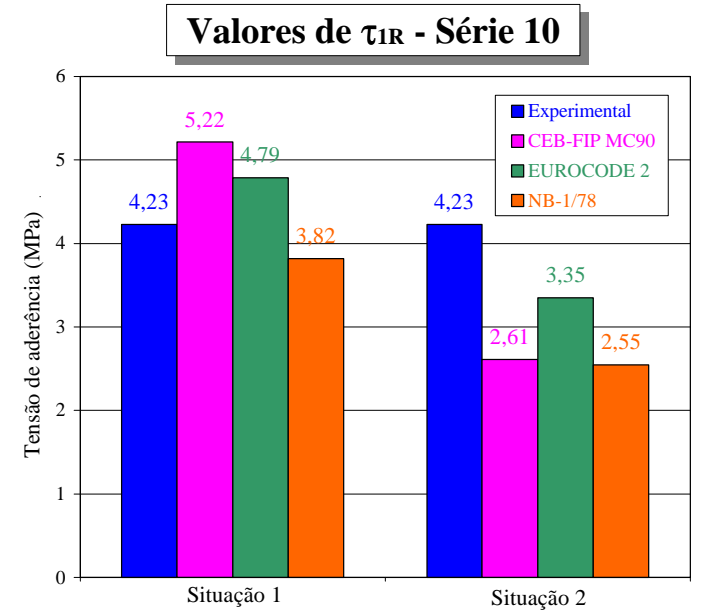

(a)

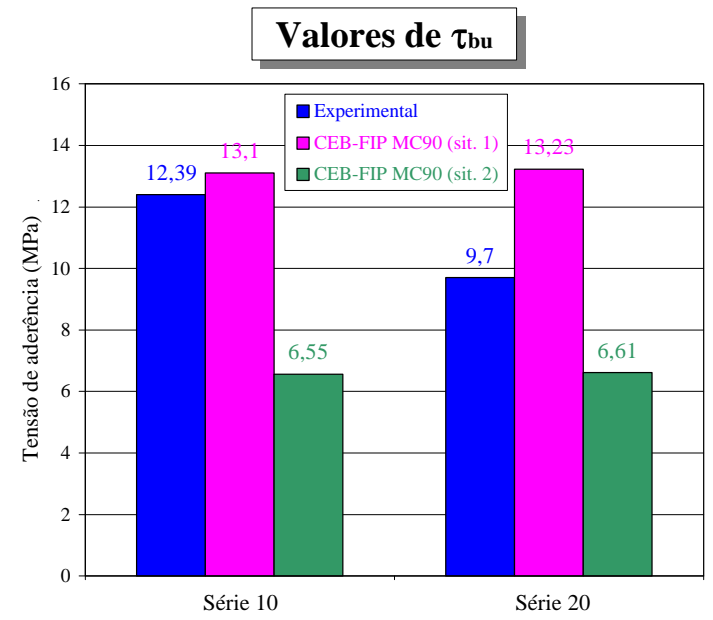

(c)

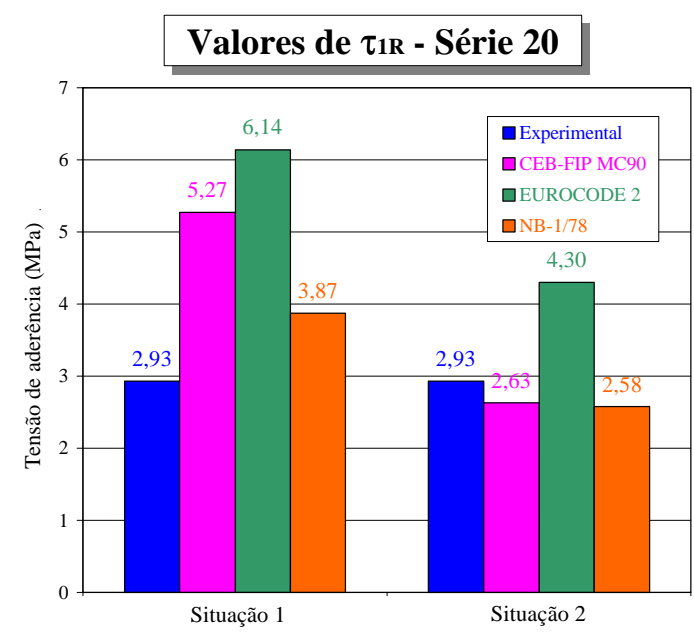

(b)

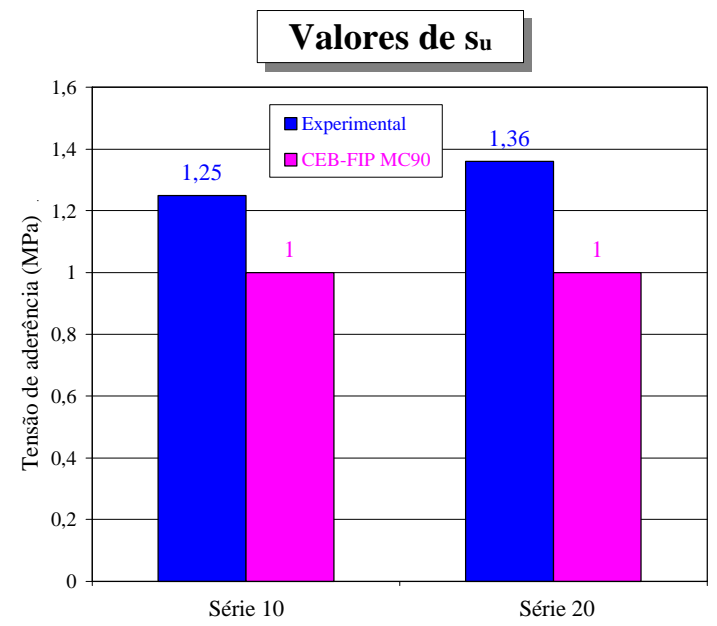

(d)

FIGURA 6.9 - Comparação dos valores de $\tau_{\mathbf{R}}$, $\tau_{\mathbf{b u}}$ e $\mathbf{s}_{\mathbf{u}}$ experimentais com os propostos pelas normas 
Da tabela 6.3 e da figura 6.9, podem ser observados os seguintes fatos:

- Em relação à resistência de aderência convencional $\left(\tau_{1 \mathbf{R}}\right)$ :

Na série 10, a NB-1/78 se mostrou a favor da segurança, nas situações 1 e 2 . Já o CEB-FIP MC90 e o EUROCODE 2 ficaram contra a segurança na situação 1 e a favor da segurança na situação 2.

Já para a série 20, apenas o CEB-FIP MC90 e a NB-1/78 se apresentaram a favor da segurança na situação 2 .

- Em relação à resistência de aderência efetiva $\left(\tau_{\mathbf{b u}}\right)$ :

O CEB-FIP MC90, na série 10, apresentou uma tensão última de aderência bastante próxima do valor experimental na situação 1, com uma diferença de 5,73\% contra a segurança. Já na situação 2, o CEB-FIP MC90 se mostrou bastante conservador em relação ao resultado experimental, com uma diferença de 43,17\%.

Na série 20, as diferenças entre o CEB-FIP MC90 nas situações 1 e 2 e os valores experimentais foram bem parecidas, sendo um resultado a favor da segurança e outro contra.

- Em relação ao deslizamento último $\left(\mathbf{s}_{\mathbf{u}}\right)$ :

Como já foi comprovado em resultados experimentais anteriores, o deslizamento último é maior que $1 \mathrm{~mm}$, proposto pelo CEB-FIP MC90. Entretanto, como a ordem de grandeza desse deslocamento relativo é muito pequena, não se pode afirmar que o ensaio teve um comportamento mais dúctil que o do CEB-FIP MC90.

Do comportamento global na figura 6.10, pode-se observar, na série 10 , que a curva ascendente média experimental está bem próxima da proposta do CEB-FIP MC90 na situação 1; entretanto, o trecho pós-ruptura da aderência das duas curvas estão bastante distantes, devido à presença de um patamar de escoamento, inclinação da segunda parte e tensão residual maiores na curva do CEB-FIP MC90. O diagrama experimental ficou bastante acima ao do CEB-FIP MC90 na situação 2. Na série 20 ilustrada na figura 6.11, a curva experimental está praticamente eqüidistante dos diagramas do CEB-FIP MC90 nas situações 1 e 2.

Deve-se considerar, portanto, a situação de aderência mais desfavorável equivalente à situação 2 , condição suficiente para se garantir a ancoragem com uma boa margem de segurança. 


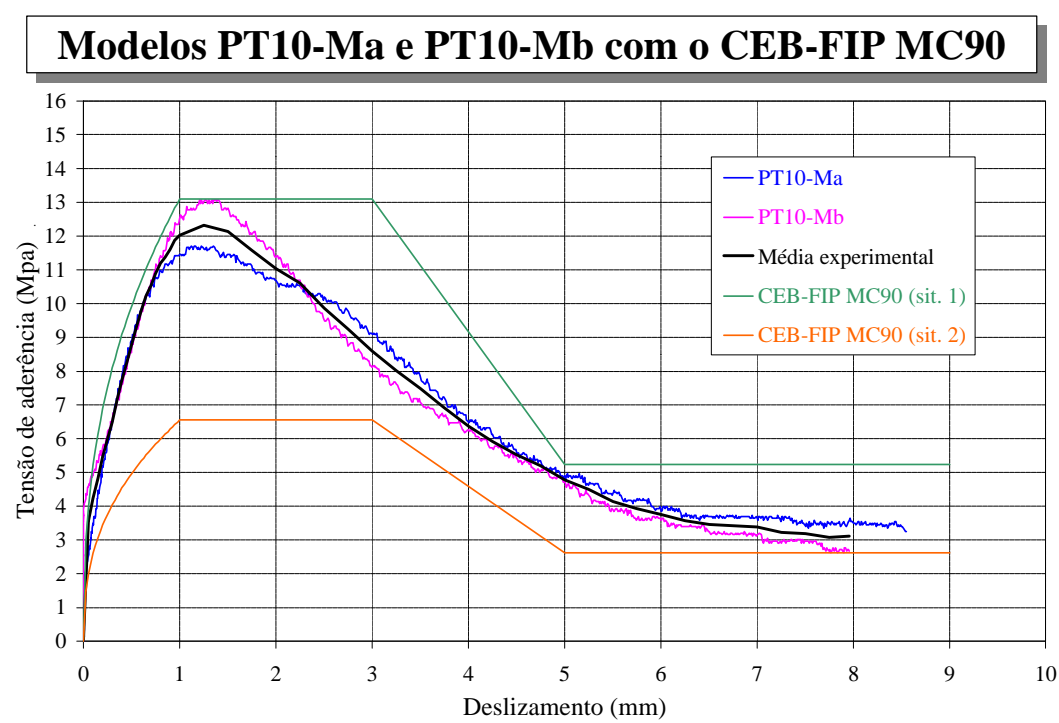

FIGURA 6.10 - Comparação da série 10 com o CEB-FIP MC90

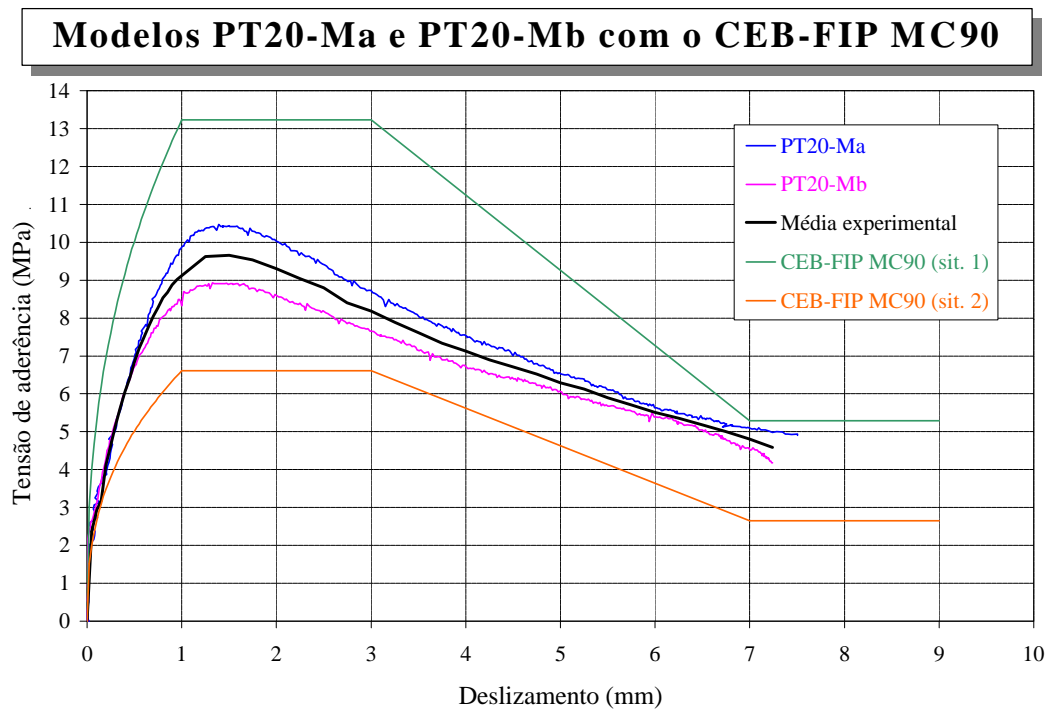

FIGURA 6.11 - Comparação da série 20 com o CEB-FIP MC90

\subsection{COMPORTAMENTO DA ADERÊNCIA SOB CARREGAMENTO REPETIDO}

\subsubsection{MODELOS PILOTO}

Na figura 6.12, é ilustrado o comportamento da aderência repetida do modelo PT10-Rpil. Observa-se que os deslizamentos aumentaram mais rapidamente nos 
primeiros ciclos e tenderam para a estabilização em um valor final. Após os 50 ciclos com nível máximo da força igual a $12 \mathrm{kN}$ (60\% da força última do modelo PT10Mref) e nível mínimo igual a uma pré-carregamento de $0,5 \mathrm{kN}$, o modelo PT10-Rpil foi levado à ruptura monotonicamente.

A figura 6.13 mostra o comportamento de ruptura monotônica do modelo PT10-Rpil juntamente com o seu modelo de referência PT10-Mref. Percebe-se a degradação da ligação ocasionada pelos ciclos de carregamento; entretanto, como esse modelo serviu apenas de piloto para a aplicação do carregamento repetido, a verificação da redução ou não dessa resistência foram verificadas nos próximos ensaios, que continham mais modelos.

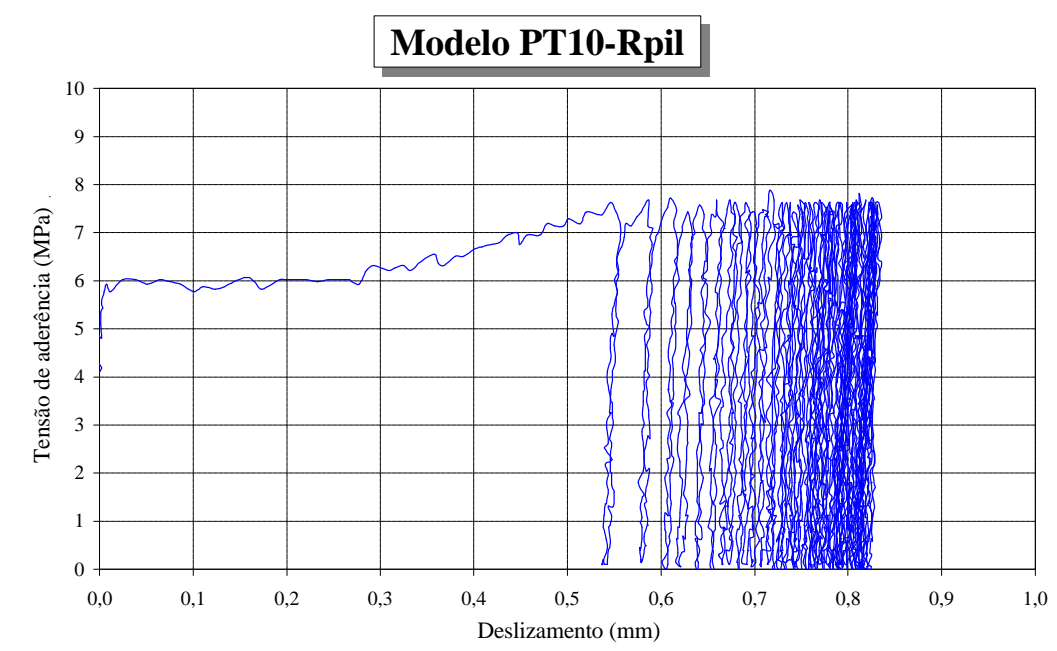

FIGURA 6.12 - Curva repetida tensão de aderência-deslizamento do modelo PT10-Rpil

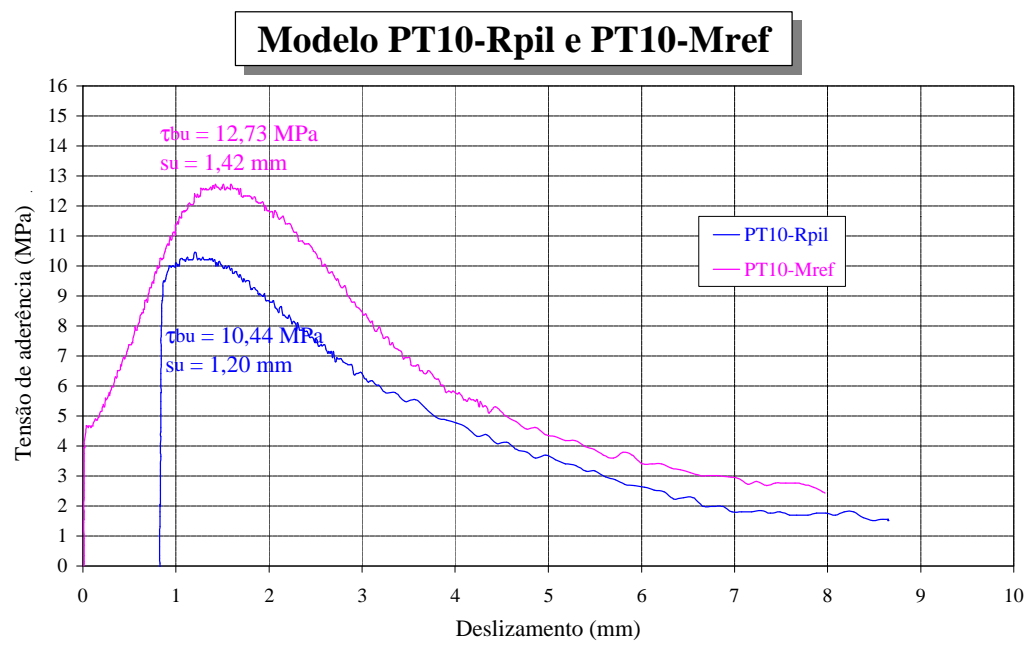

FIGURA 6.13 - Curva monotônica tensão de aderência-deslizamento do modelo PT10-Rpil e PT10-Mref 


\subsubsection{SÉRIES 10 E 20}

O comportamento da aderência repetida dos modelos das séries 10 e 20 é apresentado nas figuras 6.14 a 6.21 .

Alguns aspectos característicos foram observados durante a aplicação da ação repetida.

Uma diferença crucial entre a aderência monotônica e repetida é que a adesão $\left(\tau_{1 \mathbf{R}}\right)$ é perdida logo no primeiro ciclo. Esse fato é comprovado nas figura 6.14(a) a 6.21(a), onde a tensão máxima no meio ciclo inicial é superior à resistência de aderência equivalente ao deslizamento de $0,1 \mathrm{~mm}$. Isso só ocorre devido aos valores relativamente altos das tensões repetidas que geralmente atuam nas estruturas. Para solicitações muito baixas, portanto, o concreto permanece perfeitamente ligado à barra.

A fadiga da aderência pode ser dividida em três fases: a velocidade de deslizamento cresce mais rapidamente nos primeiros ciclos; depois, torna-se constante, com a tendência de estabilização do deslizamento em um valor final; após ser atingido o deslizamento monotônico último, com alguns ciclos adicionais, a velocidade torna-se crescente novamente, induzindo à ruptura por arrancamento da barra. Essa última fase, não pôde ser observada nos modelos, devido ao tempo de ensaio relativamente grande. As duas primeiras fases podem ser vistas nas figuras 6.14(a) a 6.21(a) e 6.14(b) a 6.21(b), onde nessas últimas, ilustra-se a redução da tangente à curva nos primeiros ciclos e depois tornando-se constante. A primeira fase nos ensaios termina em aproximadamente 10 ciclos, onde a velocidade do deslizamento é muito grande; a partir daí, o acréscimo diminui, tornando-se constante depois. Após o deslizamento monotônico último $\mathbf{s}_{\mathbf{u}}$, como foi observado nos modelos PT20-3R e PT20-4R, a velocidade ainda permanece constante com o decorrer de um número de ciclos razoável sem atingir a ruptura. Portanto, $\mathbf{s}_{\mathbf{u}}$ pode ser considerado como um critério seguro para análise da ruptura por fadiga da aderência.

Uma vez atingido um determinado deslizamento, este torna-se quase que totalmente residual; ou seja, a rigidez ou a inclinação da tangente à curva é muito elevada. Pelas figuras 6.14(d) a 6.21(d) que indicam a oscilação do deslizamento a cada meio ciclo, fica comprovada a recuperação insignificante do deslizamento na 
tensão máxima quando do descarregamento. No momento do recarregamento, o comportamento da aderência assume a mesma rigidez do descarregamento anterior até um nível de tensão um pouco abaixo da máxima $\left(\tau_{\mathbf{d}-\mathbf{r}}\right)$; a partir daí, a rigidez começa a diminuir com o aumento do deslizamento até o topo. Quando a estrutura é descarregada, a rigidez cresce até a tensão $\left(\tau_{\mathbf{d}-\mathbf{r}}\right)$, depois tornando-se constante e igual ao do ciclo anterior. 


\section{Modelo PT10-1Ra}

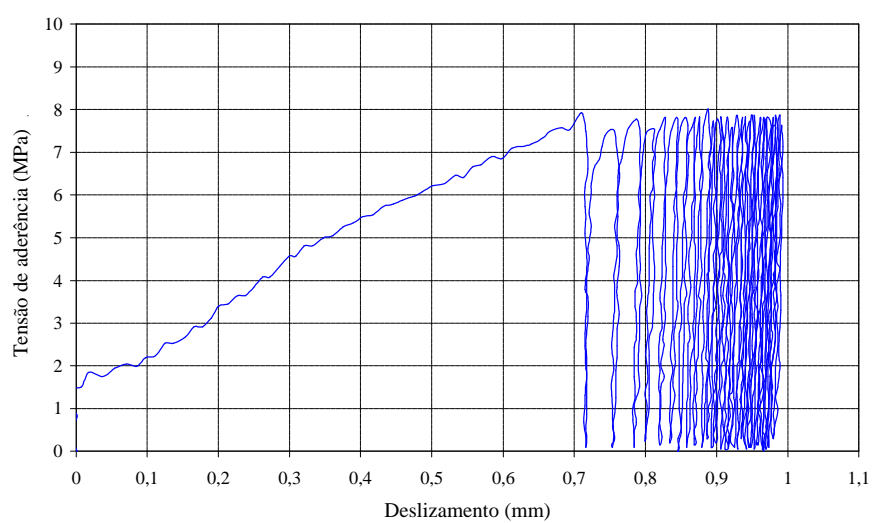

(a)

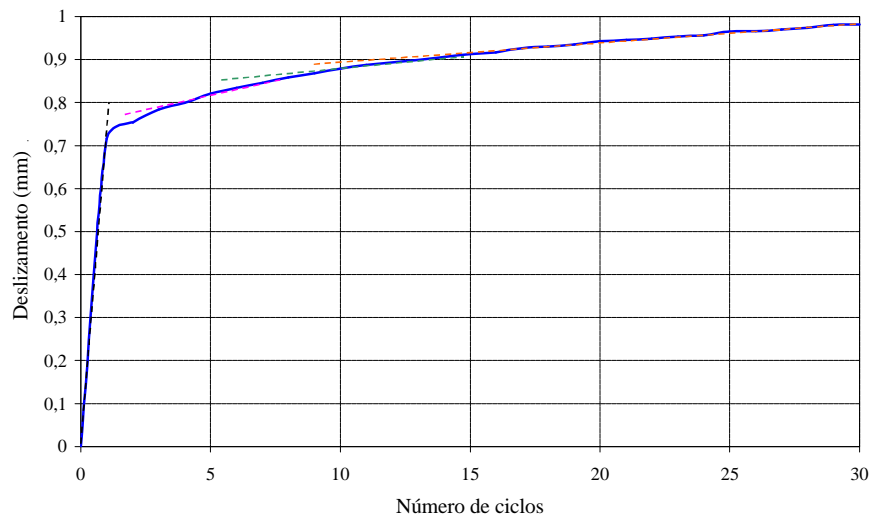

(b)

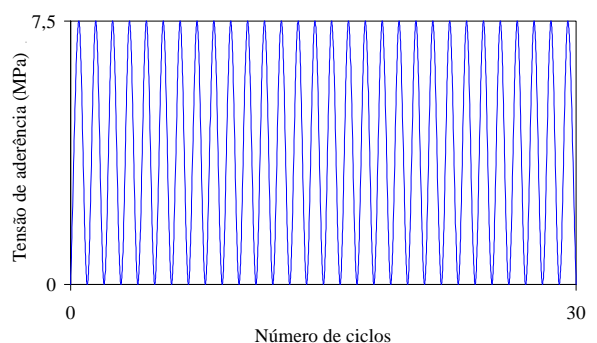

(c)

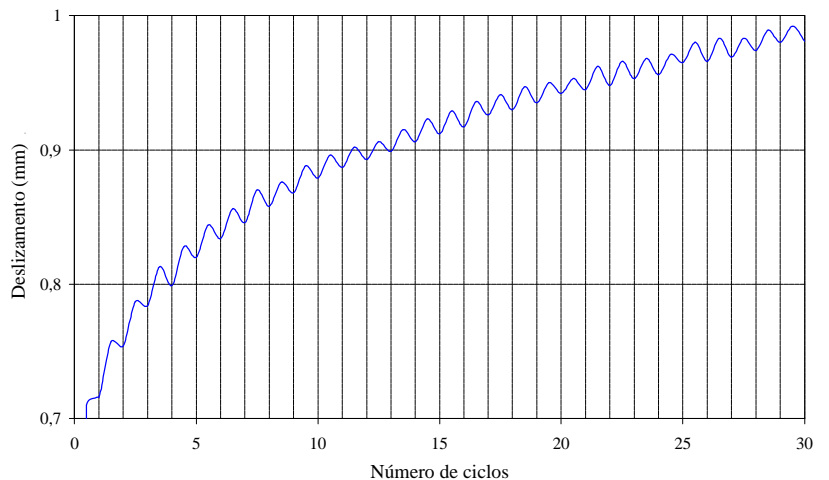

(d)

$F_{\text {máx }} \cong 12 \mathrm{kN} ; \tau_{\text {máx }} \cong 8 \mathrm{MPa} ; \mathrm{n}=30$;

$\tau_{1 \mathrm{R}}=2,20 \mathrm{MPa} ; \mathrm{s}_{\mathrm{r}}=0,98 \mathrm{~mm}$

FIGURA 6.14 - Modelo PT10-1Ra: (a) Curva tensão de aderência-deslizamento;

(b) Curva deslizamento-número de ciclos; (c) História do carregamento;

(d) Oscilação do deslizamento a cada meio ciclo; 


\section{Modelo PT10-1Rb}

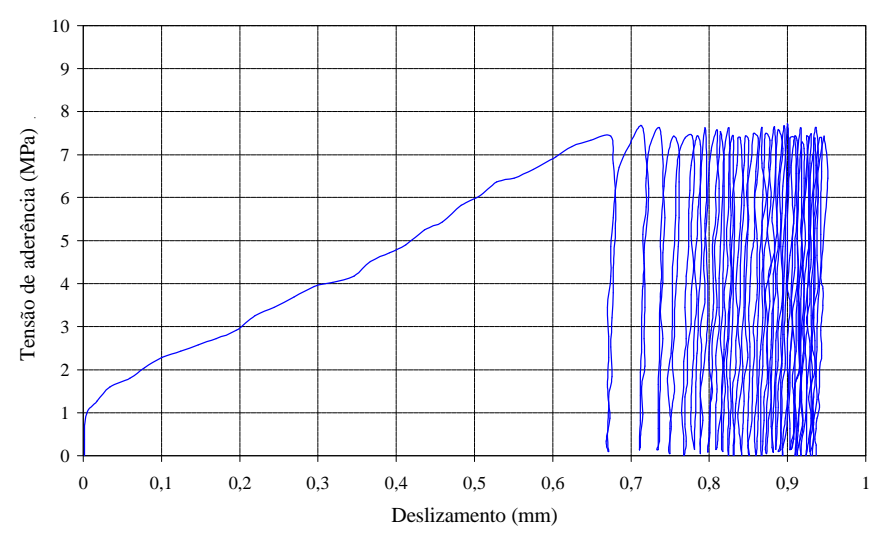

(a)

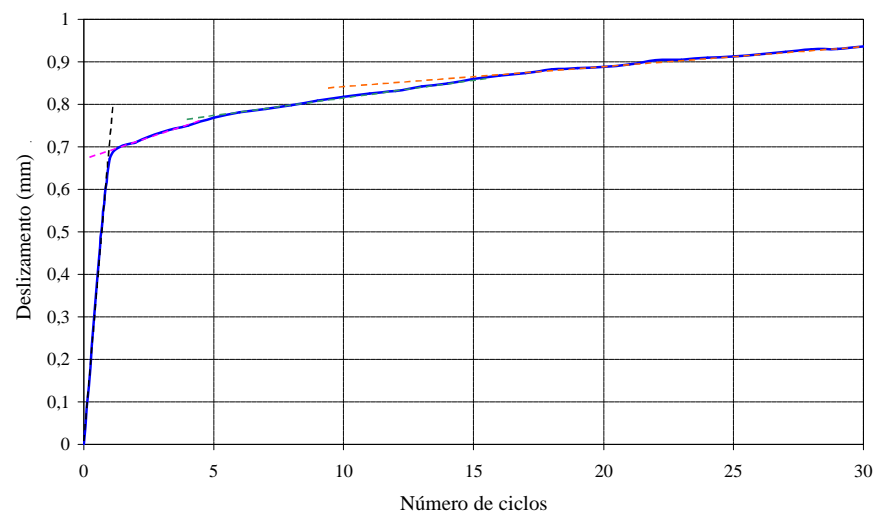

(b)

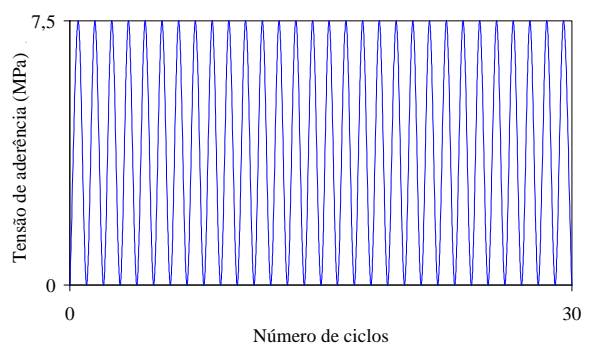

(c)

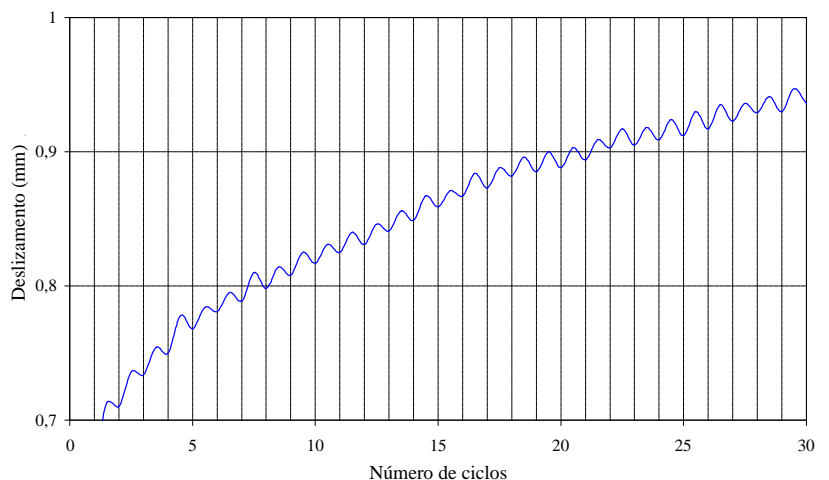

(d)

$\mathrm{F}_{\text {máx }} \cong 12 \mathrm{kN} ; \tau_{\text {máx }} \cong 8 \mathrm{MPa} ; \mathrm{n}=30$;

$\tau_{1 \mathrm{R}}=2,28 \mathrm{MPa} ; \mathrm{s}_{\mathrm{r}}=0,94 \mathrm{~mm}$

FIGURA 6.15 - Modelo PT10-1Rb: (a) Curva tensão de aderência-deslizamento;

(b) Curva deslizamento-número de ciclos; (c) História do carregamento;

(d) Oscilação do deslizamento a cada meio ciclo; 


\section{Modelo PT10-2Ra}

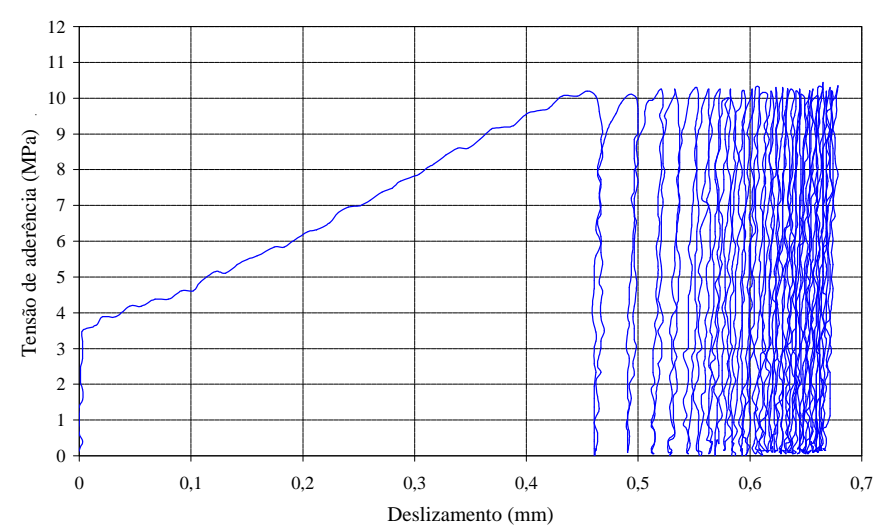

(a)

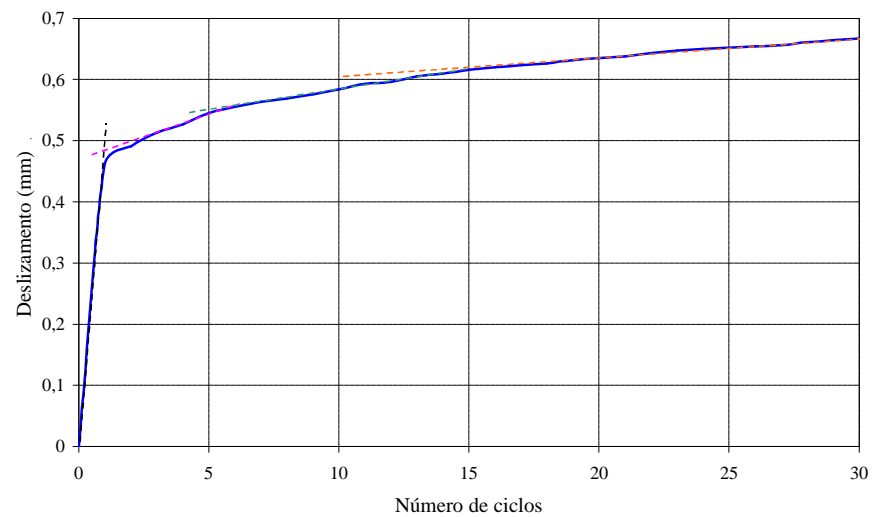

(b)

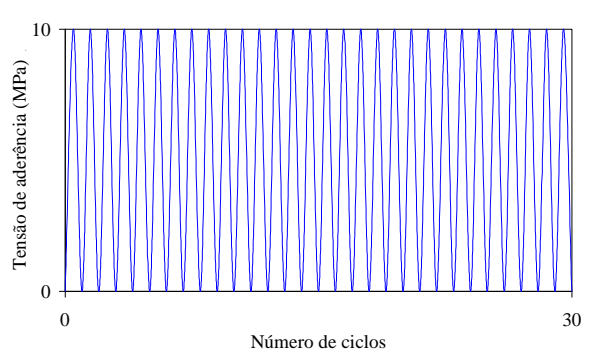

(c)

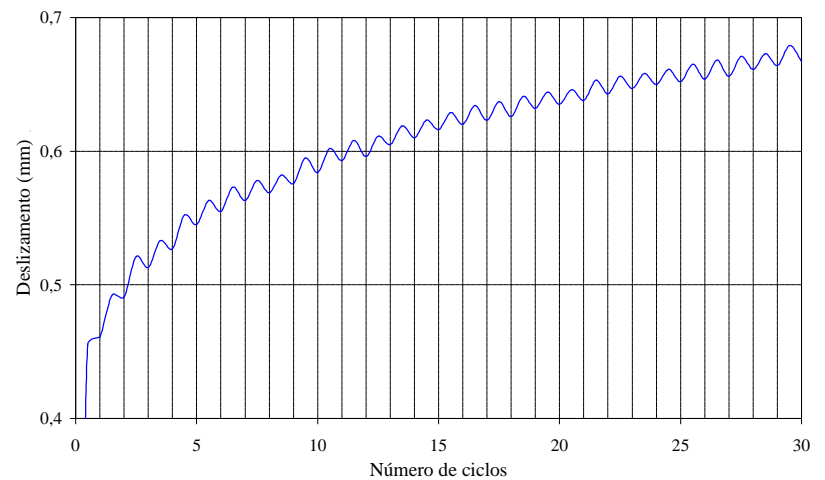

(d)

$$
\begin{gathered}
\mathrm{F}_{\text {máx }} \cong 16 \mathrm{kN} ; \tau_{\text {máx }} \cong 10 \mathrm{MPa} ; \mathrm{n}=30 \\
\tau_{1 \mathrm{R}}=4,61 \mathrm{MPa} ; \mathrm{s}_{\mathrm{r}}=0,67 \mathrm{~mm}
\end{gathered}
$$

FIGURA 6.16 - Modelo PT10-2Ra: (a) Curva tensão de aderência-deslizamento;

(b) Curva deslizamento-número de ciclos; (c) História do carregamento;

(d) Oscilação do deslizamento a cada meio ciclo; 


\section{Modelo PT10-2Rb}

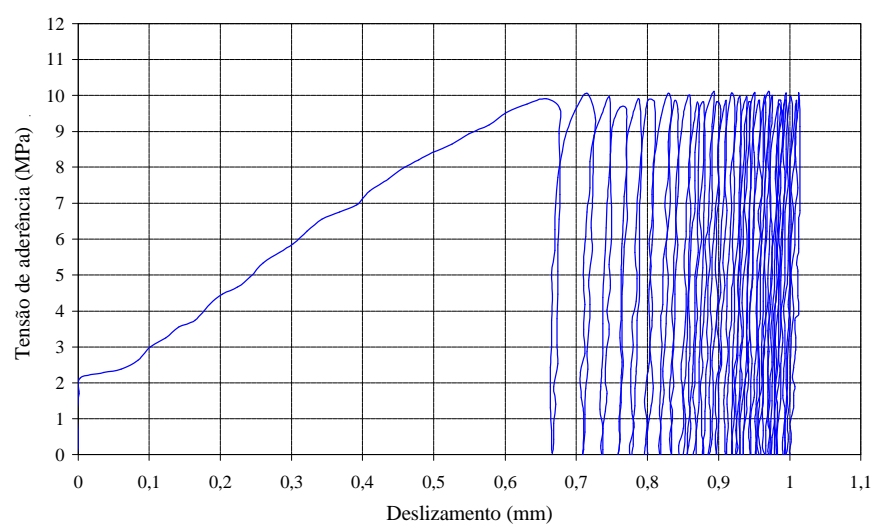

(a)

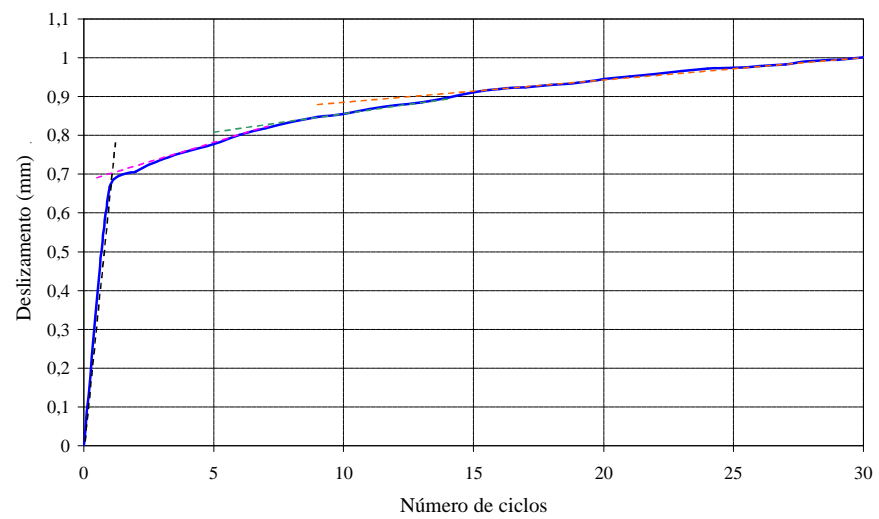

(b)

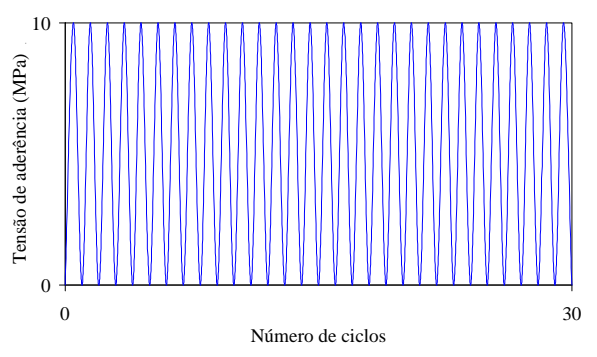

(c)

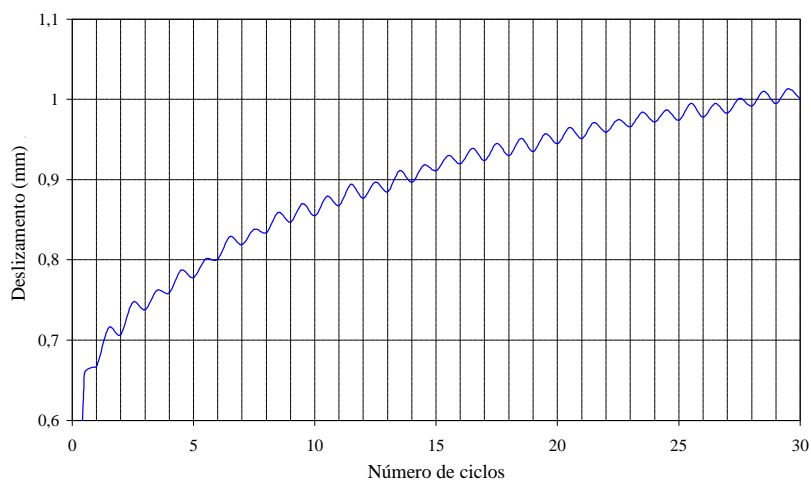

(d)

$$
\begin{gathered}
\mathrm{F}_{\text {máx }} \cong 16 \mathrm{kN} ; \tau_{\text {máx }} \cong 10 \mathrm{MPa} ; \mathrm{n}=30 \\
\tau_{1 \mathrm{R}}=3,01 \mathrm{MPa} ; \mathrm{s}_{\mathrm{r}}=1,00 \mathrm{~mm}
\end{gathered}
$$

FIGURA 6.17 - Modelo PT10-2Rb: (a) Curva tensão de aderência-deslizamento;

(b) Curva deslizamento-número de ciclos; (c) História do carregamento;

(d) Oscilação do deslizamento a cada meio ciclo; 


\section{Modelo PT20-1R}

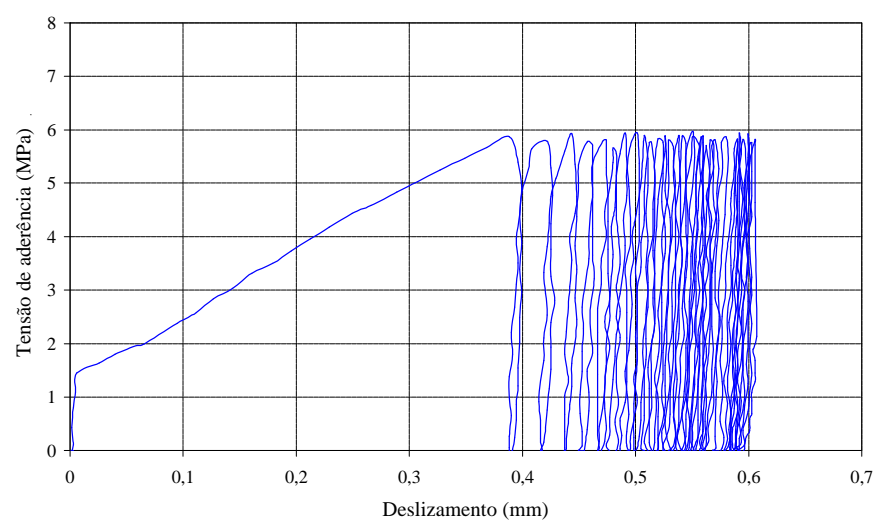

(a)

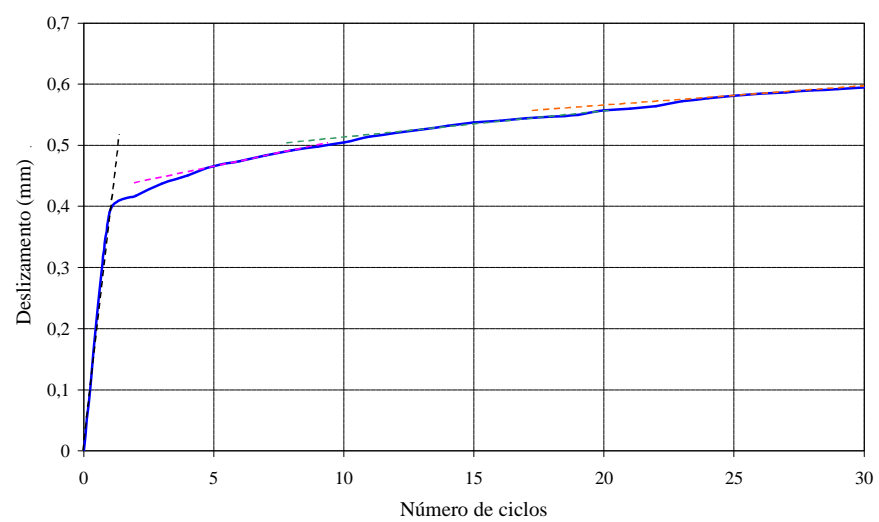

(b)

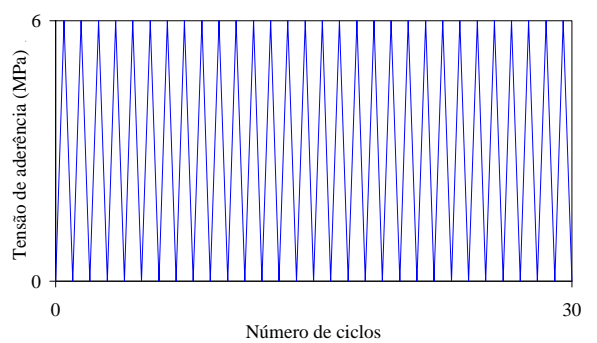

(c)

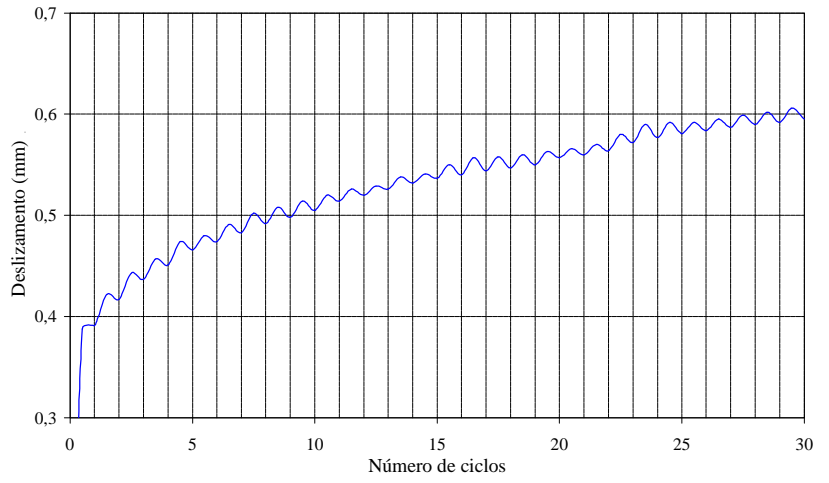

(d)

$\mathrm{F}_{\text {máx }} \cong 37 \mathrm{kN} ; \tau_{\text {máx }} \cong 6 \mathrm{MPa} ; \mathrm{n}=30$; $\tau_{1 \mathrm{R}}=2,44 \mathrm{MPa} ; \mathrm{s}_{\mathrm{r}}=0,60 \mathrm{~mm}$

FIGURA 6.18 - Modelo PT20-1R: (a) Curva tensão de aderência-deslizamento;

(b) Curva deslizamento-número de ciclos; (c) História do carregamento;

(d) Oscilação do deslizamento a cada meio ciclo; 


\section{Modelo PT20-2R}

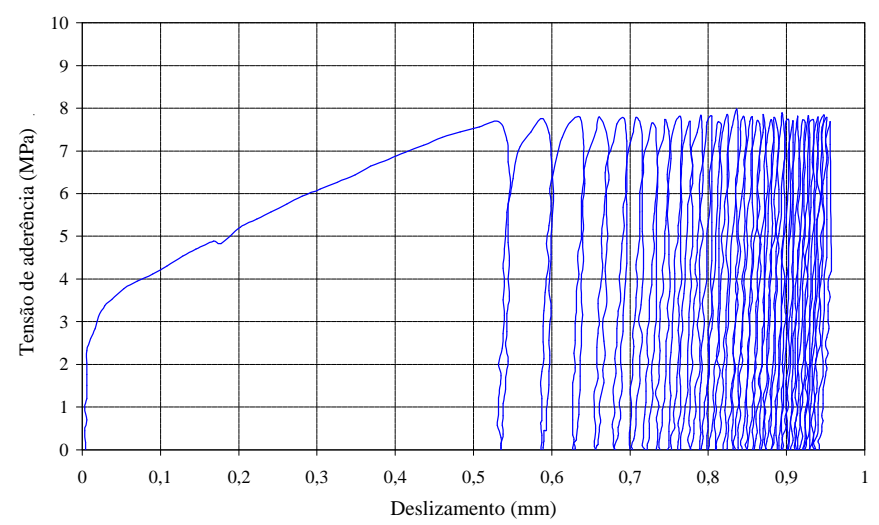

(a)

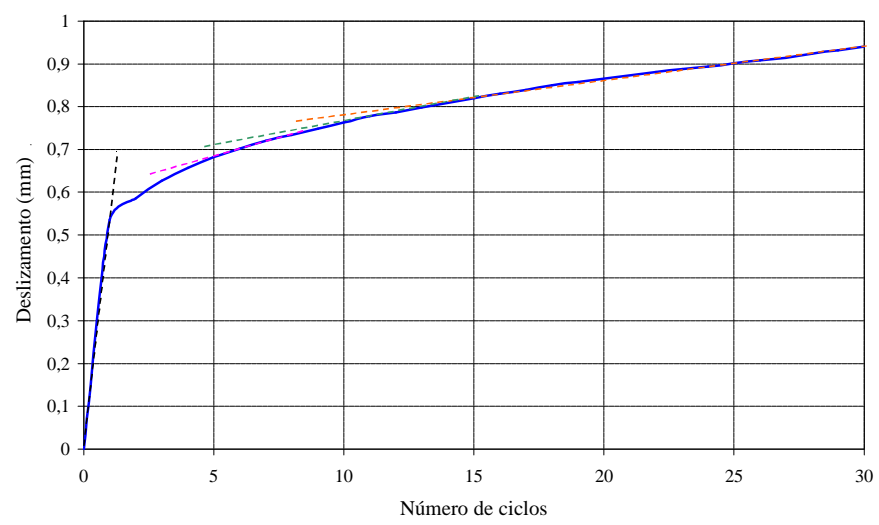

(b)

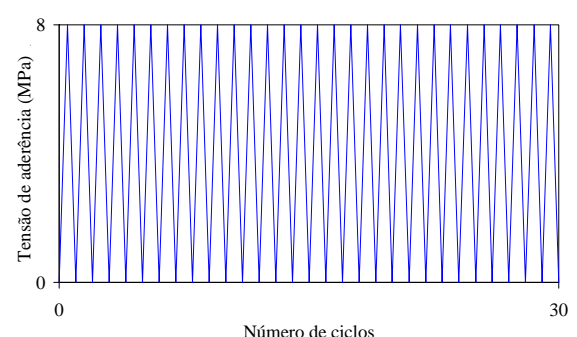

(c)

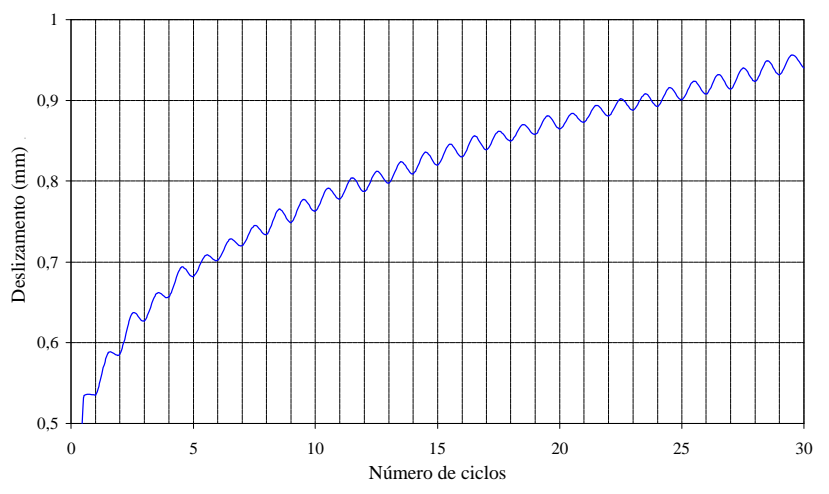

(d)

$F_{\text {máx }} \cong 49 \mathrm{kN} ; \tau_{\text {máx }} \cong 8 \mathrm{MPa} ; \mathrm{n}=30$;

$\tau_{1 \mathrm{R}}=4,22 \mathrm{MPa} ; \mathrm{s}_{\mathrm{r}}=0,94 \mathrm{~mm}$

FIGURA 6.19 - Modelo PT20-2R: (a) Curva tensão de aderência-deslizamento;

(b) Curva deslizamento-número de ciclos; (c) História do carregamento;

(d) Oscilação do deslizamento a cada meio ciclo; 


\section{Modelo PT20-3R}

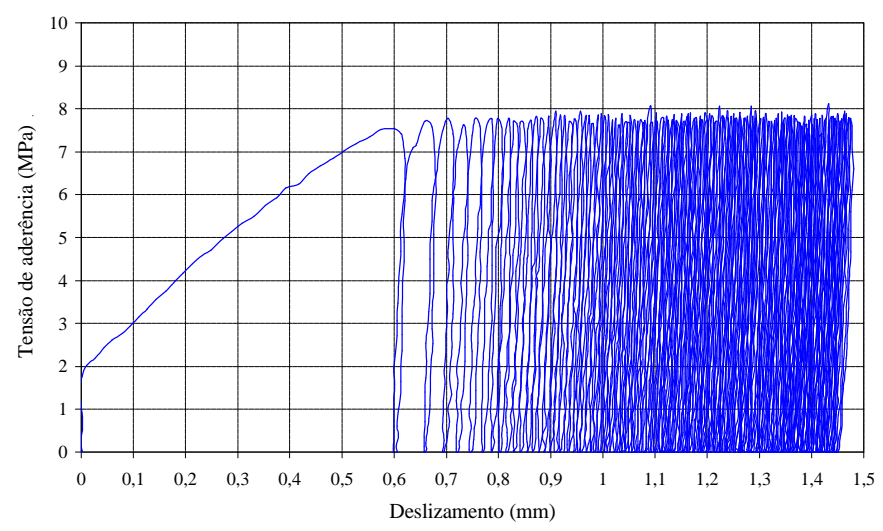

(a)

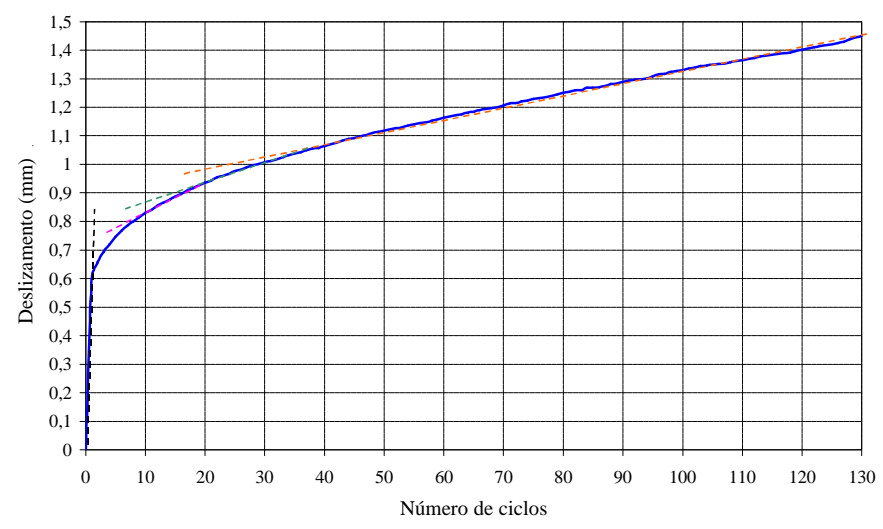

(b)

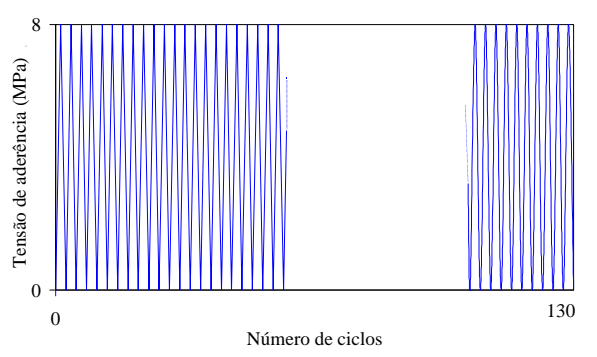

(c)

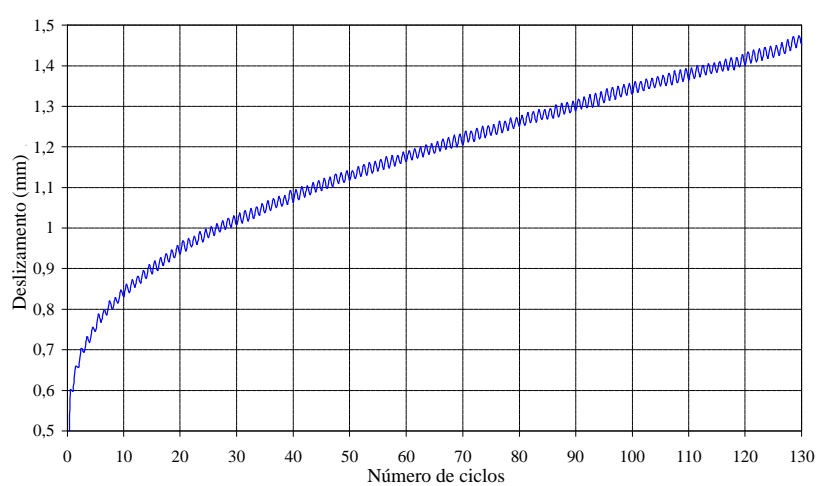

(d)

$$
\begin{gathered}
\mathrm{F}_{\text {máx }} \cong 49 \mathrm{kN} ; \tau_{\text {máx }} \cong 8 \mathrm{MPa} ; \mathrm{n}=130 \\
\tau_{1 \mathrm{R}}=3,01 \mathrm{MPa} ; \mathrm{s}_{\mathrm{r}}=1,45 \mathrm{~mm}
\end{gathered}
$$

FIGURA 6.20 - Modelo PT20-3R: (a) Curva tensão de aderência-deslizamento;

(b) Curva deslizamento-número de ciclos; (c) História do carregamento;

(d) Oscilação do deslizamento a cada meio ciclo; 


\section{Modelo PT20-4R}

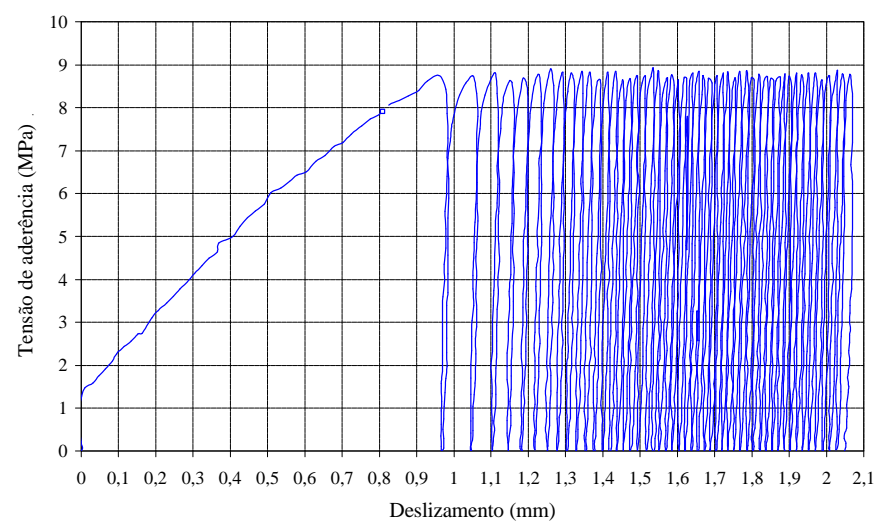

(a)

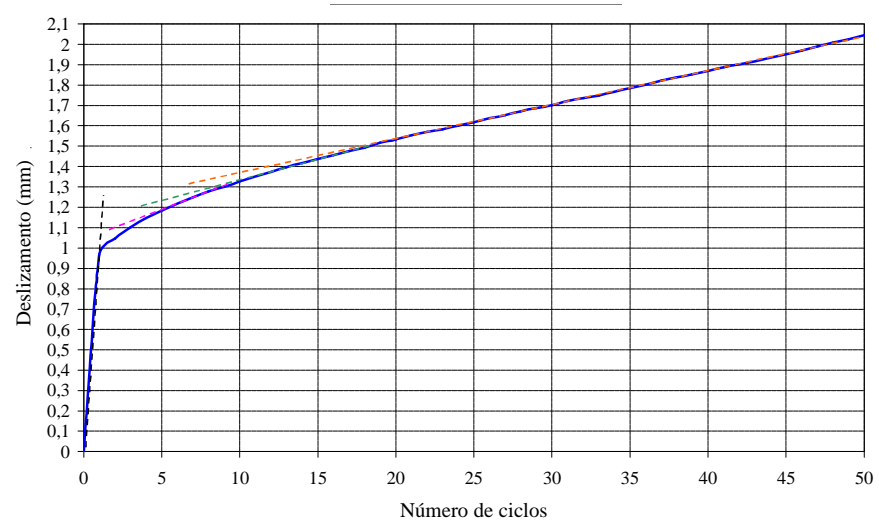

(b)

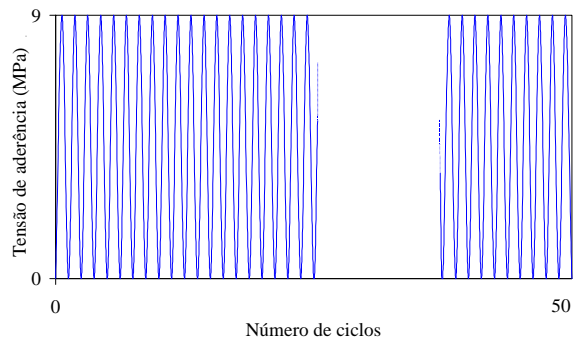

(c)

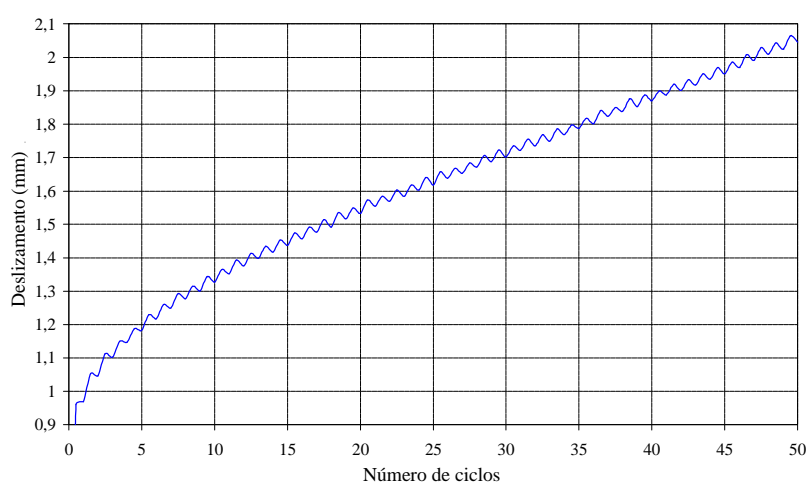

(d)

$\mathbf{F}_{\text {máx }} \cong 55 \mathrm{kN} ; \tau_{\text {máx }} \cong 9 \mathrm{MPa} ; \mathbf{n}=\mathbf{5 0}$;

$\tau_{1 \mathrm{R}}=2,31 \mathrm{MPa} ; \mathrm{s}_{\mathrm{r}}=2,05 \mathrm{~mm}$

FIGURA 6.21 - Modelo PT20-4R: (a) Curva tensão de aderência-deslizamento;

(b) Curva deslizamento-número de ciclos; (c) História do carregamento;

(d) Oscilação do deslizamento a cada meio ciclo; 
Os modelos tiveram o comportamento global da aderência semelhante, com algumas diferenças nos valores de $\tau_{1 \mathbf{R}}$ e $\mathbf{s}_{\mathbf{r}}$.

Apesar da resistência média $\tau_{1 \mathrm{R}}$ de PT10-1Ra e PT-101Rb ter sido menor que a correspondente a PT10-2Ra e PT10-2Rb, da ordem de aproximadamente 0,6 vezes, essa não foi a razão para a redução de $\tau_{\text {bu }}$ dos primeiros em relação aos segundos, pois para os modelos da série 20 , a variação de $\tau_{1 \mathbf{R}}$ foi grande também e os valores de $\tau_{\mathrm{bu}}$ foram muito próximos. Quando as barras de PT10-1Ra e PT-101Rb foram arrancadas, pôde-se observar pequenos buracos no concreto entre as nervuras ocasionadas por falha da vibração, justificando, portanto, essa redução na aderência. Esses modelos, portanto, não foram incluídos para as análises dos resultados.

O carregamento monotônico dos modelos repetidos apresentou a mesma rigidez dos ciclos anteriores até um pouco antes da ruptura da ligação, apresentando uma pequena redução até a tensão última, com exceção de PT20-1R que, quando atingiu a curva monotônica, acompanhou-a até o final do ensaio. Esse modelo, portanto, teve uma diminuição maior na rigidez antes de alcançar a tensão última.

Fazendo-se uma comparação da ruptura monotônica de PT10-2Ra e PT102Rb com a média de PT10-Ma e PT10-Mb, nota-se que a aplicação de poucos ciclos da ordem de $80 \%$ da resistência última monotônica não interfere no comportamento último da ligação, pois os valores da tensão última de aderência dos modelos repetidos foram bem próximos aos referentes aos modelos monotônicos, como indica a figura 6.22 .

Para verificar se existia ou não a redução na resistência da ligação, na série 20, variou-se, então, a força em 3 níveis e o número de ciclos em 3. Comparando-se o modelo PT20-1R com o PT20-2R, percebe-se que o crescimento do nível de carregamento de $60 \%$ para $80 \%$ aumentou o deslizamento residual $\mathbf{s}_{\mathbf{r}}$ em $56 \%$. A diferença de 100 ciclos entre PT20-3R e PT20-2R, aumentou $\mathbf{S}_{\mathbf{r}}$ em 54\%. Com apenas 16 ciclos, o modelo PT20-4R atingiu o deslizamento residual do modelo PT20-3R, ou seja, com um acréscimo de $10 \%$ em relação à força de $80 \%$, diminuiu a quantidade de ciclos de 130 para 16. Entretanto, independente da diferença entre o número de ciclos, a amplitude do carregamento e deslizamento residual atingido, a tensão última de aderência não foi reduzida, como indica a figura 6.23. Isso foi válido mesmo para a força máxima bem próxima da monotônica última (PT20-2R, 
PT20-3R e PT20-4R) e para deslizamentos residuais superiores ao deslizamento último monotônico $\mathbf{s}_{\mathbf{u}}$ (PT20-3R e PT20-4R).

Após a ruptura da ligação, o ramo descendente da curva de todos os modelos ficou bem próximo do correspondente à curva monotônica de referência.

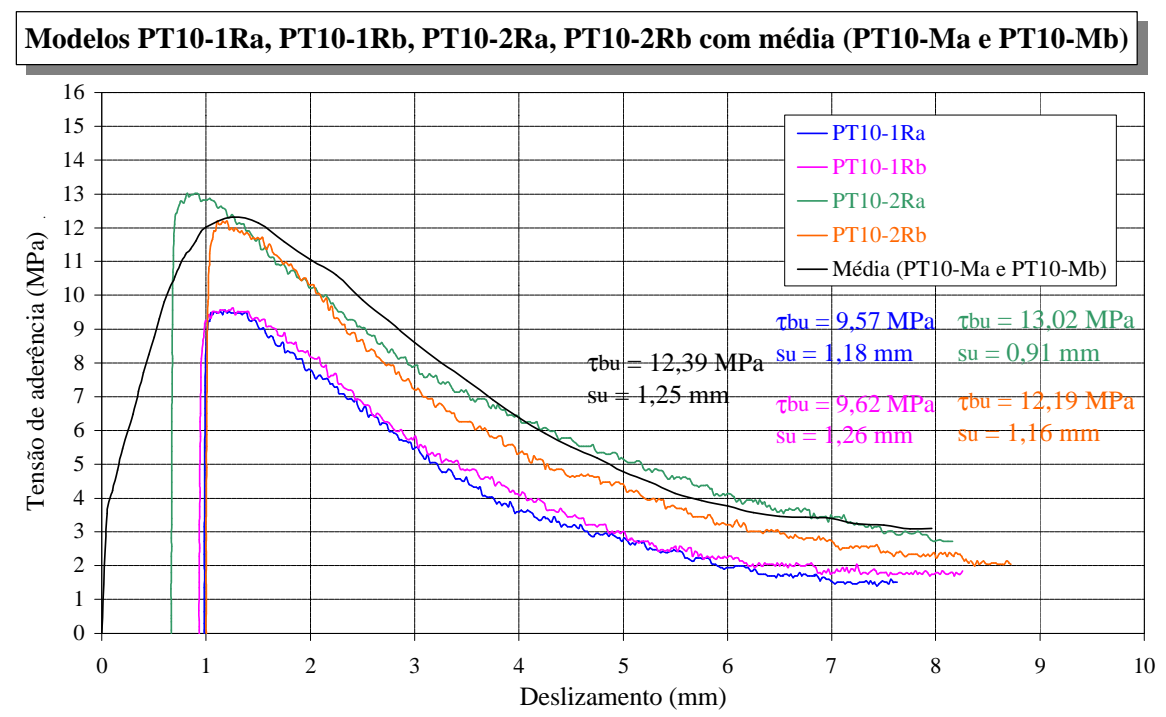

FIGURA 6.22 - Curva monotônica tensão de aderência-deslizamento dos modelos repetidos com a média dos modelos monotônicos de referência da Série 10

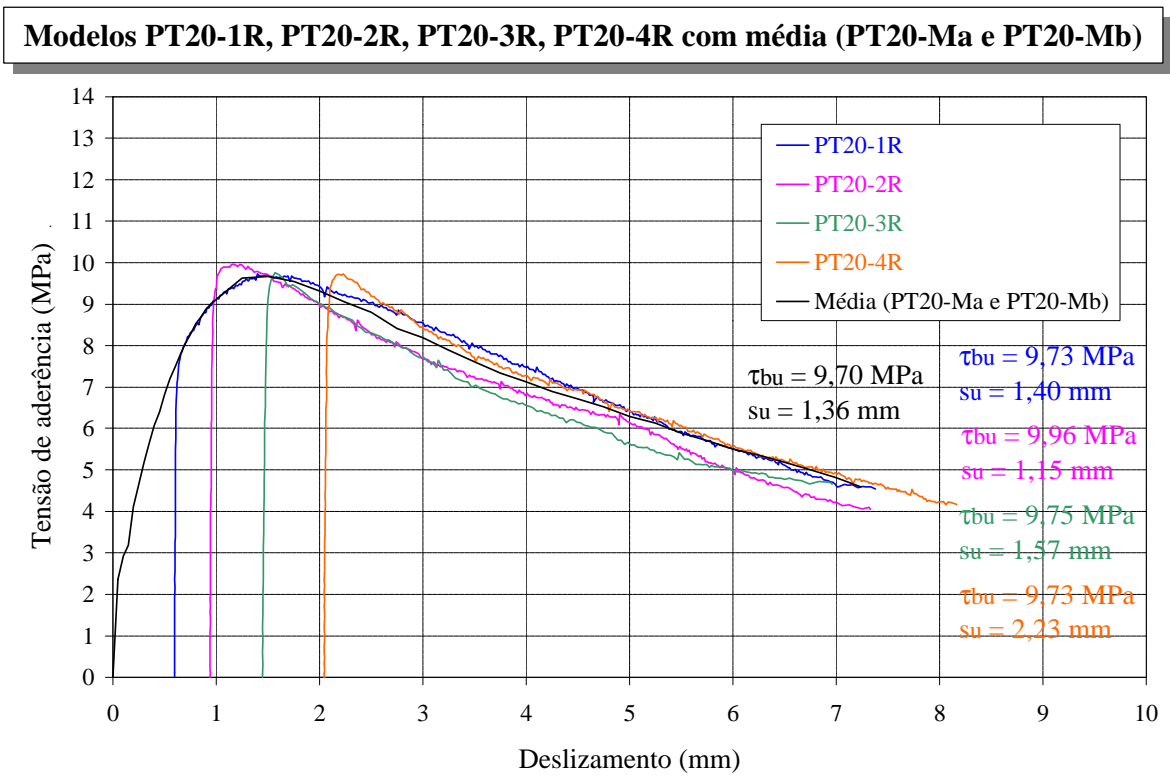

FIGURA 6.23 - Curva monotônica tensão de aderência-deslizamento dos modelos repetidos com a média dos modelos monotônicos de referência da Série 20 
$\mathrm{Na}$ figura 6.24, pode ser visualizado o resumo do comportamento da aderência dos ensaios, e com a continuação a partir de $\mathbf{S}_{\mathbf{r}}$ observada em resultados da literatura.

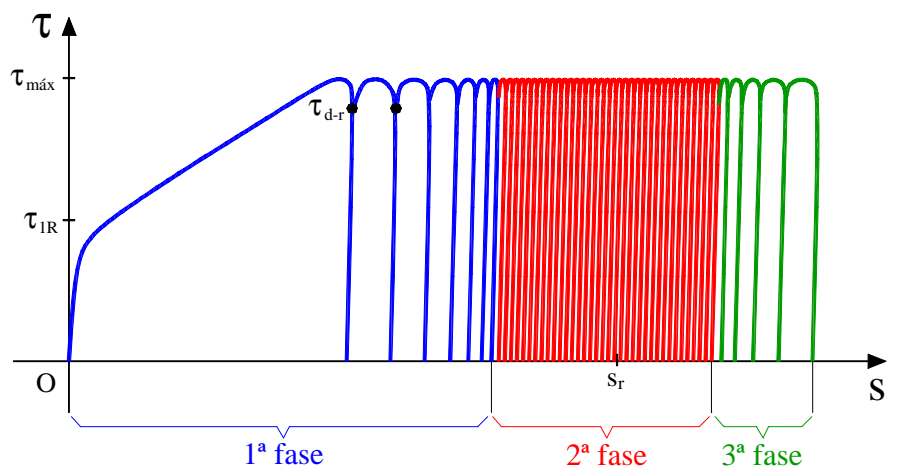

(a)

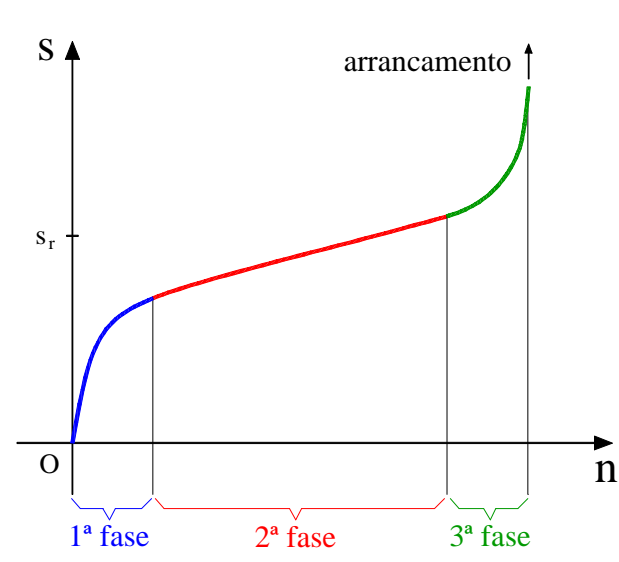

(b)

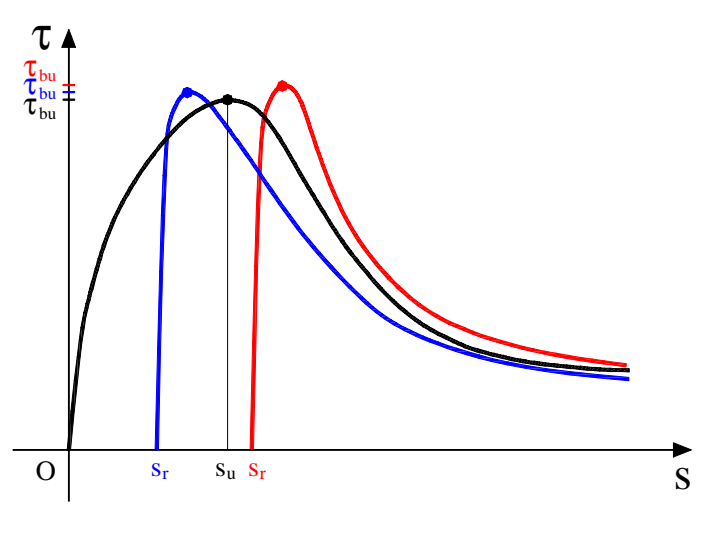

(c)

FIGURA 6.24 - Digrama representativo do comportamento da aderência dos ensaios repetidos

\subsection{ANÁLISE NUMÉRICA DA ADERÊNCIA MONOTÔNICA}

\subsubsection{MODELO PT10-2D}

Apesar das aproximações um pouco grosseiras desse modelo, alguns aspectos do comportamento do contato entre os dois materiais pôde ser observado. Em relação aos ensaios, foram feitas poucas comparações, como a deformada e a evolução dos deslizamentos com a força, devido à falta de outras medidas experimentais. 
Todos os resultados mostrados a seguir são em relação ao último incremento de carregamento, já que a evolução dos deslocamentos com a força foi linear, como apresenta a figura 6.25, e plotados em isovalores. Essa relação linear implica que esses elementos de contato não consideraram a adesão entre os dois materiais.

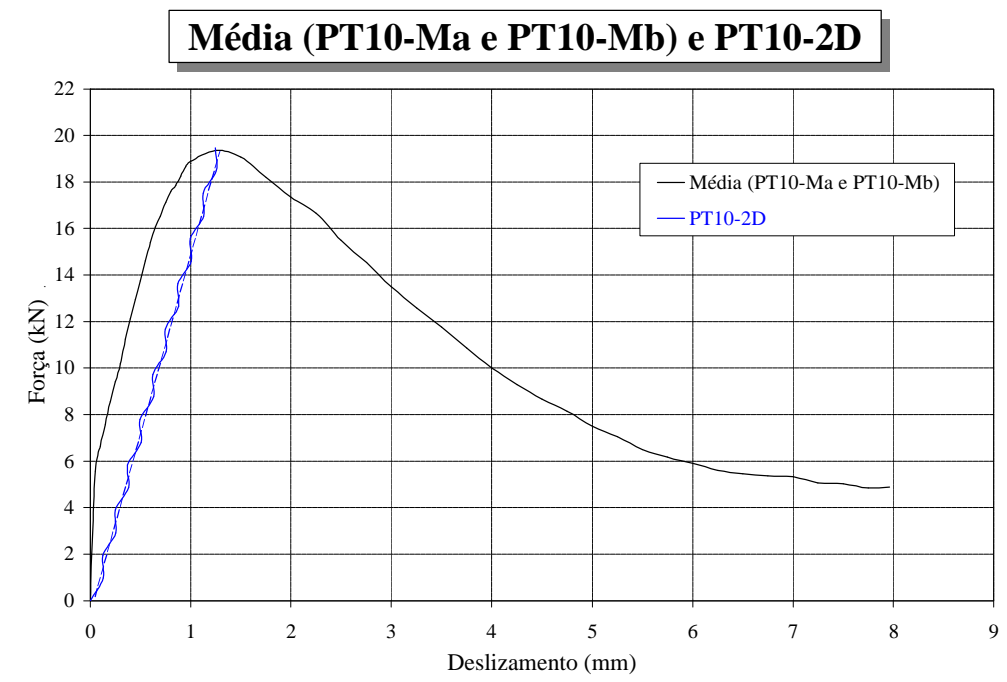

FIGURA 6.25 - Curva força-deslizamento da média (PT10-Ma e PT10Mb) e PT10-2D

A deformada da estrutura foi bastante semelhante a constatada experimentalmente, com uma pequena diferença na inclinação do concreto na região próxima à barra, como ilustra a figura 6.26 .

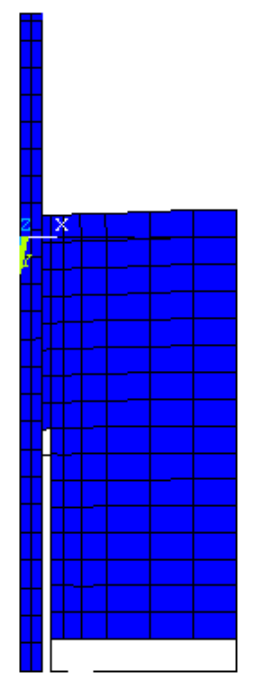

FIGURA 6.26 - Deformada - PT10-2D

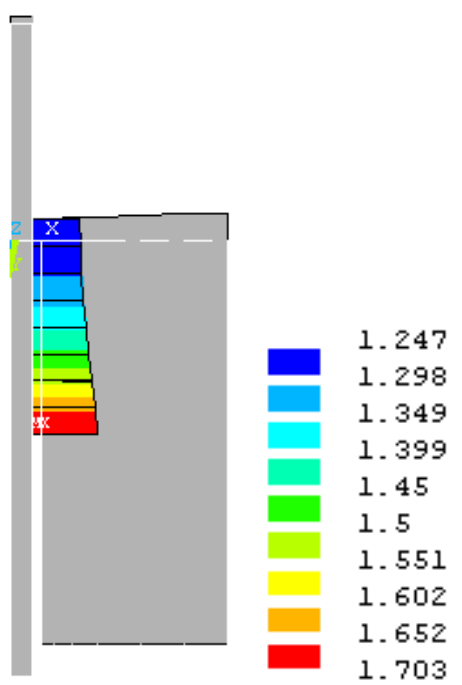

FIGURA 6.27 - Deslizamento - PT10-2D 
Pela figura 6.27, pode-se constatar que o modelo apresentou uma diferença de 0,456 mm entre o deslizamento da base e do topo da barra aderente, como espera-se teoricamente. Nos ensaios, essa diferença não pôde ser visualizada, devido os deslocamentos terem sido medidos do topo da barra em relação ao concreto.

A constante FKN de 0,335 usada para calibrar o deslizamento do modelo resultou em uma abertura e penetração de um elemento no outro praticamente desprezíveis, como ilustram as figuras 6.28 e 6.29 .

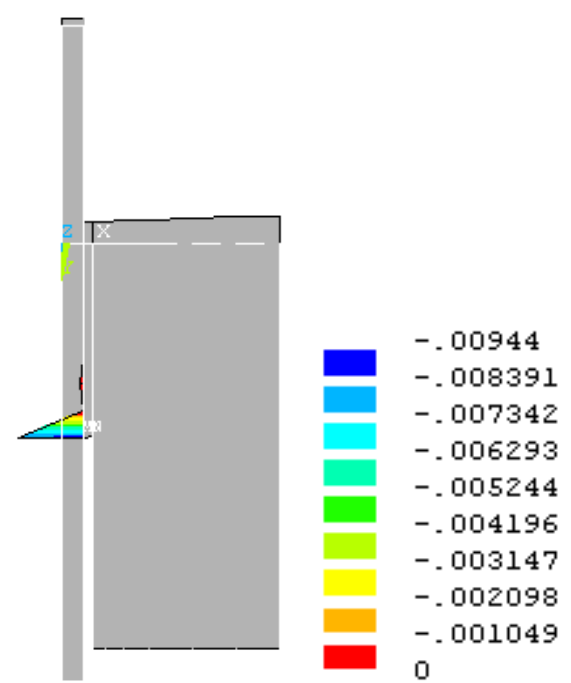

FIGURA 6.28 - Abertura - PT10-2D

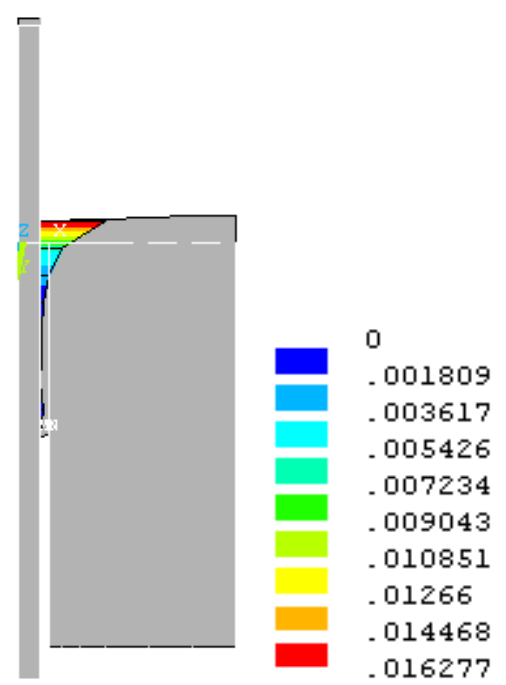

FIGURA 6.29 - Penetração - PT10-2D

A abertura e a penetração apresentaram uma relação linear com a pressão, indicada na figura 6.30, através de um mesmo coeficiente de 3,63×10 ${ }^{-5}$. Quando a pressão foi de tração no trecho aderente inferior, houve a separação do contato como indica os valores negativos da abertura. Já a pressão positiva de compressão na parte aderente superior ocasionou a penetração do contato no mesmo trecho observada pelos seus valores positivos. 


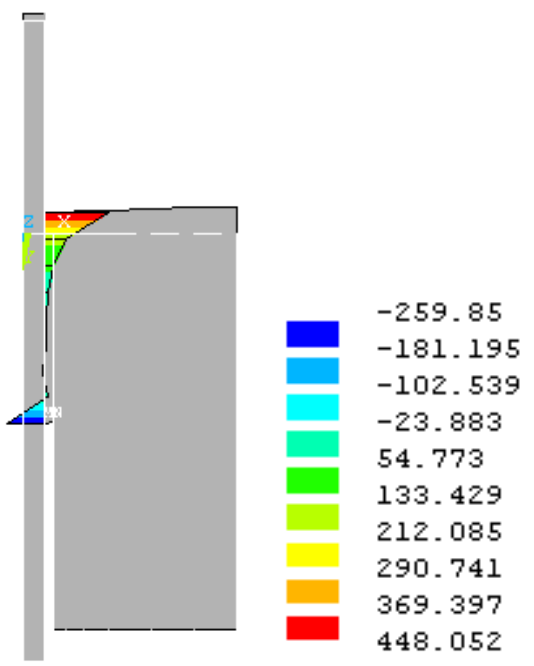

FIGURA 6.30 - Pressão - PT10-2D

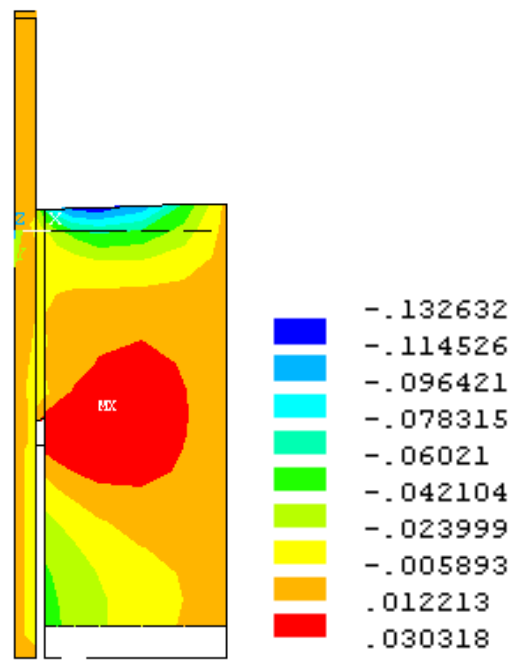

FIGURA 6.31 - Desl. em X - PT10-2D

Os deslocamentos em $\mathrm{X}$ em relação aos da direção $\mathrm{Y}$ foram muito pequenos com valores máximos absolutos na região superior e central do concreto, respectivamente, como indica a figura 6.31. Os deslocamentos maiores na parte superior do concreto ocorreram devido à tendência do corpo rotacionar e os nós da face do bloco terem sido restritos nodais em X. Entretanto, a ordem de grandeza desses deslocamentos ainda é pequena quando comparada com os deslocamentos em Y. Portanto, pode-se considerar que esse modelo apenas se deslocou no sentido Y.

Através da figura 6.32, percebe-se algumas diferenças nos deslocamentos na direção Y entre o concreto e a barra, ocasionando, portanto, o deslizamento ao longo do trecho aderente.
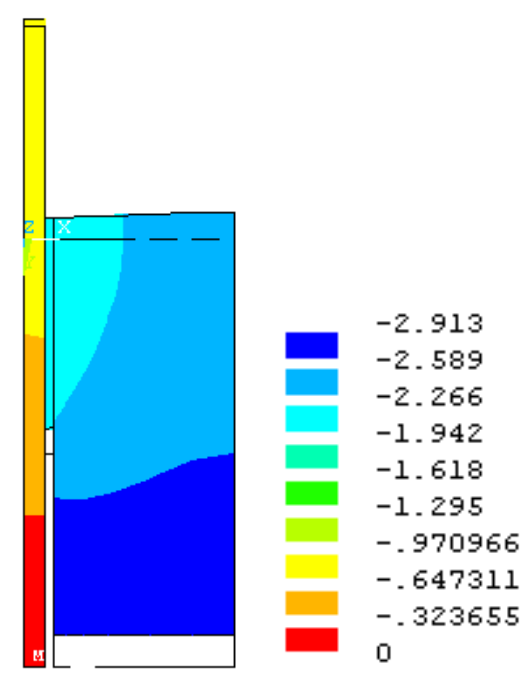

FIGURA 6.32 - Desl. em Y - PT10-2D

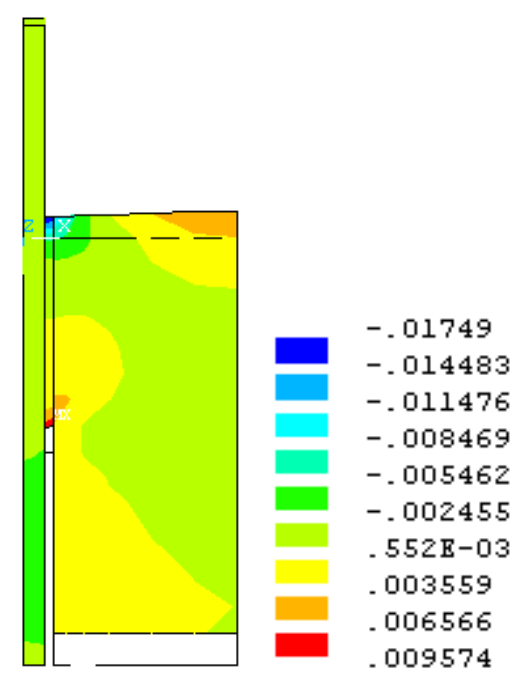

FIGURA 6.33 - Def. em X - PT10-2D 
As deformações máximas em $\mathrm{X}$ no concreto se localizaram próximo à região superior e inferior do contato e foram diminuindo gradativamente com o aumento da distância, como mostra a figura 6.33.

Na direção Y, as deformações máximas do concreto se concentraram próximo à parte inferior do contato. Pela figura 6.34, observa-se que, ao longo do bloco, essas deformações foram diminuindo com a altura.
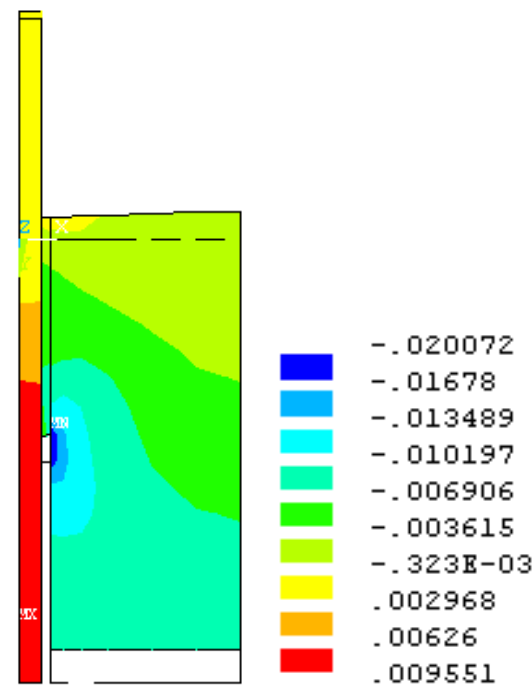

FIGURA 6.34 - Def. em Y - PT10-2D

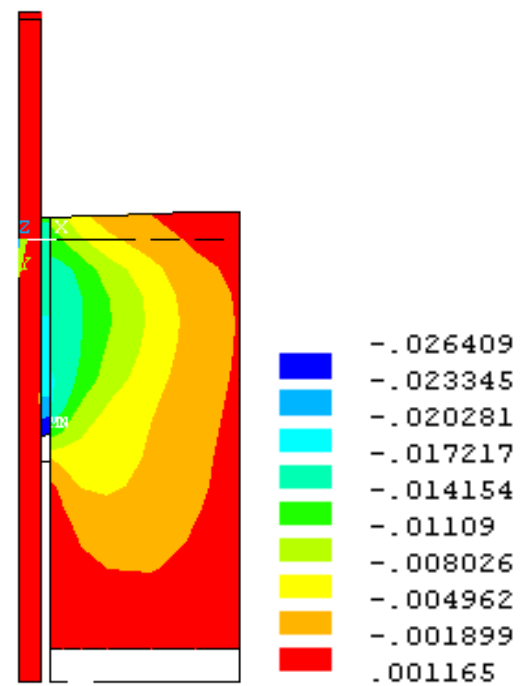

FIGURA 6.35 - Def. em XY - PT10-2D

As deformações cisalhantes XY no concreto foram superiores às relativas ao aço próximo à região do contato, ocasionando assim o deslocamento do concreto para cima. Essas deformações no concreto foram máximas no trecho aderente, diminuindo gradativamente, à medida que a distância em relação ao contato foi crescendo, como apresenta a figura 6.35 .

\subsubsection{MODELO PT10-3D}

Apesar desse modelo aparentemente fornecer resultados mais próximos da realidade que o anterior, também não foi possível realizar muitas comparações pela escassez de outras medidas experimentais. 
Similarmente ao modelo PT10-2D, esse apresentou uma relação forçadeslocamento linear, como ilustra a figura 6.36. Os elementos de contato utilizados, portanto, não consideraram a adesão e a pressão de confinamento na barra.

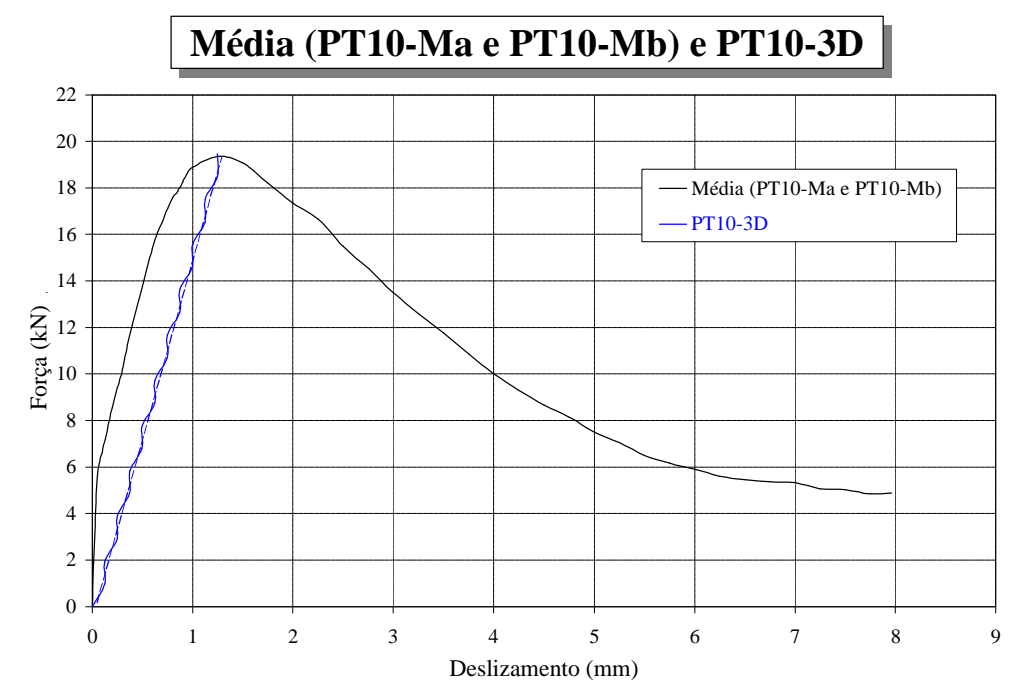

FIGURA 6.36 - Curva força-deslizamento da média (PT10-Ma e PT10Mb) e PT10-3D

Esse modelo representou melhor o ensaio, devido à consideração do seu comportamento tridimensional. Não foi necessário impor restrições radiais nos nós da face cilíndrica do concreto para evitar o giro do modelo, como indica a deformada na figura 6.37 , semelhante à do protótipo experimental.

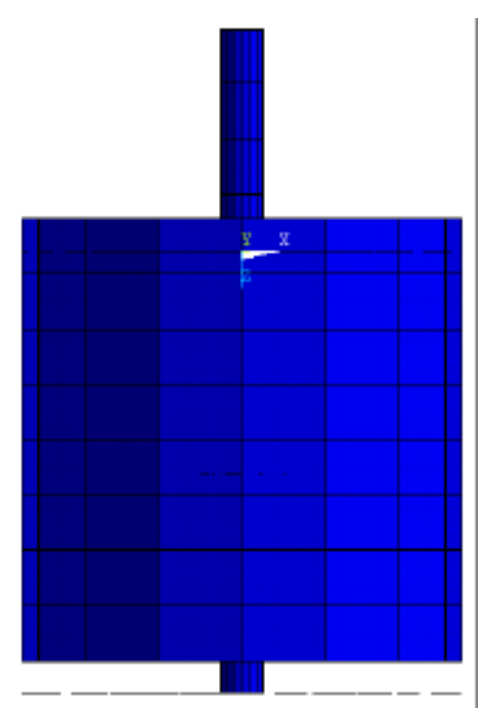

FIGURA 6.37 - Deformada - PT10-3D

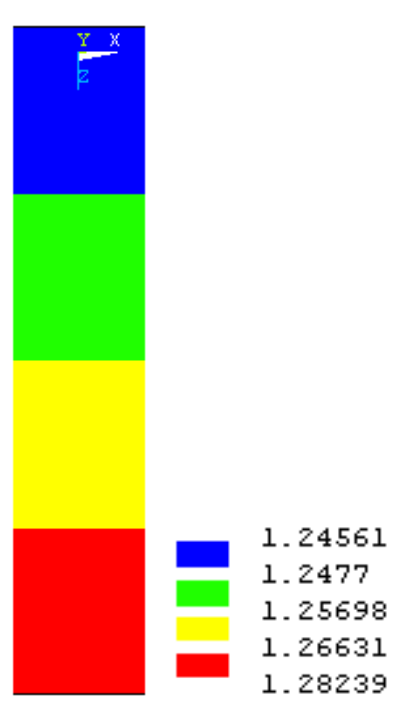

FIGURA 6.38 - Deslizamento - PT10-3D 
Os resultados apresentados a seguir são em relação ao último incremento de carregamento, já que a evolução dos deslocamentos com a força foi linear, e plotados em isovalores.

Através da figura 6.38, percebe-se que o deslizamento não foi constante ao longo do contato, com uma variação de 1,28239 na base a 1,24561 no topo. Os deslizamentos são considerados como a diferença entre os deslocamentos dos elementos CONTA173 e TARGE170, como ilustram as figuras 6.39 e 6.40. Essas variações no deslizamento não puderam ser medidas experimentalmente, entretanto.

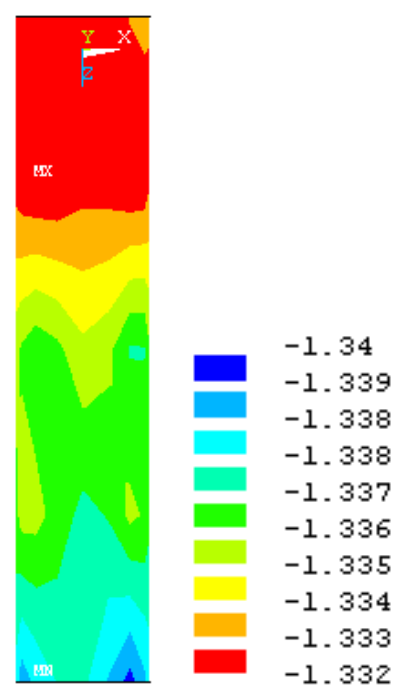

FIGURA 6.39 - Desl. em Z (CONTA173) - PT10-3D

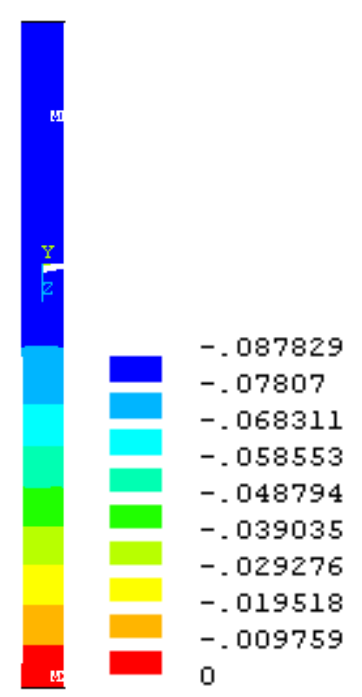

FIGURA 6.40 - Desl. em Z (TARGE170) - PT10-3D

Semelhantemente ao modelo PT10-2D, as deformações perpendiculares à direção do deslizamento, que nesse caso são X e Y, se concentraram nas regiões superior e inferior próxima ao contato, diminuindo à medida que cresce a distância em relação ao trecho aderente, como mostram as figuras 6.41 e 6.42 . 


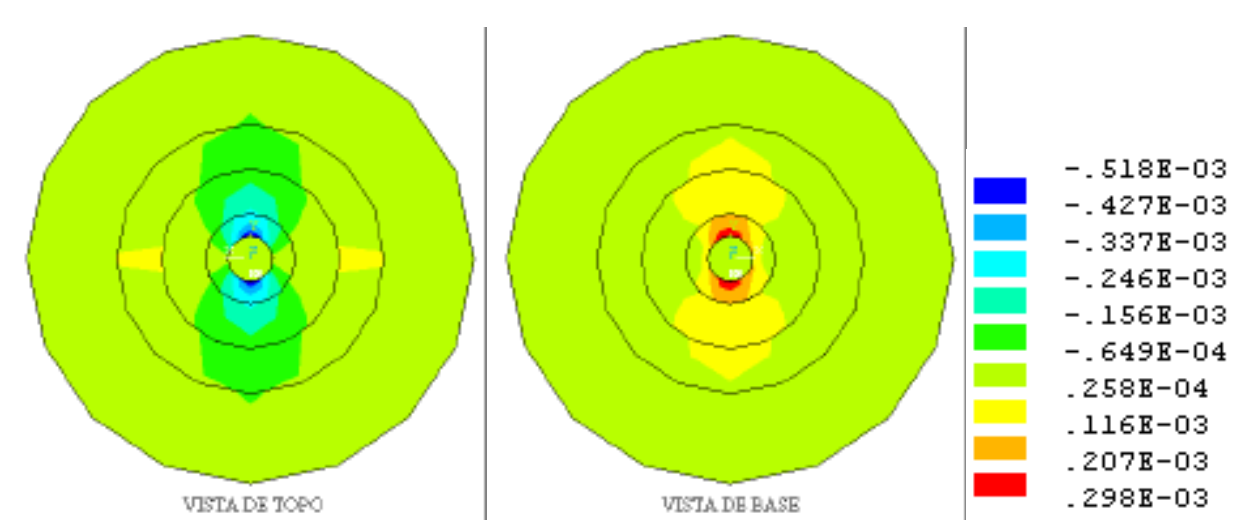

FIGURA 6.41 - Deformação em X - PT10-3D
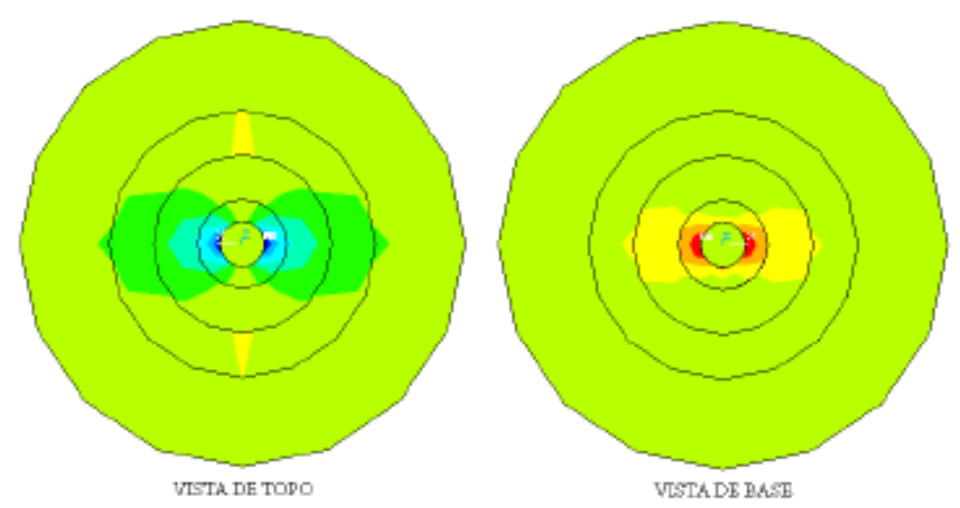

$-.521 \mathrm{E}-03$

$-.430 \mathrm{E}-03$

$-.338 \mathrm{E}-03$

$-.247 \mathrm{E}-03$

$-.156 \mathrm{E}-03$

$-.644 \mathrm{E}-04$

$.270 \mathrm{E}-04$

$118 \mathrm{E}-03$

$.210 \mathrm{E}-03$

FIGURA 6.42 - Deformação em Y - PT10-3D

Para a calibragem do deslizamento desse modelo, utilizou-se uma constante FKN de 0,0244, muito menor que a do PT10-2D, a qual ocasionou uma abertura e penetração de um elemento no outro praticamente desprezíveis, indicadas nas figuras 6.43 e 6.44 , respectivamente.

Diferentemente de PT10-2D, a abertura e a penetração desse modelo não apresentaram uma relação linear com a pressão, indicada na figura 6.45. Entretanto, a pressão negativa de tração em aproximadamente nos $2 / 3$ inferior do trecho aderente ocasionou a abertura entre os elementos de contato, como apresenta a figura 6.43. Já a pressão positiva de compressão em aproximadamente 1/3 superior da parte aderente ocasionou a penetração do contato no mesmo trecho ilustrada na figura 6.44 . 


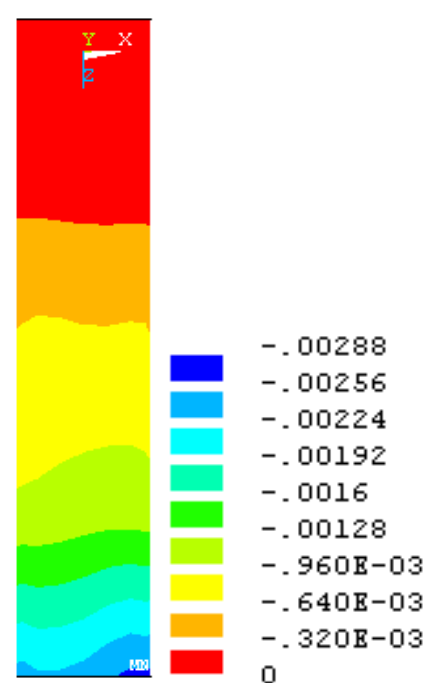

FIGURA 6.43 - Abertura - PT10-3D

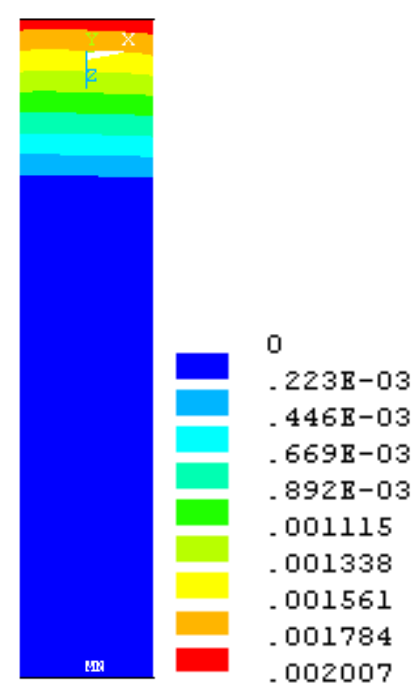

FIGURA 6.44 - Penetração - PT10-3D

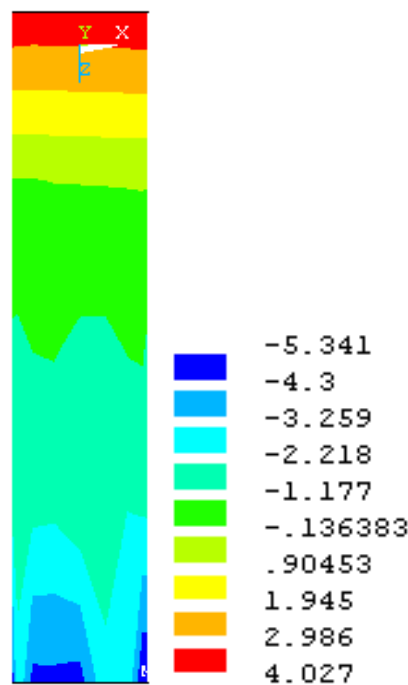

FIGURA 6.45 - Pressão - PT10-3D

Pelas figuras 6.46 e 6.47, nota-se que as deformações cisalhantes em XZ e YZ concentraram-se próximo da região do contato. Uma melhor visualização dessas deformações é apresentada nas figuras 6.48 e 6.49. As deformações cisalhantes em $\mathrm{XZ}$ e YZ foram máximas na região do contato, sendo aproximadamente nulas ao longo do restante da armadura.

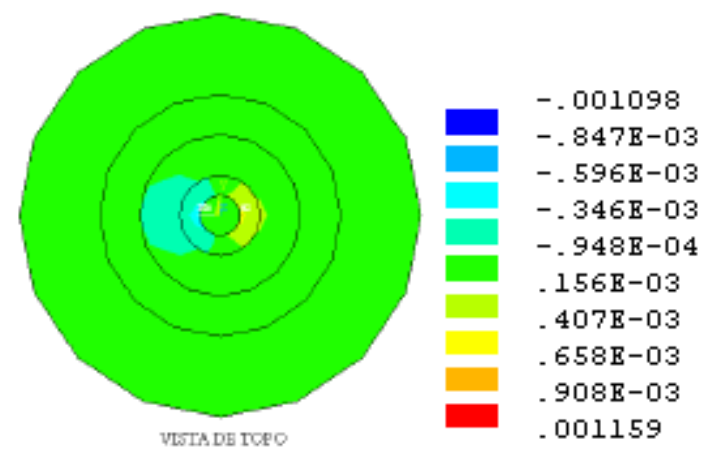

FIGURA 6.46 - Def. em XZ - PT10-3D

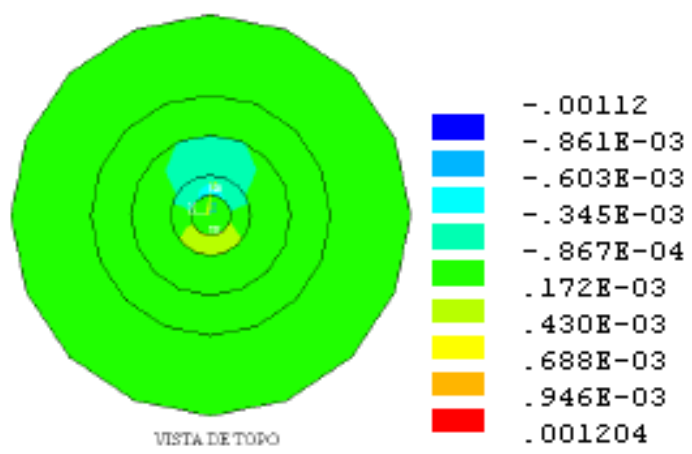

FIGURA 6.47 - Def. em YZ - PT10-3D

A modelagem numérica, apesar de não ter representado o ensaio corretamente, devido à sua relação linear força-deslizamento, serviram para uma análise primária do comportamento do contato no bloco de arrancamento. Modelos mais refinados, considerando as nervuras e a não linearidade dos materiais, poderão representar a verdadeira resposta da estrutura. 


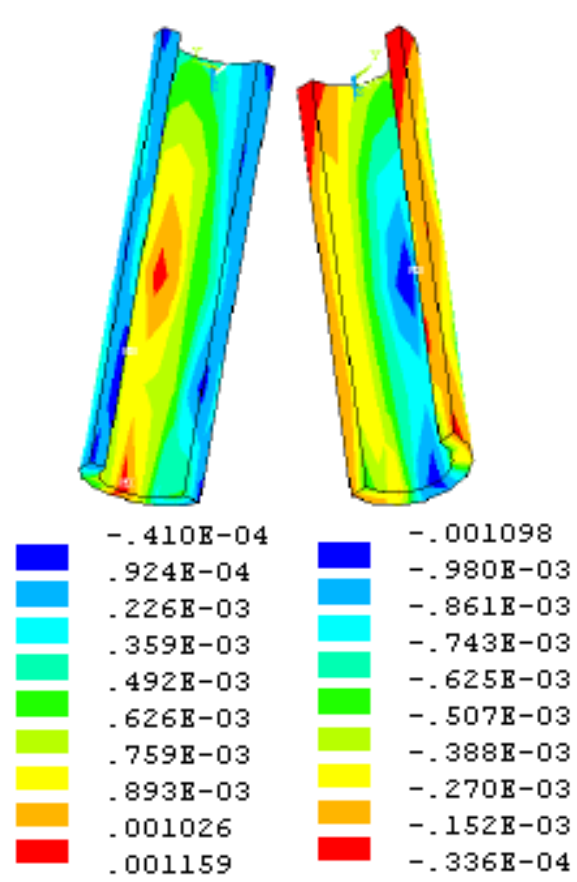

Concreto

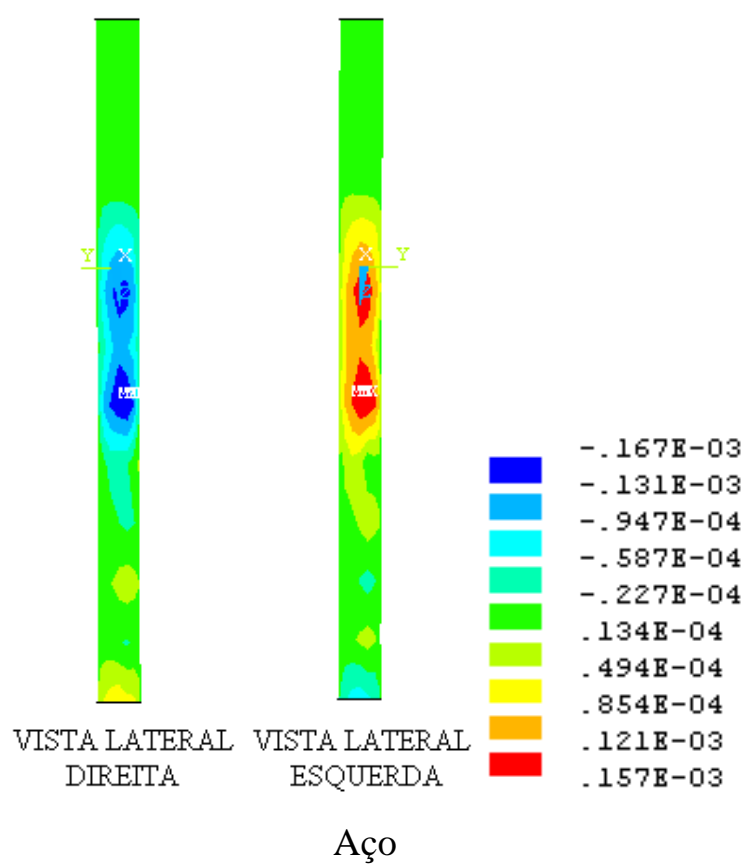

Aço

FIGURA 6.48 - Def. em XZ no concreto e no aço - PT10-3D

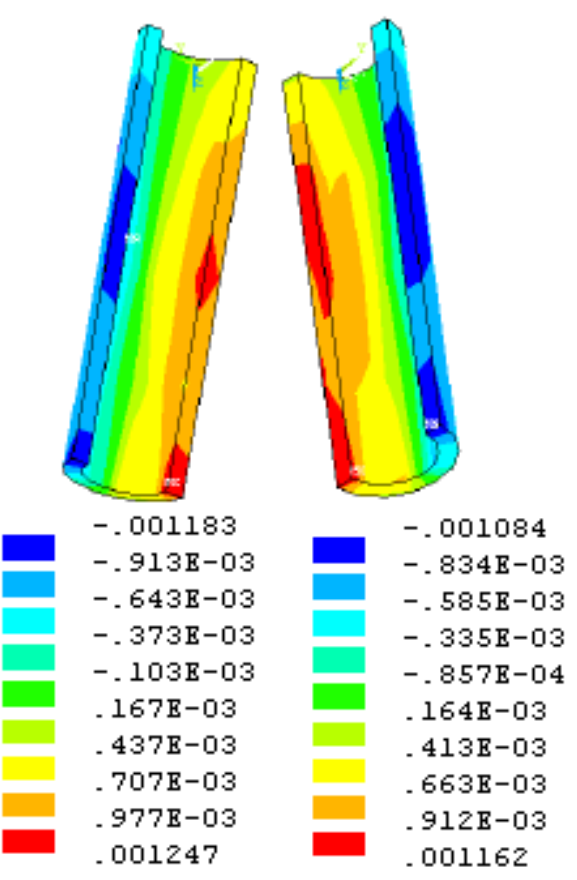

Concreto

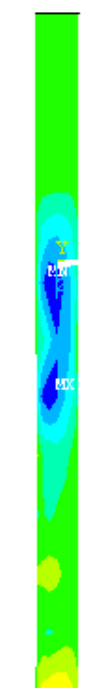

\section{VSTA} FRONTAI

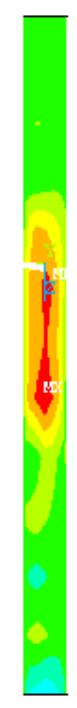

VISTA DETRASS

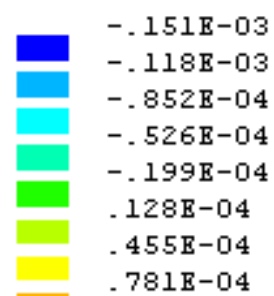

$781 \mathrm{E}-04$

$.111 \mathrm{E}-03$

$.143 \mathrm{E}-03$

Aço

FIGURA 6.49 - Def. em YZ no concreto e no aço - PT10-3D 


\section{CONSIDERAÇÕES FINAIS}

\subsection{CONCLUSÕES}

A aderência entre o concreto e a armadura é uma das principais propriedades responsáveis pelo bom desempenho do concreto armado. Além da junção complexa dos fenômenos adesão, atrito e ancoragem mecânica, a aderência está sujeita à influência de inúmeros fatores como as propriedades dos materiais aço e concreto, tipo e velocidade do carregamento, geometria das nervuras, posição das barras durante a concretagem, cobrimento, temperatura, revestimento da armadura, entre outros. O carregamento repetido é apenas uma dessas variáveis, mas possui uma grande importância por ser capaz de produzir a ruptura prematura da estrutura.

Para a avaliação do comportamento da aderência sob ação monotônica e repetida, foram realizados ensaios de arrancamento normalizados pela RILEM-FIPCEB (1973) com barras nervuradas de $10 \mathrm{~mm}$ e $20 \mathrm{~mm}$, os quais forneceram a curva média tensão de aderência versus deslizamento. A força máxima repetida foi equivalente a uma parcela da força média monotônica dos modelos de referência.

Todos os modelos ensaiados apresentaram o corte do concreto entre as nervuras, ocasionando a ruptura por arrancamento perfeito da armadura, típica de concreto confinado.

Analisando-se os modelos monotônicos, foram observadas três fases no comportamento da interface aço-concreto. Na primeira, a qual corresponde à aderência química, os deslocamentos relativos são extremamente pequenos e as 
deformações dos dois materiais são admitidas iguais. Após a ruptura da adesão $\left(\tau_{1 \mathbf{R}}\right)$, ocorre a mobilização da aderência por atrito e a engrenagem mecânica entre nervuras, equivalentes à segunda fase. Atingindo-se a ruptura efetiva da ligação $\left(\tau_{\mathbf{b u}}\right)$, dá-se início à terceira fase, originada pelo atrito concreto-concreto e travamento entre o concreto e as nervuras. O ramo da curva tensão de aderência-deslizamento, o qual só é capturado em regime de deslocamento controlado, decresce bruscamente e torna-se horizontal até a ruptura total por arrancamento da barra. Devido ao término do curso do transdutor de deslocamento, entretanto, os ensaios foram finalizados, antes de alcançar a tensão residual. O aumento da força, após o início do deslizamento, é pequeno para as barras lisas, que não foram ensaiadas nesse trabalho, e muito maior para as barras nervuradas, da ordem de aproximadamente 3 vezes, devido à mobilização da aderência mecânica.

Os modelos monotônicos da série 20 em relação aos da série 10 apresentaram um comportamento mais frágil da ligação, apesar da força última ter sido maior, e um trecho pós-ruptura mais dúctil. Uma justificativa para o primeiro fato, é que as barras de $20 \mathrm{~mm}$ possuem nervuras bem mais espessas que as de $10 \mathrm{~mm}$, fazendo com que a tensão não possa ser simplesmente considerada como um valor médio. Outra explicação possível é que a superfície relativa das nervuras $\left(\mathbf{f}_{\mathbf{r}}\right)$ da barra de 20 $\mathrm{mm}$ pode ser menor que a referente à barra de $10 \mathrm{~mm}$. Seria necessária, portanto, a obtenção desse valor para uma comparação entre as duas séries. Em relação ao segundo fato, os modelos da série 20 estiveram sob à ação de um concreto mais bem confinado e o travamento entre o concreto e as nervuras foi maior, devido à altura da nervura ser superior que a da série 10 .

Comparou-se os resultados experimentais com os oriundos das normas CEBFIP MC90, EUROCODE 2 e NB-1/78. Devido à pouca quantidade de modelos, entretanto, pôde-se tirar poucas conclusões. Observou-se que o ensaio de arrancamento ficou situado entre as condições de aderência boa e ruim, apesar da barra estar na posição vertical em relação à concretagem. Contudo, a série 10 se aproximou bastante da situação de boa aderência. Os valores da resistência convencional e efetiva da ligação entre as normas apresentaram dispersões muito grandes, como foi o caso da diferença de $67 \%$ de $\tau_{1 \mathrm{R}}$ do EUROCODE 2 em relação à 
NB-1/78. O deslizamento equivalente à ruptura da ligação foi maior que o valor de 1 mm proposto pelo CEB-FIP MC90, comprovado já em experimentos anteriores.

As duas justificativas possíveis para o ensaio de arrancamento ter apresentado condições intermediárias de aderência são:

- A tensão de aderência do ensaio é calculada como valor médio, o qual é menor que a tensão máxima que ocorre na barra, como foi explicado no capítulo 2;

- A exsudação do concreto na parte superior do modelo de arrancamento referente ao trecho aderente pode ter originado um concreto mais fraco nessa região.

Em relação à tentativa de se avaliar a distribuição de tensões ao longo da armadura nos primeiros modelos, não foi possível capturar esse comportamento com a instrumentação da barra, pois o isolamento dos extensômetros causa uma interrupção no diagrama das tensões de aderência.

Em relação ao carregamento repetido, observou-se que a resistência por adesão foi ultrapassada logo no primeiro ciclo, por causa do valor muito maior da força máxima.

O processo da fadiga de aderência é dividido em três fases: na primeira, a velocidade de deslizamento é decrescente, caracterizada pela diminuição da inclinação da tangente à curva deslizamento-número de ciclos (s-n); na segunda, essa velocidade torna-se constante, onde a inclinação da tangente é linear; e na terceira, a velocidade cresce muito rapidamente até a ruptura por arrancamento da barra, ou seja, a inclinação aumenta até tornar-se praticamente vertical. A aplicação dos ciclos dos ensaios finalizou-se na segunda fase e, após o deslizamento residual $\left(\mathbf{s}_{\mathbf{r}}\right)$, foram levados à ruptura monotônica. A primeira fase pode ser definida como uma acomodação da estrutura ao carregamento repetido, onde ocorre a maior parcela do esmagamento local do concreto próximo das nervuras. A partir daí, a região de concreto a ser esmagada é muito pequena, caracterizando a estabilização do crescimento dos deslizamentos. A ruptura por arrancamento ocorre após a terceira fase, a qual se inicia muito depois do deslizamento último monotônico $\left(\mathbf{s}_{\mathbf{u}}\right)$. Conseqüentemente, as estruturas não precisam ser ensaiadas para um número de ciclos muito grande, se o deslizamento equivalente à resistência de aderência monotônica for conhecido. A determinação do número máximo de ciclos pode ser obtida por extrapolação linear da segunda parte linear da curva até $\mathbf{s}_{\mathbf{u}}$. 
Para os diferentes níveis de solicitação, notou-se que quanto maior a força máxima repetida, maior a acomodação inicial do modelo e o deslizamento residual. As rigidezes ou as inclinações da tangente à curva para os trechos de descarregamento são praticamente iguais e muito acentuadas, indicando uma recuperação desprezível do deslizamento na força máxima.

A resistência estática da ligação dos modelos repetidos não foi alterada com um número de ciclos maior, uma força máxima repetida próxima da força última monotônica de referência e um deslizamento residual maior que $\mathbf{s}_{\mathbf{u}}$. Logo, as forças repetidas podem ser consideradas como um mecanismo de acomodação desses modelos em relação à resistência, com influência na degradação da aderência apenas pelo aumento progressivo dos deslizamentos.

Da análise numérica da aderência monotônica no Ansys, foram tiradas poucas conclusões, devido o modelo numérico não ter representado a verdadeira resposta da estrutura. Pelas dificuldades de instrumentação do modelo experimental, os valores numéricos apresentados não puderam ser comparados com os resultados dos ensaios.

Foram realizadas duas modelagens: uma bidimensional no estado plano de tensão (PT10-2D) e outra tridimensional (PT10-3D). Para a consideração da aderência e do deslizamento entre os dois materiais, colocou-se elementos de contato do tipo superfície-superfície entre o concreto e o aço.

Tanto o modelo bidimensional (PT10-2D) como o tridimensional (PT10-3D) apresentaram uma relação força-deslizamento linear, ou seja, a adesão entre os dois materiais e a pressão de confinamento, no caso de PT10-3D, foram desprezadas.

A deformada dos dois modelos foi semelhante à experimental, adotando-se, entretanto, algumas aproximações na modelagem bidimensional.

Os deslizamentos ao longo do contato foram diferentes, com um crescimento praticamente linear do topo do contato para a base. Essa evolução, não pôde ser constatada experimentalmente.

A constante FKN do programa Ansys, a qual define a rigidez de contato para calibragem do deslizamento, ocasionou uma penetração e uma abertura no contato desprezíveis. Mesmo os elementos da ligação estando submetidos preponderantemente a tensões de cisalhamento, para a estabilidade numérica do problema, surgem uma penetração e uma abertura muito pequenas no contato. 
Os modelos apresentaram uma concentração maior de deformações cisalhantes na região da ligação, diminuindo gradativamente à medida que a distância em relação ao contato cresceu. Essa deformações foram maiores no concreto, ocasionando assim o deslocamento relativo deste em relação ao aço.

Devido à variabilidade do concreto e à pouca quantidade de modelos, seria necessário, portanto, um certo cuidado na extensão dessas conclusões parciais aos casos gerais.

Como já foi exposto anteriormente, o problema da aderência sob ações repetidas envolve um conjunto de variáveis de grande complexidade: a nãolinearidade dos materiais, o mecanismo de transferência de forças, a micro-estrutura interna dos materiais, a propagação do dano, a não-linearidade do contato, a resposta força-deslizamento não linear, as deformações residuais, entre outras. Devido à dificuldade de visualização e abrangência de todos esses pontos no comportamento tanto do modelo experimental como numérico, nesse trabalho, a análise do fenômeno foi particularizada, de maneira a melhor solucionar determinadas questões sobre o assunto. Dessa forma, nesse campo de pesquisa, ainda precisam ser feitos muitos estudos englobando todas essas particularidades, alguns dos quais são propostos no próximo item.

\subsection{SUGESTÕES PARA NOVAS PESQUISAS}

A revisão bibliográfica mostrou que a influência de alguns fatores no comportamento da aderência como adições no concreto tipo resíduos, sílica ativa e fibras, a resistência à compressão, à tração e a retração do concreto, a temperatura, o tipo do aço, uma série de diâmetros da armadura, tipo e geometria das nervuras precisa ser constatada experimentalmente.

Apesar da bibliografia internacional apresentar alguns resultados sobre aderência sob ações cíclicas, um estudo experimental mais aprofundado dos modelos de arrancamento sob essas solicitações e com a variação de alguns parâmetros precisa ser feito. 
Uma outra abordagem do problema de grande importância e que precisa ser investigada a fundo se refere à mobilização da aderência na flexão em vigas sob solicitações cíclicas.

Nesse trabalho, uma série de dificuldades foram encontradas para a modelagem numérica da aderência.

Uma análise da propagação do dano ao longo da ligação dos dois materiais poderá ser feita com a implementação numérica do modelo de dano para carregamento cíclico, considerando-se as deformações residuais, no programa computacional desenvolvido por DRIEMEIER (1995).

No Ansys, uma modelagem mais rebuscada, considerando as nervuras da armadura e a não linearidade dos materiais poderá solucionar o problema monotônico do contato. Para a concepção do protótipo sob ações cíclicas, seria necessário fazer uma implementação numérica do modelo de carregamento cíclico no Ansys, considerando-se os deslocamentos residuais. 


\section{REFERÊNCIAS BIBLIOGRÁFICAS}

ACI COMMITTEE 408. (1991). Abstract of: State-of-the-art-report: bond under cyclic loads. ACI Materials Journal, v.88, n.6, p.669-73, Nov./Dec.

ASSOCIAÇÃO BRASILEIRA DE NORMAS TÉCNICAS (1978). NBR 6118 Projeto e execução de obras de concreto armado. Rio de Janeiro, ABNT.

ASSOCIAÇÃO BRASILEIRA DE NORMAS TÉCNICAS (1980). NBR 5739 Ensaio de compressão de corpos-de-prova cilíndricos de concreto. Rio de Janeiro, ABNT.

ASSOCIAÇÃO BRASILEIRA DE NORMAS TÉCNICAS (1982). NBR 7223 Determinação da consistência do concreto pelo abatimento do tronco de cone: Ensaio de abatimento. Rio de Janeiro, ABNT.

ASSOCIAÇÃO BRASILEIRA DE NORMAS TÉCNICAS (1982). NBR 7251 Agregado em estado solto: Determinação da massa unitária. Rio de Janeiro, ABNT.

ASSOCIAÇÃO BRASILEIRA DE NORMAS TÉCNICAS (1983). NBR 7211 Agregado para concreto. Rio de Janeiro, ABNT. 
ASSOCIAÇÃO BRASILEIRA DE NORMAS TÉCNICAS (1983). NBR 7222 Argamassas e concretos: Determinação da resistência à tração por compressão diametral de corpos-de-prova cilíndricos. Rio de Janeiro, ABNT.

ASSOCIAÇÃO BRASILEIRA DE NORMAS TÉCNICAS (1984). NBR 8522 Concreto: Determinação do módulo de deformação estática e diagrama tensãodeformação. Rio de Janeiro, ABNT.

ASSOCIAÇÃO BRASILEIRA DE NORMAS TÉCNICAS (1987). NBR 7217 Agregados: Determinação da composição granulométrica. Rio de Janeiro, ABNT.

ASSOCIAÇÃO BRASILEIRA DE NORMAS TÉCNICAS (1987). NBR 9776 Agregados: Determinação da massa específica de agregados miúdos por meio do frasco de Chapman. Rio de Janeiro, ABNT.

ASSOCIAÇÃO BRASILEIRA DE NORMAS TÉCNICAS (1992). NBR 6152 Materiais metálicos: Determinação das propriedades mecânicas à tração. Rio de Janeiro, ABNT.

BALÁZS, G.L. (1991). Fatigue of bond. ACI Materials Journal, v.88, n.6, p.620-29, Nov./Dec.

BALÁZS, G.L. et al. (1993). Acoustic emission monitoring on steel-concrete interaction. Otto Graf Journal, v.4, p.56-90.

BARBOSA, M.P. (1998). Uma contribuição experimental e numérica sobre estruturas de concreto armado de elevado desempenho: estudo da aderênciaancoragem e do comportamento de vigas fletidas. Ilha Solteira. 174p. Tese (Livre-docência) - Faculdade de Engenharia de Ilha Solteira, Universidade Estadual Paulista. 
BRAGUIM, J.R. (1995). O comportamento em serviço de vigas de concreto armado sob carregamento cíclico. São Paulo. 114p. Tese (Doutorado) - Escola Politécnica, Universidade de São Paulo.

COMITE EURO-INTERNATIONAL DU BETON (1991). CEB-FIP Model Code 1990. Bulletin d'Information, n.203-205.

COMITE EURO-INTERNATIONAL DU BETON (1996). RC elements under cyclic loading: state-of-the-art report. Bulletin d'Information, n.230.

DRIEMEIER, L. (1995). Considerações sobre a fadiga em metais e o comportamento do concreto sob solicitação cíclica. São Carlos. 149p. Dissertação (Mestrado) - Escola de Engenharia de São Carlos, Universidade de São Paulo.

DUCATTI, V.A. (1993). Concreto de elevado desempenho: estudo da aderência com a armadura. São Paulo. 273p. Tese (Doutorado) - Escola Politécnica, Universidade de São Paulo.

EUROCODE 2 (1992). Design of concrete structures. Part 1: General rules and rules for buildings. Brussels, CEN.

FUSCO, P.B. (1995). Técnica de armar as estruturas de concreto. São Paulo, Pini.

HAWKINS, H.M. et al. (1982). Local bond strength of concrete for cyclic reversed loadings. In: BARTOS, P., ed. Bond in concrete. London, Applied Science, p.151-61.

HOTA, S.; NAAMAN, A.E. (1997). Bond stress-slip response of reinforcing bars embedded in FRC matrices under monotonic and cyclic loading. ACI Structural Journal, v.94, n.5, p.525-37, Sept./Oct. 
KOCH, R.; BALÁZ, G.L. (1993). Slip increase under cyclic and long term loads. Otto Graf Journal, v.4, p.160-91.

KOH, C.G.; ANG, K.K.; ZHANG, L. (1997). Effects of repeated loading on creep deflection of reinforced concrete beams. Engineering Structures, v.19, n.1, p.218.

LARANJEIRAS, A.C.R. (1976). Redução da aderência aço-concreto sob a ação de cargas repetidas. In: JORNADAS SUL-AMERICANAS DE ENGENHARIA ESTRUTURAL, 28., Salvador, 1976. Anais. Salvador, IBRACON, 1976, 25p.

LARANJEIRAS, A.C.R. (1990). Fadiga das estruturas de concreto. In: SIMPÓSIO EPUSP SOBRE ESTRUTURAS DE CONCRETO, 2., São Paulo, 1990. Anais, São Paulo, EPUSP. v.1, p.187-232.

LEONHARDT, F.; MÖNNIG, E. (1977). Construções de concreto: Princípios básicos do dimensionamento de estruturas de concreto armado. 1.ed. Rio de Janeiro, Interciência. v.1.

MEHTA, P.K.; MONTEIRO, P.J.M. (1994). Concreto: estrutura, propriedade $e$ materiais. São Paulo, Pini.

MORITA, S. el al. (1992). Bond decay of beam bars in joint region under load reversals. In: WORLD CONFERENCE ON EARTHQUAKE ENGINEERING, 10., Madrid, 1992. Proceedings. Rotterdam, Balkema. p.3157-62.

POPOV, E.P. (1984). Bond and anchorage of reinforcing bars under cyclic loading. ACI Journal, v.81, n.4, p.340-49, Jul./Aug.

RILEM-FIP-CEB (1973). Bond test for reinforcing steel - 2. Pull-Out test. Matériaux et constructions, v.6, n.32, p.102-5. 
SCOTT, R.H.; HAMIL, S.J.; BAGLIN, P.S. (1999). Behaviour of high-strength concrete beam-column connections. In: CANMET/ACI INTERNATIONAL CONFERENCE ON HIGH-PERFORMANCE CONCRETE AND PERFORMANCE AND QUALITY OF CONCRETE STRUCTURES, 2., Gramado, 1999. Proceedings. Farmington Hills, ACI. P.699-713.

SOROUSHIAN, P. et al. (1991). Bond of deformed bars to concrete: effects of confinement and strength of concrete. ACI Materials Journal, v.88, n.3, p.227-32, May/June.

TASSIOS, T.P. (1979). Properties of bond between concrete and steel under load cycles idealizing seismic actions. AICAP-CEB Symposium, Structural Concrete Under Seismic Actions. CEB, Bulletin d'Information, n.131, p.67-122.

VALLE, A. (1994). Estudo da aderência entre concreto e armadura sob carregamento cíclico. São Paulo. 171p. Dissertação (Mestrado) - Escola Politécnica, Universidade de São Paulo.

VIEIRA, F.M.P.; DAL MOLIN, D.C. (1995). Comportamento da aderência das barras de aço no concreto de alta resistência com adição de microssílica. In: JORNADAS SUDAMERICANAS DE INGENIERIA ESTRUCTURAL, 28., Tucumán, AR, 1995. Anais, Tucumán, LE/FCET/UNT. v.5, p.371-82. 


\section{BIBLIOGRAFIA COMPLEMENTAR}

ALLWOOD, R.J.; BAJARWAN, A.A. (1996). Modeling nonlinear bond-slip behaviour for finite element analyses of reinforced concrete structures. ACI Structural Journal, v.93, n.5, p.538-44, Sept.

ANSYS RELEASE 5.5 (1999). Engineering Analysis System. Manuais on-line.

BALÁZS, G. L. (1993). Cracking analysis based on slip and bond stresses. ACI Materials Journal, v.90, n.4, p.340-8, July.

COMITE EURO-INTERNATIONAL DU BETON (1981). Bond action and bond behaviour of reinforcement: state-of-the-art report. Bulletin d'Information, n.150.

FILIPPOU, F.C. (1986). A simple model for reinforced bar anchorages under cyclic excitations. Journal of Structural Engineering - ASCE, v.112, n.7, p.1639-59.

GIONGO, J.S.; PEPE, S. (1993). Concreto armado: ancoragem por aderência. São Carlos, Serviço gráfico da EESC.

KRAL, E.R.; KOMVOPOULOS, K. (1996). Three-dimensional finite element analysis of subsurface stresses and shakedown due to repeated sliding on a 
layered medium. Journal of Applied Mechanics-Transactions of the ASME. v.63, n.4, p.967-73, Dec.

MONTI, G.; FILIPPOU, F.C.; SPACONE, E. (1997). Finite element for anchored bars under cyclic load reversals. Journal of Structural Engineering - ASCE, v.123, n.5, p.614-23, May.

RUSSO, G.; ZINGONE, G.; ROMANO, F. (1990). Analytical solution for bond-slip of reinforcing bars in R. C. joints. Journal of Structural Engineeing - ASCE, v.116, n.2, p.336-55.

SOMAYAJI, S.; SHAH, S.P. (1981). Bond stress versus slip relationship and cracking response of tension members. ACI Journal, v.78, n.3, p.217-25, May.

TASSIOS, T.P.; YANNOPOULOS, P.J. (1981). Analytical studies on reinforced concrete members under cyclic loading based on bond stress-slip relationships. ACI Journal, v.78, n.3, p.206-16, May.

UNIVERSIDADE DE SÃO PAULO. Escola de Engenharia de São Carlos. Serviço de Biblioteca (1997). Diretrizes para elaboração de dissertações e teses na EESC-USP. 2.ed.rev.ampl. São Carlos. 58p.

YANKELEVSKY, D.Z.; ADIN, M.A.; FARTHEY, D.N. (1992). Mathematical model for bond-slip behavior under cyclic loading. ACI Journal, v.89, n.6, p.69298, Nov./Dec.

YANNOPOULOS, P.J.; TASSIOS T.P. (1991). Reinforced concrete axial elements analyzed under monotonic and cyclic actions. ACI Structural Journal, v.88, n.1, p.3-11, Jan. 